Resistance is Futile:

\title{
Indian Cinema and Identity Construction Among Young South Asian Canadians of Muslim and Other Backgrounds
}

by Faiza Hirji Kassam, M.A.

\author{
A thesis submitted to \\ the Faculty of Graduate Studies \\ in partial fulfillment of \\ the requirements for the degree of \\ Doctor of Philosophy
}

School of Journalism and Communication

Carleton University

Ottawa, Ontario

August 3, 2007

(C) 2007, Faiza Hirji Kassam 


$\begin{array}{ll}\begin{array}{l}\text { Library and } \\ \text { Archives Canada }\end{array} & \begin{array}{l}\text { Bibliothèque et } \\ \text { Archives Canada }\end{array} \\ \begin{array}{l}\text { Published Heritage } \\ \text { Branch }\end{array} & \begin{array}{l}\text { Direction du } \\ \text { Patrimoine de l'édition }\end{array} \\ \begin{array}{l}\text { 395 Wellington Street } \\ \text { Ottawa ON K1A 0N4 }\end{array} & \begin{array}{l}\text { 395, rue Wellington } \\ \text { Ottana ON K1A ON4 } \\ \text { Canada Oa }\end{array}\end{array}$

Your file Votre référence ISBN: 978-0-494-33492-8 Ourfile Notre référence ISBN: 978-0-494-33492-8

NOTICE:

The author has granted a nonexclusive license allowing Library and Archives Canada to reproduce, publish, archive, preserve, conserve, communicate to the public by telecommunication or on the Internet, loan, distribute and sell theses worldwide, for commercial or noncommercial purposes, in microform, paper, electronic and/or any other formats.

The author retains copyright ownership and moral rights in this thesis. Neither the thesis nor substantial extracts from it may be printed or otherwise reproduced without the author's permission.
AVIS:

L'auteur a accordé une licence non exclusive permettant à la Bibliothèque et Archives Canada de reproduire, publier, archiver, sauvegarder, conserver, transmettre au public par télécommunication ou par l'Internet, prêter, distribuer et vendre des thèses partout dans le monde, à des fins commerciales ou autres, sur support microforme, papier, électronique et/ou autres formats.

L'auteur conserve la propriété du droit d'auteur et des droits moraux qui protège cette thèse. $\mathrm{Ni}$ la thèse ni des extraits substantiels de celle-ci ne doivent être imprimés ou autrement reproduits sans son autorisation.
In compliance with the Canadian

Privacy Act some supporting forms may have been removed from this thesis.

While these forms may be included in the document page count, their removal does not represent any loss of content from the thesis.
Conformément à la loi canadienne sur la protection de la vie privée, quelques formulaires secondaires ont été enlevés de cette thèse.

Bien que ces formulaires aient inclus dans la pagination, il n'y aura aucun contenu manquant. 


\begin{abstract}
This dissertation examines nationalism, tradition and religiosity in Bollywood cinema, and the way that these themes are interpreted and used by young Canadians of South Asian origin, particularly Muslims, in the construction of identity. Bollywood, the most commercially successful form of Indian cinema, is distributed and viewed around the world. The popularity of Bollywood has been attributed to any number of factors, including its frequent use of fantastic, romantic and familial themes, but British and American studies suggest an additional appeal: the ability to acquire or strengthen understandings of cultural norms and rituals. Such findings raise the question of whether similar tendencies can be found among young adults of South Asian origin raised in Canada, especially Muslims. This line of investigation is especially interesting given the peripheral or stereotyped role of Muslims in many Bollywood films despite the presence of well-known Muslim actors, writers and producers in the industry. Accordingly, this study combines a discussion of Bollywood's production and key themes with an examination of how these themes are read by young Canadians of South Asian origin. The latter is accomplished through a series of interviews with Canadians of South Asian origin between the ages of 19 and 29 in Toronto, Vancouver and Ottawa. Participants provided insights regarding their perceptions of national, ethnic and religious identity, chief influences that may have contributed to the formation of these, and their thoughts on the importance of Bollywood cinema within the context of nationalist sentiment and ethnic or religious identification. The results, analyzed using theories of diaspora, transnationalism, resistance and identity, are varied but key findings include the following: hybrid identities are being formed by these young people, and a strong sense
\end{abstract}


of Canadian national identity emerges within this, anchored by a belief that ethnicity and religion can be embraced freely within a pluralist Canadian environment. Media play a significant role in this process of identity construction, and in particular, Bollywood elicits a mixed reaction from participants. Despite its evident shortcomings in portraying religion, diaspora and gender, Bollywood appears to meet a need for representation of South Asian life that is otherwise unfulfilled. 


\section{Acknowledgements}

Many people, not all of whom I have the room to acknowledge here, contributed to the completion of this dissertation. In particular, this work could not have been possible without the interviewees in Toronto, Ottawa and Vancouver who were kind enough to make time for me and to share their ideas. Their contributions were invaluable and of great personal interest to me. I hope that I have done justice here to their insights. In writing this dissertation, I was fortunate to be guided by committee members who demonstrated a high level of engagement and expertise, led by my supervisor, Karim $\mathrm{H}$. Karim, with whom it has been a true pleasure to work for the last several years. Daiva Stasiulis and Joshua Greenberg were dedicated, accessible and helpful during this process. I also wish to thank Yasmin Jiwani and Brian Given for their time and feedback. A number of other people provided advice throughout the conceptualization and writing of this work, including - but not limited to-Rajinder Dudrah and other participants at the 2006 South Asian Popular Culture conference, Maria Bernard, Eileen Saunders, Sandy Smeltzer, and Jigna Desai. Financially, I benefited greatly from the generous support of the Social Sciences and Humanities Research Council, Carleton University, the Ontario Graduate Scholarship and the Joint Centre of Excellence for Research on Immigration and Settlement. I thank all of these organizations for making it possible to complete this work in a timely manner. This research has, in fact, consumed my time and attention for the past four years. I appreciate the patience and encouragement all of my family and friends offered during this period, particularly my husband Rahim, whose translations and companionship helped make the watching of these films a pleasure, and my parents, whose own experiences of migration shaped both this work and my life. 


\section{TABLE OF CONTENTS}

INTRODUCTION

How Canadian Are You? Mapping Nationalism, Media ANd Self ....................... 1

INVOLUNTARY MINORITIES? YOUNG MUSLIM CANADIANS OF SOUTH ASIAN ORIGIN...................................

SEEING THE SELF: THE ROLE OF MEDIA IN IDENTITY CONSTRUCTION.........................................................6

SYMBIOSIS IN ANOTHER FORM: NATIONALISM AND MEDIA....................................................................

YOUNG MUSLIMS OF SOUTH ASIAN ORIGIN IN THEIR OWN WORDS .......................................................13

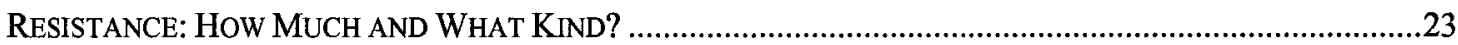

TRANSCENDING THE BELL JARS: IDENTITY, BELONGING AND UNDERSTANDING ......................................26

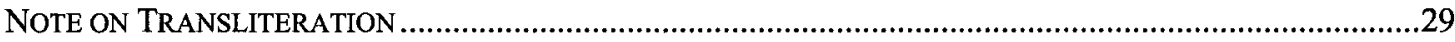

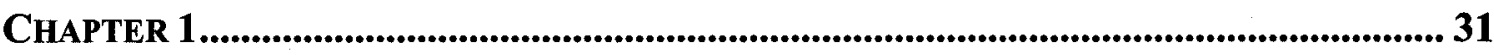

THEORIES OF THE WANDERING SOUL: INTERPRETATIONS OF DIASPORA...................... 31

ALL AROUND THE WORLD: DISPLACEMENT AND DISPERSAL ................................................................

THE SWEET HEREAFTER? LIVING OR LEAVING THE DIASPORIC EXPERIENCE …….....................................43

DIFFERENT DIASPORAS: INDIA, PAKISTAN AND THE COLONIAL LEGACY ....................................................49

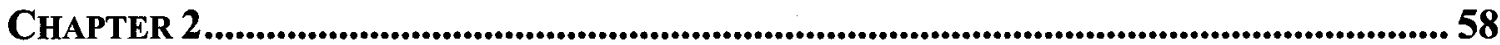

Karma Chameleon: Citizenship, Identity and the New Hybrids...................... 58

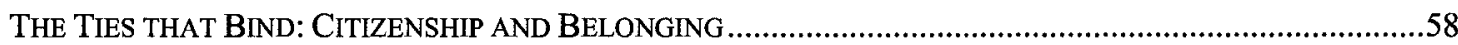

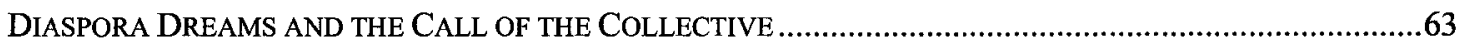

COLLECTIVITIES AND CONSEQUENCES: NEGOTIATING INDIVIDUAL IDENTITY ...........................................68

BREAKING OUT OF THE "GHETTO WALLS": A POLITICS OF PLURALISM ...................................................

THE MISTS OF TIME: BEYOND AND BETWEEN NATIONS AND NOSTALGIA ..............................................79

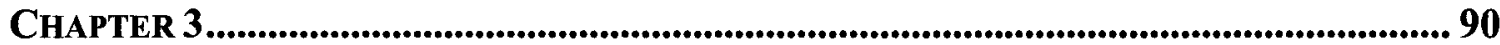

But Where Are You Really From? South Asians ANd Muslims in CanAda .... 90

SEPARATE AND EQUAL? MUSLIM AND SOUTH ASIAN IDENTITY IN CANADA .............................................90

LITTLE INDIA, BIG DIASPORA: SOUTH ASIANS CIRCLE THE GLOBE ..............................................................94

STILL WAITING FOR THE GREEN PERIL? ISLAM AS WORLD RELIGION .......................................................111

MUSLIMS IN THE MOSAIC: MUSLIMS, DIASPORA AND DIFFERENCE .....................................................

Double Binds, Multiple Marginalities: Muslim AND South Asian SelveS ...............................127

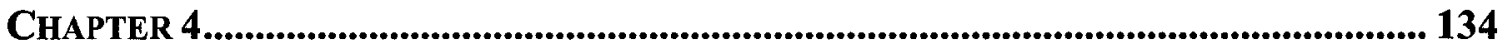

LitTle Mosques and Bollywood EPICS: MEdiA AND IdENTITY CONSTRUCTION 134

BORDERS AND STATES: MEDIATED IMAGINARIES OF THE NATION..........................................................136

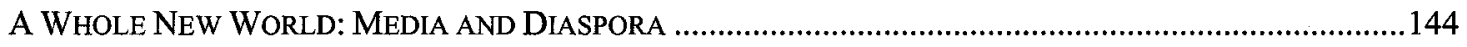

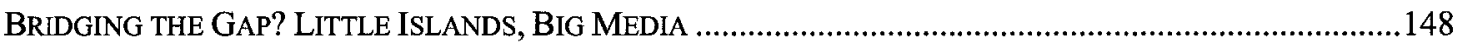

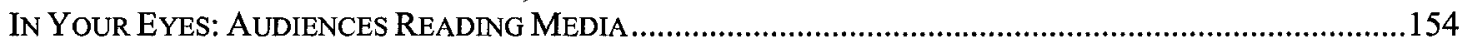

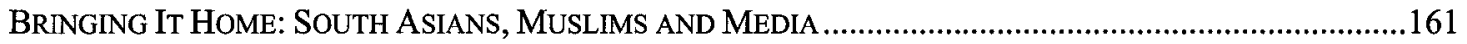

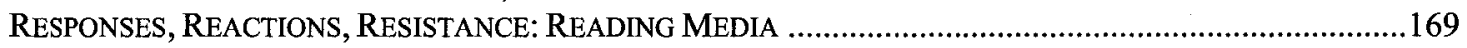

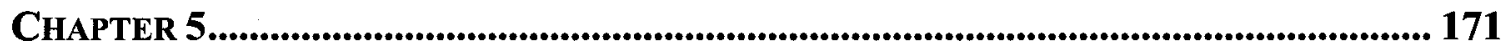

EAST Meets WeSt-AND EVERyThing ElSe: Living LA Vida Loca in Bollywood

CREATING A MONSTER? BEHIND THE BOLLYWOOD SCENES ..........................................................172

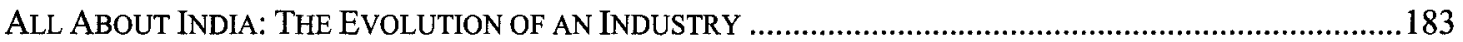


“MY HEART'S INDIAN FOR ALL THAT": THEMES OF NATIONALISM AND MIGRATION IN BOLLYWOOD ..192

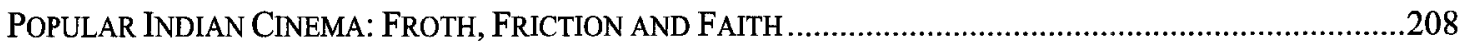
MOVING FORWARD: ADMITTING MUSLIMS INTO THE NATION? ........................................................214

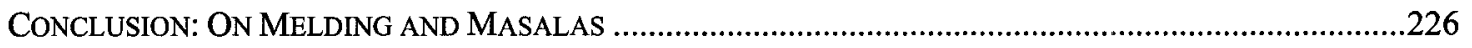

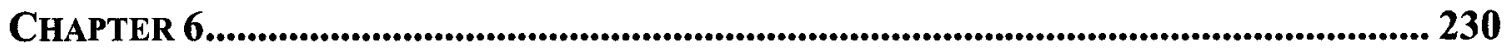

Up Close and Personal: Methodology for Obtaining Audience Opinion ... 230

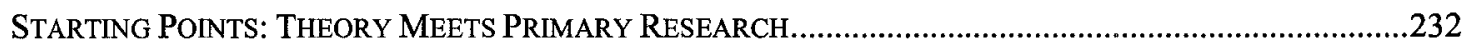

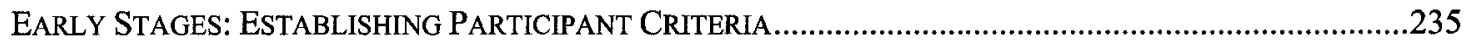

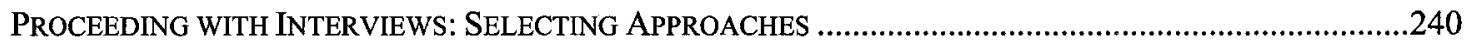

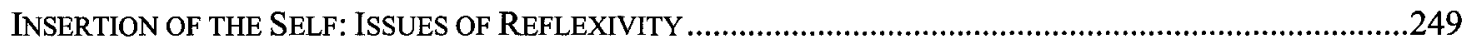

PLANNING ENDS, RESEARCH BEGINS: ADJUSTMENTS AND ACCOMMODATIONS .....................................255

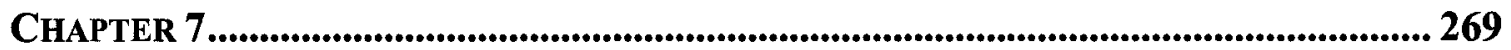

\section{"But, I dReam in Canadian": Constructing and Maintaining PluRaL}

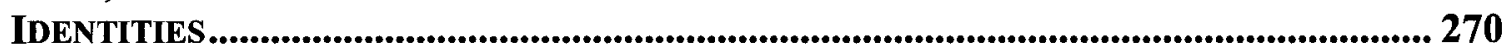

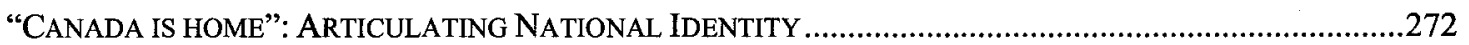

CAN YOU Go HOME AGAIN? DIASPORIC YOUTH SPEAK OUT..........................................................28

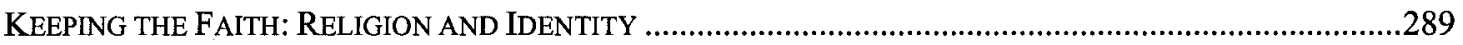

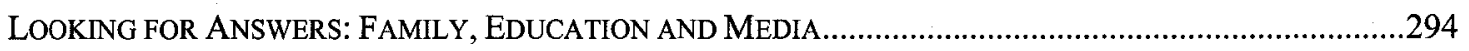

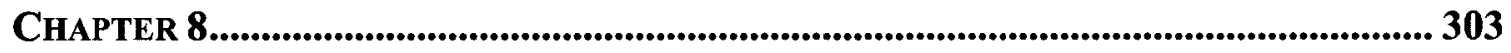

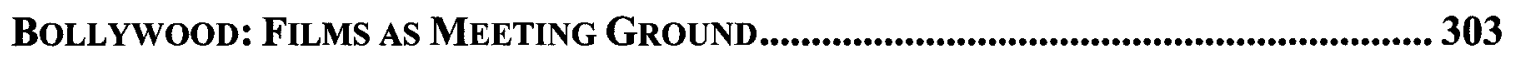

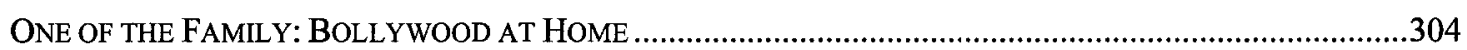

“THAT MOVIE TOUCHED MY SOUL": FILMS AS AGENTS OF SocIALIZATION ............................................309

"BOLlywOOd GAVE ME UNREALISTIC EXPECTATIONS...": REPRESENTATIONS OF SELF .........................313

"IT SHOOK MY SOUL": EVALUATING BOLLYWOOD's SIGNIFICANCE .......................................................323

DIVERSITY, DIASPORA AND MEDIA .....................................................................................................330

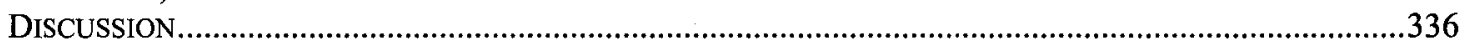

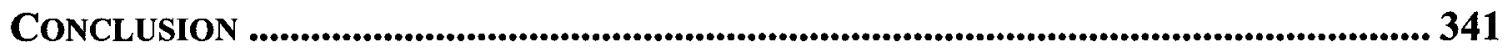

Beyond Futility: The Future of Young Canadians of South Asian Origin . 341

PART OF THE ORDINARY? YOUNG MINORITIES AND INTEGRATION …….....................................................345

You REALly ARE Global Citizens: Resistance AND ReConCILIATION..............................................362

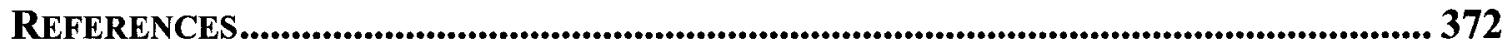

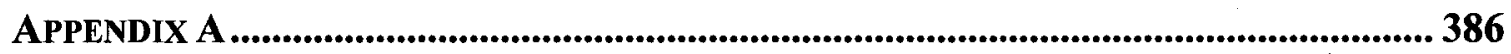

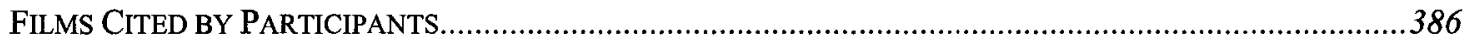

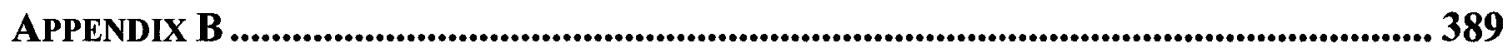

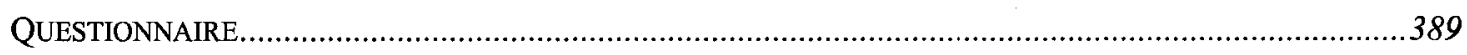

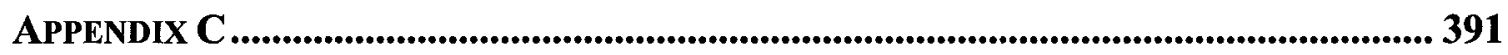

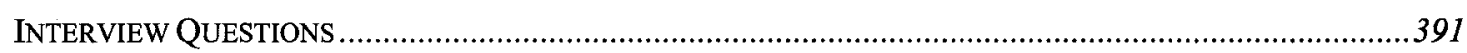


Introduction

\section{How Canadian Are You? Mapping Nationalism, Media and Self}

Visible-minority immigrants are slower to integrate into Canadian society than their white, European counterparts, and feel less Canadian, suggesting multiculturalism doesn't work as well for non-whites, according to a landmark report. (Jiménez, 2007, p. A1).

It's not that Canadians don't see racism; in the CRIC-Globe and Mail survey, twothirds said they believe it is still a problem. But University of Victoria sociologist Francis Adu-Febiri said young people...will be less willing to accept it as the status quo. "They were born here," he said. "They see themselves as involuntary minorities [unlike their parents] and full Canadians." (Valpy \& Anderssen, 2003, p. A6)

Official statistics and our own observations persuade many Canadians that the country is becoming increasingly multicultural, its traditional French-English-aboriginal composition giving way to an enormously diverse group of people, including immigrants and their children. The belief that globalization is transforming most countries, Canada among them, contributes to a perception that migration is on the rise and that the developed world will never be the same. This may well be true, although it overlooks the facts that Canada's history is more pluralist than some might acknowledge and that migration has always been a part of world history. However, the amount of attention migration receives may sometimes make its fluctuations seem exaggerated.

Similarly, the anxiety that some seem to feel in Canada over the question of immigration leads to many authoritative pronouncements over the future of the country and its citizens. Particular attention has recently been devoted to the broad category of youth, not only because those who occupy it constitute the workers and decision-makers of the future, but because they are younger and presumably adaptable, have often spent more time in Canadian educational institutions than their parents and are thus more apt to 
be fluent in English or French, to understand Canadian cultural norms and to possess the necessary training for a productive life in Canada. If the young cannot be integrated, the logic says, then there is little hope that any immigrants can be incorporated fully and meaningfully into Canadian life, and the dream of multiculturalism will be unmasked as mirage and myth. As the quotations above demonstrate, a considerable amount of time has been spent exploring the situation of these youth, yet there are no simple answers to whether or not immigrant or minority youth feel a sense of belonging in Canada.

This dissertation does not attempt to replicate such broad-based studies as the cross-generational examination of immigrant life by Reitz and Banerjee cited in Jiménez (2007) or The Globe and Mail's series on The New Canada summarized in Valpy and Anderssen (2003), but there are certainly elements of these that are relevant and that have been enfolded into the present research, which focusses on the identity construction of young Canadians of South Asian origin, with particular emphasis on Muslims. The young people in this study are asked to articulate their identities in nationalist, ethnic and religious terms, and to relate the formation of these to their use of mass media, specifically to Bollywood cinema, a popular Indian export with strong themes around patriotism and religious piety. Their comments in these areas are assessed within a theoretical framework that is unfurled in the opening chapters, covering perspectives on diaspora, constructions of nation, nationalism and citizenship, the specific positioning of these young adults within South Asian and Muslim diasporas and within Canada itself, identity construction and the importance of media in this process and critical readings of major themes in Bollywood film, especially those that relate to tradition, nation and faith. Following the establishment of this framework, the final chapters discuss the primary 
research itself and the findings, some of which are summarized below.

Involuntary Minorities? Young Muslim Canadians of South Asian Origin

The choice of young Canadians of South Asian origin with an emphasis on Muslims may seem arbitrary or overly specific, but it stems from a belief that this group is particularly well-placed to address intersecting tensions and challenges to what is sometimes defined as Canadian culture, despite that culture's amorphous and plural nature. South Asians rank among Canada's largest and most visible ethnic minority groups, and Muslims practise Canada's second-largest religion. Despite their high numbers relative to other minorities, however, South Asians and Muslims have been reminded on more than one occasion that they do occupy a marginal position in the overall Canadian population. Jiwani (2006), Karim (1997), Khan (2000) and Razack (1998) all document a long history of stereotyping of these groups, a history that became even more significant following September 11, 2001, when fear of terrorism began to be elided in the media and in policy discourse as a fear of certain religious and ethnic groups, particularly the two under study here.

This anxiety over the presence of South Asians and Muslims has only been accentuated by events around the world and at home, including rioting by immigrant youth in the suburbs of Paris, the stabbing of Dutch filmmaker Theo Van Gogh by a Muslim man, and the arrest of South Asian Muslim youth in Britain and in Canada for alleged terrorist activity. These are the kind of events that have taken place during a period when several countries, including Canada, are also debating the importance of multiculturalism and flexible policies on immigration and citizenship, particularly in the wake of crises such as the 2006 evacuation of dual citizens from Lebanon during that 
country's conflict with Israel. These are also events, however, that follow others which placed the spotlight on Canadian Muslims and/or Canadians of South Asian origin, including Québec's attempt to limit the wearing of hijab, the headscarf worn by some Muslim women, as well as the kirpan, the knife that some Sikhs consider part of their faith (see Khan,1995). Although this is less relevant in terms of cultural practice, young South Asians have also been the subject of special police taskforces and government reports as the city of Vancouver has grappled with the problem of rising crime and violence among South Asian men.

In many respects, then, South Asians and Muslims are definite minorities and they are minorities who are sometimes presented in the press or in policy as inherently problematic for their refusal to adapt to mainstream norms. This is not to suggest that South Asians and Muslims do not integrate into Canadian society; they can and do. It is, however, to suggest that Canada's official commitment to pluralism and diversity does not guarantee that all of its minorities will be completely free at all times to practise their religion and express their ethnicity, and it also highlights the fact that Canadian Muslims of South Asian origin have special challenges before them. Increased political and media attention do not seem to have mitigated these challenges. In some cases, it is possible that they have increased them, accentuating Muslims' and South Asians' difference from the mainstream, presenting a few individual viewpoints as the perspective of the majority, and simplifying religions and cultures rather than explaining them more thoroughly so as to increase public understanding.

Muslims and South Asians living in Canada belong to tremendously diverse groups. Muslims who are South Asian can be equally diverse, although they may be 
particularly marginalized as public attention turns towards an image of Islam that is associated with Middle Eastern countries, as one participant of Pakistani origin pointed out to me during this study. However, the opposite also holds true: South Asians of different religious backgrounds may identify more strongly with Muslims who are marginalized, especially if they are mistaken for Muslims, which did happen in North America following September 11. In short, they are people visibly marked as different, their cultural practices subject to intensive observation and judgement, and they are so internally diverse that even this small, specific group becomes more sprawling and extensive than one might imagine.

Hence, for a number of reasons, these young people present an interesting case for study in the Canadian context, which remains central but does take into account concerns expressed in other countries over ways to integrate immigrants, particularly Muslims. In some places this concern has expressed itself through a pronounced degree of attention to some Muslim women's practice of veiling or covering themselves, while other countries have struggled to contain what they see as the violence and extremism endemic to alienated Muslim men. Many of the cases that have attracted attention have involved youth, and this has raised anxiety levels as governments ask whether their policies on integration or assimilation have failed them. Canada is no stranger to such worry, with some politicians and pundits opining that its venerated multiculturalism policy has failed its people, including immigrants. Since Canada's requirements for human capital make it unlikely that the flow of immigration or the reproduction of new generations will cease, there is an ongoing question in the minds of educators, politicians and interested citizens about the best way to merge the disparate elements of a diverse society, and more and 
more often, that question locates itself in relation to minorities such as Muslims and South Asians, with their visible signs of difference. This study thus aims to examine the ways in which young people belonging to these groups identify themselves and the factors that lead to these forms of identification, specifically mass media.

Seeing the Self: The Role of Media in Identity Construction

Over the last few years, some scholars (Bhabha, 1994; Karim, 1998; Khan, 2000; Kraidy, 1999; Nandy, 1983, 1995) have begun to re-interpret notions of cultural resistance and purity, theorizing that these ideas may be more complicated than previously assumed. Accepting that traditional resistance to assimilationist pressures may be a thing of the past, these theorists have altered their focus by examining the survival strategies employed by immigrants and their children as they struggle for acceptance in their adopted countries but insist on retaining a foothold in the communities of their birth. For example, members of the diaspora may live thousands of miles apart but share interests in indigenous media such as film.

In the case of South Asians, media such as popular Indian films entertain members of the diaspora but they also serve an important purpose, offering a vision of South Asia and South Asian culture to those who may never have visited a South Asian country, but who seek some sense of cultural heritage and have no alternate means of satisfying that need. Here I have centred my study around the interpretation of Bollywood films partly because of their consistent focus on issues of nationalism, identity, tradition, and integration into different cultures, and partly because of their astonishing audience reach. As Jigna Desai points out in a summary of her own study of Indian film and its 
reception by South Asian Americans, various media can be seen as formative in the identity of youth, but the role of film in diaspora is particularly noteworthy:

I maintain that film is unique in the ways it constructs a shared South Asian diasporic identity. Indian films have a significant impact on second-generation South Asian American youth, even on those who seldom watch films, because they provide much of the vocabulary for understanding culture, authenticity, the nation, and cultural difference. (2005, p. 62)

South Asian Muslims' readings of Western films are also of interest because there is a clear sense of nationalism and cultural affirmation found in many of those, as well. Likewise, there are non-Bollywood films that address issues affecting South Asians; these often speak of diaspora and are marketed to audiences living there. They are made frequently by diasporic filmmakers living in North America or Europe, but some are coproduced with Indian companies and may demonstrate some overlap with Bollywood films. However, Bollywood films are very different from those produced in Western centres, especially in places such as Hollywood, because of their target audience and because they often aim so blatantly at fulfilling a cultural need, a sense of yearning experienced by those whose early years in countries such as Canada may have been marked by a sense of cultural alienation and hence an inability to blend in. Despite accusations that Bollywood is little more than a poorly rendered imitation of Hollywood, the recurrence of certain themes around nation, family and faith is specific to this particular genre, and in recent years, particularly since the mid-1990s, some Bollywood producers have begun restructuring their work with particular attention to the experiences of those living in diaspora.

This apparent willingness to engage with the perceived concerns of immigrants from South Asia highlights Bollywood's defining characteristics as well as its embedded 
contradictions. Bollywood is the producer of numerous films, not all of which display the same themes, but it can often be seen engaging with imperialist tropes, eschewing foreign influences and simultaneously courting them while offering its own form of domination, silencing regional or somehow Othered voices. Its dual identity can be seen in its frequent attempts to portray American culture while pointedly referencing an East/West dichotomy. For the most part, it asserts independence from cultural imperialists while simultaneously neglecting the diverse forms of Indian culture and language in favour of a homogeneous, glossy pan-Indian identity. It valorizes global consumer culture, but also points viewers back to religion and tradition as all-important guides. All of these factors are important in the current study. The intersection of religion and ethnicity within Bollywood content, and how this is read by its potentially marginalized viewers, is a focal point of the research here. Although others have studied the importance of South Asian film in the lives of its viewers, very few have examined this importance through first-hand interaction with those viewers. The exceptions that exist (Desai, 2005; Durham, 2004; Gillespie, 1995) do not place Bollywood viewing within the Canadian migratory experience. ${ }^{1}$

Most importantly, however, while a number of studies have investigated issues of Indian culture and Hindu rituals in Bollywood film, very few have seriously examined the complicated portrayal of Muslims in an industry that constantly seeks to homogenize the India shown in its films. In itself, a study that examined the role of Islam in Bollywood content would be a pertinent contribution to communication studies, given the complex history between Hindus and Muslims in South Asia, and the high level of

\footnotetext{
${ }^{1}$ The exception is unpublished research by Yasmin Jiwani, some of which extends as far back as the late 1980 s and is cited in this study.
} 
interest in understanding Islam and ways to represent it. Further benefit may be gained from gathering input from young Muslims at a time when they are most likely to be seeking ways to better understand their identity and their place within various communities. If media offered within the country fail to satisfy, the transnational nature of electronic mass media allows for many other possibilities, from the political to the popular to a complicated combination of the two. The project of identity formation and maintenance among young Muslims of South Asian origin, living in a country that considers itself among the most pluralistic in the world while occupying a place within two large and dispersed global communities, is one worth studying. Such an examination would contribute not only to studies of Bollywood cinema generally, it would also contribute to research that investigates the ways minority youth may engage with media in order to make sense of a multicultural society that presents them with numerous options for identity creation.

\section{Symbiosis in Another Form: Nationalism and Media}

Although the young adults in this study spoke frequently of the role that Canadian institutions and North American media played in shaping their identities, many also pointed to the formative role of travel to their ancestral countries, usually India and Pakistan. A training ground for many engineers, computer experts and health care professionals, India has joined other third-world countries in watching those talents move away. The colonizer no longer has to come to India--Indian subjects move willingly to the United Kingdom, the United States, Canada and other places, in search of a new life. For the Indian government, there is the perception of a net loss. Its citizens may have found new upward mobility but despite funds sent home or visits back to the mother 
country, the proceeds are not all available to the Indian government. In 2002, India responded to the challenge posed by the loss of human capital by extending the option of overseas citizenship for the first time. Moving away from a stalwart position on the necessity of residing in India exclusively, it has offered non-resident Indians the ability to come back home, as it were. This is an offer with definite limits, of course. It is made only to diasporic Indians living in specific countries and provides a different form of citizenship, one which could eventually be upgraded and whose implicit purpose is to promote investment from a group assumed to be affluent and constructed in government discourse as people who still feel attached-which is to say obligated-to home.

At the same time that the Indian government has had to devise a more flexible strategy, film, too, has taken on a new life, whether by coincidence or as a result of global and economic pressures, particularly policies of economic liberalization traced back to the early to mid-1990s. This is true on two levels: films made within and marketed to the diaspora, such as Bend It Like Beckham (2003), Monsoon Wedding (2001) and Water (2005), manage the neat trick of being not-completely-Indian and yet-just-Indian-enough. The rise of such films and their filmmakers, diasporic talents of South Asian origin such as Gurinder Chadha, Mira Nair and Deepa Mehta, was perhaps inevitable as the South Asian diaspora grew larger, stronger and more mature. The real surprise, perhaps, lies in the concurrent transformation of Bollywood films, with their tried-and-true formulas of romance, song-and-dance intervals and overwhelming Indian pride. Film is hardly the only medium involved in nationalist efforts, but it is one of the most effective.

In various ways-by controlling or commissioning production, by censoring content, by providing financial or official support—governments may provide signals for 
what types of media are acceptable and should be watched. Pakistan has attempted to protect its own national identity by filtering the amount of Indian films entering the country, but as participants in this study observed, citizens sometimes have their own ways of deciding what media to watch, a decision that is assisted greatly through technologies such as black-market satellite dishes. India is no stranger to protectionist or paternalistic techniques. At one point, India exercised an iron control over the popular film industry, strictly monitoring any potentially sexually explicit content, although it is not otherwise linked clearly to the industry as sponsor or facilitator. Nonetheless, there is a distinct cohesion in the narratives that emerge from Indian politicians, particularly following the 2002 establishment of citizenship for Indians overseas and the 2004 establishment of a Ministry of Overseas Indian Affairs, and those that circulate through various Bollywood films. Many of these narratives demonstrate the growing importance of the diaspora in policy and in media, and quite a few of the film discourses, Desai (2005) suggests, are more accepting of the fact of diaspora than ever before.

Beginning with pivotal films such as Dilwale Dulhania Le Jayenge (The Lover Takes the Bride, 1995, commonly abbreviated as $D D L J$ ), a massive domestic and international success, Desai detects a change in the tone of major filmmakers:

Almost without exception NRIs are now portrayed as sometimes wealthier than Indians in India but no different culturally from them. Indianness is now determined less by geopolitical location than by the performance ("maintenance") of cultural and "traditional Indian values" that encapsulate the "real India." (2005, p. 61)

I concede this point to an extent and certainly understand Desai's assertion that Bollywood film has evolved in many ways in respect to its treatment of diasporic Indians. At the same time, however, there are clearly many aspects of representation in 
Bollywood films that do not speak to the realities of diaspora or to living in countries outside of South Asia. As several of the participants here noted, Bollywood films may indeed be willing to speak to NRIs (non-resident Indians) but they do not do so in ways that accurately depict the realities of living in countries that are loosely categorized as Western and usually translate to Canada, the United States, England and Australia. Most significant to those same participants, Bollywood showed a definite refusal to depict people who are of South Asian origin but who have been born and raised elsewhere. There are exceptions, as in the case of $D D L J$ and the later Kal Ho Naa Ho (Tomorrow May Not Come, 2003), but they are few and far between. Where they occur, they are frequently negative, as evinced by even earlier examples such as Hare Rama Hare Krishna (1970).

Heavily nationalist discourse in Bollywood is nothing new and has not receded noticeably in contemporary film, where subjects are expected to be overtly pro-Indian, to preserve their beliefs and to respect traditional rules of Indian/Hindu culture, such as deferral to parents and other elders. The nature of nation does not appear to have changed substantially either, although Mishra (2002) points out that Bollywood's effort to market to the diaspora is one possible reason for a softening of rigid patriotic commentary. Punjabi culture seems to be incorporated slightly more often into popular films, and the film Veer-Zaara (2004) went so far as to promote a Hindu-Muslim, Indian-Pakistani romance that dwells continually on the unity of South Asia and its peoples. However, as I note in later chapters, discourses around Islam and Pakistan often remain exclusionary and rooted in longstanding Orientalist archetypes about Muslims. Ironically, while Said (1978) popularized the term Orientalism in reference to negative discourses constructed 
by the West about Islam and the East or "the Orient," the same tendencies seem to have been imported into Bollywood, a setting where the presence of Muslim writers and actors does not appear to have resulted in fewer exoticized or superficial portrayals of Muslims.

The identity promoted in Bollywood, then, is often nationalist to the point of denigrating any and all potential threats to the nation, from neighbours such as Pakistan to foreign influence from the United States or England. It is generally Hindu, often middle-class and also offers images of the nation that are gendered in significant respects. The moniker of Mother India, attached to a classic $1957 \mathrm{film}$, is no coincidence. In a genre whose storylines often circle largely around romance, marriage and procreation, women are invested with the responsibility of maintaining cultural rituals in order to teach them to children, thereby ensuring the safe continuation of the traditions that define this imagined India. Although these women can now be seen in educational and professional settings, and sometimes declare their independence, it is frequently the case that they are eventually led to marriage as the ultimate act of importance in their lives, with the assumption that they will be raising children and looking after their husbands. The protection of women, especially mothers, is an overriding theme in many such films, which suggest that the nation is feminine, nurturing and a space of nearly inevitable return.

\section{Young Muslims of South Asian Origin in their Own Words}

With all of the above in mind, I set out to interview young Canadians of South Asian origin to obtain their own impressions about nationality, ethnicity, religion, media, and the purported portrayals of themselves found in Bollywood cinema. The details of the methodology, including the specific reasons for conducting interviews, are elaborated 
upon in Chapter 6, but in brief, I felt that group and individual interviews would allow me to find out answers to my questions in sufficient depth. Ethnography and/or interviews have often been favoured choices in similar studies, as in Maira (2002), which combines the two, or Gillespie (1995), which uses survey data to supplement ethnography, but the kind of personal observations I sought on the subject of identity formation and media influence could, I felt, best be obtained here through interviews. Originally these were expected to be conducted in a focus group format, and some were still carried out in smaller groups while others were conducted individually, but the process and findings did not seem substantially different from one format to the next. My original intention was to conduct focus groups in Toronto and Vancouver, given the considerable diversity of both, their prominent South Asian and Muslim populations, and their positions as nodes in a widespread South Asian diaspora. Vancouver, a relatively small city when viewed on a global scale, has nonetheless been the source of several South Asian Members of Parliament at the federal level, a South Asian Muslim Senator and the country's first South Asian Premier (who later served as a federal Cabinet Minister). Toronto boasts the country's largest population of South Asians and demonstrates enormous plurality.

I limited my search to Canadians between the ages of 19 to 29, operating on the assumption that these years, while representing a wide range of experience, marked a period where ideas about identity and adulthood had already been explored to some extent but were not necessarily cemented. Certainly identity is also explored at younger ages, but notions around this may still be nebulous and influenced strongly by parental input. Indeed, several of the participants in this study noted reflectively that they began to give more thought to who they were and how they fit into their various communities as 
they aged, as they came into contact with more sources of education, and as their social networks altered. The change may not have been as pronounced as that identified in Maira (2002), where several interviewees seemed to experience a marked increase in their sense of belonging or ethnic identification once they entered university, but it did seem to be there to a certain extent. Moreover, participants at this stage of their livesundergoing or finishing education, beginning careers, entering or cementing serious relationships - were well-positioned to address questions of belonging, integration or nationalism, as they had already undergone relevant experiences and were also thinking of the future, their place in various communities, and how their own lives could be interpreted in relation to that of previous or future generations. These young people also possessed the acumen to convey their opinions in ways that were thoughtful and significant.

One of the primary goals of this study was to find out if minorities who had been mainly raised in Canada were indeed, as Reitz and Banerjee (2007) suggest, alienated and felt a lack of belonging to Canada, or, as the CRIC-Globe and Mail survey on The New Canada suggests, well-integrated, happy to mix with and marry into other cultures and faiths, and notably tolerant (Anderssen, 2003, pp. F1, F3-7, F12). Accordingly, I sought out participants who had lived in Canada from the age of five or younger, a seemingly arbitrary distinction but one that I considered useful given that primary education in Canada is likely to start around that time. Since most of my participants were born in Canada, this did not raise many problems although it did result in pre-screening exclusions for a few young people who arrived in Canada after the age of five.

I canvassed schools, community organizations, and social networks in order to 
recruit participants, but the most successful of these techniques was the use of social networks, or a form of snowball sampling. Friends, colleagues, relatives and acquaintances all sent recruiting e-mails or made telephone calls on my behalf, as well as providing me with contact information so that I could recruit directly through e-mail. Some participants also recruited on my behalf, sending out e-mails or providing contact information for acquaintances who might be willing to give interviews. Eventually, I obtained 22 participants altogether, travelling back and forth between Toronto, Vancouver and Ottawa to interview them. In an amendment to my initial plan, I added Ottawa as a research site for reasons of accessibility, and this yielded some excellent interviews. In fact, the very first group interview was conducted in Ottawa, one of only four small group interviews - another was held in Toronto, two others in Vancouver. Altogether, I spoke to 5 participants from Ottawa, 9 from Vancouver, and 8 from Toronto. Due to issues around participants' availability on scheduled focus group dates, interviews in small groups or on an individual basis did become the preferred means of obtaining input, rather than the larger focus groups I had originally envisioned, and these took place at different intervals throughout the year 2006, with a very few interviews occurring in early 2007.

In total, I interviewed 12 people through groups and another 10 individually. One unforeseen advantage of the smaller groups and the individual interviews was that I soon discovered a level of detail and depth emerging in some interviews that would have been impossible to manage appropriately in the larger groups of 8-10 that I had first projected, a factor that Durham indicates as well when explaining why she chose to use a small focus group in her own study of South Asian girls (2004, p. 146). In a study that asked 
questions about less broad issues, the larger focus groups I had projected might have been more feasible, but in this case, the smaller groups and the individual interviews seemed more suitable. Although my research plan maintained a distinct emphasis on the Muslim experience, I interviewed young South Asians who practised Hinduism, Sikhism and Christianity, in order to ascertain whether there were any nuances particular to Muslim participants' responses. The resulting sample is too small for widespread generalizations, as I interviewed only 4 Sikhs, 5 Hindus, and 2 Christians, as opposed to 11 Muslims, but it did provide detailed, contextualized commentary on complex issues.

Despite the inability to generalize on a large scale, however, it is interesting to note a distinct consistency in some respects between my findings and those of Desai (2005), Durham (2004), and Haji-ar-were (2006), which may imply that a larger sample would reaffirm the results. Like the young South Asian American participants in Desai (2005), informants here indicated that popular Indian cinema can play an important socializing role, acquainting viewers with rituals or behaviours that were otherwise foreign to them, or, conversely, reminding them of practices they had witnessed at home or during visits to South Asia. A consumerist undertone to some of this viewing emerges both in Desai's findings and those here; while the young people I interviewed appeared embarrassed at times to admit this, their motivation for watching the films was sometimes linked to their desire to know what was fashionable, although this was not always funnelled directly into the notion of products for purchase - trends in music and dance were also important. The adolescent girls in Durham (2004), also Americans of South Asian origin, indicated their sentimental attachment to Indian song and dance as well, agreeing with the participants here that the films could be as absurd as any mainstream 
Hollywood confection, but nonetheless finding a meaningful cultural connection to Bollywood that they could not find elsewhere.

However, while some of these same themes emerge in Maira's (2002) interviews with South Asian American youth, she also indicates a sense of nationality and belonging that is complicated and uneasy. Observing young people in their university years, she documents a growing tendency for some to model behaviours that they consider authentically South Asian. Their rigidity, combined with a mainstream American emphasis on strict patriotism, combine to place some young people in an uncomfortable position; some marginalize themselves within American society, others do the same in Indian communities, and others attempt an awkward balancing act of competing norms that they see as equally unfair and demanding. Trips to India do not necessarily alleviate a sense of alienation from American society, as these individuals are judged in both places. This sense of duplicate foreignness is also identified by the British youth of Pakistani or Kashmiri origin in Cressey (2006), whose trips to Pakistan and Kashmir can provide belonging, but can also provide a painful reminder that they do not really fit in anywhere. In contrast, only a few of the young people in this study seemed to grapple so strongly with these issues. Several did comment on an ongoing existential debate regarding the true nature of home and their place in the various societies with which they were familiar, but many from each of the cities in question indicated the importance of having grown up in Canada. They saw this as important because they possessed the correct tools to succeed in Canada, but they also viewed Canada as a place whose very existence was defined by the processes of migration and integration. In that respect, my findings were unique to the setting of my research, but may also have been influenced by 
the timing of my study, which took place 18 years after Jiwani's (1989), where the sense of Canadian identification is emergent but less pronounced. The age group of my participants was possibly also significant-slightly older than the young people in Cressey (2006) or Maira (2002), they were simultaneously youthful enough and old enough to have given considerable thought to who they were, how they wanted to live, and where they belonged.

Haji-ar-were's (2006) study, dealing with different generations of Pakistani Muslim immigrants in Bangkok and Sydney, straddles some of these same fault lines. Second-generation immigrants to Sydney are somewhat more able to adapt to the norms of Australian life than their elders, although they do demonstrate uncertainty about where they belong and how accepted they are. Immigrants to Bangkok are relatively wellintegrated and identify easily as Thai, because they find Thailand to be a warm and accepting place. In this setting, where they feel utterly free to be Muslim, they are less likely to question themselves about their identity and their practices than their Australian counterparts, meaning that they were more likely to continue the same practices older generations had brought with them, while immigrants to Australia re-visited these and reinterpreted them as necessary. As an example, marital relations and gendered duties were viewed rather differently from one generation to the next and one city to the next. In Haji-ar-were (2006), as in nearly every other study in this area, approaches to gender and the way these must be considered and evaluated in light of changing social norms arise repeatedly, even if gender is not an intended focus of the study. This consistency is fascinating in itself and indicates the importance of discussing gender relations in studies of South Asian and/or Muslim life. 
Findings from one study to the next, then, must take into account various factors, and if the results here are any indication, the perception of Canada as an accepting and multicultural place is a key factor that may not be replicated elsewhere. Other findings indicated definite diversity on some topics, particularly in reference to the relationship with media, but there was also some endorsement of findings in Desai (2005), Durham (2004), Gillespie (1995) and Maira (2002). I found both the differences and the similarities to be revealing. The most important commonality may lie simply in the finding that Bollywood does appear influential; it does elicit a reaction even from those young people who would prefer not to acknowledge it. I had hypothesized that some or most participants would be relatively unmoved by the messages in this type of film and that this lack of reaction might in itself be telling. After all, even those youth who are interested in their South Asian origins do, as several participants pointed out, have numerous venues available for the exploration of their culture, and Bollywood can be, in some respects, an acquired taste: its length, its language, its format and its rather heavyhanded storytelling are not for everyone. However, as participants in Desai (2005), Durham (2004), Gillespie (1995) and Maira (2002) have indicated, Bollywood film is unique in its impact. Even those young people who do not admire it in any pronounced way had opinions on it, and these opinions were far more complex than one might imagine. A few disliked Bollywood more than they liked it, but the parameters of this antipathy were noteworthy. Informants' comments were often framed in relation to their own social positioning, not only in Canada but as members of a diaspora. They referenced the way these positions had changed, and explained the manner in which upbringing, education, peers and other media all combined to frame their interpretations. 
Bollywood's attempt to offer a pan-Indian, all inclusive vision does not seem to resonate significantly with many of the viewers interviewed here, some of whom spoke critically and perceptively about the portrayal of diasporic individuals in these films, a finding which is so far unique to this study. At the same time, few abandoned these films entirely, and one participant, whose stance was the most oppositional of all, concluded her interview by stating that she could understand the movies' appeal. Moreover, despite their critical comments, at times the reasons for enjoying selected films appeared to be rooted in consumerist, sentimental or escapist readings of the work. This was not true for all participants, but for some, there was a slippage between this desire to be oppositional and this enjoyment of the dominant messages that was simultaneously perplexing and understandable. Some young people recognized the contradictions embedded in their own patterns of media consumption and spoke of this guiltily, while others appeared quite unconscious. Few felt that they were receiving everything they needed from any of the media to which they had access, but they dealt with this lack in different ways, combining different media forms, applying informal knowledge to the reading of texts, or accepting that complete fulfillment was not possible. All the same, media were important to them, and Bollywood was, as Gillespie (1995) has already noted, particularly significant within a familial setting, allowing for cross-generational enjoyment and discussion.

The resistance alluded to in the title of this work, then, came to take on far more meaning than previously anticipated. I employed the word as a reference to theories surrounding immigrants who refuse to assimilate completely into the host society, resisting the temptation to become part of the mainstream, holding on valiantly to what 
they see as their defining, original identity. The combination of resistance and futility in the title referred to the fact that even those individuals who struggle most ardently to retain a sense of their origins and cultural difference are unlikely to engage at every stage of their lives in an unwavering repudiation of the host society. Resistance may not be entirely futile, but it is complicated and laden with ambiguities for those who must live in a society while juggling competing demands for national, ethnic and religious authenticity. I had anticipated hearing as much from my respondents, and I was not disappointed. However, I was surprised by the applicability of this finding to a number of issues explored throughout the dissertation. In this work, resistance, and the difficulty of enacting resistance in a straightforward manner, came to signify a number of issues: Bollywood itself, as a counterpoint to Westernization/Americanization, exhibited a form of resistance to cultural domination but also emulated American cinema in some respects. Similarly, the Bollywood viewers interviewed here recognized that the act of consuming popular Indian cinema could signify resistance to dominant North American media, but they also indicated that this was not a wholly empowering act, as Bollywood film itself did not represent the realities of South Asian lives, particularly diasporic lives.

Most importantly, in light of the aims of this research, resistance did indeed have a nuanced and complicated meaning in terms of identity construction. The young people in this study rejected nationalist or ethnic labels that they considered inappropriate, whether or not these stemmed from other South Asians. They resisted exclusion from Canadian society, but also claimed their ethnic origins and their faith with pride, while offering generally clear-sighted critiques of the aspects of their cultural and religious communities that concerned them. In this, they both aligned with and moved away from 
the American youth of South Asian origin in Durham (2004) and Maira (2002). Like my Canadian participants, the American youth-who, notably, were often younger than my own respondents — had a variety of experiences with culture, religion and nationality, but theirs appeared to be buttressed by stronger nationalist and communal pressures. The young people in this study did offer accounts of cultural and religious absolutism that others tried to apply to them, as well as purist notions of nationalism that some used to try to exclude them, but these did not seem quite as pronounced as in the American cases, where the desire to be all-American warred with a cultural conservatism so pronounced that it began to be expressed within youth subcultures. The differing experiences in this regard may explain why the young people here did express serious concerns and issues around the question of identity, yet many did not see these as unsolvable. At the same time, their self-proclaimed comfort levels did give way to varying levels of doubt, confusion, and acknowledgement of difference.

Resistance: How Much and What Kind?

As indicated by the articles from Valpy and Anderssen (2003) and from Jiménez (2007), as well as the studies by Desai (2005), Durham (2004), Handa (2003), Hoodfar (2003) and Maira (2002), first- or second-generation immigrant youth living in diaspora remain a source of preoccupation at a number of levels. Common to all of these works is an interest in identity — what is the identity claimed by these youth, and why? How do they construct that identity and then maintain it? The young people in this study indicated firstly that this was a process whose nuances differed from one person to the next, and they also suggested that identity construction began early, in the home, and continued into the twenties with the potential to fluctuate even beyond that. These respondents 
could be defined loosely as youth—in fact, internships and similar programs offered by the Canadian government identify youth as individuals between 19-30 years of age-but they also fell into a liminal category in terms of age, not simply their ethnicity or nationality, which meant that they both corroborated the findings in earlier works on youth and added to it, providing a developmental arc that indicates what may follow the stages identified in Durham (2004), Gillespie (1995), Handa (2003) and Maira (2002). Unlike Durham's (2004) teenage respondents or Maira's (2002) university ones, these young adults spanned more than one category. Some were still completing school, one had already started a family, and the rest were old enough to consider seriously the ways in which their past could create a bridge to their future, allowing them to move out of a childhood defined by seemingly simple influences and into an adulthood marked by a diverse pantheon of cultures, interests, and people. Their occupation of such transitional space might explain the deep levels of insight and thought they had devoted to the topic of identity. Identity was not static nor was it the same for everyone, although there were some definite common denominators, such as an attachment to their Canadian citizenship.

All of the respondents also indicated, however, a distinct consciousness that questions from others about their nationality were rarely asking about their citizenship or place of residence - rather, it was an inquiry aimed at uncovering their ethnic origins, which most of the young adults here saw as an attempt to characterize them as other than fully Canadian. The wryness - and resistance - with which many of the respondents met these kinds of inquiries suggests their familiarity with a racialized discourse that would push them to the margins of the nation, as visitors or temporary residents rather than full 
citizens, a discourse that Jiwani suggests recurs in many sectors of Canadian society despite its claims to openness and pluralism (2006, p. 112). Their frequent refusal to legitimate this discourse, with the possible exception of occasions when the questions issued from other South Asians, illustrates their equal awareness of those Canadian claims, best expressed through a policy of multiculturalism that purports to welcome and accept people of all cultures and faiths. Several young people made explicit reference to this policy, highlighting its shortcomings in actual practice but striving all the same to see it realized as fully as possible.

Hence, on the surface, there was less contradiction than one might expect in reconciling ethnic or religious identity with nationalism. More than one participant suggested that Canadian policy ensures that there is no dissonance in proclaiming fealty to Canada as well as to one's ethnic or religious communities. However, interviewees were not naïve in their understanding of the layered identities they had constructed or were constructing. Several commented on experiences of racism, on the diversity within their communities, or of differences in cultural and religious practices from one country to the next. Some spoke of a very conscious process of identity formation, and noted that they had experienced far more confusion as children. Young Muslims seemed to have devoted substantial thought to their own positionality as well as to that of their peers, many of whom were spurred to understand their religion better by the intense external focus placed upon it in recent years.

Not all of these young people had purposefully sought out information on their ethnic ancestry or religions, with some suggesting that they were shaped in fundamental ways by parental and community influences, which tended to be more profound than 
anything else they had encountered. However, the entire group was able to comment on media in some way, indicating their awareness of the skewed representations found in a variety of media, including mainstream North American and Indian sources. The responses that did filter through or were offered at the very beginning revealed that various media were meaningful, even if they contained depictions that were not especially popular or accurate. Reactions abounded to those media, including film, which claimed to speak to nationalist, ethnic or religious constructions. These reactions are detailed further in the following chapters, particularly Chapter 7, but it is fair to say that media, including Bollywood and sometimes especially Bollywood, did appear to play a significant role in identity construction for participants, both assisting and hindering resistance to marginalization, racism and stereotyping.

\section{Transcending the Bell Jars: Identity, Belonging and Understanding}

We children of immigrants often seek to return to the country that our parents have left behind. I have made my own wanderings through Malaysia, through Hong Kong and China. We know there is something to be recovered, we want to open what our parents have closed, we are ever curious. I make these journeys not because I hold onto the belief that there is another place and culture in which I might be more at home, but because I place my trust in empathy, in what Michael Ignatieff describes as the possibility that "human understanding is capable of transcending the bell jars of separate identities." (Thien, 2003, p. A13)

The ambivalence demonstrated in the use and interpretation of media was also demonstrated in the complicated relationships these young people had with place, however. One young woman, raised to think of herself as fervently Pakistani, spoke eloquently of the fact that she benefitted from a hybrid culture that her parents would be unable to recognize, but at the same time having a foot in each world meant not being able to stand completely in one. Taken to Pakistan, she did not find home there; brought back to Canada, she could not say that she always felt a complete sense of belonging 
there either. In part, where a sense of belonging was incomplete, it did not seem to be for lack of trying on the part of these young people. As I go on to discuss in subsequent chapters, the individuals in this study speak articulately and sometimes poignantly about learning how to live with multiple identities, and they sometimes work actively to construct solutions to cross-generational and cross-cultural differences that could create conflict. They are aware of the issues around nation, diaspora, media representation and identity that are raised in this study, but they insist on defining themselves, rather than submitting to the constructions placed upon them by others. Undoubtedly, this is a more self-aware process for some than for others, and some encounter greater obstacles than the rest, yet in the end they provide analyses that suggest their experiences with difference have shaped them in meaningful ways.

Critics such as Homi Bhabha (1994) have spoken at length about the possibilities provided by inhabiting what has been dubbed the third space, a place that embodies the realities of being neither here or there, and have suggested that this is a space of infinite potential for creativity and change. This is not always the case, of course- the third space can also signify loneliness and alienation. Not all of the young people cited in this study would even agree that they fit into a third space. Several seemed to describe themselves in ways that suggested complete peace with an entirely Canadian identification. In this mode of thinking, people who did not understand that being Canadian means having an ethnic lineage that should be embraced were simply misinformed, and had minimal effect on the identity formation of these young adults. Some, however, did see themselves as occupying a rather unique position in the Canadian mosaic and even in the world, and this perception led them to be particularly sensitive to other groups. Indeed, while a few 
respondents commented in passing that neither their parents nor Canadian society really demonstrated the tolerance that they preached, they themselves seemed invested personally in understanding others' ethnicities and traditions, and they also had a stake in promoting evolution and change within the communities they inhabited. This kind of change may not be the sharp-edged innovation some envision in the third space, but it is perhaps notable as it can come to its most fruitful realization there.

This dissertation opens with a discussion of questions around diaspora and nationhood, including those related to hybridity, community and citizenship. Although they discuss these concepts in their own words, the respondents' comments do speak very much to the realities of globalization and responses to deterritorialization, the pressures placed upon diasporic young individuals to construct and protect community, the role that media can and do play in the formation of identity, and strategies for survival in a society that is increasingly marked by hybridity and diversity, characteristics that trigger fear for some but hope for others. Plurality - both in the sense of possessing multi-faceted selves and in the sense of a society populated by peoples of all kinds-did not appear to pose a threat to these respondents, although they were accustomed to encountering others who felt that it did. Many spoke of the ease with which they could interact with people of other faiths and ethnicities, an ease that had escaped some of their elders but that they felt was an inevitable byproduct of living in Canadian society. This is not to say that differing levels of power were not present in particular situations, or that there was no misunderstanding regarding other groups--indeed, even the most positive of the participants here sometimes implied, however unintentionally, that undercurrents of racism, ignorance and judgement were or had been realities of their lives. It is to say, 
however, that these individuals have been doing their best to learn about others, going beyond the simplistic media representations they critiqued here yet applying active interpretations to those that tried to offer messages about nation, ethnicity and religion. As Thien (2003) posits above, these are second-generation immigrants who are aware of their place in the world, and who retain an interest in that world.

\section{Note on Transliteration}

Words and names in Arabic, Hindi and other languages recur throughout this dissertation, and they are presented differently in various sources. Where I have quoted directly, I have retained the original spelling used by the author in question. In other areas, I have chosen the spelling that appears to be the most standardized, although I recognize that native writers and readers of each language may not see this as the most exact rendering possible. As much as possible, I have attempted to retain consistency in spellings of film titles, actor names and religious and cultural terms in order to simplify the reading of this text.

The participants in this study were kind enough to provide me with names and spellings of their favourite movies. In a few cases, I have found alternate spellings that I believe to be the standard spellings, and have thus utilized these rather than the ones provided. Many of the movies cited throughout this study have been released under English titles or can be translated, and where possible I have provided these English names in parentheses following the Hindi title. However, in some cases, the title merely refers to the name of a character (e.g. Veer-Zaara) or it may be interpreted in a number of different ways. In the first case, I have usually refrained from adding any explanation unless the character's name may signify an additional meaning (e.g. the title Fiza refers 
to the heroine but can also be translated as "Air" or various synonyms of same). In the second, I have offered the translation I believe to be the most apt but this is generally based on the information provided by other sources, including academic works, webbased databases such as The Internet Movie Database (IMDb) and more informal references such as friends or family. 
Chapter 1

\section{Theories of the Wandering Soul: Interpretations of Diaspora}

The sense of uprootedness, of disconnection, of loss and estrangement, which hitherto was morally appropriated by the traditionally recognized diasporas, may now signify something more general about the human condition. (Cohen, 1997, p. 196)

\section{All Around the World: Displacement and Dispersal}

The notion of diaspora is central to this study, and to many of the current inquiries occupying news headlines and policy reports about the perceived problem of individuals who do not fit into the so-called host society. Age-old patterns of immigration and of displacement have created dispersed communities of people around the globe, a tendency that has become especially notable in recent decades as migration becomes more frequent, partly due to a need on the part of emigrants but also to the need of host countries, many of which are now dependent on immigration to maintain their populations and competitiveness as birth rates decline. This tendency is also significant in part because of perceived outcomes: in the past several years, as problems from planned terrorist acts to riots to complaints about sharia law and cultural practices have seriously troubled the foundations of self-proclaimed tolerant nations, political pundits have blamed any related or resulting social unrest on the inability of some immigrants to integrate. Pro-assimilation discourses suggesting that recalcitrant minorities must blend into the host society as much as possible are hardly new. Yet these commentaries are interesting and perhaps problematic due to the change in the population being discussed. No longer are these policymakers or journalists necessarily addressing new immigrants. In France, the Netherlands and Canada, the events which caused those societies to question their policies and beliefs around pluralism and acceptance revolved chiefly 
around young second-generation immigrants - members of the Muslim or South Asian or Middle Eastern diasporas, to be sure, but citizens and longtime dwellers in the countries where they were accused of burning cars, committing murder, and planning terrorist acts.

Whereas some may associate diaspora with immigration and resettlement, there is a less clearly defined middle ground for the children and grandchildren of those who left their countries and started anew. This is in part because the notion of diaspora itself is so difficult to define. Some theorists are content with loose definitions, recognizing any globally dispersed ethnic group as a diaspora. However, writers such as William Safran (in Cohen, 1997) and Robin Cohen (1997) have made game- - though slightly differentattempts to offer specific criteria for the identification of diaspora. Cohen endorses Safran's original explanation of diaspora, in which the members or their ancestors have been dispersed from some central point to at least two foreign places; the members have formed collective memory or myth around the homeland; they do not expect to be fully integrated into their new host societies and hence occupy a separate position; they idealize the homeland and hope to return at some point; they work to maintain or further the interests of the homeland; and they retain a sense of kinship and solidarity with that homeland. Cohen's additions refine two of these traits, firstly suggesting that the original dispersal would often occur in relation to a traumatic or unjust event, the recollection of which acts as a unifying factor for members of the diaspora. He adds that the effort to maintain or restore the homeland may even be extended to create the homeland itself, since there are instances_-as will be discussed here_-of diasporas that do not actually have a geographical point of origin to which members may return. 
The notion of diaspora is hence both complex and contested partly because there exists, as Cohen (1997) suggests, different forms of diaspora-examples include labour, imperial and victim diasporas-but also because diasporas are often in a state of flux. This complexity explains, to a certain extent, why apparently dissimilar configurations may be referred to as diasporas. It also explains why the term is sometimes used interchangeably with others that refer to the dispersal or movement of peoples e.g. exiles, transmigrancy, deterritorialized nations. A diaspora may consist of some exiles, who have been forced to depart their home country due to political unrest or persecution, or transmigrants, immigrants who may have left home in search of greater opportunity but continue to "maintain multiple relationships_familial, economic, social, organizational, religious, and political-that span borders" (Basch et al., 1994, p. 7). A diaspora may also be linked to a deterritorialized nation whose members have been similarly removed, through circumstance or choice, from the actual physical territory they consider home, but diaspora is not necessarily synonymous with any of these terms. Although there are some commonly recurring characteristics that can be associated with the notion of diaspora, such as dispersal across more than one country, a collective nostalgia for a shared homeland, or the maintenance of bonds through cultural products and media, there is no essential model of what a diaspora is or should be. Indeed, as migration becomes increasingly common for some individuals, new ideas of diaspora evolve accordingly. The historical roots of the term diaspora lie in the idea of forced migration, with the Jewish diaspora serving as the archetypal example of this. At first glance, this seems to be a clearly defined model for diaspora. Unable to remain settled due to factors such as recurring persecution, the Jews, no matter how far apart they were from one another, 
developed a sense of kinship that transcended the borders separating them. Regardless of how well they integrated into their host societies, they maintained a belief in a Jewish homeland to which they would eventually return. However, even this classic example is complex on many levels. As Cohen notes, Jews, like Sikhs, present an interesting case because they can be viewed as comprising a religious community, a cultural one, or a nation (1997, p. 106). This makes it impossible to easily extrapolate from this example to others, and it also demonstrates the vast diversity found within diasporas.

Diasporas can represent the outreaches of imperial power, the dispersal of persecuted or harassed communities, or the spread of workers to regions where they are needed. Although the circumstances under which these types of dispersal occur may have changed throughout the decades, these basic models are still found today. While the era of colonization may be officially over in most parts of the world, its effects on the countries once held in its grasp remain. Residents of former colonies may migrate elsewhere due to economic or political instability wreaked by a colonial regime, or simply to improve their fortunes in bigger or more thriving places. In some cases, due to familiarity with a colonial language or school system, the colonized may find themselves departing for the "home country," the nexus of imperial power. In other cases, the reasons for departure may be even more mundane: as Wanning Sun (2002) suggests, once exposed to a foreign way of life, people may contemplate how that life could be better and more interesting, and may consider departing their countries or cities in search of it.

Sadly, it is also true that diasporas may still be formed out of necessity, if groups of people face some form of danger or harassment, as in the case of the Iranians documented by Hamid Naficy (1993, 2001, 2003) and Annabelle Sreberny-Mohammadi 
and Ali Mohammadi (1994). Wars, political unrest or restrictive regimes still provide impetus for migration. Similarly, economic interests still play a role in the movement of people, although it is possible that those people who migrate for work or education have more control now over their movements than would have been the case for the Africans who crossed the Atlantic as part of the slave trade (Gilroy, 1993) or the indentured Chinese or Indian labourers who were sometimes imported into countries to carry out dangerous or menial work. Now, as Aihwa Ong (1999) notes, it is still the case that Asians may circumvent the globe for work, but this migration is more often triggered by their own desire to better themselves and to acquire the social status linked with mobility and foreign achievement.

These tendencies towards continual movement are facilitated, if not encouraged, by the evolution of media technologies. Diasporas have often been reliant upon media to retain a sense of internal cohesion and closeness among their members, but the type of media used can vary. Marie Gillespie (1995) documents the use of Indian dramas on television to educate Punjabi youth living in the UK about their culture and history; Bollywood films also play a role in the formation of community and identity among any number of Indian expatriates (Mitra, 1999; Nandy, 1983, 1995; Ray, 2001, 2003); music videos perform a similar function for dispersed Vietnamese (Cunningham and Nguyen, 2003), and other examples exist of the way media can be used to provide news from a home country or from other diasporics, to offer a sense of culture that cannot necessarily be accessed in the host country and to create a common place for meeting or discussion. In fact, diasporas are particularly distinguished by the fact that they can actually exist entirely in a mediated form. For instance, Anthony King (2003) explains how the Internet 
keeps alive the memory of a Rhodesian community, despite that country's demise. Although this is a rare case, media do manage to foster a sense of community and belonging among people who may otherwise be unable to retain any connection. This function is similar to that offered by newspapers and novels in Anderson's Imagined Communities (1983), although the increasing sophistication of media forms means that communities are now able to retain a more constant and personal sense of connection through e-mail, chat rooms, and the Internet, no matter how widely scattered they may be.

This reliance on media, as well as the fact that these diasporas are not necessarily joined by any common territorial link, helps explain why diasporas are often labelled imagined communities. Unlike deterritorialized nations, where there is a distinct awareness of what constitutes the homeland and a relationship with same, diasporas may consist of people who have never visited the so-called homeland, or who lack any ambition to do so. Lisa Tsaliki's (2003) discussion of a Greek virtual community is not so much specific to a connection with Greece as it is to a more nebulous, overarching sense of Greekness that may be held by second- or third- generation immigrants, in the same way that Manas Ray's doubly-displaced Fijian Indians living in Australia (2001) do not all retain a sense of belonging to India as a country; rather, they maintain a commitment to some hybridized form of Indianness.

In short, there is no essential and universally recognized definition of what constitutes diaspora, but in a sense it is characterized by what it is not: it is not a nation in the same structured way as a legal polity, but it does contain elements of nationalist feeling. It is not necessarily a community of exiles, but exile may be part of the diasporic 
experience. It is an imagined community in the sense that it is very often, like the communities described by Anderson, held together by media, although the media being used may vary, and may hold more importance in some diasporas than in others. These media may be utilized independently by individuals or may be tools of the nation-state. Indeed, while some diasporas may arise without the assistance of a steering hand or cause, there are cases where the state works consciously to establish or maintain this notion of a community that retains its links to the homeland. Diasporic bodies can challenge the existence of some states but they can also provide important economic and political benefits, a fact recognized by a number of governments. As migration increases, travel becomes more accessible or conflict creates new generations of displaced groups, the idea of diaspora continues to evolve, with different examples constantly emerging.

While some European diasporas were consciously established by colonial powers in an effort to facilitate the spread of empire (Cohen, 1997, p. 67), other diasporas are defined by a continued sense of connection and loyalty to "the old country", even if the old country no longer exists or never existed as the migrant now recalls it (Cohen, 1997, p. ix). Immigrants who feel alienated from the nation-state(s) in which they now reside may find the embers of patriotism to their homeland rekindled. Shahnaz Khan's study (2000) of female Muslim immigrants in Canada finds that while some of her subjects reacted to discrimination by attempting to assimilate into the larger Canadian population, masking as many markers of cultural difference as possible, others asserted their Islamic, South Asian and/or Arab identities more fiercely than ever before (also see Hoodfar, 2003). Paul Gilroy documents a similar pattern among diaspora blacks who "sought to construct a political agenda in which the ideal of rootedness was identified as a 
prerequisite for the forms of cultural integrity that could guarantee the nationhood and statehood to which they aspired" (1993, p. 112), a logical response to the neglect of black history and culture these individuals so frequently confronted. Although Stuart Hall (1990) agrees that marginalization helped create a sense of a larger black community with an understanding of its history and origins, he adds that this realization was achieved at least partly through the mediating effects of cultural texts such as film. The Internet plays a similar role for displaced Chinese, some of whom cling to the idea of Chinese sovereignty with more determination "than do their compatriots at home, in spite of the fact that for these migrants, a peopled and territorial nation called 'China' is becoming increasingly a fantasy space" (Sun, 2002, p. 114). The mental confusion created by physical displacement is being assuaged through alignment with a "strategically essentialist discursive position that corresponds with the PRC's official discourse of the nation" (Sun, 2002, p. 115).

However, this is only partly due to the influence of media controlled by China. Chinese living abroad can turn to mass media for different forms of community, but, Sun suggests, Internet chat groups and websites promoting a sense of Chinese victimization at the hands of Japanese hold a particular appeal for these migrants. Their efforts to provide a sense of community for themselves are assisted by other Chinese who use cybertechnology to argue that China is oppressed. As with other diasporas, these Chinese migrants then feel an additional measure of loyalty to China and outrage at those who might attempt to challenge its sovereignty (Sun, 2002, p. 133). In this case, it is merely convenient for the Chinese government that the transmigrants' attempts to come to terms with their condition result in renewed patriotism. After all, "transnational bonds no longer 
have to be cemented by migration or by exclusive territorial claims. In the age of cyberspace, a diaspora can, to some degree, be held together or re-created through the mind, through cultural artifacts and through a shared imagination" (Cohen, 1997, p. 26). Thus, a strengthened sense of nationalism does not mean that transmigrants are more determined than ever to return to the homeland. Rather, they seek other means of asserting their identities alongside the more conventional ties that the home and host countries may impose (Karim, 2003, p. 9). Hall dismisses the conventional idea of dispersed peoples and nostalgia for an ethnically pure past in the definition of diaspora, pointing instead to the "recognition of a necessary heterogeneity and diversity", "a conception of 'identity' which lives with and through, not despite, difference" (1990, p. 402).

Ray points out that it is no longer really possible to view territorial nations as entities clearly delineated from diasporas, since the latter can be "networked to the homeland culture to such an extent that the traditional divide of outside/inside loses much of its analytical purchase" (2003, p. 31; also see Mitra, 1999). In Ray's discussion of Fiji Indians living in Australia, the repeated migration of these individuals does not remove the significance of the original homeland, but a shared ethnic identity also does not completely bind dispersed Indians into a nostalgic group attempting to replicate patterns of India-as-home. These migrants are equally aware of their positioning now, and their ties to the past. Appadurai echoes this, pointing to the dialectical relations that underpin the existence of diaspora:

For every nation-state that has exported significant numbers of its populations to the United States as refugees, tourists, or students, there is now a delocalized transnation, which retains a special ideological link to a putative place of origin but is otherwise a thoroughly diasporic collectivity. (1996, p. 172) 
Although Appadurai is right to highlight both the diaspora's dependence on its origins as well as its difference, it is, as mentioned previously, difficult to arrive at a definition of "a thoroughly diasporic collectivity". As Clifford admits, diasporas "are ambivalent, even embattled, over basic features. Furthermore, at different times in their history, societies may wax and wane in diasporism" (1997, p. 249). Nonetheless, he maintains, as does Robin Cohen, that diasporas do have certain unique traits that separate them from the nation-state: "Nation-states are about welding the locals to a single place, gathering peoples and integrating ethnic minorities. Diasporas, by contrast, imply multiple attachments" (Cohen, 1997, p. 135).The specificity of these definitions may work to exclude certain groups, or to overlook the different characteristics of various members. While diasporic communities may well be formed by those who physically relocate, second or third-generation immigrants may also consider themselves members of an ethnic diaspora. Others may consider themselves part of a diaspora on the basis of religious feeling, even if they do not necessarily claim belonging to a diaspora that coalesces around ethnicity, race or nationalism.

Despite having been raised in a particular country or countries, individuals may have been raised with evocations of a homeland, and may associate themselves with those. Sometimes a homeland may not be the compelling unifying force. As discussed, the idea of Rhodesia manages to hold together an online diasporic community that evokes memories of a time and place lost to the past; Zimbabwe itself is not the entity that attracts the members of this group together (King, 2003). In the arena of religion, Peter Mandaville (2001) points out the way that online discussions of Islam draw together a widely dispersed group of individuals who may be vastly different and who may live 
anywhere in the world. Their interest in the interpretation and practice of Islam finds a virtual place of gathering in online fora, as they have no particular shared point of origin in which they might gather for a reunion.

In fact, Mandaville (2001) goes on to point out that diaspora can sometimes function as the very space that inspires a desire to connect more intimately with religious or ethnic traditions. At the least, it may serve as a place, geographical or otherwise, in which knowledge can be pursued and accepted wisdom can be questioned. He details the way in which diaspora has allowed some young Muslims to approach the subject of Islam with a more open mind than their parents or community leaders, seeking knowledge from disparate sources and challenging conventional understanding of Islamic practices. The concept of diaspora is particularly pertinent in the case of religions such as Islam, as Muslims cannot claim any particular homeland. Even in the Middle East, historically the place many people think of as the cradle of Muslim thought, there are vastly different approaches to the practice of Islam. For the young people in this study, all of whom are of South Asian origin, their ethnic origins had occasionally separated them from Muslims of Arab or other extraction. Yet, placed in a position where the mere practice of Islam itself came under continuous attack, several of the participants felt drawn towards other Muslims, regardless of how widely their beliefs might differ in terms of specific aspects of the faith. Acknowledging the fragmentation within a sprawling, worldwide group of approximately one billion Muslims, not all would characterize this group as a cohesive community. However, there was an entity to which they felt some allegiance, and this factored into their readings of Indian cinema, their use of media, and their beliefs regarding themselves and their identity. 
While activities such as the exploration of religious or ethnic traditions may be alternately applauded or frowned upon by policy-makers such as those in Britain who currently bemoan the failure of immigrants to adopt fully "British" values, Appadurai (1996) argues that nation-states must accept the realities of migration. People and communities, far from leaving their beliefs and values behind when they go to other countries, bring them along and often transform them. Radhakrishnan (2003) agrees, noting that diaspora is a place of promise if utilized correctly. Identities and history cannot possibly be left behind, and nor should they, in this analysis:

the diaspora is an excellent opportunity to think through some of these vexed questions: solidarity and criticism, belonging and distance, insider spaces and outsider spaces, identity as invention and identity as natural, location-subject positionality and the politics of representation, rootedness and rootlessness. (p. 129).

Jigna Desai, while acknowledging the potential for diaspora to be a space of creativity and invention, nonetheless warns against heralding diaspora and its possibilities with unmitigated optimism, suggesting that "the dangers of diasporic studies can be summarized as a valorization of migration without attention to citizenship and the nationstate, an emphasis on the global at the price of the local, and consequently, a subsumption of race to political economy" (2004, p. 23)

This process of coming to terms with competing identities is also mapped out in other works relating to diaspora, such as Naficy (1993) and Sreberny-Mohammadi and Mohammadi (1994) while the South Asian diaspora in particular is discussed by Brah (1996), Gillespie (1995), Handa (2003), Nandy (1983, 1995), and Ray (2001, 2003). In these works, the variety of reactions possible to living in diaspora becomes obvious: Naficy and Sreberny-Mohammadi and Mohammadi note that people living in diaspora 
can mobilize politically on behalf of their perceived homeland, while others, particularly younger members for whom the idea of migration may be less jarring, may embrace the possibilities of life in a host country and leave behind any sense of obligation to the life and people left behind. To some young people, the notion of cosmopolitanism comes easily and is facilitated by financial privilege and a global imagination; for others, as Brah, Gillespie and Handa document in different ways, the experience of movement and settlement may lead to conflicting emotions over their community's role in a larger society and mutually acceptable ways to conform to cultural standards of behaviour. Nandy points out that some of these conflicting emotions are also foregrounded by the complex legacies of colonialism and attendant beliefs about self-worth and identities, while Ray adds the multiple forms of subjugation and repression, as well as the creative responses, that may take place when members are forced to regroup continually-and literally-on the move from one diaspora to the next. Nandy and Ray both document a more painful and politicized coming-to-terms than the positive one described by Handa, as one of the few writers in this area who has looked mainly at youth who are settled apparently comfortably in Canada. Yet her work seems to glide over some of the crucial questions of diaspora that do indeed preoccupy even the second and third generations.

\section{The Sweet Hereafter? Living or Leaving the Diasporic Experience}

While diaspora may be regarded as concomitant with transnationalism, or even in some cases consequent of transnationalist forces, it may not be reduced to such macroeconomic and technological flows. It remains, above all, a human phenomenon-lived and experienced. (Braziel \& Mannur, 2003, p. 8)

As mentioned previously, this project focusses particularly on young individuals who may be considered members of South Asian or Muslim diasporas, despite the fact that they may not be familiar with all of the characteristics of diasporic living described 
by Safran or Cohen. Some are immigrants who came to Canada at a young age, while others are the children of immigrants. Although the participants in this study are Canadian-born or have lived in Canada most of their lives, diaspora nonetheless remains a highly relevant concept to nearly all of them, even if they are unable to articulate a clear definition of the term. As descendants of immigrants, they are conscious of their ties to other countries, to other cultures and to a past that did not include them but affects them in meaningful ways.

Studies of diaspora have often tended to look at the experience of those who actually move, the people who physically disperse and thus form or contribute to a diasporic entity. For the young people in this study, most of whom are second-generation immigrants, it is not necessarily the case that they have ever been to South Asia, or that they have undergone the experience of immigration first-hand. Yet they are conscious that such movement underpins their existence and their current situation. The individuals in this study mainly identified as Canadian above all, yet, as demonstrated by Reitz and Banerjee (2007), this identity was informed by the fact of difference. Reitz and Banerjee sought to uncover whether or not second-generation immigrants had a sense of Canadian identity, and pursued this inquiry by asking their informants about their citizenship and their ethnic or cultural identity (p. 539). The answer to citizenship was clear; the second answer surprised Reitz and Banerjee because "Canadian" was rarely the reply. In light of my own findings, admittedly derived from a small group, this is perhaps not very surprising. Although my own participants spoke clearly of themselves as Canadian, very few would dissociate themselves from an understanding that they have a membership, however tenuous, in a larger, not necessarily cohesive, community. Most saw 
resemblances to other South Asians; others identified membership in a religious diaspora; some could identify a number of places and groups with which they felt kinship, in part because their family history was one of multiple migration. Several were of South Asian origin but their parents had immigrated to Canada from countries outside of South Asia.

For these participants, the connections to diaspora are not necessarily the same as those made and maintained by people for whom the experience of displacement is more direct. The young informants in this study may well have family living in another country; they may embrace aspects of that country's culture and consider it a second home or a place of great meaning. However, for most of the participants, and perhaps for many others in a similar situation, this is not a place of return. Never having left this supposed homeland, and hence an entire life, these young adults do not display the same nostalgia that some of them have witnessed in their parents and other relatives. This may be particularly true for those raised in families where multiple migrations have taken place, so that the connection to South Asia is, in fact, both remote and mysterious, despite the fact that their appearance readily identifies them to others as South Asian.

These informants have been raised in Canada and consider it their home. Simple though this conclusion may seem, it actually muddies the waters of diasporic interests. For the Haitians and Filipinos described in Nations Unbound (Basch et al., 1994), living in diaspora is a way of giving back to their real countries, of supporting their families. The experience of living in diaspora described by Amitava Kumar (2002) is one of poignancy and grief, where an immigrant leaves behind family and friends in the belief that he will return soon, only to find the host country a place where-however bewildering that place may be initially-he can pursue different dreams and hopes. Soon 
the host country becomes the place of permanent residence, and the homeland becomes the place for infrequent visits and the recipient of guilt-ridden telephone calls and unfulfilled promises of return. For these immigrants, living in diaspora can mean a sense of conflict, of being torn between competing commitments that can rarely be resolved successfully. In this case, it is difficult to live in diaspora without being conscious of this fact at nearly all times, yet diaspora also functions as a space of necessity, where employment, economic opportunity or refuge may be sought, regardless of whether or not it is found. In Bollywood cinema, as will be discussed, it is frequently a space where one goes to improve oneself, only to discover that such improvements are merely superficial when compared to the richness of knowledge found in the homeland.

The experience of diaspora is no less complex for the young adults in this study, but it is significantly different. The notion of such movement is largely something that has been communicated to them through oral history. They are aware of holding a heritage derived from a place outside of Canada, and in some cases they may be quite knowledgeable about it. However, the difficulties they have undergone, if any, are not the same. They live in the only home country they have ever known-they have not been separated from it. For the most part, their views of their ancestral country or countries are relatively clear-eyed, not tinted with longing to return permanently or with existential angst. While many have pride in their heritage and actively seek opportunities to learn more about it, few are conflicted about their national identity. Their understanding of the places that weaned their parents may be based simply on familial stories, or on gleanings from media, or on occasional visits. They may maintain ties with friends and relatives, but rarely with the same intensity displayed by some first-generation immigrants. For the 
most part, the knowledge that they came from somewhere else opens up the desire for knowledge about places of origin and history, but it does not necessarily portend a sense of loss.

Thus, the question arises: are these young people members of a diaspora? Some would agree that they are, others would not. The notion of diaspora itself is so nebulous, and the experience of diaspora so varied, that there is no definite answer. Diasporas can form in very different ways depending on the time, impetus and attendant history, but they are often linked to clear understandings of homeland. If we accept this linkage, the young people in this study may not appear to be part of a diaspora, given that they are mainly Canadian-born and may maintain very little connection to South Asia. For the purposes of this study, however, I would like to suggest that these individuals are members of a diaspora - at the absolute minimum, they are engulfed in a diasporic consciousness, but I think they may well be positioned as part of a diaspora that takes pains to acknowledge them. While they may not all experience a longing for return, many are conscious of some allegiance to other South Asians or other Muslims. Some maintain ties to the countries of their birth or their parents' birth, through visits, communication with loved ones, exchange of goods, and by staying abreast of current trends in fashion and media. These links may assume superficial forms at times but they do exist, and they do shape the lives of these individuals in meaningful and lasting ways.

Few are as relentlessly peripatetic as the economically privileged individuals described by Aihwa Ong (1999), flitting easily from one place to the next, yet they experience greater ease of movement and a wider range of options than the rural peasants in Wanning Sun's (2002) work. They do rely on diasporic media for education, but they 
are absorbing the reverse of the images seen by those peasants. While Sun's subjects may build imaginaries of diaspora through film and television, the individuals in this study rely on the same in order to absorb imaginaries of a so-called homeland.

For them, diaspora may not occur exclusively through the auspices of mass media, but these certainly open up possibilities that might not otherwise exist. While travel to India, Pakistan or elsewhere is a possibility on which many of the participants have capitalized, it is not a constant possibility. Individuals living in diaspora often rely on communicative devices to keep them informed of what may be happening in the place of origin, if such it can be called. Several of the participants interviewed here suggested, some with a hint of embarrassment, that their consumption of Bollywood cinema had more to do with a desire to know what was happening in the world of dress and music than with a sincere interest in the plotlines. This appears to be, in fact, a common experience, accentuated by other diasporic media such as television shows, magazines, websites and newspapers aimed at non-resident Indians (NRIs); some of these media do legitimately aim to inform readers of current events but many have a stronger consumerist emphasis.

While Bollywood itself will be discussed at more length in subsequent chapters, there is little question that media producers in India and elsewhere are quite aware of the existence of a diasporic audience, and they take pains to address this group. Some media forms are produced exclusively in Hindi or Punjabi, but there are many that incorporate English to varying degrees, and a number of websites and magazines cater specifically to the English-speaking members of the diaspora. These media serve different purposes but they all speak to the significance of the diasporic population, a significance now 
acknowledged by the Indian government in its recent extension of overseas citizenship to NRIs, and in its staging of an annual event, called Pravasi Bharatiya Divas, that is held in India and celebrates the achievements of diasporic Indians. While adults who participate may be exhorted to remember their obligations to India, youth may also be enrolled in programs enabling them to become better acquainted with Indian culture, history and religion. The Indian diaspora is certainly not the only one discussed in this study, but it is significant and highly relevant on a number of levels.

\section{Different Diasporas: India, Pakistan and the Colonial Legacy}

Who is an N.R.I.? The one who goes back-with many suitcases instead of that single one that he or she had brought on the first journey. The tourist citizen. (Kumar, 2002, p. 21)

One must, of course, be careful to avoid the trap that Jigna Desai identifies in her own clarification of terminology. South Asia, she notes, is often identified as India, when in fact the region encompasses great diversity, spanning places as varied as Bangladesh, Bhutan, India, the Maldives, Nepal, Pakistan, Sri Lanka, and Tibet (2004, p. 5). People from all of these regions, scattered around the world, can be considered a kind of Brown Atlantic (p. 31), in which the members have been labelled differently (South Asian, Asian, Indian, black) depending on the norms of their host countries (p. 6). In this particular study, all of the participants can trace their origins back to South Asia, most often India or Pakistan, but they may be two or three generations removed from that region, or may have complex relationships to it, as in the case of one young woman whose parents moved from India to Pakistan following Partition and became fervent Pakistani nationalists. Several individuals were of Indian origin but their parents were born in East Africa and migrated from there to Canada, so even the parents had little 
direct contact with, or experience of, South Asia. Despite this gap in time, space and experience, most had some knowledge of South Asia and were very conscious of the existence of South Asian diasporas, particularly the large, influential Indian diaspora. Aside from its size, this diaspora is also overwhelmingly diverse. Many of the informants in this study traced their origins back to the northern parts of India, yet-as one young woman of South Indian ancestry pointed out — this heritage only represents a portion of Indian culture. India is home to numerous languages, cultures and religions, some of which have overlapping characteristics and some of which are diametrically different. This diversity is reflected in the Indian diaspora, perhaps one of the largest in the world, with roughly 20 million people spread out over dozens of countries. Statistics compiled by the Indian government in 2001 suggest that in 39 of those countries, an overseas Indian population (including both Indian citizens and PIOs, people of Indian origin) numbering 20,000 or more can be found. In Canada, of course, this number is considerably higher, with over 850,000 people of Indian origin settled there, constituting $2.8 \%$ of Canada's total population of 30 million and exercising considerable influence. Canada has the eighth highest number of overseas Indians, following Malaysia $(1,665,000)$, Myanmar $(2,902,000)$, Saudi Arabia $(1,500,000)$, South Africa $(1,000,000)$, the United Arab Emirates $(950,000)$, the United Kingdom $(1,200,000)$ and the United States $(1,678,000)$ (High Level Committee on the Indian Diaspora, 2001). While early Indian emigration initially could be attributed most often to labour flows-the need for cheap labour in more developed countries balanced against the high population and relative underdevelopment in India - it now occurs for a variety of reasons. 
As members of a former British colony, Indians were exposed to the English language and variants of the British educational and political systems. While many welcomed the end of official colonialism, marked by India's independence in 1947, the British presence in India had inevitable consequences, including Partition, the division of the country based on religious lines. In an attempt to rectify religious conflict between the Hindu majority and the Muslim minority, British rulers gave each group its own country, leaving India a Hindu nation while carving out a portion for Muslims in the new nation of Pakistan. Left in a country wracked by political unrest following Partition, with limited opportunities for economic or social advancement, some Indians and Pakistanis opted to leave and find out if peace and prosperity could be found elsewhere. Not surprisingly, given their familiarity with the British, many saw the United Kingdom as a different kind of motherland. If the United Kingdom seemed like an inappropriate option, countries such as the United States, Canada and Australia also had some degree of familiarity, given the use of English and their own traces of British administration, although this was likely less pronounced in the United States. These same countries also became the recipients of multiple migrants, Indians who may have sought new lives in places such as East Africa or Fiji, only to encounter even more political or social problems, as in the case of South Asians living in Uganda who were expelled from the country during the 1970s reign of dictator Idi Amin. Persuaded or forced to leave by political, social and economic factors, such migrants continued their pattern of movement by settling in ever more developed countries.

As Indian and Pakistani communities became more established in host countries, residents sometimes sponsored other family members or potential spouses, a practice that 
remains common. At the same time that South Asians were integrating into their new societies, obtaining citizenship and employment, India itself was changing. Although it remains a country with considerable poverty and vast disparity between classes, it has produced a large number of qualified professionals, particularly in fields such as information technology and medicine. Those professionals often, although not always, move elsewhere in search of high incomes, a more luxurious lifestyle, or simply better educational opportunities for their families. The loss of these professionals is what the Government of India's revised policies on overseas citizenship are intended to address. Although it is a limited form of citizenship, restricting rights on voting, for instance, it is nonetheless an acknowledgement of the fact that India tends to export many of its greatest human resources. With the loss of such talent comes a concomitant drain upon the economy, since remittances are not as common in the Indian diaspora as with some of the diasporas described previously. Nonetheless, the diaspora does have a major role to play in the maintenance of the economy, a fact that goes beyond the considerable revenues generated by NRI tourists and visitors purchasing expensive garments and jewellery for extravagant events such as weddings and festivals.

Members of the diaspora may invest in India and may well maintain homes or businesses in India as well as the country of residence. Moreover, for producers in India, there are distinct advantages in marketing to the diaspora. Fashion, jewellery, magazines, newspapers, television, music and film, the subject of this study, are often exported to the diaspora. Bollywood indicates in a number of ways that it recognizes the importance of the diaspora, incorporating English into its dialogue, adding subtitles in a number of languages and addressing themes that it considers relevant to Indian diasporic life. The 
Pakistani diaspora does not do this in quite so cohesive a manner, but it does attempt to foster its own diasporic industries. Members of the Indian and Pakistani diasporas subscribe to many of these efforts by purchasing DVDs, satellite dishes and CDs that allow them to stay current in viewing movies and television programs and listening to popular music, often the music associated with new hit films. Many forms of media help members of the Indian and Pakistani diasporas maintain their connections to one another and to the so-called homelands, and film may be one of the most powerful, offering images of places that may exist in no other form for viewers.

These places may literally occupy no space in the existence of diasporic individuals. Some have never been to India; others left it so long ago that their understanding of it is both mediated and frozen in time. Braziel and Mannur cite the specific case of Ismaili Muslims who emigrated to East Africa, the Caribbean and North America from Kutch, Sindh, Katiawar and Gujarat in the nineteenth century, establishing themselves so firmly in their new countries that in the present day, some of their descendants "do not necessarily accord much importance to connections with South Asia, making questions of looking back to India as a homeland irrelevant, or at best, inappropriate" (2003, p. 9). Since a number of the participants in this case were in fact Ismaili Muslims, this assertion bears more interrogation, as noted in the following chapters.

However, Braziel and Mannur's point is well taken: multiple migrants, even if they do have origins somewhere in South Asia, do not necessarily identify strongly or singly with that region. There are, of course, other ways that diasporic immigrants may come to feel dissociated from India or Pakistan — that is, as these countries actually exist. 
Having left many years ago, they may prefer to maintain their distance in order to preserve the image they still recall. Amitava Kumar (2002) recounts the experience of his aunt and uncle, who had immigrated to the United States well in advance of any of their relatives or peers. Isolated for many years, living an existence more difficult than they had imagined prior to emigration, the two do not return to India for even an occasional visit, yet Kumar's aunt tells him that she can still see it in her mind's eye. Recognizing the importance of this vision, Kumar hesitates to tell her that "the India she had known was no longer there. It had changed" (p. 173). While his initial reluctance stems from a belief that she may judge him on the basis of his own change, he opts to help maintain her illusions once he realizes that the place "they left behind had been precious. They liked to believe it was still all intact. It was they who had not changed. They had lost so much that they wanted to hold on to what was left of the past" (p. 174, italics in original). As evidenced by the commentaries of participants in this study, this is by no means a unique incident. The desire to preserve the past, to observe an idealized image of India from afar, is one that several interviewees witnessed in their own parents, grandparents and other relatives. While most were able to view this tendency with a critical eye, few were unsympathetic to it. Most recognized the extent to which this was a common feature of diaspora: the strain of occupying multiple worlds is only slightly less pronounced when one country is settled mainly in the imagination. Although it may seem obvious that change would have occurred in a place left behind so long ago, the temptation to fossilize the past is strong for individuals who may occasionally struggle with the challenges of a new country and culture. Radhakrishnan remarks on this temptation, and its possible consequences: 
Very often it is when we feel deeply dissatisfied with marketplace pluralism and its unwillingness to confront and correct the injustices of dominant racism that we turn our diasporan gaze back to the home country. Often, the gaze is uncritical and nostalgic. Often, we cultivate the home country with a vengeance. Several dangers exist here. We can cultivate India in total diasporan ignorance of the realities of the home country. By this token, anything and everything is India according to our parched imagination: half-truths, stereotypes, so-called tradition, rituals, and so forth. Or we can cultivate an idealized India that has nothing to do with contemporary history. Then again, we can visualize the India we remember as an antidote to the maladies both here and there and pretend that India hasn't changed since we left its shores. These options are harmful projections of individual psychological needs that have little to do with history. (2003, p. 128)

Obviously, not all individuals living in diaspora glamourize the past and the notion of a culture more meaningful than the one they currently inhabit. Living in diaspora signifies a variety of experiences. For the cosmopolitan citizens described by Ong (1999), diaspora is a place of choice, variety, and cultural richness. However, as Mitchell points out, diaspora is a markedly different space for those whose colour or class place them in vulnerable positions: "As bell hooks has noted of Clifford's somewhat playful evocation of travel and 'hotel lobby' culture, the actual, terrorizing experience of border crossings for many people of color is effectively ignored" (1997, p. 109). While some people may flit back and forth across borders with great ease, others make a painful pilgrimage to a new country and spend the rest of their lives trying to form a new existence. Much of the focus thus far has been on the Indian diaspora, a place where history may be interpreted or re-created selectively. Several of the participants spoke of their early ignorance regarding Partition, the 1984 Golden Temple massacre-in which a large number of Sikhs, including both soldiers and civilians, who had occupied the holy shrine were killed in a firefight with the Indian army at the order of then-Prime Minister Indira Gandhi-and the tense relations between different cultural and religious groups in India. Without understanding the reasons, they knew that their parents and grandparents 
had preserved some of their enmity towards other religious groups, and, as Appadurai suggests, transported it to their new country.

Within diaspora, then, tensions around class, caste and power remain. Diaspora is by no means a space so virtual, so postmodern or hybrid that it negates all economic, political or social struggle. Rather, it is a space where these struggles fragment and may acquire new meanings. The participants of Pakistani origin discussed their parents' changing sentiments towards India and Pakistan, and towards South Asian media as the political relations between those countries changed. The Sikhs and Muslims in this study viewed South Asian media more critically than their Hindu peers, perhaps because they knew their positionality would always differ, even when living in a diaspora removed from the actual geographical pressures of a side-by-side existence. Asked about the possibility of a Muslim diaspora, the interviewees approached this notion from a variety of perspectives, but several agreed to a heightened awareness of belonging to a global Muslim community following September 11, 2001, when media and politicians turned their focus on the so-called Muslim world. While they might not have given this idea of belonging any protracted thought before, they felt compelled to do so once a perceived threat came into sight. Even as full citizens of their new countries, safely established in homes, schools or jobs, they experienced a sense of fear that drew them closer to their fellow Muslims throughout the diaspora.

As the following chapter makes clear, this condition of living in diaspora or multiple diasporas, even as members removed from the physical act of migration, has a distinct effect on the identity construction of these young people. The notion of having some connection to people or places outside of Canada affects their choice of media, their 
perspective on global events and media, and their sense of self. At the same time, they were nearly all affected strongly by the fact that the particular node of diaspora they inhabited was Canada. While suggestions abound in the popular press that firstgeneration and second-generation immigrants tend to place too much importance on their places of origin, this study's findings tend to align with those works which point out the impossibility of ignoring the country of residence (Gillespie, 1995; Karim, 2003; Kumar, 2002; Ray, 2001, 2003). Living in diaspora is not as simple as holding onto the past, or forging a new future. It is an uneasy tightrope walk between the two, and not all will follow the same steps in negotiating that tightrope. Within that slender, virtual space, identities and societies can be negotiated; Bhabha (1994) suggests, in fact, that this place of betwixt-and-between may be the best arena in which to create change. As Ulrich Beck $(1994,2000)$ points out, and these interviewees affirm, remaining static is rarely an option in societies transformed by migration and capital flows, all connected by a politics that is unquestionably global. Within this framework of connectivity and reflexivity, the rootlessness Clifford describes at the very beginning of this chapter can, and sometimes is, replaced by a determined effort to weave together competing identities and loyalties, creating a new hybrid culture in a space whose very unfamiliarity allows for possibility. 


\section{Chapter 2}

Karma Chameleon: Citizenship, Identity and the New Hybrids

[O]ur daughters consider themselves members of a number of global cultural clubs, as yet perhaps not fully aware of the complexity of their inheritance. The new hybrids, they feel at home in many locations in the global cultural ecumene. (Sreberny-Mohammadi \& Mohammadi, 1995, p. 193)

\section{The Ties that Bind: Citizenship and Belonging}

The subject of diaspora is one that often becomes entangled with questions of citizenship, nationalism, and identity. This is inevitable in some respects, given that diasporas and diasporic identities present alternative conceptions of community and nation to more conventional understandings of countries bordered within a clearly defined nation-state. Membership in diaspora is often presented as a rejection of the citizenship associated with nation-states, with such rejection occasionally metamorphosing all the way into cosmopolitanism, a kind of global citizenship or, in Bruce Robbins' terms, internationalism (1999, p. 17). The participants in this study did not present themselves as adherents of cosmopolitanism, but related questions of citizenship and multiple forms of belonging did arise and appeared integral to identity construction. Amitava Kumar notes that a "seasoned traveler" who moves between cultures can also be seen as a "global soul" whose unique standpoint allows for translation and understanding of these very cultures (2002, p. 178), and it appeared that many of these young people saw themselves positioned in this way, drawing their sense of identity partly from their beliefs about citizenship and nations. This chapter investigates the question of whether diaspora complicates traditional understandings of citizenship by offering different spaces and affiliations to individuals, and also looks at the way in which a sense of national identity may be formed or affected within diaspora. 
As it is currently conceived in much of the Northern world, citizenship requires a commitment to join a particular national group whose borders are defined by a legal set of practices and regulations. Inclusion in this group is often valorized above membership in any other community, which may be problematic for citizens who have meaningful ties elsewhere and do not consider themselves to be exclusively bound to the nation-state. Indeed, for members of diasporic communities, this presents a particularly troubling conflict, as the notion of belonging to one collectivity may be constructed as necessarily singular in dominant legal or political discourse, but in actual practice citizens are aware that they may belong to overlapping communities.

Even when diasporas are not present, transnational networks may form that also influence perceptions and practices of citizenship. Satzewich and Wong suggest that a "transnational perspective emerged in the mid-1990s as a challenge to the more traditional understanding of immigration, which implicitly or explicitly assumes that immigrants leave behind their countries of origin upon entering a new country" (2006, p. 3). Such a perspective acknowledges the complex and overlapping political, economic and social relationships that migrants may retain outside of the host country. These transnational networks, which are defined more broadly than diaspora, may not all constitute forms of diaspora (Satzewich \& Wong, 2006, p. 6). Transnational and diasporic practices may unfold in ways that are far more explicitly political than any cited by the participants here. However, there is a definite duality or multiplicity to their identities that is characteristic of many transnational and diasporic subjects (Satzewich and Wong, 2006, p. 11), as discussed here. 
A sense of multiple belonging need not take on a legal aspect, but it can be formalized through "multiple citizen frameworks" which may at times "coexist uneasily and sometimes in outright conflict with each other" (Shafir, 1998, p. 23). This is not simply a case of individuals living in the diaspora fighting for recognition from a hostile state that refuses to acknowledge the possibility of multiple affiliations, although this is one element of the conflict. Rather, the tension is further nuanced by the fact that the entire notion of pledging citizenship and surrendering one's individual self to the national collectivity, forsaking all others, exposes an inherent contradiction in the liberal democratic idea of the nation-state in North America, which envisions a collective linked by a commitment to the idea of liberal individualism. While the nation-state's reluctance to recognize a transnational sense of citizenship may constitute a breach of the rights so confidently ascribed to emancipated individuals, the challenge of retaining belonging in the diaspora alongside other memberships is equally complex. Displaced persons who attempt to integrate into their host society in some way risk criticism and isolation from members of their traditional cultures. Whether one's belonging in a collective is dictated by the demands of citizenship or of culture, it seems that individuality is always at stake.

Vince Marotta (2000) suggests that conflicts between individuality and collectivity are hardly new issues. Taking issue with John Dewey's holistic understanding of individuals constituting democracy at a spiritual and ethical level, Marotta critiques underlying assumptions that the individual and society are "organically and interrelated," arguing that these notions fail to account for individuals whose "self-identity seems to be at odds with the collective identity of the host identity" (p. 206). An argument can be made that self-identity does not need to be at odds with the collectivity, 
but this is only possible if the collectivity fosters a belief in individual rights and in a plurality of discourses. This is an entirely different visualization of the nation than that noted by Van den Bulck and Van Poecke, among others: "Nationhood, or the identification with a nation, is based on a perceived or ascribed common history (possibly including territory) and culture" (1996, p. 160). Clearly the idea of common histories, territories, and cultures-often based in notions of shared or similar ancestry-is increasingly problematic at a time when many citizens are embroiled in migratory flows that may provide them with different histories and competing cultures, all juxtaposed against a backdrop of what Erin Manning calls ephemeral territories: "we continue to be in a state of flux whereby the homes we construct remain ephemeral"' (2003, p. xx).

Bryan S. Turner (2000), adapting the concept of hot and cold from Marshall McLuhan, goes so far as to suggest that a high (hot) level of loyalty to one particular culture is in fact ruinous, and contrasts this to a more cosmopolitan, global perspective. "Cool," or less engaged, loyalty to more than one group is one element of what Turner celebrates as cosmopolitan virtue. In contrast to those who have cool, or distanced loyalties, those with hot loyalties and traditional allegiances to the nation-state are dangerous because they are most likely to provoke conflict. Those who have cool loyalties, described as postmodern citizens, are able to flit from one nation to the next without incurring damage, similar to Ong's (1999) international travellers. Turner's discussion of the postmodern individual is problematic both in its glib description of transient loyalties and in its class-based assumption that mobile populations are upperclass and educated, while hot loyalists are working-class and territorially bound. 
However, his presentation of cosmopolitanism does present an alternative to the idea of individuals being persistently bound to a single collectivity (2000, p. 28).

Turner's interpretation of cosmopolitanism tends to be more extreme than any version embraced by the young people in this study, few or none of whom demonstrated hot loyalties. At the same time, cool loyalty was also not entirely apt; while there was a commitment to various forms of identity and an interest in different countries and cultures, this was not necessarily disengaged or distant. Rather, it tended to carry a certain sense of ambivalence. Hence, Turner's model is not highly applicable in this case, and this is also true of most of the forms of cosmopolitanism offered by Derek Heater $(1996,1999)$. However, in providing what he sees as the initial definition of cosmopolitanism, Heater touches upon a state of mind that does align with that described by several participants here:

Cosmopolis meant viewing the whole of the universe and all its inhabitants as if they were a social entity. A cosmopolite was one who recognised his membership of this cosmopolis. It meant little more in human social terms than accepting all men as brethren. (1996, p. 181)

Similarly, Everett Rogers posits that "[c]osmopoliteness is the degree to which an individual is oriented outside his immediate social system" $(1969$, p. 147 , italics in original), "motivated to look beyond his environment, when most others are content to maintain a localistic frame of reference" (p. 149). Despite the fear that this outward approach engenders in some, Rogers views it merely as "an indicator of modernization, as well as a possible initiator of the process" (p. 150). Cosmopolitanism and world citizenship can be viewed in far more specific ways, as Heater explains, suggesting that world citizenship can range from a broad "feeling of identity with the whole of 
humanity," to a sense of responsibility for the world's other inhabitants, and all the way to a specific belief in transnational laws, political activity and governance (1999, p. 136).

As Heater notes, "[c]itizens need to share a sense of community. This consciousness is nurtured most efficaciously by growing up and living in a society that has an identifiable common, especially linguistic, culture, a strong historical narrative and compelling myths" (1999, p. 151). Heater marks here the challenges of constructing a cosmopolitan ideal of citizenship in a world marked by different languages, cultures and histories, and he is entirely correct. If the challenge was simply to offer a model of citizenship that the entire world could participate in actively, then " $[\mathrm{t}]$ he problem is that there is no similar culture, history or mythology that is fully universal in scope and in which may be embedded a firm cosmopolitan identity" (Heater, 1999, p. 151). Richard Dagger offers a related critique, suggesting that the republican ideal of citizenship —in which citizens come to a sense of their obligations through education aimed at promoting civic virtue-cannot be fulfilled through a cosmopolitan model. Current conceptions of the cosmopolitan ideal, he argues, offer empty methods of constructing unity, such as building a community based on telecommunications (2002, p. 155). In chapters to follow, this argument will be investigated at more length, but the current focus is on the cosmopolitan ideal, and whether or not it can operate independently or in conjunction with more traditional notions of state-bound citizenship to offer some kind of useful alternative for those living in diaspora.

\section{Diaspora Dreams and the Call of the Collective}

Unlike the more recognized legal ties of a nation-state, the pull of the diaspora is embedded in a sense of cultural, historical and social unity: "In broad terms, culture may 
be viewed as the symbolic construction of the vast array of a social group's life experiences. Culture is the embodiment, the chronicle of a group's history" (Brah, 1996, p. 18). This is not to say that a cultural sense of allegiance is lacking in the national collectivity, but it is more often the case that a culturally grounded and less formally political sense of affinity binds together members of a diaspora, sometimes unwillingly. A lack of acceptance in the nation-state of residence, or a consistent reminder of one's ethnic or religious origins, may serve to emphasize the sense of belonging to the diasporic collective. Hamid Naficy, in fact, suggests that exile differs from diaspora in the sense that the latter is intrinsically dependent upon the notion of collectivity: "unlike exile, which may be individualistic or collective, diaspora is necessarily collective, in both its origination and its destination" (2001, p. 14). He adds that the "nurturing of a collective memory, often of an idealized homeland, is constitutive of the diasporic identity" (Naficy, 2001, p. 14). This concurs inadvertently with Coleman and Higgins' idea of the civic nation, "which suggests, at least in its liberal version, that the nation is a voluntary collection of individuals" (2000, pp. 66-67). This implies that no matter what differences may exist between the official nation-state and the unofficial diaspora, the call of the collective is strong in both cases.

While the lure of belonging to a collectivity is a powerful one, the requirements of fealty may sometimes, rather perversely, impinge upon individual rights at the same time that a sense of self-identity is fostered. This limitation is visible not only within the nation-state, but within more nebulously connected and defined groups as well. Shahnaz Khan (2000) documents the disparate cases of Muslim women in Canada who handle the challenge of belonging to a Muslim community while living in a non-Muslim country in 
various ways. Some disavow their religious and/or cultural heritage in favour of a secular, so-called modern lifestyle, but are nonetheless haunted by an identity that follows them wherever they go, marked by their skin colour, accent or secret beliefs. Others are punished for attempts to embrace what they see as Western ideals of liberation; transgression of familial and cultural norms may result in ostracism or shame. Those Muslim women, however, are equally punished by the non-Muslim community that initially counselled their rejection of the Muslim collective in favour of the "Canadian" secular collective. Upon seeking affirmation from those same non-Muslims, who often represent supposed havens such as women's shelters, the women in Khan's study found that their problems were dismissed or constructed as a result of their cultural identity (also see Jiwani, 2006). Similarly, the young Muslim women studied in Hoodfar (2003) report experiencing a constant refusal on the part of some Canadians to try to understand their religion and culture(s), while other Muslims try to dictate cultural or religious norms that these women feel have little basis in a real understanding of religious texts, resulting in a sense of being consistently misunderstood and disrespected. Their attempts to negotiate movement from one collectivity to another, or to belong simultaneously to both, placed them in a state that Abdolmaboud Ansari calls dual marginality (cited in Naficy, 1993, p. 131). Leila Ahmed's memoir (1999) points out that this experience is not limited to women of a certain class or in a particular country: living as an academic in the United Kingdom and in the United States, circulating among apparently liberal-minded scholars and professionals, she was constantly aware of the pressure upon Muslims and South Asians to renounce membership in their religious and cultural collectives if they wished to be treated as intelligent and worthy of respect. 
Paradoxical relationships such as these, in Coleman and Higgins' opinion (2000, p. 68), represent a failure of the nation-state, which has a moral obligation to respect and foster individual freedom, a sentiment echoed by Annabelle Sreberny-Mohammadi (1996, p. 18). This includes support for cultural evolution and formation: "the vast majority of cultures have formed and still develop in inter-action with others which they overlap; and there is usually a process of negotiated change going on within them" (Coleman \& Higgins, 2000, p. 68, italics in original). Couture, Neilsen and Seymour suggest that the development of culture and citizenship occurs best in a "pluricultural political community," a community built upon, among other things, a variety of institutions that "equip all citizens with the cultural skills to participate effectively in a culturally specific public life and yet continue to practise the way of life of a minority culture into which they may have been born" (cited in Coleman \& Higgins, 2000, p. 68).

This is a vision of community that denies that it is possible to move from one community to another, as it is presented in Arnold Van Gennep's rites of passage detailing changes in social position. Naficy details these rites to demonstrate one theory of how one might eventually re-enter the collective into which (s)he is born: in the first stage, one is separated from that community, followed by a transitory or liminal state which is eventually succeeded by re-integration into the original community (Van Gennep cited in Naficy, 1993, p. 8). Dated though this concept may seem, and is-Van Gennep's work was published in 1908-it is sometimes presented as a workable solution to the issue of competing collectivities. In the current state of world affairs, where borders shift and deterritorialization has become the norm for small clusters of people, it 
is less and less possible to continue romanticizing the idea of return to an original home community.

This is true because the transitory movements of individuals ensure a certain amount of change on their part, but also result in some kind of transformation in the societies they touch. Sarah Wayland describes models of assimilation, where immigrants are urged to abandon their original identities, and differential exclusion, where immigrants are integrated in limited ways, and notes that these models do not allow for the possibility that immigration will "significantly change the dominant culture of the receiving society. Advocates of cultural pluralism, on the other hand, view heterogeneity and the expression of different cultures as compatible with national unity and identity" (2006, p. 23, italics in original). This was the model identified by most participants here in their descriptions of Canadian society, even when they acknowledged its imperfections in practice.

These imperfections are linked at least partly to the fact that the people involved may not be embracing one or two different cultures. They may be balancing several, which may become further complicated by the realization of ongoing change. The existence of diasporas and transnational networks seems to rest upon the notion of fluidity, diversity and negotiation. Naficy himself acknowledges the fact that not all migratory citizens dream of a return to the original collective, choosing instead to live with many identities:

The deterritorialization that produces exile is pandemic and endemic in the postmodern era, and has created seemingly permanent "other worlds" of disaffected people who voluntarily or involuntarily are not, or do not want to become, fixed in any identity. By their status as liminal hybrids and syncretic multiples, they form a global class that transcends their original or current social and cultural locations. (1993, p. 2) 
William Kaplan may well be correct in his insistence, then, that world citizenship "is hardly an idea whose time has arrived, much less one that has been satisfactorily defined. If it is difficult for the citizens of one nation to articulate a national identity, what are the prospects for a global identity?" (2000, p. 260). However, the model that Naficy describes speaks less to a formalization of global identity or citizenship than to the conundrum that preoccupies so many individuals who occupy multiple citizen-subject positions. Unable to choose one identity, even if they wanted to, these citizens may lead a hybrid and complicated existence. At its best, this can be an existence founded on the notion of choice and the affirmation of an identity that arises naturally rather than being imposed from above, but it can also be an existence forged out of necessity.

\section{Collectivities and Consequences: Negotiating Individual Identity}

In recognition of the complications of such a hybrid existence, at least as they existed in 1920s America, Horace Kallen argued in favour of a cosmopolitan Americanism and a pluralist democracy. In his conception, living as an American would mean being "a citizen of the world" (cited in Marotta, 2000, p. 211), one who would want to work with other cultures and would forgo an investment in a united or common culture that swallowed all smaller entities. This brings back the notion of state-mandated cultural pluralism and marries it to the idea of individuals who recognize and respect "the radical otherness of other people" (Marotta, 2000, p. 211). If minorities were allowed to form their own schools, institutions or organizations and thus to maintain their sense of difference, understanding and a thriving sense of comfortable co-existence would result. "For Kallen," Marotta suggests, "ethnic and religious differences are the centre of an individual's identity and emotional life, and any political system that suppresses this is 
morally unacceptable" (Marotta, 2000, p. 211). Being progressive, free, and a functioning member of democracy would not demand adherence to the overall principles of community, but instead would allow for operation in specialized pockets of society. The danger that arises, of course, when minorities establish their own space, is that their space will become marginal space. If Kallen's idea was adopted in its fullest potential, however, this would be an empowering and affirming space recognized both by the collective that inhabited it and the larger state that fostered it.

Naficy is not discussing diaspora specifically but he is also exploring the issue of citizenship for those whose "sense of a certain territorial homelessness" (Manning, 2003, p. xvii) raises the risk of marginalization, whether imposed externally or internally. Naficy, investigating why exiles allow themselves to live in a state of liminality to the point that they sometimes do not claim the rights, and fulfil the obligations, of their host country, advocates political involvement and an explicit forging of links with a particular community. He does not name the community within which this process should take place, which suggests that he offers this solution not as a way of promoting a particular lifestyle or set of values, but as a way of diminishing a sense of individualism so pronounced that it borders on the dysfunctional: "the way to live differentially- to produce difference - without creating psychic dissonance and social weightlessness is to live not individually but socially according to the norms of culture(s) or group(s) with whom one identifies" (Naficy, 1993, p. 193). Living in any kind of collectivity, then, need not and should not elide individual difference — rather, it should celebrate it. As Cairns (1995) argues and as Anderson implies (cited in Mandaville, 2001, p. 13), a polity must offer its citizens a certain degree of protection and rights in order to attain the sense 
of patriotism and loyalty that Joseph Carens alludes to in his definition of conventional citizenship:

It is expected, both empirically and normatively, that people will feel a strong sense of emotional identification with, and only with, one political community, namely, the state in which they possess legal citizenship...The conventional view does not deny that people may have other important forms of collective identity besides citizenship, and that these other identities may influence the political ideas and activities of citizens. Nevertheless, people are assumed to draw their primary political identity from membership in the state... (Carens, 2000, p. 166)

The traditional formulation of citizenship Carens describes suggests that political affiliations should, in a sense, overwhelm socio-cultural ties. If this dichotomy fails to emerge, which is more commonly becoming the case as diasporic communities maintain ties to both a transnational community and to the nation-state in which they reside, social conservatives are quick to raise the issue of divided loyalties. Assuming that loyalties to one's ethnic or religious community can never be different from, but equal to, a sense of political identification with a nation, these critics suggest that diversity strikes at the very heart of democracy, an accusation that Will Kymlicka characterizes as "the opening of a new front in the "multiculturalism wars," in which minority rights are considered a threat to "long-term political unity and social stability. They may promote justice in principle, but in practice they are dangerous" (2001, p. 31; see Bissoondath, 2002, for one example of such criticism).

These dangers are further emphasized when nation-states that have lost citizens to migration attempt to stake a claim to those same individuals, encouraging them to maintain ties to their original homes through investment, political involvement and/or new forms of citizenship. However, there is an even more puzzling situation presented when individuals allow for a diasporic consciousness that is not fixed to a certain place. 
For instance, the young people in this study mainly saw themselves as embedded in Canadian society, yet the distinct sense of otherness of which they were aware sometimes prompted them to claim a loose allegiance with other Muslims (where applicable) or other South Asians, but this was not necessarily tied to a Muslim state or to specific countries in South Asia. They may have had some interest in any number of states, including those where their parents were born or those where they saw a similarity in culture, but they were not always part of any one diaspora tied directly to an original nation-state.

Saskia Sassen (2006) argues that the national is inevitably involved to some extent in processes of globalization, in some respects aligning with Beck's (1994, 2000) commentaries on reflexive modernization. This is undoubtedly true in a number of instances, but in her description of the transformation of the medieval state, there is some foreshadowing of the situation in which the diasporic young adults described here find themselves: "the territorial sovereign state, with its territorial fixity and exclusivity, represents a set of capabilities that eventually enable the formation or evolution of particular global systems-itself a partial condition-that require neither territoriality nor exclusivity" (Sassen, 2006, p. 21). There may be some participants in this study who do subscribe to a form of diaspora that is largely territorial, as in the case of one young woman who returned to her family's previous home in India every year; certainly the Indian government is working to convince some young people of South Asian origin that their roots are precisely in India. Others interviewed here, however, saw themselves as being linked or akin to people in diasporic formations. Speaking intelligently about the importance of understanding their origins, they nonetheless did not uniformly present 
themselves as people who are, as Sassen goes on to suggest, involved in a kind of "renationalizing of membership politics" where a weakened nation-state articulates itself in new ways:

Use of religion and "culture," rather than citizenship, to construct membership may well be a function of the changed relationship of citizens to the state and the insecurities it produces. In this regard, use of religion is not an anachronism but a formation arising out of particular changes in the current age. (2006, p. 414)

Certainly the use of religion and culture is key and in all likelihood it does express a kind of insecurity vis-à-vis the state. In fact, this point was emphasized when participants spoke of the role nation-states play elsewhere in accepting—or rejectingdifference. However, while there was some discussion around restrictive political situations that cause youth in the United States or elsewhere to turn to religion or culture as ways of establishing membership, very few individuals spoke of this as an alternative to citizenship. Citizenship was also important to these young adults and several expressed this importance in explicit ways. The factors Sassen names, then, are indeed significant, particularly in understanding the way some states and industries envision the positioning of these young people, but ultimately, as second-generation immigrants, they live in a complicated space that may straddle several forms of diasporic consciousness. Some found this space confusing while others dismissed its complexity, but most were aware of occupying it and they knew that this meant accepting a certain level of change and constant adaptability.

Homi Bhabha, examining such spaces, has established a reputation for celebrating the very instability so feared by others. For him and for the other postcolonial theorists he speaks of here, instability and the dissolution of borders cannot be denied as they are the truest signs of the postcolonial condition: "Their concepts of community come from a 
precarious sense of survival: on the liminal borders of the homogenizing discourses of nationality; in contention with the domineering narratives of civil society; effecting salutary acts of cultural translation between here and there..." (2001, p. 43). This can be read, with some justification, as an endorsement of marginalization for the displaced. However, it seems more fair to say that Bhabha argues for a politics that operates on the margins but with a full awareness of, and connection to, what takes place outside the periphery.

Although he does not fully articulate the strategies he would offer to carry out the position he espouses in the following quote, I interpret this passage as a reminder that no politics can operate completely and independently on the margins, but rather must function as part of a dialectical, historically informed and contextualized relationship between the subaltern and the dominant:

In order to understand the cultural conditions and the rights of migrant and minority populations, we have to turn our minds to the colonial past, not because those are the countries of our 'origins,' but because the values of many so-called 'western' ideals of government and community are themselves derived from the colonial and postcolonial experience. (Bhabha, 2001, p. 49, italics in original)

Bhabha offers a contextualized way of understanding the self, as well as the setting in which the self resides. If an individual feels some connection to a variety of settings, even a diasporic one that is more imagined than physical, this challenges conventional understandings of citizenship, identity formation, and nationalism. Small wonder, then, that "[s]ome theorists have started to work towards envisaging more inclusive forms of citizenship whose criteria for membership are not limited by the spatial extension of the modern state" (Mandaville, 2001, p. 13). Small wonder as well that the colonial past 
refuses to remain in the past, instead infiltrating notions of group borders, inclusion, and citizen rights.

Breaking Out of the "Ghetto Walls": A Politics of Pluralism

All the others who succeeded in this country did so only by changing. They became someone else. (Kumar, 2002, p. 247)

In the age of mass migration and the Internet, cultural plurality is an irreversible fact, like globalization. Like it or dislike it, it's where we live, and the dream of a pure monoculture is at best an unattainable, nostalgic fantasy, and at worst a lifethreatening menace. (Rushdie, 2005, p. A27)

That setting of cross-border inclusivity, multiple affiliations and community ideals is what gives weight to Neil Bissoondath's pronouncement that the "individuals who form a group, the 'ethnics' who create a community, are frequently people of vastly varying composition. Shared ethnicity does not entail unanimity of vision" (2002, p. 98). The truth of this has been discussed already and will be further demonstrated in more detailed examination of South Asians and Muslims in Canada, but this statement also skims over the possibility that the "ethnics" to whom Bissoondath refers are able to share a vision with others depending on the issue at stake. Maintaining a sense of one's origins does not necessarily translate into a politics so narrow that it is impossible to unite on issues of importance, a truth demonstrated by the globally linked but extraordinarily diverse nature of the opposition to the war on Iraq, and by the anti-globalization movement. It is this model of civic engagement, where activism is not mandated by national or even ethnic lines but instead by commitment to particular issues, that affirms Sherry Devereaux Ferguson's conclusions (2002) regarding youth and citizenship. Ferguson suggests that fears of disengagement are entirely valid if the histories and identities of different individuals are not acknowledged in educational and political 
institutions (also see Harzig \& Hoerder, 2006, p. 43). However, she adds that what was once viewed as marginal now has new significance for Canadian youth who are well aware of the global realities of dispersed communities and the far-reaching implications of political and military events that occur outside of their own borders. Educating and maintaining ethnic identity will not cause them to experience more interest in what takes place outside, rather than inside, Canada — this state of affairs already exists (2002, p. 6). Moreover, second- and third-generation immigrants are unlikely to dismiss the natural concern that first-generation immigrants feel for their country of origin; instead, they sometimes acquire even more interest in the cultural identity that eludes them in their adopted country (Ujimoto, 1990, pp. 211-212; also see Patel, 2006, p. 159). Since these young people consider that a responsible citizen is a citizen of the world, not simply of the nation-state, there may be some truth to Annabelle Sreberny-Mohammadi and Ali Mohammadi's prediction that the exilic wanderings of people such as themselves represents a transition stage - the next generation is more cosmopolitan, more accustomed to the idea of operating in different transnational contexts.

A new reality of local and global pluralism is ill-served by arguments that diversity and true citizenship are inherently opposed. The youth Ferguson (2002) describes can benefit both the Canadian community and the other different communities and causes to which they feel allegiance. In moving from one activity to the next, they do have to exercise caution; as Cairns (1995) suggests, they need to fulfil the terms of their legal obligation to the nation-state as long as the nation-state offers the rights and protections befitting a citizen. However, they should not feel that citizenship restricts them from concern for their homeland or for causes that fall outside of the range of 
official Canadian concern. Rather, the polity's support for the occasional crossing of borders and an increased level of interest in international affairs implies a global concern for humanity, and fosters an environment where citizenship arises freely, of its own accord. Without such support, citizens do risk becoming permanent exiles whose constant quest to carry out change on the periphery confines them, as Bissoondath (2002) warns, behind "ghetto walls" (2002, p. 225).

In Bissoondath's analysis, and in a number of political and media commentaries around the question of minority citizens, immigrants and visible minorities have a pronounced responsibility to assimilate- that is, to leave behind signs of difference, including language or cultural beliefs, in favour of the host society's language, culture and attitudes. American and Canadian policies on immigration and pluralism have often been viewed as substantially different, with the former generally leaning towards a proassimilation stance commonly described as a kind of "melting pot," where individual identities and affiliations are secondary to American patriotism. Canadian policy is seen as more of a cultural mosaic, wherein specific cultural practices and identifications may be maintained and nurtured as long as individuals seek to integrate themselves into society. While this is the theory, the practice has sometimes appeared to be different. American society, shaped profoundly over the years by waves of immigration and by its own ethnic enclaves, has not managed to absorb its new citizens nearly as completely as the melting pot metaphor implies, and the idea that it ever could remains at least partly a mythology (Glazer \& Moynihan, 1963, p. 13).

In fact, despite the existence of strong levels of American patriotism and an emphasis on the responsibility of new citizens to adapt to American culture, the United 
States does not appear entirely distinct from Canada, whose national identity is rooted in a notion of diversity and tolerance that often seems to carry its own hints of mythology. Despite boasting of the country's openness and acceptance, Canadian citizens sometimes revolt against what they consider to be excessive nurturance of difference at the expense of all-Canadian fealty. The 2006 arrests of several young men, all of whom are reportedly Muslim and/or South Asian, in the Toronto area accused of plotting terrorist attacks, as well as the government-sponsored evacuation of dual citizens from Lebanon, are merely two of the events that have given rise to criticism of policies regarding multiculturalism, dual citizenship and immigration. Writing in The Toronto Star as part of a series on multiculturalism, Daniel Munro notes a recent Strategic Council poll finding that nearly 9 out of 10 Canadians "believe that immigrants should be encouraged to integrate into broader Canadian society rather than maintaining their ethnic identity and culture" (2005, p. A27). If such findings signal an increased tendency to endorse a politics of assimilation, this may explain commentaries such as the following from Desai (2004), who suggests that Canada is far from the bastion of tolerance and pluralism that it is made out to be. "Multiculturalism assumes," she says in her analysis of South Asian migration, "that immigration is a teleology of progress in which the Asian immigrant modernizes and joins the Western (Canadian) nation, never to seek to return or re-turn to the homeland" (p. 175).

If this is so, clearly there are some contradictory assumptions about the process of integrating into a new nation, including the belief that this is a task easily completed. Roadblocks may in fact exist on the way to achieving a sense of belonging, begging the question of what might happen when a citizen does not feel himself or herself to be one: 
"Can a person truly be a citizen in an age of nation-states without feeling and behaving as part of the national culture?" (Heater, 1999, p. 103). The query might hold less relevance if perceived alternatives did not exist, forcing individuals to choose between the nationstate in which they live and any other nations to which they may feel some sense of loyalty: "the either/or choice has persistently refused to be denied. In the minimalist scenario prime allegiance would seem to remain with the state; in the maximalist scenario it would seem to be transferred from the state" (Heater, 1996, p. 180).

Keeping this in mind, Heater goes on to ask if there is a form of citizenship, separate from the state, that is worth looking at and more relevant in times of movement and change (1999, p. 160). While he is speaking of a global consciousness, his question could perhaps be answered differently if one looks at citizenship as a product of a nation, rather than the state. As Appadurai (1996) has implied, people do not make clean breaks from their sense of nationalism when they move from a place. Even if they wanted to, they may face obstacles at times to integrating into the host society, such as lack of acceptance from that society - which may cling to a myth of national unity that has been shattered by an influx of foreigners - or a concurrent plea for loyalty from the former home(s) or others of the same cultural origins, some of whom may cling to their own myths of a nation whose values, beliefs and practices can be transported wholesale into diaspora and maintained with no inconsistencies. As Kumar notes wryly, "these days one can't ask for an inch of nostalgia without getting a mile of nationalism in return" $(2002$, p. 218).

These competing pressures are very real and may exercise different effects, depending on one's individual positionality. Bruce Robbins, like Heater, rejects the 
clearcut distinction between state-bound patriot and aimless citizen of the world, arguing instead that neither cosmopolitanism, which he sees as a detached global concern, nor internationalism, a more engaged interest in world affairs, need to be viewed as the repudiation of nationalism (Robbins, 1999, pp. 5-6). Echoing Appadurai (1996), he suggests that even a seemingly mobile existence may carry its own attachments, and hence neither the cool cosmopolitanism of Turner, nor the displacement of diaspora, may help individuals stake out clearly defined territory in a world marked by migration. Since it is nearly impossible to disclaim all ties to the past, and equally fraught to renounce the present, new strategies must be forged in order to reconcile difference.

The Mists of Time: Beyond and Between Nations and Nostalgia

Diaspora space is the intersectionality of diaspora, border, and dis/location as a point of confluence of economic, political, cultural, and psychic processes. It is where multiple subject positions are juxtaposed, contested, proclaimed or disavowed; where the permitted and the prohibited perpetually interrogate; and where the accepted and the transgressive imperceptibly mingle even while these syncretic forms may be disclaimed in the name of purity and tradition. Here, tradition is itself continually invented even as it may be hailed as originating from the mists of time. (Brah, 1996, p. 208)

Writing as early as 1963, Glazer and Moynihan observe that fantasies of cultural pluralism are "as unlikely as the hope of a "melting pot"" given that language and culture are difficult to retain after the first generation, let alone the second (p. 13). Despite the fact that their study of visible minorities in the United States now has a ring of outdated quaintness, this conclusion is more layered and meaningful than it may initially appear. Language and culture are indeed difficult to retain in an ideal, pure formulation, since there is rarely, if ever, a definitive ideal of either that all members of a group can agree upon, although it does not stop many from searching. Moreover, the circumstances of each generation may differ, and this may also play a role in how cultural legacies are 
handed down and interpreted. As Shukla points out, it would be surprising if each generation did not have its own concerns about the issue of identity, but these concerns may vary widely given the different processes and outlets available to members of those generational groups. The experience of the first generation immigrant, or the older immigrant, cannot necessarily speak to that of young people who are expected to acculturate into a host society while maintaining the values of their ancestors (2003, p. 217).

For the most part, it seems unlikely that language and culture will have been transmitted, untouched and unaltered, from one generation to the next, when a change in environment has taken place. The interviewees in Murji and Hébert (1999), whose insights are discussed further in the next chapter, touch on the extraordinary swiftness with which their Indian dialects were replaced by English in Canada. Such disappearance was not seen commonly in East Africa, where many of these immigrants of South Asian origin had lived before coming to Canada, yet upon their arrival in Canada, they felt compelled to acquire proficiency in English, even though their focus on doing so gradually resulted in the concurrent loss of their mother tongue(s). In the cases Murji and Hébert describe, this loss is met not only with acknowledgement and mourning but with a form of compromise, in which language is consciously retained in certain rituals but removed in others: "this process is lived as a cultural loss, as a source of emotional grieving for some...and yet also an occasion to provide solace, to facilitate the passage to another language so as to ensure community cohesion" $(1999$, p. 8). Hiebert and Ley (2006), in their own study of immigrants in Vancouver, emphasize the importance of language: 
Those respondents who speak only a non-English language at home engage in more intensive transnationalism in terms of several of the activities explored in our survey: they keep more regular contact with family and friends, and they are more apt to own property and businesses in their premigration country. Similarly, those who speak only English at home are the least transnational. (p. 84)

Perhaps not surprisingly, linguistic education and retention are significant aspects of the appeal of Bollywood film, even when the language being learned and maintained is not one that the individual would identify as native to his or her family.

This indicates the many factors that come to bear on the construction of cultural identity. Not only do Canadians of South Asian origin contend with the dominance of English (or, less commonly, French), their own languages can be moved subtly to the periphery when some South Asian dialects come to be accepted as the closest to normative. The young people in Maira (2002) fight to retain their specific languages, but nonetheless, some cultures and languages emerge as dominant in a society that can perhaps accommodate only so much difference. Even when one makes the best effort possible to resist the erasure of culture by sheltering oneself from the outside world, it seems unusual that no influences from that world would seep in. Yet this does not suggest that all ties to the cultural past are erased automatically as the years pass. "At any given time," states Brah, "a group will inherit certain cultural institutions and traditions, but its acts of reiteration or repudiation, its everyday interactions and its ritual practices will serve to select, modify, and transform these institutions" (1996, p. 18). The resulting forms and institutions sometimes come to be known as hybrid, or in Ulf Hannerz's terms, creolized. Unlike hybridity, creolization is not a term that emerges specifically out of postcolonial theory, but the meanings are very similar. As Mandaville explains, the "defining feature of creolisation for Hannerz is the confluence of widely disparate 
cultures which interact in the context of a centre-periphery relationship" (2001, p. 94, italics in original).

The notions of hybridity and creolization have often alarmed those who believe that culture can be delineated and preserved clearly, and that any form of change or injection of other elements may signify contamination. As Mandaville notes, the meaning of hybridity has undergone some transformations of its own: "the connotations associated with the term have changed quite significantly over the last hundred years. It was originally seen to represent a loss of purity, an authenticity compromised by the insertion of an alien element which tainted the whole" (2001, p. 90). In the field of biology, hybridity eventually assumed a rather different meaning, where cross-fertilization came to be seen as a method for producing "stronger, richer offspring" (Mandaville, 2001, p. 91). In the transmission and practice of cultures, however, the previous meaning does hold resonance for some, who would reject signs of newness or change, believing it best to try and preserve the past in as pristine a form as possible. Such cultural preservation in the face of occupation or immigration can be seen as resistance to colonizing forces, and is counselled strongly by those who fear the loss of their traditions.

There is some merit to the notion of cultural preservation, considering the ongoing loss of languages, artistic production and rituals by some groups around the world. In spite of this, however, to fossilize and transmit rites and practices in a different environment that changes over time is obviously a matter of great difficulty. Members living within this new setting may observe and accept different practices; in order to belong, or because these new practices have some meaning for them, they may adopt them in their own lives. Even if they are determined to hold on to the cultural practices 
that they associate with their place of ancestry or with their religion, they may-in fact, almost certainly will — confront fragmentation within their own communities regarding the correct practices, particularly given the fact that their culture, religion or place of origin will undergo its own evolution. In light of all this, the fight for resistance and the pursuit of true, pure culture may at times seem the equivalent of tilting at windmills, giving chase to enemies or goals whose existence is questionable.

It is this kind of singlemindness, perhaps, that opens up certain ethnic groups for attacks from commentators who oppose multiculturalism, such as Bissoondath, in his accusation that immigrants enclose themselves in segregated communities and promote their own cultural practices at the expense of Canadian culture. This judgement may appear harsh, particularly given the fact that Canadian culture itself is to some extent a tapestry of the cultural markers, rites and celebrations provided by its immigrants, but it does bolster the argument of those, like Rhoda Howard-Hassman (1999), who suggest that there is a dominant Canadian ethnic identity (chiefly anglophone and Christian) which is endangered by the state's encouragement of cultural specificity. This argument is expanded upon in the discussion of findings, which indicates that participants here identified a clear national Canadian identity, relatively separate from ethnicity, but they also saw Canadian culture as the byproduct of many different, syncretic cultures. If their perceptions are any indication, Bissoondath's warning is best directed at those who continue to believe that culture is static and can be imported into different countries and decades without any change. Radhakrishnan offers a gentle rebuke to individuals who pursue cultural purity and truth without acknowledging the complexities or pitfalls of such a search, asking “[i]s 'authenticity' a home we build for ourselves or a ghetto we 
inhabit to satisfy the dominant world?" (2003, p. 127). Like other theorists, he views diaspora as a space of possibility, creation and promise:

the diaspora has created rich possibilities of understanding different histories. And these histories have taught us that identities, selves, traditions, and natures do change with travel (and there is nothing decadent or deplorable about mutability) and that we can achieve such changes in identity intentionally. (2003, p. 126)

Similarly, Boyarin and Boyarin eschew the notion that hybridization weakens cultural transmission and preservation, positing that " $[\mathrm{d}]$ iasporic cultural identity teaches us that cultures are not preserved by being protected from 'mixing' but probably can only continue to exist as a product of such mixing. Cultures, as well as identities, are constantly being remade" (2002, p. 108). Indeed, in Hannerz's theory of creolization, this intermeshing of different cultures is what permits for communication and interaction: "the periphery adopts some of the language and organization of the core" and thus can “"talk back' to it" (in Mandaville, 2001, p. 94). Regardless of whether or not all opinions on this topic are as favourable as this, there does seem to be some agreement that hybridity constitutes "a form of encounter, a coming together of disparate cultural forms into a new fusion or mélange" (Mandaville, 2001, p. 92).

This does not imply that the practice of blending new cultures is simple or formulaic. There is no set routine for how this might take place, and the variety of ways that hybrid cultures arise and sustain themselves appears to both disprove and affirm Glazer and Moynihan's suggestion that language and cultures are rarely retained after the first or second generations $(1963$, p. 13). Retention is not what takes place, nor is it the easy conjoining of two different entities. Rather, in the crevices between cultures, between places both physical and virtual, something new emerges: 
transnationalism creates forms of political identity which do not fit the taxonomies of political modernity. Hybridity and cultural melange often feature heavily in these spaces, and such syncretisms often give rise not only to new postnational forms but also to reformulated understandings of what and where the nation can be. (Mandaville, 2001, p. 46)

This is not to say that immigrants, or their offspring, all work together to produce a new kind of identity that fits all. Instead, individual identities emerge that are fluid and imperfectly defined, existing in an-between place that Homi Bhabha has identified as the third space, where a certain sense of marginalization contributes to creative solutions. For Bhabha, the third space is not a place of exile, but one in which "hybridity is seen to be an anti-hegemonic force which seeks to force any would-be totalising narrative to come face to face with a challenge to its own supposed purity: the absolute rendered contingent by the positing of a dialogic difference" (Mandaville, 2001, p. 93).

Hybridity, then, for some postcolonial theorists, is in its own way a tool for resistance, a way of overcoming a sense of isolation or marginalization while fighting against dominant culture(s). There is doubtless some validity to this, yet I think that the work of theorists such as Homa Hoodfar (2003) and Shahnaz Khan (2000), with its emphasis on the wide variety of adaptive techniques minorities employ, suggests that a process more complex than either resistance or assimilation is taking place in many cases. The use of the present tense here is no coincidence. Even for individuals who have lived in Canada for many years, for instance, certain ambiguities may crowd into their conception of identity, even if they can state proudly and without a shadow of a doubt that they are Canadian. Resistance and assimilation themselves are far from simple, with each requiring a certain amount of decision-making and acquisition or retention of cultural capital. In this study, the individuals involved have very different lives and 
answer to different obligations, yet their comments indicated the extent to which they must move between worlds, adapting their behaviour as circumstances require. At times, their worlds collide, sometimes for better, sometimes for worse, but it is often the case that these young people develop chameleon-like tendencies, playing certain roles as they move from one setting to the next. This may be part of a hybrid strategy for survival, or it may indicate a type of avoidance that arises in lieu of a positive strategy for identity formation. This study examines the details of such strategies, the factors that may contribute to the choice of one over another, and the consequences of juggling worlds or, alternately, melding them.

The implications of such strategies, and the necessity for them, may be perceived differently by various citizens. Canada is a country that has promoted a policy of multiculturalism and diversity as an integral part of its national identity and appeal. Diversity in unity has been promoted by a host of prime ministers and politicians, and gladly embraced by many Canadian citizens. Writing about Muslims and their integration into Canada, Husaini says enthusiastically: "Canada is a unique country in the world where preservation and advancement of multiculturalism is an official governmental policy. It is Canada's ingenuity and inner security that could allow freedom of cultures and their enhancement" (1990, p. 98). She adds that eventually newcomers to Canada move away from nostalgic longings for return, concentrating instead on establishing roots. Their children, at least those born in Canada, assist greatly in this process, becoming "the final tether to the new society with two concerns: one, how to equip them to face a future in their country of birth, and two, how to pass on to them their ancestral cultural/religious heritage" (Husaini, 1990, p. 3). 
It may be true that these are the two chief goals, and the process of working towards these may be a fairly simple one. However, examined more closely, both raise multiple questions about belonging, civic engagement, and the reconciliation of different cultural demands. These will be discussed more specifically in terms of Muslim and South Asian identities in the following chapters, but in general, there is a question about whether the form of citizenship at work is as personally meaningful as the less statebound kind described earlier by Heater. Is there some truth to Turner's assertion that citizenship "grasped from below tends to be more active and radical than citizenship that is handed down by the ruling class through the state apparatus" (2002, p. 269)? If so, what does this mean for nations or states that determinedly lobby their citizens for loyalty? Husaini describes the generational transmission of heritage, but does not enter into the question of whether or not this heritage offers any kind of departure from the parameters of the nation-state.

Mandaville and Brah both suggest that living in diaspora means an awareness of other connections, although Brah is also clear that diaspora does not, as some would argue, signify primarily a desire for return to a homeland (1996, p. 16). Rather, she sees diaspora as a space separate from "casual travel" or "temporary sojourns. Paradoxically, diasporic journeys are essentially about settling down, about putting roots "elsewhere"" (p. 182). This desire to sink roots does not always find friendly or fertile ground. In this case, it is understandable that individuals might turn to other groups or communities where acceptance is more easily offered, or where pressures to integrate might be more direct or couched in familiar terms. Even when welcome arrives from the host society, there is perhaps a rather natural desire to maintain ties with those who may share beliefs, 
practices and memories. More to the point for the individuals studied here, the need for connection may also arise from a wish to explore and discover aspects of heritage that are not found as easily in the place of residence. Mandaville refers to this ability, or need, to "engage in, sustain, or reproduce particular forms of community across great distances and in the face of competing traditions" as a kind of "distanciated community. This designation alludes to those groups who make use of the infrastructural trappings of globalisation (e.g. telecommunications, electronic information transfer, and air travel) in order to bypass the geographical barriers to social interaction" (2001, p. 31).

One may ask why people who were born in Canada, or who have lived there for many years, would feel compelled to foster and maintain the kind of ties that Mandaville describes. Undoubtedly, the nation-state has its own claims on these individuals, and in many_possibly most — cases, these claims are well-respected. The nation-state, however, can exercise laws and policy to the best of its ability, but for many citizens, nations ultimately "only really exist in the collective imagination," as Wiwa claims. "In other words," he goes on, "nations are fashioned by the base metals of language, signs and symbols that tap into and speak for the collective unconsciousness of groups" (2005, p. A15). The desire for a sense of origins, identity and belonging is hardly unique to the individuals studied here. However, they have been raised in an environment where it is hardly possible to ignore the different aspects of their personhood:

The city is a place of cultural fusions and confusions, of communication networks that straddle boundaries, gated communities and immigrant ghettoes... (Wiwa, 2005, p. A15).

In a time when communication networks, settlement patterns and increased ease of global travel expose so many groups to others, and raise so many questions within and between 
those groups about cultural or religious practices, it is perhaps not surprising that individuals are constantly asked about their identity, and then turn those questions upon themselves. Even if they have never visited the place that is associated with their origin, they may be identified indelibly with it, one more reason why I would argue that the subjects of this research are indeed living in diaspora, and may be able to speak to its ambiguities and challenges in a way that is powerful, varied and meaningful: "[d]uring times when the demographic flows of people across territorial boundaries have become more the norm than the exception, it is counterproductive to maintain that one can only understand a place when one is in it" (Radhakrishnan, 2003, p. 126).

As the following chapters go on to explain, these participants have faced, and continue to face, complex challenges to the process of identity construction. As people of South Asian origin, most of whom are Muslim, many feel that it is almost impossible not to take any interest in their culture or religion, and many feel compelled to explain both of these to others who may hold longstanding assumptions about South Asians, Muslims, or minorities in general. Their strategies for building, reinventing or questioning their identity can differ significantly, but they do demonstrate elements of the hybridity and creolization described here. There is no one solution for how to create belonging and nationalism in communities that are so internally fragmented and home to such myriad strands, but there can be acknowledgement of what it means to be the new hybrids. These individuals may not demonstrate the same easy sense of self and place as SrebernyMohammadi and Mohammadi's daughters, but they do know that their identity is about more than themselves, and few of them believe that it is possible any longer-if ever it was-to enclose that identity within the strict borders of any nation, or any state. 


\section{Chapter 3}

\section{But Where Are You Really From? South Asians and Muslims in Canada}

\section{$\underline{\text { Separate and Equal? Muslim and South Asian Identity in Canada }}$}

Young adults in nearly any diaspora would present an interesting opportunity for the study of identity. The choice of Muslim Canadians of South Asian origin is certainly specific, yet despite the apparent narrowness of this selection, multiple possible identities and affiliations abound. Speaking specifically of South Asian Canadians, Patel (2006) suggests that they live a life markedly different from that of other Canadians for a number of reasons:

... factors such as religion, multiple identities, and the capacity to live with the contradictions and ambivalence that the enormous diversity of South Asia engenders, indicate that Canadians of South Asian origin currently function within a very different set of dynamics than do most other Canadians. (p. 157)

At the same time, there are also numerous points of intersection and overlap between Muslims and South Asians, ones that may sometimes go unacknowledged while contributing to a sense of confusion about the ability to delineate and define identity.

Although I will describe them on occasion as communities for the sake of simplicity, it is fair to say that Muslim and South Asian groups in Canada and around the world demonstrate high levels of internal diversity, and they may experience conflict within and between one another while also enduring external criticism. In spite, or perhaps because, of their growing numerical presence in Canada, there have often been significant problems with integration that Muslims and South Asians have faced. Highly publicized conflicts over the wearing of turbans and hijab certainly contribute to the distinct marking out of these groups as different from "real Canadians," but at the same time, the period following September 11, 2001 has been one in which a Muslim and 
South Asian identity has been defined not only by difference, but also by a sense of threat, particularly following the 2006 arrest of several young Canadian men accused of participating in a terrorist plot. Although there have been few to none opportunities to hear from these men directly, their names and appearances, combined with comments from family and friends, seem to suggest that they were all Muslim and at least several were of South Asian background. The result of incidents such as these, mirrored in the arrest of young South Asian Muslims in Britain, has been that South Asian Muslims now share the spotlight with Middle Easterners, once viewed as the archetypal image of a Muslim. The role played by South Asian Muslims' sense of self-or lack thereof-is one that has come under increasing scrutiny as young Muslims and/or South Asians in Britain, France, the Netherlands and elsewhere have appeared vulnerable to a feeling of marginalization and alienation from the countries in which they live.

This chapter will discuss the distinctive issues Muslims and South Asians face in the Canadian context, including historical similarities and differences imported from elsewhere, as they attempt to carve out a space for themselves. While Muslims may be seen as forming a religious diaspora, whereas South Asians could be seen as more of a racial or ethnic group, there are various points of intersection, overlap and melding. As discussed in previous chapters, conventional definitions may not allow for the possibility of viewing religious groups, such as Muslims, as constituents of diaspora, yet more elastic applications of the concept might allow, as in Mandaville (2001) and Khan (2000), that Muslims do demonstrate some of the qualities (dispersal, shared memories, beliefs, the use of media for community formation and cohesion) that would allow them to be viewed as part of a diaspora. South Asians may belong simultaneously to more than one 
diaspora, including ones formed around religion, nationality, race and specific ethnicity. Although diaspora does provide a unique space for the transformation of individual and group identities, this space can prove discomfiting for those who prefer the stability of perceived tradition. As Lila Abu-Lughod points out:

the self is always a construction, never a natural or found entity, even if it has that appearance. Second, the process of creating a self through opposition to an other always entails the violence of repressing or ignoring other forms of difference. (1991, p. 140).

This chapter investigates the context in which the self may be constructed for the young subjects of this research, taking into account global and national factors, religious, cultural and political pressures, and more simply, the evident challenges of inhabiting a generational and geographical position where there are few trails to follow-rather, there are ones to be explored and others to be blazed.

At times, people living in diaspora may tend to hold more firmly to inherited values and rituals than those living in the homeland, creating confusion and conflict for other migrants, families, and relatives or friends left behind. Others may do their best to integrate in a way that would be considered acceptable by the host society, although increasingly it seems to be the case that in Canada and elsewhere, the host society cannot come to a unified conclusion about acceptable levels of integration. Accordingly, it is not surprising that Muslims and South Asians may hold differing opinions about issues such as their future role in a society where Muslim and South Asian populations are growing steadily, confusing or incomplete media representations of Muslims and South Asians, internal differences within the two communities, and the use of diasporic media, which can ameliorate a sense of alienation in an unfriendly host society but can also further establish difference. 
South Asians form one of Canada's largest and most visible ethnic minority groups, while Muslims practise Canada's second-largest religion, although South Asians and Muslims alike constitute only a small proportion of the Canadian population overall, with nearly 917,000 South Asians and 600,000 Muslims in a Canadian population of roughly 30 million people. Both groups experienced considerable fear and isolation following September 11, 2001, when Canadian anti-terrorism legislation and antiimmigrant sentiment were perceived as directly affecting their communities in a markedly negative manner. Such events illustrated the fact that South Asian Muslims occupy a rather uneasy place in Canadian society as double minorities, despite Canada's ostensible commitment to pluralism and diversity, and despite the fact that South Asians and Muslims have both been part of the Canadian cultural and religious mosaic for many years.

South Asian Muslims represent a particularly interesting example of a minority group not only in the current political climate, but in larger cultural terms. Some Muslims may have experienced an increased sense of marginalization following September 11, but it is possible to surmise that others have occupied a marginal position in the past. Those who have South Asian ancestry may have been exposed, in varying degrees, to different forms of South Asian culture, but the dominant forms of these may be strongly accented by Hinduism or Sikhism. Muslims living in South Asia may have their own strategies for adaptation, but Muslims of South Asian origin living in Canada face separate challenges in terms of their positioning within the South Asian diaspora, within the Muslim diaspora and within the Canadian reality of a purportedly multicultural environment that nonetheless struggles to understand difference. While this study is specific to Canada, the 
following sections do attempt to provide some global context, however limited, regarding South Asians and Muslims.

Little India, Big Diaspora: South Asians Circle the Globe

Probably the uniqueness of Indian culture lies not so much in a unique ideology as in the society's traditional ability to live with cultural ambiguities and to use them to build psychological and even metaphysical defences against cultural invasion. (Nandy, 1983, p. 107)

The struggle for identity is not only about religion but also about national and ethnic association. (Smith, 2002, p. 15)

The South Asian diaspora is one of the largest in the world, and encompasses a number of countries within its reach. Jigna Desai explains that while South Asia is a region containing the nation-states of Bangladesh, Bhutan, India, the Maldives, Nepal, Pakistan, Sri Lanka, and Tibet, it is also used more loosely to indicate alliances and identities both within the diaspora and in these countries (2004, p. 5). South Asian is frequently conflated with Indian and is particularly apt as a descriptor for those individuals who departed India prior to its partition, when more specific national identities emerged with considerable suddenness and some confusion (Desai, 2004, p. 6). South Asian manages to act as an umbrella term for these identities, creating an impression of shared identity despite a history of religious, cultural and class-based division amongst and within some of the countries of South Asia.

Canada itself contains a large South Asian population, and among Canadians in their 20s, the largest group of visible minorities is South Asian (Anderssen \& Valpy, 2003, p. A8). Overall, Canadians of South Asian origin number roughly 917,000, representing 3.1\% of Canada's population. Between 1996 and 2001, the South Asian population in Canada grew approximately $37 \%$, a growth that outpaced even the Chinese- 
Canadian community, which currently represents the highest visible minority population in Canada (Statistics Canada, 2003, p. 11). While Muslims who could identify any South Asian origins were recruited for this study, the majority named Indian roots and several had Pakistani origins. Partly for this reason, a discussion of the Indian diaspora, and the relationship between India and Pakistan will constitute a large part of the analysis here. This is also because of the undoubted influence of India within the South Asian diaspora, given the size and breadth of India's diaspora, estimated at roughly 20 million people (Desai, 2004, p. 5).

In the South Asian diaspora, as with Muslims, the nature of immigration has changed significantly. In Canada, where policy once attempted to balance the need for affordable labour with the desire to please white citizens who objected to South Asian immigration, South Asians were present in small numbers from at least the 19th century. However, they possessed limited rights and by the early twentieth century, the provincial and federal governments passed laws intended to prevent more South Asian immigration, leading to the memorable 1914 refusal to accept numerous South Asians aboard the Komogata Maru, a ship that arrived in Vancouver and was eventually forced to turn back. Not until the 1960s did immigration rules in the United States and Canada change significantly enough to allow South Asians to enter these countries in substantially higher numbers. As Kumar notes, in the United States, the Barred Zone Act, enacted in 1917, and the Asian Exclusion Act of 1924 had previously prevented Asian immigration, and even when the laws were amended slightly in 1946, only 100 Indians were allowed into the U.S. per year. In 1965, seeking to add more skilled professionals to its workforce, the United States passed the Immigration Act of 1965, opening its doors to over 27,000 
Indians in the 1960 s and an additional 164,000 in the 1970 s, paving the way for what are now millions of Asian immigrants in the United States (Kumar, 2002, pp. 167-168).

Indian migration clearly did not commence with these waves of movement to the United States, having been preceded by the wide dispersal of Indian labourers throughout the globe, but it was a different kind of immigration that began to take place. Immigration to England was not uncommon, but it had often been initiated by people who moved into menial professions. The exodus of professionals to the United States caused that country and India to reconsider their thoughts on migration and difference. As Shukla notes, in the 1960s and 1970s the United States and England were forced to confront questions of nationhood and diversity that had already preoccupied India for many years:

India was always and already a fragile whole of many cultures, religions, languages, and regional groups, well before Jawaharlal Nehru's popularization of the motto 'unity in diversity.' And the British empire, one prominent example of globalism, employed ideologies of unhomogenized multiplicity to establish sovereignty over its totality. (Shukla, 2003, p. 6)

Even after the dissolution of the British empire, the role of Indians and other Asians in England remained tinged by colonial hierarchies. If the United States advocated a melting pot strategy for absorbing its new citizens, British Asians were expected to remember their place. However, in the 1970 s, Britain began to undergo some changes of its own, acknowledging its transformation into a "more pluralistic sense of itself. Racial uprisings, other forms of community rebellion, and popular and scholarly writings had prompted government studies and commissions that translated the need to respond to social change into a more generalized 'multicultural,' antiracist program" (Shukla, 2003, p. 67).

While countries such as Britain struggle to adjust to a changed social and cultural landscape, countries in South Asia undergo battles of their own. The colonizer may still 
visit the developing world in a search for cheap labour or new markets, but the real success of colonialism, the ripple effect still being felt decades after the fact, is the willingness of former colonial subjects to seek their fortunes in the urban centres of empire. Freed in theory to be master of its own destiny, India now finds that the colonial presence takes a very different form than had previously been the case. The lure of living abroad, of making one's fortune elsewhere, looms large for many Indians, a phenomenon best encapsulated in the new popularity of the term NRI, or nonresident Indian. While the term is sometimes used casually to indicate a person of Indian origin or citizenship who lives outside of India, it is derived from government terminology used to refer to people who maintain a relationship_-whether in name or in terms of the ability to maintain property-with India while living abroad (Shukla, 2003, pp. 10, 59).

Despite the dominance of India within the South Asian diaspora, a dominance that will be discussed further when examining the question of Bollywood, this diaspora is one that is marked by diversity, difference, and even conflict. Dominique-Sila Khan (2004) suggests that this has not always been the case, describing a medieval South Asia where individuals made strategic choices all the time regarding the beliefs and practices they were willing to embrace. Less preoccupied with the need to distinguish themselves from other groups than might be the case now, these South Asians sought identity through a number of sources, including their geographical positioning, their relationships with their neighbours and their belief in folk tales and oral history that sometimes placed universal importance on shrines, temples or festivals that would otherwise have been the provenance of a particular religious group. United at least loosely through their opposition to colonialism, the peoples of South Asia began to demonstrate some 
splintering following the Partition of India in 1947. As Hindus and Muslims moved physically and ideologically into separate spaces, South Asians around the globe began to be aware of their difference, affirming individual identities: “An increasingly complex field of affiliations began to distinguish the histories of 'Indians' from those of 'Pakistanis,' and later 'Bangladeshis', and other South Asians" (Shukla, 2003, p. 45). Another layer of complexity was added by multiple migrants, those individuals who had left a South Asian country and immigrated elsewhere, only to end up moving again, either through necessity or choice. Warah discusses the question of "triple heritage," a legacy handed down to several of the participants in this study, who have Indian ancestry, parents who lived in another country, and upbringing or education in the West. Due to a need for labourers to work on plantations and railroads, the British sent many Indians to various colonies in the nineteenth century, including parts of East and South Africa (Warah, 1998, p. 12).

Discussing the experience of Asians living in Africa, Warah suggests that they tend to have more in common with one another than they would with Asians living elsewhere, given the relative uniqueness of their economic and social status in both East and South Africa. Positioned above blacks in the social and economic hierarchy, but beneath those with European origins, Asians did not fit in with either group, remaining "highly visible, urbanized minorities whose culture and style of living have remained largely intact" (1998, p. 13). This cultural retention may have been a reactive measure to the dislike and scapegoating they apparently experienced from the rest of the population (p. 13), but whatever the reason, in Kenya, at least, Warah suggests that Asians tended to stay "fairly insulated against the culture of the country of their adoption. Most people of 
Indian origin in Kenya speak their mother tongue, follow their religious rituals, eat Indian food and have some vision of what their ancestral country is like, even if they have never been there" (p. 12). This observation aligns to some degree with Shukla's commentaries on the reclamation of Indian identity by Ugandan Indians following their expulsion by the dictator Idi Amin in the 1970s:

As stateless peoples, many Ugandan Indians began to see the cultural and psychic usefulness of 'becoming Indian' and submitting to the sense of a past rooted in a more abstract 'homeland'. Ugandan and Kenyan Indians brought to existing Indian immigrant communities a set of experiences that both complicated and buttressed pan-ethnic nationalism. The memories of multiple migrations, the histories of indentured labor, the triangulation of colonial sympathies and anticolonial resistance all broadened the discourses of Indian identity. Likewise, during this period, the presence of Indians from the Caribbean from Trinidad, Jamaica, and Guyana-challenged the linear narratives of class ascendancy being created by an earlier generation of now middle-class Indians in Britain. (Shukla, 2003, p. 64)

Both Warah and Shukla are correct in identifying the multiplicity and complexity of Asian identity in Africa. While Asians were indeed the target of scapegoating, they could also be perceived as agents of the oppressors in Africa, middle-class labourers and administrators who filled positions in the British regime: "However, as 'agents of imperialism' in Africa, the Indians soon found that their role was a double-edged sword which left them with neither the authority of the oppressor nor the humanity of the oppressed" (Warah, 1998, p. 19). South Asians in Africa and elsewhere in the diaspora, then, were affected by colonial politics in a different way from Indians in the homeland, yet some similarities existed. Warah suggests that the effects of Indian independence and Partition could be felt as far as East Africa, dividing Muslims from non-Muslims who aligned themselves either with the new India, with Pakistan, or with no place at all, as the 
carving up of the country confused their understanding of home, place and borders (1998, pp. 28-30).

Elsewhere in the diaspora, South Asians continued to put down roots, even if their position could be tenuous, as in Africa, or in more developed countries that proclaimed a willingness to accept their labour, if nothing else. Throughout the United Kingdom, the United States and Canada, Little Indias—and, to a lesser extent, Little Pakistans—sprang up, suggesting "the reproduction of a national (Indian) formation elsewhere, as well as the building of an ethnic enclave within the United States or Britain" (Shukla, 2003, p. 83). The existence of such enclaves raises some of the same questions regarding citizenship as those discussed previously, such as the following query: "is being part of a 'little India' to be part of Britain, the United States, or India?"' (Shukla, 2003, p. 83). Although Shukla's focus is mainly American and British, the same question has certainly been applied in the Canadian context, with no definite answer. One possible answer is that it is not necessarily the case that one must choose; another might note that belonging to a Little India can rarely be the same as belonging to India. Rather, it is a particular version of India, with some natural connections to that country as well as ones that are forged with purpose and intensity. For some, the automatic response to change is to try and find some kind of mooring in culture, a difficult task if that culture has always been experienced at a distance:

New generations of any formation always seem to elicit the prospect of disappearance and loss, and this is certainly the case with new Indian diasporic cultures. A very old question, of what is Indian, less Indian, more Indian, and still Indian appears as the quality of Indianness becomes unmoored from nation, state, or any other mechanism of surveillance. Immigrants from India to the United States and United Kingdom lament that their children are not 'Indian' anymore, precisely when youth express desires and longings that are distinct from those consolations of their parents. (Shukla, 2003, p. 217) 
Movement may cause a desire to recapture origins that are perceived to be lost, a loss that is mourned even when the moment of its occurrence cannot necessarily be pinpointed.

These attempts at claiming an identity take many forms. Shukla discusses the eliding of religious identity with a sense of nationhood, pointing to the phenomenon of Hindu youth groups whose commitment to the maintenance of culture or religion may often satisfy an exclusivist and nationalist understanding of Indian identity. Religion here, as more generally in the diaspora, I would argue, is a language for nation. Other religious articulations, as they might occur through Islam and Sikhism, which have active youth groups, too, may be a counterpoint, even a challenge to India, by espousing other forms of nationalism. (2003, p. 233)

Others may immerse themselves in mediated forms of culture in an effort to understand whence they came. At the level of high culture, one example might be the Indian Bengalis described by Ray, who attempt to differentiate themselves from the more mainstream, mass market aspects of Indian culture, instead "attempting to become 'better' Bengalis: evoking a past when Bengal's 'today' was India's 'tomorrow' is what frames Indian Bengali diasporic cultural life" (2001, p. 143). A less elite example would be those double or triple migrants who have no direct connection to Indian culture and thus seek it from the easiest source:

Many Asians in Kenya have never read an Indian classic, learnt Indian history or fully grasped the philosophical meaning of the Indian scriptures. If they learn about India at all, it is from the worst source possible - commercial Indian cinema which tends to be shallow, melodramatic, and very often, a poor and distorted depiction of life in India. (Warah, 1998, p. 48)

While Warah's judgement may appear to be harsh, it does have some validity, and it is the implications of this media-assisted identity formation that will be discussed in the following chapters. However, while commercial Indian cinema has a way of ignoring or simplifying difference, Warah suggests that another way of seeking authenticity in real 
life is by observing strict hierarchies: "Even among themselves, Asians rarely refer to themselves as a race, but as members of the religious, linguistic or caste group to which they belong" (1998, p. 49). There seems to be some evidence in this study to suggest that this level of specificity does not hold quite as much significance for younger generations, but nonetheless, they are aware that the constant establishment of difference is one means of reasserting a sense of South Asian self. They are also aware, as several participants noted in this research, that their refusal to subscribe to these notions of division may not prevent them from experiencing attendant implications in their own lives and personal relationships.

The role of nationality in creating barriers is quite evident in the aftereffects of Partition, with its overtones of religious segregation. However, even among Hindus and Sikhs, there may be further segregation on the basis of a specific sect or caste. Warah critiques division on the basis of the latter, noting that the caste system is not indigenous to India but rather an import from Aryans who appeared in Northern India around the $15^{\text {th }}$ century B.C. and proceeded to craft their own version of Hindu religion, one based on a strict social hierarchy $(1998$, p. 50). This hierarchy can still be seen in India and throughout the diaspora, although not all Hindus or all Indians adhere to it equally. Light skin remains a selling point for prospective brides and grooms, especially brides, suggesting higher caste and beauty. This form of prejudice, Warah speculates, explains why intermarriage and integration is easier between some groups than others, "why intermarriage between Asians and Europeans is still acceptable to many Asians, but such a marriage if the partner is African is not. It also explains why integration of Asians in Africa has been slow compared to integration of Asians in say, Canada" (p. 51). 
Colour is only part of such division, and internal hierarchies are not unique to Hindus; Gillespie (1995) notes the way South Asians of different religions attempt to maintain caste and sect distinctions in England, albeit with mixed results, given the impossibility of preventing lower caste members from pursuing economic and social success outside of India's borders (p. 32). Brah (1996) describes the way the separation of castes among Indians was carried over to Britain during the first decades of immigration in an attempt to prevent people of lower castes from interacting with those of higher ones. While such segregation did prevail at times, it underwent a transformation of sorts due to the fact that British society viewed all of these people as members of the same class. Caste can mutate in diaspora, then, but Brah also cautions that it is simplistic to suggest that caste is completely static in any location, including India (p. 30).

Hierarchies do have a way of changing, despite the most determined efforts at preservation. Cohen quips that transnational migration provided an opportunity for social mobility that had never existed before in India's rigid social hierarchy: "A common ingroup joke among contemporary Indo-Trinidadians is that while there were no Brahmins when the ships set out from Calcutta, by the time they arrived in Port of Spain (Trinidad) several gentlemen had assumed a haughty, priestly mien" (1997, p. 61).

These kinds of prejudices, however, are not the only ones that divide South Asians. Politics and religion intertwine in the portrayal of Sikhs as essentially different from Hindus and frequently extremist, a depiction that is sometimes applied to Muslims as well and can be found in several examples of Bollywood cinema, as several participants in this study were quick to note. These divisions are only partly based in religion, with more of them attached to political acts such as the Sikh campaign for its 
own homeland, and the violence between Hindus, Sikhs and Muslims that exploded after Partition and echoed in events such as the Hindu-Sikh fighting following the 1984 assassination of Indira Gandhi by two Sikh bodyguards, and the Bombay intercommunal riots of 1993 . While many Sikhs continue to maintain their difference from other groups in India, some Indian nationalists have attempted to overcome division by minimizing ethnic or religious difference (Cohen, 1997, p. 62), an attempt that would likely find favour with those who argue, like Dominique-Sila Khan (2004), that careful study of South Asian literature, customs and history can uncover surprising similarities among Hindus, Muslims and Sikhs. In theory then, this may seem like a positive attempt to establish unity but in practice, the outcome of efforts to stoke Indian nationalism has been the ascendance of a Hindu Indian identity, both within South Asia and within the diaspora (Gottschalk, 2000, p. 18).

"In general," Cohen reports, "orthodox forms of Hinduism became predominant in the diaspora and were the principal means whereby the Indian labour diaspora was reconnected to the 'Great Tradition' of India" (1997, p. 63). He goes on to cite Dhaliwal's opinion that diaspora may ultimately be the space that resolves the differences between polarized religions and cultures:

She argues that, while the South Asian diaspora has multiple and shifting relationships with India, these do not automatically challenge the Indian nation. Indeed, she suggests that the diaspora may provide a means of resolving the unconstituted nationhood of India itself - in particular the unresolved difference between Sikh and Hindu. (in Cohen, 1997, p. 136).

This is certainly an optimistic point of view, and echoes Mandaville's (2001) beliefs regarding diaspora as a unique space for exploration and resolution regarding religious and ethnic issues (pp. 109-115). 
While making reference to Hindus and Muslims, rather than Sikhs, Ray does emphasize that divisions between South Asians can come to seem artificial when meeting the challenges of displacement. The Fiji Indians living in diaspora that he describes refused to conform to old notions of separation and hierarchy, instead going

to great lengths to fashion new hybrid diasporic realities. During the indenture period and the early days of post-indenture, both Hindus and Muslims participated in the major ritual festivals like Holi, the riotous Hindu ritual of reversals, and the Tazia, the Shi'a Islamic Moharram re-enactment of the martyrdom of Husain and Hassan. (Ray, 2001, p. 155)

This may be a step in a new direction for some, but it may also signal a revival of the longstanding traditions of communal celebration and sharing described by DominiqueSila Khan (2004) in her discussion of identity in South Asia (also see Gottschalk, 2000, pp. 36, 155-156). Khan points out that in medieval South Asia, certain practices and beliefs might be maintained jointly by groups that would now view these quite differently. The proximity between groups living in the same villages often led to the forging of complicated bonds, including ones that eventually came to be disavowed as religious and cultural groups sought to carve out a clearly delineated identity.

This kind of hybridity and accommodation can be forgotten or rejected for those who view diaspora as a space where changes must be met with stubborn attempts to recreate the past in order to resist incorporation into a different social order: "Ashis Nandy makes the point that exiles often develop a fixed and backward-looking image of their homeland. Thus, he argues that, in the Indian case, diasporic Hinduism is often more exclusive and homogenic than that in India" (Morley, 2000, p. 49). However, there can be several stages involved in this, and many contradictions. In a sense, Gottschalk argues, identity within present-day South Asia is defined at least partly by what it is not: Indians 
and Pakistanis know that their affiliations are opposed, driving them to immerse themselves further in practices that will further differentiate them, while South Asians in general know that they are not Westerners, a fact that can unite them rather loosely (2000, pp. 60-63). When individuals are taken out of an area where they can at least identify some surface ethnic similarities, they may follow unusual steps to preserve a sense of self, however artificial. The same blurring of religious and cultural identities identified by Khan (2004) in South Asia can also be seen in diasporic Indian Muslims whose proximity to Hindus has resulted in the creolization of various practices:

During the indenture period, Muslims had little opportunity for religious and cultural expression of their own; they used to regularly take part in Hindu festivities and folk cultural gatherings. However, with the visit of several Imams from India, attempts were made to reconstitute their identity in religious lines. (Ray, 2001, p. 169)

There is no clear and distinct answer to whether diaspora will help South Asia evolve, or merely preserve and even feed existing rivalries. It does seem possible to say that the differences perceived among South Asians may not be evident to outsiders, and hence in diaspora South Asians may tend to be grouped together, a tendency demonstrated by the evolution of a vocabulary to describe all of them equally. There is a superficial level of unity that can be encompassed in such descriptors as the term "desi", used loosely to apply to any number of South Asians living in diaspora. "Desi is a chameleon-like word," explains the Masala Trois Collective in their book Desilicious, "evocative more than descriptive, adopted most comfortably by young South Asians who appreciate the irony of naming a mind-bogglingly diverse number of cultural communities, spread across continents, using a word that simply suggests home" (2003, p. 13). In particular, the term desi is used often in reference to youth, a fact noted by 
Malkani in his analysis of the way desi identity in Great Britain can be South Asian and

British without any contradiction or compromise:

our desi identity feels more like a youth subculture than an ethnic identity. (The word desi is derived from Sanskrit for "countryman," but among the young its meaning is closer to the hip-hop slang "homeboy.") As a subculture, the desi scene is as British as punk rock or acid house, and therefore less fundamental and more porous than an ethnic identity - but without being any less South Asian. (2006, p. A15)

Malkani notes the new diversity within Britain, and its acknowledgement of a desi culture that can fuse the disparate influences of places as far apart as London and Mumbai. It is within places such as this, offers Desai, that one can examine migration in all of its complexity and in relation to "dominant discourses on modernity, capitalism, and the nation. The Brown Atlantic, located in the heart of the beast, provides a foray into understanding negotiations of South Asian transnationalities with U.S. imperialism, British colonialism, and global capitalism" (Desai, 2004, p. 31). It is impossible to study, as Ulrich Beck has (2000) indicated, local spaces that are seemingly new, pluralistic and modern, without understanding that locality maintains a symbiotic relationship - what Beck labels a kind of reflexivity — with the global, and neither Malkani's Britain nor Desai's America are immune to the interaction between city and world, village and diaspora. There may be a desi culture spread across all of these, but it differs in whatever nooks and crannies it occupies, and it is by no means organic, simple or static. Indeed, some of the young people interviewed for this project note the intermittent trendiness of so-called desi culture, and the implications of its commodification and mainstream popularity.

Malkani's version of the Brown Atlantic locates both diversity and unity in the person of youth, making only implicit reference to the forces of capitalism or 
imperialism. Yet in his description of acculturation, as explained by his interview subjects, it is clear that culture is linked to a number of other factors: "The boys and girls I interviewed would describe assimilated 'coconuts' (brown on the outside, white on the inside) not in terms of ethnic characteristics but of street-savviness and gender: they were either 'saps' (uncool), 'ponces' (effeminate) or 'batty' (homosexual)" (2006, p. A15). Those who insisted on maintaining a strict observation of Indian culture, at least as they understood it, were linked to impressions of hypermasculinity, while those who gave in to the temptations of assimilation were lacking in strength and virility.

There are several aspects of this observation that are worth interrogating. First, neither assimilation nor cultural assertion is entirely unproblematic; the young people being interviewed saw issues with both. Second, contrary to narratives of immigration that suggest generational change, the youth did not demonstrate simply one technique in response to perceived challenges to culture. Even within the youth, there was vast difference. Gender also melded with cultural retention in a way that is hardly unique to South Asians in Britain, yet here there is a far more explicit link made between gender and sexuality, and culture, than any suggested by the literature looked at so far. This link, however, is not so far removed from traditional discourses by colonized people in which women serve as fragile purveyors of indigenous culture, while the strong masculine force protects female space, which doubles as national or cultural space. This connection between gender, culture and sexuality reasserts itself repeatedly in Indian cinema, especially popular Indian cinema.

This relationship evokes the term intersectionality, which Desai explains was first used by Kimberlé Crenshaw as a way of explaining the "simultaneity of multiple 
differences in the experiences of women of color" (Desai, 2004, p. 26). While that usage will certainly be applicable here and in following chapters, the more broad version, focussing on the analysis of layered aspects of difference and power relations, offers an excellent way of examining the contradictory positionality of Malkani's interviewees, as well as the ones discussed here. Rejecting assimilation as a form of selling out or emasculation, Malkani's youth nonetheless understood that there was some element of posturing or exaggeration associated with the assertion of cultural identity and authenticity. The intense resistance to assimilation, not just from these youth but to a wider extent, indicates the extent of the temptation it offers. If this were not so, there would be far less attention, not to mention antagonism, focused on this question.

Gillespie (1995) and Handa's (2003) separate studies seem to imply the importance of this temptation, or presence, even in the lives of their young participants, most of whom seemed to exist in an interesting state of hybridity. Modern, well-adjusted, and generally integrated into mainstream society, these young people nonetheless occasionally turned up their nose at those who insisted on the public display of culture. Gillespie's examination of Punjabi teenagers in the United Kingdom finds internal discrimination at work among South Asians, who explain their social hierarchy to her. Recent immigrants or highly traditional Punjabis reside at the very bottom, their Indian origins too clearly marked by their clothing, hairstyle and mannerisms (1995, pp. 180197). Although Amita Handa's South Asian female subjects, residing in Toronto, are vehement that they do not endorse racism and support the right to a multicultural society, their comments regarding Indians who are "typical" or "fresh off the boat" are decidedly 
critical and demonstrate the perception that a divide persists between South Asians who are more assimilated to Western culture and those who are not (2003, pp. 82-89).

Handa's participants offered this observation despite appearing, at least to Handa's eyes, far more comfortable with their culture and selves than she could have imagined being only ten or twenty years before. To a certain extent, then, as Desai suggests, the influences of colonialism still persist in diaspora, even in a country such as Canada - the site of Handa's research - where different identities are expected to flourish (2004, p. 12). What has changed, perhaps, is the means by which diasporic subjects internalize their beliefs about the culture to which they should belong. For those immigrants who came from South Asia during or soon after colonialism, it was perhaps natural to believe in the superiority of English-speaking, fair-skinned individuals dressed in Western clothes. For the youth in Gillespie (1995), Handa (2003) or even this study, those beliefs may be fostered simply in the new environment, a natural byproduct of living in an arena where one is not the majority.

Certainly differences do exist between and within the generations, a difference that can also be noted with young Muslims. As waves of immigration continue, coming from and going to disparate parts of the globe in a time when many states struggle with the implications of such movement, there is no unified process by which all immigrants come to a specific and obvious understanding of identity and ethnicity. There is little validity to "nationalist constructions of belonging that link racialized and gendered bodies and space in seamless tales of bloodlines and family to the land" (Desai, 2004, p. 18). Despite this, there do seem to be some confused remnants of these narratives in the comments of the young men to whom Malkani spoke, several of whom held embedded 
notions regarding gender, strength and culture. Gender was also an overwhelming preoccupation of some of the participants in this study, several of whom felt that gender inequity was constructed as an essential part of South Asian culture despite the contradiction this posed when living in an era where many traditional understandings of gender relations have been judged out of date. Commentaries around gender arose frequently and without prompting, and in this area in particular, it was obvious how the occasionally incoherent collapsing of religious and cultural categories had combined to place young South Asian women in a difficult position. There is perhaps no aspect of identity that is irrelevant in this study or in any other similar investigation. Gender, race, ethnicity, religion, class - all of these and more combine to create a complicated understanding of personhood and where one stands within a community. $\underline{\text { Still Waiting for the Green Peril? Islam as World Religion }}$

Religion can be viewed both as a way to overcome difference and as a way to accentuate it, depending on the context and circumstances. The emphasis in the media and by some academics on Islam as a supposed motivator for acts of terrorism (for examples, see Pipes, 2001; Pipes \& Hedegaard, 2003; Wente, 2001) around the globe might lead some to believe that Islam is a strong religious and political force. In reality, while Islam does bind together upwards of one billion people around the world, it is by no means a way of creating political or social unity, and the vast disparities in methods of practice also ensure that the religious bonds can be tenuous. Although the phrase "Muslim world" is bandied about regularly in the press and occasionally in political speeches, the fact is that Muslims in Canada, or around the world, are no more united or homogeneous than any other religious group. Globally, they are widely dispersed, with 
large concentrations in countries such as Indonesia or parts of the Middle East, accompanied by growing numbers in North America and Europe. These shifts into the latter have caused some consternation as countries in the global North struggle to accept the reality of a Muslim presence that has moved within their borders, as opposed to the days when colonial forces occupied Muslim-dominated places such as North Africa.

Smith (2002) notes that former colonial powers have had their expectations turned upside down, believing initially that their move out of colonial territories would be the first step in a process of modernization and economic independence. Instead, facing political unrest and lack of opportunity, some Muslims began a type of reverse migration, moving to the very countries associated with imperialism. Possessing some degree of assumed familiarity with the language and culture of former occupiers, however fleeting, these immigrants arrived in places such as Germany, France and England, where the visitors and the hosts alike assumed that their stay would be fleeting, a temporary sojourn in search of economic prosperity that would end with a return journey. Instead, many of the immigrants settled down, producing second generations of children who came to view the new country as their home, forcing everyone concerned to confront the reality of a permanent Muslim presence, one that also spread to points further west, such as North America.

Some would describe this process of dispersal as the formation of a religious diaspora, while others would question the possibility that such an entity might exist. A religious diaspora, like an ethnic or national one, is necessarily diverse and decentred, but this condition is further exacerbated by a lack of state connections. There is, practically speaking, no real homeland or gathering place for most Muslims. While Israel may serve 
as an ideological — and occasionally physical—point of return for many Jews, there is no particular place to which Muslims are expected to return, or where all of them would look for spiritual guidance. Mecca is perhaps the only unifying point, as a place for pilgrimage and as the direction for prayer. It is not a homeland, although it may constitute a seat of nostalgia in the sense that —as Mandaville (2001) notes-some Muslims, unsure what constitutes religious authenticity, have tried to focus their attempts by recreating the seventh-century society of the Prophet Muhammad, seen by Muslims as their last and final prophet (p. 90).

While Muslims may disagree in a number of areas, they would all accept that Prophet Muhammad was the final prophet of Allah, and that Allah is the only God. They submit to the will of Allah, with the word Islam literally translating into submission. After that, as in many major religions, Islam houses a number of sects, many of which are further differentiated by the cultural practices which operate in each region. Following the death of the Prophet, a series of fault lines began appearing among his followers over time, most often over the question of succession. Shi'ites believe that the Prophet appointed his son-in-law Ali to lead his followers after his death and expected leadership to continue through the family line, a belief that some followers disputed. Those who disagreed chose instead to rely on different systems for appointing leaders, including elections, and they came to be known as Sunnis. Sunnis constitute the global majority, while the Shia, for the most part, maintained their belief in the hereditary transmission of leadership.

Despite the high representation of Sunnis in overall global figures, which suggest that Shi'ites constitute a mere $15 \%$ of the world's Muslims (MacFarquhar, 2007), it is 
worth noting that this proportion is not always replicated in every region where Muslims are found. For instance, in some Canadian centres, Shia Muslims may have relatively strong representation compared to their position in the Middle East, South Asia or even the United States, where the ratio of Shi'ites to Sunnis mirrors the global average (MacFarquhar, 2007). Ismaili Muslims, for example, are well-known and wellrepresented in cities such as Vancouver and Toronto, and they identify themselves as Shia (and continue to endorse the notion of an Imam, or religious leader, who can trace ancestry back to Prophet Muhammad), despite the fact that other Shia and Sunnis sometimes disclaim them as pseudo-Muslims who do not follow the same practices as other Muslims. The same accusations have also been applied to Sufis, known for their more mystical approach to the spiritual, and Ahmadiyyas.

Islam originated in seventh-century Arabia but would eventually spread around the globe. Its influence is concentrated perhaps most visibly in parts of the Middle East and Asia, including India, where religion is sometimes portrayed as a divisive force in spite of the fact that many Indians once shared the same religion, and a significant number continue to demonstrate overlap in terms of their practices and rituals. Waves of proselytizing forces moved through the subcontinent after the Prophet's lifetime, converting a large number of Indians to the Islamic faith. It is perhaps for this reason that Hindu rituals can still be seen at times in the cultural practices of South Asian Muslims, despite the apparent perception of difference. Dominique-Sila Khan (2004) suggests, in fact, that the purported division between religious groups in South Asia is one that has been exaggerated, providing a false picture of the hybrid religious and cultural practices seen historically in South Asia. She offers a historical commentary on the ways that 
various religious groups interacted in South Asia, celebrating some of the same festivals and worshipping at the same sites. This intertwining of various sects was so complicated and mysterious to colonial administrators that they did their best to categorize each group as simply as possible, with the result that individuals eventually came to realize their difference and the behavioural expectations placed upon them.

Nonetheless, the confluence between different religious and cultural groups did persist to a certain extent and can be seen repeatedly throughout this study, and is still relatively pronounced in Canada. While Canada is home to a steadily growing and very visible South Asian population, it is also the possessor of a relatively young Muslim population whose numbers show no sign of declining. Between 1991 and 2001, the number of Muslims in Canada more than doubled, jumping from 253,300 to 579,600. This increase was due mainly to immigration, but the relatively young median age of these individuals - 28 years old —also suggests steady growth may take place through reproduction (Statistics Canada, 2003, p. 8). This being the case, it is important to investigate the role that Muslims have played and continue to play in Canadian society. Muslims in the Mosaic: Muslims, Diaspora and Difference

I have heard my mother pointing out to her friends, with some pleasure, that the world has turned upside down and they have ended up learning their religion from their Canadian children rather than from their Muslim parents back home. (anonymous interviewee in Hoodfar, 2003, p. 23)

Although her study is somewhat dated, Zohra Husaini’s (1990) points regarding the history of Muslim immigration to Canada still retain considerable value. She notes changes in the nature of Muslim immigration, which commenced mainly with Turkish or Arab labourers. Karim points out that historical documents indicate a Muslim presence, however small, in Canada from the mid-nineteenth century, and an official record of 13 
Canadian Muslim residents provided by the 1871 census (2002, p. 263). In the 1960s, changes to Canada's immigration policy helped diversify the class and ethnicity of newcomers, including Muslims, who began to arrive as skilled immigrants from Asia and Africa (Husaini, 1990, pp. 21-22). Despite the common portrayal of Muslims as Arabs, then, Muslims in Canada demonstrate rich internal diversity in terms of their ethnic origins and background.

Inquiring about the needs and concerns of Canadian Muslims with particular emphasis on Albertans, Husaini found that Canadian Muslims, in general, are "concerned about what they would call the 'Future of Islam.' In essence they are anxious to pass their rich and valued Islamic heritage to their Canadian-born generation, which is nurtured and educated in the secular values and outlook of Canadian society" (1990, p. 36). Related to this, they expressed a desire for Muslim social networks and a strong sense of community, as well as for successful means of providing religious education (p. 52). Interestingly, their answers did not seem to indicate insularity or repudiation of a culture populated by non-Muslims: they suggested to Husaini that another key concern would be "to create harmony and co-existence between Islamic values and the values of the broader society so that 'Canadian Muslims' can relate to their peers" (p. 37). Since this is still the challenge that many Canadian Muslims take up today, wondering how to reconcile a Canadian upbringing and education with religious and cultural values that some perceived as being opposed to this, Husaini's study, rather than appearing stale, seems to suggest that the concerns of Muslims have not changed so much as they have intensified and, perhaps, clarified. 
At the same time, Canadian society has undergone changes of its own, some with great reluctance. While the Muslim population has grown in Canada and shows few signs of declining, some Canadian cities have reacted to the Muslim presence by attempting to limit its reach. Isin and Siemiatycki (2002) document the problems of seeking out space for mosques in Toronto, while Shahnaz Khan (1995) notes the debate over permitting head scarves or other examples of hijab (veiling) to be worn in Quebec schools. Razack (1998) suggests that the intensity of the debate over veiling and female genital mutilation, practices depicted in the media as Islamic when in fact they are largely cultural, serves to reinforce notions about “the brutalities of 'Islamic' and Asian states" (p. 6). Such emphasis upon religion and culture as oppressors of women-as-victims refuses to acknowledge the possible context and reasons for the practices named above, and also turns a blind eye to different, yet very real, forms of sexism in North American society. Proposals to introduce sharia, a form of Islamic law, in Ontario created such overwhelming controversy and concerns over the repression of women's rights that Premier Dalton McGuinty finally resolved the debate with a 2005 decision not to grant authority to any religious tribunals in the province (Allemang, 2005). While other religious groups, including Ismaili Muslims, have administered tribunals for years, the sharia case prompted widespread fears over the consequences of empowering Islamic extremists.

The case of the Ismaili Muslim community, in fact, is somewhat unique, as several participants in this study note. Taking into account the high level of mainstream integration displayed by this group, Husaini takes a few moments to discuss its status in the province of Alberta, where her study was based: 
...the Ismaili Muslim community in Alberta is the most organized, cohesive and motivated of all other groups of Muslims in Alberta. Except in the economic and educational sphere, they maintain an intense form of "institutional completeness" in Breton's sense of the term. They also display a unique combination of adaptability to the Canadian way of life with total dedication to Ismaili faith and practices. Even the Ismaili youth and children are well versed in the Ismaili practices and would remain faithful to the community. (1990, p. 35)

This case is particularly interesting and will be raised again throughout the study.

Canadian Ismaili Muslims may come from any ethnic background but many tend to derive their origins from parts of South or Central Asia. The earlier immigrants, many of whom arrived in Canada in the 1970s, are more likely to be of South Asian ancestry, but if they can trace their roots back to India, it is often by way of other countries, such as East Africa, where many Asians resided before taking their leave during the 1970s exodus. Central Asian Ismailis are generally more recent immigrants, their arrival in Canada prompted largely by the political unrest in their native countries.

The strong adaptability and cultural retention pointed to by Husaini do exist, yet this does not imply that Ismaili Muslims, more than any other Muslim or South Asian group, feel entirely comfortable with their multiple sources of difference. Karim (in press) notes their willingness to accommodate different cultural practices within their community and alongside it, embracing mainstream social and political causes while maintaining those traditional rites and beliefs that they view as necessary for the continuation of their faith. In fact, they demonstrate an ability to integrate that could be seen as assimilationist and that some may criticize for its secular appearance. Persecuted intermittently over the centuries for their esoteric practices, different from those of other Muslim groups, Ismailis historically developed a policy of taqiyya, or concealment, often assuming the guise of other religions in order to escape danger (Karim, in press). 
Parin Dossa (1988) also remarks on the integrative ability of Ismailis in Canada, and attributes this to their cohesiveness as a community, an observation similar to Husaini's institutional completeness, which helps sustain not only Ismailis but a number of Muslims as they adjust to a new society. Again, taking into account the fact that much has changed in Canadian society, and for Muslims, since Husaini's study, it is still interesting to note that the respondents' own commentary regarding integration coalesces almost exactly with the comments of individuals interviewed for this dissertation. Asked about the significance of the cultural and religious institutions to which they belong, Husaini's participants suggested that these organizations helped them integrate into mainstream Canadian society, assisting with "overcoming cultural nostalgia by meeting others, by creating social networks, by getting involved in various cultural activities. An equally large number of respondents found adjusting to this society easier because they found a familiar religious environment" (1990, p. 52). This worked to strengthen their faith and to educate their children in matters of religion. In other words, the confidence these organizations provided in terms of constructing identity and community helped them feel at ease to the point where they perceived fewer barriers to involvement in mainstream Canadian society.

Similarly, one respondent in this study, speaking sixteen years after Husaini's research was conducted, notes that he feels more Canadian because he is encouraged to maintain his own faith as he wishes. This ability, he offers, makes him feel proud to be Canadian, and allows him to feel that there is no conflict at all between Canadian patriotism and Muslim practice. Likewise, Murji and Hébert's Muslim interviewees praise Canada's openness to the notion of retaining one's faith and heritage. At the same 
time, however, they also indicate occasional "resentment of not being identified as being 'Canadian' because of one's colour or practice, of being the other, of experiencing discrimination and prejudice" $(1999$, p. 13). Razack suggests that such discrimination is more widespread than the official state view acknowledges, arguing that multiculturalism exists side by side with a tacit "assumption that, in choosing to come here, immigrants relinquish their right to the conditions under which their cultural identities might flourish. Such an argument...sidesteps the point that immigrants seek...a protection that can come from maintaining their own cultural practices" (1998, p. 28). Husaini passes over multiculturalism's possible limitations in describing Canada as a "free, democratic, peaceful and tolerant society which, at least formally, does not pressure the incoming immigrants to renounce their cultural and religious heritage" (1990, p. 100). "Living in such a conducive atmosphere for cultural preservation," she posits, "it is much easier and psychologically smoother for Canadians of different nationalities of origin to forget their original conflicts, and come together to build upon points of similarities and common loyalties" (p. 100).

While it may still be the case that Canadian minorities have some freedom to express loyalties to other nations or entities, recent political events, including but not limited to the wars in Afghanistan and Iraq, have clarified the degree to which certain minorities are considered problematic in the functioning of the nation-state. The sense of global obligation felt by many Canadian Muslims to their fellow practitioners around the world came into stark relief during these conflicts, when an expression of faith came to be seen as a repudiation of a supposedly secular state and, therefore, of democracy itself. Joseph Carens describes the type of scrutiny Muslims must undergo in such a situation: 
One question that one encounters frequently, either implicitly or explicitly, is whether Muslims can be full members of liberal democratic societies given the strength of their communal identity. In the view of some democratic theorists, participation in the democratic process requires a capacity to distance oneself from one's identity. (2000, p. 141).

This separation from one's identity appears to pose considerable difficulty for many

Muslims, particularly as a sense of injustice fuels their interest in matters related to other

Muslims. Acknowledging the extent to which Muslim loyalties are in constant question, Siddiqui responds to thinly veiled commentaries in the media about the need to review multiculturalism, dual citizenship and immigration by stating bluntly, "[ $\mathrm{t}]$ he latest handwringing on multiculturalism and its first cousin, immigration, in reality is a debate about Muslims" (2006, p. A17).

Whether it is acquired recently or the product of accumulated years of discomfort, the idea that Muslims should keep their focus strictly Canadian is one that contradicts the sense of global concern reported in Husaini's study:

the majority of Muslim immigrants themselves come from the developing countries. Many Canadian Muslims reported that they feel a sense of obligation, empathy and responsibility not only for Muslims in their own countries of origin, but also for all those in other countries of Asia and Africa, where people are not only victims of poverty and deprivation but also of wars, foreign subjugation and displacement. They have often stated that Canada has given them a chance to acquire education and prosperity, freedom and dignity. As true Muslims and as Canadians, it is their responsibility to share their wealth, knowledge and expertise with those who are not as fortunate as they are. (1990, p. 59)

Arguably, any departure from this notion, which signals that cosmopolitanism is not merely an interesting theory as much as a practice that is already taking place-albeit with an interesting ethnic twist on Heater's version-would weaken the foundations of a

free, democratic, peaceful and tolerant society which.....acknowledges and respects all differences. Living in such a conducive atmosphere for cultural preservation, it is much easier and psychologically smoother for Canadians of 
different nationalities of origin to forget their original conflicts, and come together to build upon points of similarities and common loyalties. (Husaini, 1990, p. 100) After speaking with a number of Canadian Muslims, Husaini expresses her conviction that it is possible for these citizens to continue their religious practices, engage fully with Canadian society, and to maintain an overarching interest in current events and concerns around the world. Indeed, she argues, it is even desirable, for the Canadian model may be the best one available at the moment, one which may serve as an example to other countries and societies (pp. 101-102).

In theory, the situation elsewhere is rather different. While much attention is devoted by policymakers to comparing and contrasting the Canadian and American models, with a supposed emphasis on plurality in the former and assimilation in the latter, the example of Europe has its own lessons and bears further consideration. Speaking of Europe in general, the influential intellectual Tariq Ramadan (2002) remarks on the necessity of being able to combine a thoughtful interpretation of the Muslim faith with an equally reasoned and invested concern in European practices, culture and social justice. Britain has had specific issues stemming directly from its own post-Sept. 11 attack, with the July 7, 2005 bombings of the London subway. All three of the countries named here have grappled with their own understanding of the Muslim problem - and it is indeed framed as a problem in media and policy discourse - and Britain's eventual reaction has certainly aroused considerable controversy. Lyall and Fisher comment on the British government's attempts to reach out to the Muslim community within its borders, suggesting that British Muslims retain unremitting hostility towards their adopted country despite these persistent efforts $(2006$, p. 6). This is perhaps not as surprising as it might seem at first, given that high-ranking representatives such as Home Secretary Jack Straw, 
as well as Prime Minister Tony Blair, have located the source of their ongoing communication problem in an area that seems to attract persistent attention around the globe: Muslim women's clothing. Specifically, Straw decided to address the issue of cultural difference by announcing his unwillingness to meet with Muslim women who would not remove facial coverings, despite the fact that those same women interpret this form of covering as a religious obligation.

While the religious necessity of such practices is debatable and is indeed debated within and outside Islam, the fact that they are singled out and cited as examples of Muslims' refusal to integrate into society may make the following poll results from the Pew Global Attitudes Project unsurprising:

81 percent of those surveyed in Britain said they considered themselves Muslims first and Britons second. That contrasts with Spain, where 69 percent of those surveyed considered themselves Muslims first and Spaniards second; Germany, where the comparable number is 66 percent, and even Jordan, with 67 percent. (Lyall \& Fisher, 2006, p. 6)

This disparity was not always quite so extreme. Lyall and Fisher cite experts who suggest that previous generations of Muslims in England experienced less difficulty in balancing their Muslimness and Englishness:

Many of the first wave of immigrants were from rural Pakistan, spoke poor English and never integrated much. But the generation that is coming of age now is caught between the traditionalism of their parents and the Western ideas they have been born in to, and the result can be toxic. $(2006$, p. 6$)$

While conservative parents and the traditional mentality of older generations are sometimes cited as important influences in the radicalizing of young Muslims, this does not always seem to be the case. Jocelyn Cesari describes a growing number of young Muslims in France who choose to express their identity by adhering more strictly than ever to religious rules and practices. This number, she notes, is small in comparison to 
those Muslim youth who are flexible about religion, tending instead towards a customized approach where they embrace those rituals or beliefs that fit into their lives and whose purpose makes sense to them, rather than hewing to a strictly orthodox line without question (2002, pp. 41-42). In fact, when studying the reasons why young Québecois Muslim women cover themselves, a practice that can range from the assumption of a light headscarf to the use of an all-encompassing garment, Hoodfar (2003) was startled to discover that very few of the parents of these women wanted them to veil, as such covering is commonly described. Most considered the practice unIslamic, but were unable to dissuade their daughters from veiling. While some daughters were motivated by their parents' strictness, and felt that veiling would convince others of their modesty, hence allowing them to go out in public without encountering harassment or disapproval, others began veiling as a reaction to their sense of marginalization in Canadian society. At times, then, the traditionalism of parents may be a factor, but at other crucial times, this does not appear to be the case.

In the much-discussed case of the eight young men in an affluent British suburb who were arrested in 2004 for allegedly attempting to make and store explosives for a planned terrorist attack, observers have been at a loss to explain adequately the motives that might have driven these youth. The parents of two of the young men have been described by friends and neighbours as moderate Muslims, whose sons encountered a sheikh known for his extremist views. Commenting on the challenges of raising Muslim children in British society, one friend of the family offers,

Our children are born here and grow up here. But we couldn't pass the real Islam to them because we don't know it ourselves. We were too busy working 12-hour shifts to support the kids and family back home. We just didn't know there was a problem. (Ghafour, 2006, p. A16) 
Similarly, in other parts of Europe where assimilation is more highly touted than in places such as Britain and Canada, Muslim immigrants who raised their children in the host society, educated them in its schools and ensured that they spoke its language(s), are now bemused and occasionally frightened to realize that their children are no more integrated than they are. Rather, they can be more isolated. In those parts where Muslims were imported to provide cheap labour, they may still be considered unwelcome as permanent residents and citizens (Morley, 2000, p. 264), despite having the same skills and cultural capital as other non-Muslims. The resistance these young people face has less to do with their continued difference from the majority; rather, it is a product of their similarity. Speaking of French society, Ben Jelloun argues that the "more these young people react like young French people from their own social set, the more het-up the xenophobes get"' (in Morley, 2000, p. 264).

Results do vary, depending on the influences surrounding these young people. Cesari points out that religion may provide a sense of belonging for youth "whose schools, political parties, trade unions, and professions have failed to provide a collective sense of common good" (2002, p. 42). Smith suggests that the creation of hybrid identities is of particular interest to young Muslims, many of whom have a vested interest in finding a way to accommodate their religion and their national identity, the latter being derived from their present place of residence rather than any real or imagined homeland (2002, p. 15). Ramadan agrees, suggesting that the notion of homeland may provide ideas as young Muslims meld parts of their experience into a new identity, but these ideas should not weigh down attempts at innovation and creativity: "The formation of such a culture is a pioneering endeavor, making use of European energy while taking into 
account various national customs and simultaneously respecting Islamic values and guidelines" (2002, p. 163). This kind of pioneering is best done by committed young people who refuse to be exiled to the margins, instead finding new ways of existing. Smith may well be correct when she opines that it "is the youth of the communities, members of the second and third generations, who are the vanguard in helping think through the positive relation of Islam to the adopted country" (2002, p. 15), but for young people who lack employment or other means of self-fulfillment, the ensuing vacuum can sometimes be filled by religion. However, this religion can be transmitted by numerous sources, some of which may be strongly opposed to one another.

Karim (in press) notes that some Muslims, particularly intellectuals, are working towards a serious engagement with modernity, seeking to address the tensions and contradictions between perceived Muslim/Western values. Well aware that some Muslim youth are questioning the traditions and mores of their elders, many of which are often explained vaguely under the rubric of religious necessity, self-proclaimed progressive Muslims have identified key priorities:

a critical review of the broad range of Islamic tradition, looking anew at Islamic scriptural teachings on social justice in the context of the contemporary world, striving for an 'Islamic feminism,' and a pluralistic openness towards human sources of compassion and wisdom that goes beyond Islamic ones. (Karim, in press, p. 7)

Finding ways to reconcile tradition with modernity, and to cross generational and cultural bridges, may offer refuge to some young Muslims. Others, exposed to a more conservative brand of Islam, may seek a different kind of refuge, withdrawing from mainstream society and looking for new ways to become ever more religiously "pure." In the cases discussed by Lyall and Fisher (2006), this form of religion is often taught by 
imams from rural Pakistan, whose teachings may be infused with conservative understandings of religion and culture. After all, while Mamdani (2004) notes correctly that the so-called Islamist fundamentalism so often discussed in the media is not really about religion, but politics, it is equally the case that many of the controversies and misunderstandings around perceived religious questions are better discussed in terms of their intersection with culture. This may be true of numerous cultures, but here it is the various forms and meanings of South Asian culture that are being investigated for their confluence with the practice of Islam.

Double Binds, Multiple Marginalities: Muslim and South Asian Selves

Works that have focused on religion to the exclusion of larger social issues often project onto Indians religious identities (with particular focus on Hindu and Muslim) that appear internally singular and absolutely exclusive. Although some authors have challenged such monolithic portrayals, they often note only the internal schisms that divide a group into smaller groups and fail to consider the identities by which individuals can claim membership in multiple religious and other social groups. This tendency, coupled with the long-standing, predominant interest of Western scholarship in Indian religiosity, has mistakenly led some to overemphasize the considerable importance of religious belief, practice, and institutions in India at the expense of other important social factors. (Gottschalk, 2000, p. 174)

In a study by Salima Bhimani (2003), one participant provides an account of her upbringing which is specific to an identity as South Asian Muslim, yet the same may be applied to South Asians of other religions who are taught to regard cultural imperatives as religious dictates, ones that must be obeyed at all costs. Similarly, cultural standards may also be used to compel compliance from Muslims. Born in Karachi and living in Toronto, this young woman offers the following:

My history as a Muslim woman is inextricable from my history as a South Asian woman living in the global North. As a child, and then as an adolescent, my principal experience of Islam was as a set of cultural taboos and prescriptions that were presented as religious ones. My parents' views on things like dating, for 
example, had far more to do with their cultural identity as South Asians than with their religious beliefs, but they articulated their perceptions in religious terms rather than cultural ones. I don't think that the decision to couch their views in that particular way was a conscious one, but it was hardly an uncommon practice among first-generation immigrant families. (in Bhimani, 2003, p. 46)

The confusion between culture and religion is indeed common and has persisted over generations, not only in the South Asian and Muslim case but perhaps most significantly there, given the fevered scrutiny of these groups. While the global focus on Muslims is particularly well-known, South Asians are hardly immune from racism and misunderstanding. Commentaries on Hindu nationalism, Sikh extremism, turbans, kirpans, arranged marriages and domestic violence suggest as much confusion over what it means to be South Asian as what it means to be Muslim. Following September 11, 2001, harassment of even non-Muslim South Asians indicated a widespread misapprehension within the wider North American population in terms of how to recognize specific ethnic and religious groups. More insidiously, perhaps this perplexity reflects that the tendency to exoticize and isolate those who appear to be Other is hardly a thing of the past, persisting even in an avowedly multicultural society.

These Others, then, exist under a burning spotlight, balancing various identities, from those they create to those that are imposed upon them. While Naficy quotes Maya Jaggi's use of the term "double exclusion" as well as Abdolmaboud Ansari's “dual marginality" to describe those who are isolated both in the host society and from the homeland (1993, p. 131), in this case double exclusion or dual marginality may sometimes only scratch the surface. At times, as with Hoodfar (2003), the young people being examined may find themselves facing down a number of marginalizing and oppressing factors. In other cases, even multiple exclusion or multiple marginality may 
not be the appropriate terms to describe the liminality of diasporic young individuals.

Cesari describes this liminality for young French Muslims in a way that renders it promising, uncertain and challenging all at the same time:

Politically speaking, they identify themselves locally; they include themselves within the communities in which they were born and raised, while downplaying their French nationality. Nor do these young Franco-Muslims necessarily define themselves as Arab. They may, in fact, criticize political circumstances in their parents' countries of origin as freely as they do those within French society. They are often called overly westernized by relatives in North Africa who misunderstand their individualized religious observance and their political outspokenness against North African regimes. Such criticism distances them still further from feelings of global Arab membership. (Cesari, 2002, p. 43)

Certainly the lives of South Asian Muslims in Canada are equally complex on a number of levels, and there is no general description that would cover the way all of them perceive their positionality.

While Canadian multiculturalism is indeed different from the forms of integration endorsed in France, England and elsewhere, in practice it demonstrates some of the same qualities. For all that critics of multiculturalism insist vehemently that they simply want to see minorities join the majority, to leave their markers of difference behind, there seems to be a widespread confusion over how to react when these minorities do indeed acquire the language, education and symbols of belonging. Rightly or wrongly, Muslims and/or South Asians residing in Britain, France and the Netherlands demonstrated that despite living in those countries for years, they continued to feel a lack of acceptance, fuelling the violent outbursts that made headlines around the world. While the economic situation of these groups may be more positive in Canada, nonetheless the participants in this study were well aware of their status as quasi-outsiders, embodied perhaps most simply and most pervasively in that nagging question, "But where are you really from?" 
Attempts at simply claiming Canadian identity were rebuffed constantly, to the point that several of these participants had given considerable thought to strategies for responding to the persistent inquiry regarding their real origins. Interestingly, then, it was not the minorities, but the members of the majority who seemed unable to allow for the possibility of Muslims and South Asians being true members of the Canadian mosaic, struck perhaps by what Homi Bhabha has referred to as "the strangeness of the familiar" and the way in which this "renders cultural difference...most problematic" (Morley, 2000, p. 265).

A retreat into difference is not the necessary outcome of such strangeness. However, as young Muslims and South Asians confront constant reminders of their incomplete integration into the national fabric, ranging from questions about their origins to more stark signposts such as the banning of turbans and kirpans in some institutions and the prohibition against hijab in Quebec schools, it is not surprising that many seek alternative forms of community and identity. Many may even consider this a natural part of their lives, rather than a conscious construction, yet it does appear that individual and group identities can only be maintained with some degree of active effort:

The cohesion of collective identity must be sustained through time, through a collective memory, through lived and shared traditions, through the sense of a common past and heritage. It must also be maintained across space, through a complex mapping of territories and frontiers, principles of inclusion and exclusion that define "us" against "them". At certain moments the established and normative bases of collective identity enter into crisis. Coherence and continuity are threatened by fragmentation and discontinuity. (Morley \& Robins, 1995, p. 72 , italics in original)

Certainly fragmentation and discontinuity are present in the communities described here, but at the same time that very discontinuity, the effects of societal and historical ruptures, may drive some people further towards an active affiliation with their culture or religion. 
In other words, rather than simply occupying the racial or ethnic category into which one is born, a passive affiliation, one identifies at a more meaningful level as a member of a particular group (Shohat \& Stam, 1994, p. 20).

For South Asian Muslims living in North America, Leonard (2002) argues that membership is coming to mean something different than was previously the case. Although historical stereotypes of Muslims are often linked to images of the Middle East and Arabs, Leonard suggests that South Asians are, in fact, becoming the new leaders of Muslim communities in North America. The very fact that they, and their countries, do not share the same fractious relationship with North America as the Middle East, has allowed South Asian Muslims to integrate with more ease. South Asians are also more likely to have some experience of living in a democracy, however imperfect, and they are already aware of what it means to be minorities, and the political processes they must engage in if they want to increase their profile and standing. Leonard names several instances where South Asian Muslims are beginning to assume control of major organizations, and notes that in her opinion, second-generation South Asian Muslims will contribute significantly to the creation of a diasporic community where specific identities will become less important than an "increasingly transglobal movement toward a 'modern' and meaningful ummah" (2002, p. 233). If Leonard is correct, this sudden emphasis on the South Asian role may also help overcome linguistic difference within Muslim groups, a key aspect of compartmentalization and a primary obstacle to the interrogation and interpretation of religious texts, many of which are in Arabic, a language not necessarily familiar to all members of the diaspora. 
It is clear that the mere fact of difference does not translate into an automatic desire to be a cultural standard-bearer. Yet, while there are multiple ways of approaching this difference, and of being defined by it, there does not appear to be a means of escape. Given this fact, Muslims of South Asian origin, living in a country that proclaims its pride in pluralism while nonetheless demonstrating apparent unease with this fact, may feel compelled to examine their selves further. This investigation does not always yield a definite answer regarding who they are, where they belong or how to handle confusion, but it is a worthwhile process. These individuals live the theories of hybridity and creolization discussed in the previous chapter, sometimes consciously, sometimes less consciously, but rarely by mistake. Muslims and South Asians have been part of major migratory flows and settlement processes for some time, but the implications of these have perhaps rarely been studied and considered with the dedication currently being applied. While the shock of September 11 left some observers feeling that they had entered a whole new world, others might consider that the world itself did not changerather, many citizens were alerted to the need to re-assess their society, and their place within it.

Muslims of South Asian origin, looking around, have been reminded that they are not necessarily understood by others, but they are also aware that they are not always understood by themselves and their own communities. Patel (2006) points out that young South Asians, at least, may attempt to distance themselves from their roots in an effort to fit into mainstream Canadian culture, but ultimately, he suggests, they are likely to reclaim them, unable to sever strong ties to family and community:

Some even attempt to learn about their heritage through "Bollywood" movies (Segal, 1991). Racism and/or the realization that they are different lead many to 
begin the often complicated and challenging process of working through the issues around their dual or even multiple cultural identities, including ethnicity. (p. 158)

As the following chapter discusses, this complicated process may be filled with numerous attempts at information and education, but since these attempts are not always going to be effective or appropriate, the individuals in question must employ a number of resources in the complicated business of establishing, maintaining and understanding identity. Murji and Hébert point out the importance of numerous factors, including linguistic loss and competence, and the freedom to choose those fragments of self and community that should be melted down into new, hybrid selves (1999, pp. 10-11). Convoluted as this process of identity formation may be, there are few other options for people who do want to use their status as diasporic subjects to create a space for the articulation of new and meaningful identities in which they can declare confidence, rather than recycling the patterns and pitfalls of a history whose weight might become too great to bear. 


\section{Chapter 4}

\section{Little Mosques and Bollywood Epics: Media and Identity Construction}

Although many psychological and sociological factors can contribute to identity formation and to a sense of belonging and/or civic engagement, this dissertation focusses specifically on media, partly because media can be powerful conveyors of nationalist and cultural sentiment and partly because media are so crucial to sustaining connections and collective memory for those living in diaspora. While complaints abound at times about a dearth of mass media in Canada and elsewhere that speak adequately to the issues of ethnic minorities, this situation is beginning to shift slowly, with the 2007 debut of Little Mosque on the Prairie, a situation comedy aired by Canada's public broadcaster, the Canadian Broadcasting Corporation (CBC), which examines the cultural clash between Muslims and non-Muslims in a small town in Saskatchewan. Similarly, the Hindilanguage film Water (2005), directed by Toronto filmmaker Deepa Mehta, marks Canada's first foreign-language Oscar nomination for a movie filmed in a language other than French.

Nonetheless, it is still much more likely in Canada that South Asian or Muslim audiences will find themselves viewing content that does not represent the racial, religious or geographic realities of their lives, particularly given that so much media content in Canada is not even generated in that country, but most often comes from the United States. In a sense, then, Canadians of South Asian origin and/or Muslim background have no real recourse to a representative, indigenous form of media, in the national or cultural sense. The result is not that these groups eschew media altogether. Some adjust, perhaps due to the lack of other options or perhaps out of preference, to 
North American media, while technology has provided new alternatives for those who desire programming about the Islamic faith or about South Asian cultures. Satellite dishes and pirated DVDs expand the range of options available, but at the same time, the changing face of Canada has also prompted a transformation in the making, marketing and distribution of movies, with major theatre chains now screening Bollywood epics and other forms of cinema that have definite appeal to South Asians, such as Bend It Like Beckham (2003) and Bride and Prejudice (2004).

It is not possible here to examine all of the forms of media that have some element of appeal to young Canadian Muslims of South Asian origin, but subsequent chapters will touch on the media that were identified by participants as major sources of interest, education and socialization. News media, for instance, have often been targeted by Muslims and South Asians, among other groups, for misleading representations of minorities (Cottle, 2000; Jiwani, 1993; Poole, 2002; Shoemaker \& Reese, 1996; van Dijk, $1988,1991)$ and there does seem to be evidence that these portrayals can have a deleterious effect on some readers and viewers. This chapter examines mass media with specific emphasis upon their connection to the creation and maintenance of a national identity, their relevance in diaspora, and their significance when weighed against the interpretive powers of audiences.

While the field of communication has moved well beyond the simple belief that audiences automatically absorb everything they see and hear, nonetheless few would suggest that media have no effects at all. From corporations to nation-states, a number of forces harness the power of media in order to win public opinion-in the case of some nation-states, it might even be more accurate to say that they employ media in an effort to 
win their publics, although Canada seems either disinterested or incapable of participating in this game. Consistently conscious of the danger of losing their ties to their citizens, many other nation-states do attempt to forge ties in a number of ways, a fascinating process in and of itself, but rendered even more layered and multidimensional by the fact that publics often engage in their own mediated dialogue with nations, whether in the form of states or other communities.

Borders and States: Mediated Imaginaries of the Nation

Ultimately, the role of media in constituting nations or nationalisms cannot be summarized cleanly, but undoubtedly media are fundamentally important in changing or confirming notions of identity, citizenship or belonging within the framework of the nation-state. The political scientist Karl W. Deutsch $(1966,1969,1974)$ saw nation-states as avenues for peace, prosperity and growth on a global scale. In this vein, he averred that citizens must be loyal to the nation-state and work for its betterment, and if this did not occur naturally, then governments had both the right and the responsibility to use media to remind citizens of their national duties, even if this meant that individuals were subjected to propaganda or media surveillance. Ominous as this may sound, Deutsch clearly believed that democratic governments would only be using these tools in the spirit of the collective good and in his support of the patriotic collective, he bemoaned the media-sending and consuming habits of those immigrants to one nation-state who maintained a connection to another through letters, telephones and other media. Such opposition to the use of media to foster connections to countries outside the "host society" are, as Karim notes, frequently found in many governments where transborder links are seen as a sign of inability—or unwillingness—to integrate (2003, p. 15). In the 
Canadian context, Neil Bissoondath dismisses any nostalgic longings for the past or connections to home as signs of unpatriotic feeling, and criticizes official multicultural policies for fostering such sentiments through their "insistence that There is more important than Here" (2002, p. 122).

Opposition notwithstanding, those citizens who find their previous national identities impossible to abandon continue to discover and develop avenues for fostering them. James Clifford suggests that individuals living in diaspora, "once separated from homelands by vast oceans and political barriers, increasingly find themselves in border relations with the old country thanks to a to-and-fro made possible by modern technologies of transport, communication, and labor migration" (Clifford, 1997, p. 247; also see Cohen, 1997; Gillespie, 1995; Kolar-Panov, 2003; Sreberny-Mohammadi and Mohammadi, 1994). Whether or not Deutsch was correct to fear such ties, their increasing strength means that nationalism can no longer be discussed strictly within the territorial boundaries of the nation-state, if ever this was the case. More and more, the idea of the traditional and firmly defined nation-state must give way to the notion of an imagined community that is deterritorialized, nebulous and dispersed. At the same time, the latter does not displace the former. In fact, the nation-state may even work to cultivate a sense of patriotic obligation among diasporic individuals, or may go further and encourage the establishment of diasporic groups that retain political, economic or cultural ties to the country of origin. The nation-state, at least a partial imaginary in itself, must contend with competing visions of nations and nationhood, visions that are sometimes held together by no more than the connections forged by various forms of media. 
Although some nation-states benefit from the projects of transnational corporations, including media corporations, others fear the prospect of diminished relevance when the goal is to acquire consumers who will no longer be subject to national boundaries, perceived "as arbitrary and irrational obstacles to this reorganisation of business strategies. Audiovisual geographies are thus becoming detached from the symbolic spaces of national culture, and realigned on the basis of the more 'universal' principles of international consumer culture" (Morley \& Robins, 1995, p. 11). These corporate and state forces operate in ambivalent conjunction, occasionally with perfect cohesion, other times in opposition as their goals diverge. In the case of China, a country that has studied processes of propaganda with some care, "the project of the Chinese state to promote patriotism offshore would not have taken off without the Chinese Central Television (CCTV hereafter) now covering its satellite footprints in many parts of America, Europe, and Oceania" (Sun, 2002, p. 4). The Internet, film documentaries, television dramas and state broadcasting of global media events also bind this loosely interwoven community, helping to shape "the formation and transformation of a Chinese transnational imagination" (Sun, 2002, p. 5) while simultaneously promoting government values and interests to the population within China's borders.

In some cases, the attempts to use media as an agent of cohesion go beyond the national or the diasporic. The European Community must contend with varying levels and forms of nationalism, all juxtaposed against the influences of migration and global politics. Struggling to define its role and establish itself in conjunction with nationalist imaginaries, the European Community has enlisted media in the effort "to articulate the 'deep solidarity' of our collective consciousness and our common culture": 
at the same time, they are asked to reflect the rich variety and diversity of the European nations and regions. There is the belief, or hope, that this cultural project will help to create the sense of community necessary for Europe to confront the new world order. (Morley \& Robins, 1995, p. 174)

The central role allocated to media here is hardly unusual. As Sreberny-Mohammadi and Mohammadi note, mass media used in the home on a regular basis "are far more subtle carriers of ideology than a state propaganda unit, because they infiltrate private space with an illusion of being value-free, yet establish very powerful mythologies" $(1994, \mathrm{p}$. 15).

Effective as some of these media may be, nonetheless they must conform to certain global and local realities. Fears of cultural imperialism aside, wholesale attempts at promoting a Eurocentric or Americanized global culture have rarely been wholly successful. Neither political nor financial means ensures a nation-state's complete domination over others. Morley and Robins point out that, in Europe at least, foreign programming is successful only when the home country fails to produce a viable alternative (1995, p. 63). The steady increase in the news channel Al-Jazeera's international popularity with Arabic-speaking populations, despite opposition shown by several nation-states that consider its programming to be biased propaganda (Miladi, 2003), demonstrates the way cultural imperialism can be countered, as well as the occasional inability of nation-states to fight back effectively when media technologies have introduced alternatives to citizens. Ultimately, Cohen concludes, nation-states wishing to address these issues must be able "to manage diversity while permitting free expression and the degree of social cohesion sufficient to ensure legitimacy for the state and its principal institutions" (1997, p. 196). 
The first step in managing diversity is admitting that attempts at building nationstates on a basic ethnic model are (literally) misplaced and misguided: "What the nationalists wanted was a territorializing of each social identity. What they have got instead...is a chain of cosmopolitan cities and an increasing proliferation of diasporic, subnational and ethnic identities that cannot easily be contained in the nation-state system" (Cohen, 1997, p. 196). Those who view the processes of globalization with trepidation, assuming that powerful nation-states will succeed in implementing widespread control, do not always realize the extent to which these nations have had to adapt to a new global politics. Some nation-states may be simply incapable of doing so; others have learned new techniques for survival and growth.

In the case of Asia, Ong says, mass media offer hybrid images that blend East and West in a palatable way, painting migrant Asians as individuals who can transfer between different worlds but ultimately return to their places of origin carrying symbols of their success $(1999$, p. 169). Images such as these help reconcile wandering subjects to a permanent "sense of uprootedness" (Cohen, 1997, p. 196). Although the media may assist in the kind of transformative sub-politics described by Beck $(1994,2000)$, they can also be used to create a new space of acceptance for those who might otherwise question their circumstances. Inasmuch as displaced Chinese workers wish to retain some affiliation to their home country, China does not want to forget them. However, in order to reconcile themselves to their new reality, "they strategically 'haggle' with China and carve out a space of being Chinese in relation to the 'motherland' and the Chinese state, as well as to the new worlds in which they find themselves" (Sun, 2002, p. 8). 
While the new worlds may not always be vastly removed from previous ones, there are certainly some significant changes that must be taken into account. Both Brah (1996) and Appadurai (1996) seem to suggest that while media have always played a role in the formation and maintenance of nations - of the political variety and otherwise - this relationship has been fundamentally altered by developments in technology, so that the books and newspapers cited by Anderson (1983) or the letters and telephones cited by Deutsch as powerful transmitters of patriotic thought cannot be seen as exercising the same effect as electronic media in the construction of nationalism. Morley and Robins add that the post-war period has particularly demonstrated that broadcasting is the most significant form of media "in which the imaginaire of a national community is reflected and shaped, and as the pre-eminent forum through which the democratic life of the nation state has been represented" (1995, p. 181). Rey Chow adds a commentary on the importance of the visual when conveyed by electronic media with clarity and immediacy, allowing "entire histories, nations and peoples to be exposed, revealed, captured on the screen, made visible as images" (cited in Sun, 2002, p. 54). These histories are then emblazoned in the collective memory in a distinct and lasting manner, as Dayan and Katz (1992) chronicle in their discussion of the way certain events come to have a certain cast, or enduring resonance, through the power of media transmission.

Beyond the technology itself, the global face of capital has also altered, affecting the ownership and reach of media. This transformed relationship also affects the abilities of nation-states to manage and connect with populations:

In the informational age, getting strategic information to the global media-TV, film, newsprint, website - is controlled less by politicians than by media and corporate elites who regulate, for instance, the diversity and type of cultural images in 'a new galaxy of communication.' Media barons and tycoons are the 
technical agents who are 'in charge of' time-space compressions....In short, emergent publics are not merely an effect of mass media flows but rather translocal fields in which media and corporate networks compete (with each other and with state power) in the production, distribution, and regulation of particular kinds of images, norms, and knowledges across political spaces. (Ong, 1999, p. 160)

The power of the nation-state, while it is challenged by developments in media technology, is rarely completely undermined by them. As Deutsch counselled, governments have undertaken strict management of media at times in order to create a sense of unity and to corral loyalties. While "developments in satellite technology have meant that many people can bypass state-regulated mechanisms to interact with people and images from afar" (Sun, 2002, p. 159), such developments have also ensured that propaganda can be broadcast more effectively than ever before, entering more homes and offering a compelling nationalist message (Sun, 2002, pp. 161-162). Similarly, after using portable media such as audiotapes in promoting the overthrow of the Shah in Iran, Ayatollah Khomeini went on to institute rigid controls over other forms of media, recognizing their potential for fomenting anti-government rebellion (SrebernyMohammadi and Mohammadi, 1994).

The use of mass media to consolidate - or to complicate — national feeling and power is hardly new, as Ella Shohat and Robert Stam point out in their discussion of colonial cinema. Colonial powers supported the production and distribution of films that they hoped would impose imperial sentiment over the disparate peoples they governed (1994, p. 102), but the reverse has also been true. Filmmakers attempting to forge a sense of national unity in countries still shaking off the vestiges of the colonial era have turned to the cinema as well, only to be reminded that "the concept of the national is contradictory, the site of competing discourses" (Shohat and Stam, 1994, p. 285). 
Naficy, studying diasporic and exilic filmmaking, agrees that nationalism is a complicated concept for peoples who have been doubly or triply misplaced, and poses another challenge: "it is not enough," he contends, "that accented filmmakers have oppositional politics. They must also act oppositionally by engaging in alternative practices that have an 'organizing function"' (2001, p. 100). Gilroy does discuss the organizing function that stemmed from media such as film, which helped establish a more unequivocal sense of black nationalism transcending time, space and the outdated construct of the nation-state (1993, p. 16; also see Hall, 1990, p. 401). For Naficy and Gilroy, then, media can be powerful forces for change, while Shohat and Stam are more ambivalent about the media's ability to create a sense of nation if this reinforces patterns of global domination, with more economically powerful nations or transnational organizations exerting cultural influence over weaker partners (Shohat and Stam, 1994, p. 31). These concerns are clearly applicable in this study, where a massive Indian film industry allows minimal breathing room for alternative forms of cinema and overshadows neighbouring industries, yet that same Indian industry also feels the pressure of competition from popular global products, such as those created by Hollywood. The paradoxical nature of these interwoven and conflicting relationships is exemplified by the fact that young Canadians of South Asian origin who have access to media products created by Canada, parts of South Asia, and Hollywood, among others, declared in this study that they felt no real nationalist sentiment about any of these, and did not feel that even this diverse array managed to represent their lives accurately. 


\section{A Whole New World: Media and Diaspora}

If the connection between nation-states and media has grown increasingly complicated and difficult to summarize neatly, the removal of borders only renders this discussion more nebulous. In many cases, the relationship between media and nation, particularly with diaspora, can be a dialectical one, where power can shift back and forth and the participants rely crucially upon one another. Sinclair and Cunningham note that both diaspora and broadcasting are based on the same model of dispersion and border crossings: "the concept of 'broadcasting' is based on precisely the same organically rooted metaphor of the scattering of seed, implying both dispersal and propagation" (2001, p. 11). Diaspora is not solely a creation of the media, but its close relationship to media rests at least partly on the fact that diasporas often use and develop media in order to assist in the necessary business of strengthening ties, staying informed and mobilizing politically. At the very least, "diasporas are disproportionately advantaged by" advances in media technology (Cohen, 1997, p. 175), and may often be leaders in technological change, adopting or developing new media in order to reach their widely dispersed audiences (Karim, 2003, p. 12). Ackah and Newman add that while media such as information communication technologies should not be viewed as the means whereby cohesive communities are forged out of thin air, these technologies may, and often do, assist in reinforcing relations that already exist (2003, p. 212). If these media help strengthen cultural values and a sense of diasporic belonging, then, they may be seen as operating in conjunction with more territorialized forces.

In contrast, other territorialized populations compensate for their inability to travel by watching television shows depicting world cities: "viewing representations of 
these places at once fulfills and stimulates - to some extent - the wanderlust of homebound audiences. Moreover, watching and identifying with characters living in faraway foreign places provides, to some extent, a mediated experience of desired cosmopolitanism" (Sun, 2002, p. 70; see Mandaville, 2001, p. 16 for a similar analysis). In the same way that narratives of the nation-state are helped along through the media, narratives of individuals who are, as Erin Manning puts it, no longer "homed" (2003, p. $\mathrm{xvii)}$ also find expression in the media, although resolution may not be reached as easily. Stories of dispersal and exile, so difficult to normalize in some societies and yet such a fact of life, may come to seem more common and thus more acceptable through these media, while also introducing nonmigrants to the hardships or challenges suffered by their travelling family and friends.

These are the means of communication available for those whose lives are so decidedly transnational that, as Sun says, "'home' is often where a television set, computer terminal, or DVD player is" $(2002,159)$. Shohat and Stam note that these means of communication "'deterritorialize' the process of imagining communities. And while the media can destroy community and fashion solitude by turning spectators into atomized consumers or self-entertaining monads, they can also fashion community and alternative affiliations" (1994, p. 7). At this point, media move beyond functioning as agents for the creation or affirmation of identities; rather, they assist in creating a new and complicated form of deterritorialized politics that may have substantive implications for the nation-state. In addition to ethnic media, "transmigrants have access to reporters for U.S. radio, television and newspapers and U.S. media are increasingly global with 
stations like Cable News Network broadcasting throughout the world. From this vantage point, they can challenge dictatorial regimes" (Basch et al., 1994, p. 274).

While there is a less political tinge to Peter Mandaville's notion of travelling Islam, in which young Muslims who embrace Islam do not see the need to return to a homeland, there is a similar level of empowerment that is only possible in diaspora. For these young people, Islam itself becomes the place they wish to inhabit (2001, pp. 121122), and mass media help foster debate, discussion and some sense of unity that may create an Islam uniquely suited to the challenges of living in diaspora (2001, pp. 132135). Mandaville sees the development of a translocal Islam in web-based debates, in the live broadcast of religious ceremonies (2001, p. 145) and in the online accessibility of religious learning materials offered in language familiar both to Muslims and those living in the West $(2001$, pp. $165,167,169)$. While these technologies can be appropriated by Islamist political agendas, creating the kind of conflicts Turner (2000) hopes will dissolve in a cosmopolitan era, they can also promote heterogeneity within the community, and provide the "basis of a new framework within which Muslims might reimagine the umma" (Mandaville, 2001, p. 175).

Paul Gilroy has also argued that developments in communications were at least partially responsible for creating a sense of collective memory and nationalism in the pan-African diaspora (1987, p. 157), a precursor to Appadurai's suggestion that the "politics of diaspora, at least within the past decade, have been decisively affected by global electronic transformations" which provide "part of the engaged cultural and political literacy that diasporic persons bring to their spatial neighborhoods" (1996, p. 197). These diasporic persons may then participate in the formation of a public culture, a 
form of culture that arises as an expression of the different interests and individuals found within a place such as diaspora. "Public culture," Desai explains, “...is a site of contestation of class and other interests, often articulated through the production of differences in terms of power relations" (2004, p. 9).

Tensions on the basis of class, ethnicity or other factors can certainly take place within the boundaries of the nation-state, and few would deny that they do. However, as migration increases, cities and states gradually assume a different mien, propelled by the collision and collusion of global and local forces. Unable to untangle themselves from one another, these cities and states soon discover that "their significance resides more in their global than in their national roles" (Cohen, 1997, p. 167). In some places, a global culture emerges and infiltrates a variety of local spaces-it may be affected by the local but nonetheless some characteristics are the same from one place to the next. While size may be one of the simplest factors that affects a diaspora's cultural influence, Cohen suggests that there is also something intrinsic to diaspora itself that allows its members to make such an impact on various communities: "Many members of diasporic communities are bi- or multilingual...Often they are better able to discern what their own group shares with other groups and when its cultural norms and social practices threaten majority groups" (1997, p. 170). This may well be the reason, he offers, that diasporic groups often have strong representation in various forms of arts and media, as well as more conventional areas of achievement such as business or science (1997, p. 170).

Media in diaspora, then, take a variety of forms, from the political version offered by Sreberny-Mohammadi and Mohammadi (1994) to the community-building operation identified by Gilroy (1987). Desai, speaking of diasporic film, notes that diasporic media 
need not assume any particular politics or even a spirit of opposition. Yet, in the films she discusses, there are some recurring themes that have weight and meaning for those whose lives have been affected by a history of movement. She identifies a constant refrain around the ideas of difference, displacement and loss (Desai, 2004, p. 43). These notions certainly echo lived experience, but they also represent one side of a continuing dialogue, a conversation between those media that speak consciously to members of diaspora, and those that ignore diasporas' increasingly visible presence. The emergence of a wave of diasporic filmmakers, such as Gurinder Chadha, Deepa Mehta and Mira Nair, who talk at length about culture shock, transformations of culture within spaces and over generations, and racism, can be attributed in part to their perception of a vacuum within media at large. While some aspects of Bollywood and Indian culture appear to have entered the mainstream, many others have been ignored or repressed for years, leaving South Asians and Muslims living in diaspora to the consumption of media that do not speak to their lives and realities.

\section{Bridging the Gap? Little Islands, Big Media}

As Mira Kamdar has written: "India was far, far away. Airline tickets were expensive. There was no direct dial international calling, no fax machines-cumanswering machines attached to people's phones, no e-mail. We were a little island of India in a vast land of Leave It to Beaver." (Kumar, 2002, p. 168)

While culture has been used at times to offer a superficial nod to inclusion in the nation-state, genuine acceptance and appreciation of the media enjoyed by minority groups can indicate a growing level of cosmopolitan-ness in the host society (Sinclair et al., 2001, p. 63). The opposite pattern occurs as well, although slightly differently, with immigrants showing interest in the host society's media "as a means of access to mainstream language and culture" (Sinclair et al., 2001, p. 66). In her study of advertising 
images in India, Leela Fernandes argues that Western-based transnational corporations are finally realizing that global success depends on how well they are able to address national imaginaries and cultural nuances: "the production of meanings of the global occurs through the idiom of the nation. Moreover, this depiction of the local and the national does not attempt to mask or disguise the transnational organization of production relations" (2000, p. 616). Cases such as these, resolved through an emphasis on hybridity, may indicate a growing move towards the self-confrontation Beck cites as an essential byproduct of reflexive modernization (1994, p. 5).

Hybridity seems to be one defence in an environment where North American and European cultures are seen as overwhelmingly influential. It is hardly possible to ignore these cultures entirely, in the same way that the global finds it increasingly difficult to ignore the local. However, unless or until a satisfactory resolution is achieved, there can be a sense of isolation or alienation experienced by those who feel that they are not sufficiently addressed by the cultural products of the society in which they live. This is particularly pertinent in the case of the young Canadians studied here, whose television and film are most often produced by the United States, and thus represent neither their ethnic identities nor their national realities. Reactions to this may differ, but it is not surprising that the active cultivation of alternatives may be one response. Kumar suggests that the popularity of diasporic media is easily explained when juxtaposed against the lack of representation and acknowledgement that minority groups experience outside of their places of origin. Discussing Indian fiction written in English, Kumar notes the yearning of some diasporic individuals to consume this literature, given that "the excitement of reading new Indian fiction is almost palpable because they have not had the 
stories of their lives told except through the stamps and signatures in the pages of their passports" (2002, p. 26).

While Kumar's example indicates one sense in which South Asian minorities, at least, may find a medium that speaks to their realities, it still represents a specialized niche, one that does not allow them to see themselves reflected in a mainstream setting. Growing up as members of a society in which they speak the language and attend schools, they may question why their existence is not depicted in mass media. Speaking of the African-American community, the rapper Ice Cube notes the damage that can be done to youth by a society whose media refuse to acknowledge minorities. Complaints of unattainable images on television abound, focussing on impossibly slender, young or otherwise attractive people who do not reflect society as a whole. When that kind of unattainability is magnified, offering a vision of blondeness or whiteness that cannot possibly be replicated by the viewer, the possibilities for developing self-hatred and a negative self-image may multiply. No wonder, says Ice Cube, that young AfricanAmericans, for instance, may do their best to downplay their blackness in any way possible, trying to change their hair, eyes or features to reflect the supposed reality captured on televisions and film screens across America (cited in hooks, 1994, p. 127). While Ice Cube is speaking of a very specific group of people, arguably the shadow effects of such media images can also be seen in the young people in Handa's (2003) and Gillespie's (1995) studies, who proclaim pride in their identity, yet sometimes seek to look as much like the majority as possible.

This effect is perhaps sharpened by the fact that it is not simply mainstream media that turn a blind eye to difference; a number of observers, as well as participants in this 
study, have noted that even cinema and television which attempt to demonstrate sensitivity to cultural issues can fall into the trap of presenting a homogeneous vision of the world. Water (2005), Deepa Mehta's probing look at the poor treatment of widows in some parts of India presents as its heroine the light-skinned, light-eyed Lisa Ray, while the equally fair-skinned, grey-eyed Aishwariya Rai headlined Gurinder Chadha's Bride and Prejudice (2004). This is hardly unique to Indian productions, or even to Asian cultural productions in general, although the ties to the caste system-where lighter means better-may be specific to certain Indian cultures. In the North American context, the concern with skin colour represents a longstanding problem in African-American entertainment where the performers considered to have the most European looks (i.e. light skin, fine bones, slender physique) have the most industry currency, with examples including former Miss America Vanessa Williams, Oscar-winner Halle Berry, singer Beyoncé Knowles, and actress Jada Pinkett Smith.

However, problems such as the nature of representation may seem like irrelevant quibbles when so many groups struggle for representation of any kind. A 1994 survey of British viewers found that "members of ethnic minorities were considerably less satisfied than the general population with the programme services provided on terrestrial television" (Morley, 2000, p. 122), a finding echoed in a subsequent 1999 report by Sreberny and Ross (cited in (Morley, 2000, p. 123). If this dissatisfaction was visible in the United Kingdom, where South Asians, at least, are recognized through programming such as the sitcom Goodness Gracious $M e$, it is quite possible that similar sentiments can be found throughout North America, especially Canada, which so rarely produces successful indigenous programming and relies instead on American productions for 
entertainment. North American programming does make more of an effort to acknowledge minorities than was previously the case, but nonetheless criticism of these efforts can be intense if a minority character is brought in as a perceived token, as in the case of Parminder Nagra's British South Asian doctor on ER, lamenting her confused identity at nearly every turn in her first season, or even Little Mosque on the Prairie, carefully including a progressive imam, an educated woman in hijab, a stern traditionalist man, a white convert and a black Muslim woman (confined to doing her best work behind the kitchen counter, no less). Major hits such as 24 have danced around tokenism, presenting an extraordinary number of South Asians and Muslims who engage in terrorist plots, even if they lead apparently all-American lives, while simultaneously fending off accusations of racism by offering the occasional Muslim and/or South Asian hero, loyal to America and fiercely opposed to terrorism. While these heroes often die or disappear, nonetheless their temporary presence is used as a clear countermeasure against critics who see 24 as fearmongering and discriminatory.

It may be the case that television and film produced within North America and Europe will often be criticized for its inability to understand not just minorities but more specifically, those living in the developing world. Shohat and Stam note that it is still common to perceive a kind of one-way global media flow, wherein North America exports tremendous amounts of highly influential media, but receives very little in return. What exceptions there are, such as Bollywood cinema, telenovelas or Hong Kong action movies, tend to be produced by transnational corporations (1994, p. 31). Nonetheless, they argue, prognostications of media imperialism and the eradication of local culture are overly simplistic. Some media industries in the developing world have arrived at a level 
of significant influence in their own countries and in other regions, creating "reverse currents" in this overall media flow and also demonstrating that a strong local culture is entirely capable of thriving alongside a global one.

At the same time, Johnson points out the degree to which filmmakers in multicultural countries such as Canada have become increasingly internationalist in their focus, to the extent that Toronto-based filmmaker Deepa Mehta received an Oscar nomination for her Canadian movie, Water (2005), filmed in India and in Hindi. Directors such as Mehta have helped pave the way for Canada's film industry to follow a path already adopted by some of the country's most successful novelists; they tell stories with a strong global component while seeing their work as Canadian. The producer and director of Partition (2007), a Muslim-Sikh love story set in South Asia, describes the scope and setting of his movie by saying, "It's a totally Canadian film" (in Johnson, 2007, p. 55), while Hussain Amarshi, whose Toronto-based Mongrel Media has helped to distribute films such as Water and A Touch of Pink (2004), says "he's loath to classify the country's South Asian cinema as such," adding that "Water could not have been made in any other country...There is a deep desire, given the cultural makeup we have, for films that are more internationalist" (in Johnson, 2007, p. 55). Arguably, then, audiences are now treated to a more diverse offering of films and entertainment than was previously the case, and this plurality is becoming the norm, rather than the exception. If anything, it may speak to a new meaning of what it is to be Canadian, and what is meant by national productions. Asked about the programming with which they most identified, the young people in this study were unlikely to identify many Canadian works, but where they did, they often cited films such as Mehta's, which may be classified equally as Canadian or, 
as above, in the internationalist category. Perhaps not surprisingly, there was some confusion in their minds as to whether they considered these types of films to be part of the Bollywood system, the Hollywood system, or something else, but it did not appear that a filmmaker such as Mehta was cited because of her Canadian roots, nor were her films universally cited as texts to which these young people could relate. While there is plenty of evidence to track production and distribution of these different sorts of media, then, the reception of such texts is a far more open question, and constitutes the basis for this study. Debates over the meaning and themes of media are rendered irrelevant in the absence of proof regarding the way these media are read, and there are far more ways of reading than may be assumed.

\section{In Your Eyes: Audiences Reading Media}

More persons throughout the world see their lives through the prisms of the possible lives offered by mass media in all their forms. That is, fantasy is now a social practice; it enters, in a host of ways, into the fabrication of social lives for many people in many societies. (Appadurai, 1991, p. 198)

While early models of communication flows tended to assume passive and simple acceptance of media messages by the audience, key studies indicating that media users do not always act as expected led to a gradual shift in the direction of functionalism. Elihu Katz (1987), who is perhaps one of the greatest proponents of an active audience, notes that media effects do exist, but they may be far more limited than previously thought. One key reason for this is selectivity: audiences can in fact be relatively selective about what media they consume and how they interpret the information they do receive. Uses and gratifications, one of the paradigms most closely associated with Katz, suggests in fact that audiences are extremely selective, using only those media that benefit them in some way. In such cases, media may work more to reinforce preexisting beliefs than to 
create new ones or to alter them, and the emphasis is on the way audiences decode information, rather than on the way media present that material. George Gerbner's idea of cultivation analysis looks at content chiefly to determine what kind of attitudes may be encouraged in audiences, a notion that stemmed from his research questioning whether audiences' understanding of reality can be affected by the consumption of media content (Lorimer \& McNulty, 1996, p. 144). While Gerbner and his colleagues did conclude that audiences may be affected by content, they also placed emphasis on other factors, such as the frequency of viewing.

Many scholars do agree that a model of absolute media effects, in which a passive audience merely absorbs the messages of an all-powerful media, is outdated. However, there is no definite agreement regarding alternative models. Some theories of critical research consider that one must still hesitate to attribute too much power to the audience, given the vast economic resources available to producers. The Frankfurt School, for instance, which was formed at a time when many marvelled at the success of the Nazis in disseminating propaganda, continued to believe that the media maintained the social order, feeding meaningless entertainment to the masses and distracting them from reality and the possibilities of individual critical thought. Other theories do take power disparities into account, but they also acknowledge the diversity within audiences. For instance, Ien Ang (2001) notes the influence of David Morley's 1978 and 1980s research regarding reception of the British show Nationwide. Discovering that people in different economic and social positions interpreted the same television in a wide variety of ways, Morley's reaction was to question the then-prevailing preoccupation with the messages embedded in texts. While Morley did not rule out the significance of media messages, he 
did conclude that analyses of media must recognize the fact that meaning depends to some extent on the context of reception.

The release of The Nationwide Audience coincided with an overall shift in the social sciences and humanities towards a more audience-centred approach, best exemplified by the 1960s and 1970s rise of British cultural studies and its most famous practitioners, such as Raymond Williams and Stuart Hall. In an oft-cited article on encoding and decoding, it is Hall (1980) who suggests a typology for the ways in which messages embedded in media may be read. Offering the possibility that readers or viewers may interpret media messages exactly as the producer intended (a dominant reading), in complete opposition or with a certain amount of selectivity and criticism (negotiated), Hall argues that both sides of the production/consumption equation must be taken into account. Hall's model becomes particularly significant in this study, where participants alluded to all three possible readings. Although most were able to identify people they considered to be passive consumers of media, they generally indicated a tendency towards negotiated or resistant readings, confirming Desai's theory that diasporic "viewers do not eagerly and passively consume ideologies and products exported by the homeland nation but actively produce meanings through translation, negotiation, and adaptation" (2004, p. 114). Ang suggests that the publication of Morley's book provided an important acknowledgement within cultural studies that television viewing is a practice involving active production of meaning by viewers (2001, p. 181). Nonetheless, this does not translate into a concession that all power resides with the audience. 
The labels for perspectives vary, but in general, critical researchers, or scholars who would define themselves as Marxists or political economists, have gradually allowed some authority to the audience while maintaining a belief in the influence and power of producers and of some economic and social structures. As Kellner notes, even Stuart Hall's encoding article, with its attention to receivers, maintained cultural studies' original emphasis on "political economy, process of production and distribution, textual products, and reception by the audience" (1995, p. 5). Uses and gratifications scholars may have gradually developed more of an ability to apply these same critiques, yet a gap does remain between these perspectives. Ang notes (2001) that uses and gratifications scholars continue to maintain a focus on audience members as free-thinking individuals, while critical researchers tend to see individuals in relation to the society in which they exist - often this relationship is viewed in economic terms but generally speaking, there is a concern with power and the myriad ways in which it manifests itself. Acknowledging that media can be used in a variety of ways, Morley and Robins advocate a cautious compromise, suggesting that we "must balance an acceptance that audiences are in certain respects active in their choice, consumption and interpretation of media texts, with a recognition of how that activity is framed and limited, in its different modalities and varieties, by the dynamics of cultural power" $(1995$, p. 127)

The split over interpreting the limits of agency is not merely confined to that between critical researchers and functionalists. Even within cultural studies, with its emphasis on the interaction between producers and consumers, there is considerable variation. While the Birmingham School and its British variant of cultural studies retained an emphasis on the power of oppositional thought and action, some critics have 
complained that later strains of cultural studies attribute far more agency to audiences than is reasonable or realistic. As postmodernism has crept into many corners of academia, challenging overarching narratives and established truths, some doubt began to arise regarding the overwhelming power of the media producer. More troubling for those who value the audience's ability to actively demonstrate defiance against oppressive forces, resistance began to be perceived in a number of acts, from the large to the small to even the seemingly non-existent.

At times, some have argued, cultural studies practitioners have moved away from their emphasis on demonstrating resistance and towards a mere assumption that resistance must be taking place (see Kellner, 1995). In a specific critique of American cultural studies, Gripsrud (2002) argues that "the idea of audience resistance has gone too far in the opinion of many, almost to the point of caricature: it is as if, the dumber, more simplistic and reactionary media offerings become, the more creative and sharp the audience's resistance" (p. 58). Authors such as John Fiske, for instance, have presented theories suggesting that certain television shows may provide viewers with an enhanced sense of confidence and esteem by catering to their dominant skills. Fiske cites game shows as one instance where female viewers, especially homemakers, feel empowered by their success as vicarious players, using everyday skills that help them succeed in the domestic sphere. Brought into a public forum for all to see and celebrate, these skills take on new significance and glamour, as do the viewers by association (in Martin, 1997, pp. 122-126). While Fiske's view certainly presents a positive explanation for the success of shows that appear to promote consumerism or fantasy, it leaves open an avenue for criticism on the basis that not everyone will invest so much of themselves in the act of 
viewing. Even if they did, perhaps the overall success of media producers in offering shows that are so patently removed from reality yet provide a solid venue for advertising, suggests that empowered audience reception is an act whose significance can be overstated substantially.

Studies like Morley's help indicate the individual factors, such as gender, race and class, that underlie interpretation, while Janice Radway's work on romance readers affirmed the importance of these factors as well as the context in which consumption takes place. In Radway's case, her readers recognized the formulaic nature of much of the material they read, yet they felt there was importance and relief in the act of reading itself. The actual act of reception provided an escape from the demands of their daily lives, where they rarely had time to themselves. Radway's readers also saw themselves as active in their ability to reject narratives they saw as oppressive or demeaning. However, some question remains regarding the actual degree of resistance offered in such a situation—are Radway's participants active negotiators of meaning, or people who engage in escapist tactics in order to justify existence in a patriarchal, capitalist society? Unlike the research conducted by British cultural studies scholars in the 1960s and 1970s, where academics identified the formation of subcultures and specific acts of resistance, Radway's readers do not really provide any alternatives to the patriarchal capitalist machine. They continue to make its existence possible and even valorize it. If this is the case, a split emerges regarding both the possibilities for resistance and the dangers of patronizing media users who may be able to reconcile their behaviour in a way that makes sense to them and adds meaning to their lives. 
To a certain extent, what is taking place here is a layering of interpretations - the scholar researching reception relies on the audience's explanation of its readings, then suggests some possible meanings for these. What remains clear is that numerous possible interpretations exist. While Ang (2001) discusses key research such as Morley's, her own work has contributed to a belief that positionality may play a major role in reception. Ang's 1985 study of Dallas, that quintessentially American drama about a family of Texas oil magnates, and its reception by Dutch audiences, suggested that viewers are individuals who actively create their own meanings while still retaining an understanding of the storylines (in Lorimer \& McNulty, 1996, p. 152). Similarly, Elihu Katz and Tamar Liebes conducted their own study of viewers of Dallas in Jerusalem and produced a smorgasbord of readings. Again, while Israeli audiences of Russian, Arab, Moroccan or American origin could all understand the plot, they approached the specifics of the story in very different ways, with the American Israeli participants decoding storylines on the basis of production and financial issues, such as contract negotiations, while Russian Jews were concerned more with the producers of the content, rather than the characters, and participants of Arab and Moroccan ancestry were interested in the characters' place within their family structure (in Martin, 1997, pp. 141-144). Perhaps surprisingly, readings appeared to suggest that there is indeed a cultural difference that influences audience interpretation, an interesting finding for this research, which is very much concerned with the overlap between reception and national identity.

Certainly the connection between national identity and reception is not lost on media producers, some of whom consciously manipulate feelings of patriotism. The reasons for this may vary - government propaganda may be used to recruit citizens to a 
cause, politicians or lobbyists may seek to attract individuals back to a homeland, others may seek to spur social cohesion, and so forth. In the case of media targeted at Muslims and South Asians, national identity may take on a new meaning. Muslims have no unitary state--South Asians belong to a region but that region is diverse, fragmented and may not have a genuine connection to people who have never been there. This complicated state of affairs, as well as a new interest in Muslims and South Asians around the world, means that media offerings to these groups are equally complex, providing attention to patriotism but also to a sense of loss, confusion and displacement.

Bringing It Home: South Asians, Muslims and Media

Media offerings to minorities in Canada may take a variety of forms, including books, newspapers, magazines, websites, movies and television. Not all of these can be discussed here, although each is important in its own way. Books by authors of South Asian origin, for instance, have done very well throughout the diaspora and Canada has some literary stars of its own in this regard, including Anita Rau Badami, Rohinton Mistry, Shyam Selvadurai and M.G. Vassanji. However, while books may provide an educational, moving or familiar experience, they may not be able to speak fully to Ice Cube's earlier observation that the inability to see oneself reflected in electronic mass media can have deleterious effects on self-esteem and confidence. While mainstream television and film have made improvements in this regard, it is still rare for Canadian Muslims of South Asian origin to see themselves reflected positively in most electronic mass media. Interestingly, while the young people in this study commented critically on the fact that it was difficult to see representations of themselves as Muslims and/or South Asians, very few offered any real commentary on the limited offerings available from 
Canadian producers overall. Perhaps this was because they saw Hollywood productions as sufficiently representative, but several suggested that film in general-Indian, American or otherwise-rarely spoke to them in a meaningful way because the topics were so frivolous.

For those young people who do wish to see cinematic representations of South Asians or Muslims onscreen, they work around the lack of mainstream options by seeking out alternative sources of information and entertainment. Advances in technology, such as satellite dishes, DVDs, and the Internet, facilitate ethnic narrowcasting, "a manifestation of the emergence of new media sites that address the experience of hybridity, migration and diaspora, speaking to the disruptive spaces of postcolonialism" (Sinclair et. al, 2001, p. 44). These new media sites may appear marginal at times, such as the websites and satellite programs about religious issues accessed by some of the young Muslims in Mandaville's research (2001), but their effect can be powerful within specific groups. Moreover, their use does not preclude the consumption of more mainstream forms of information and entertainment. The 2007 premiere of CBC's Little Mosque on the Prairie is perhaps the most mainstream example of all, offering a nationally broadcast show that aims to portray Muslims within the context of that idyllic Canadian setting, the Prairies.

Like Muslims, South Asians have access to a wide variety of specialized media. Most commonly, South Asians living in Canada have often drawn upon a global system of circulating videos or DVDs in order to view entertainment that would not be widely available in theatres or on television, such as Bollywood films or other movies with reference to South Asian culture. However, as the South Asian population has grown, it 
has become more common —although not widespread—to see Bollywood films in theatres, as well as alternative films that are equally popular among youth while tackling issues of identity in a relatively less traditional way, as in East is East (1999), American Desi (2001) and Bend It Like Beckham (2003). Both genres command a loyal following and offer commentary, however implicit, on cultural values, national ideologies and belonging.

While some of the participants in this study indicated that they did not see any particular difference between Bollywood films and these alternative movies, Desai offers a clear division, one that I consider justified given the consistent distinguishing marks of most Bollywood films in terms of production, distribution and content. Bollywood is not the only form of Indian cinema, but it is the best-known, based on its enormous commercial success, its widespread distribution, its carefully fostered star system, and the song-and-dance formula that can draw in viewers as easily as it can alienate them. In contrast, movies like Mississippi Masala (1991), American Desi (2001) or Monsoon Wedding (2001) can be identified, using Desai's terminology, as South Asian diasporic films, which "are located in relation to the expanding (dominant but not hegemonic) power of Bollywood, which has sought to challenge the global domination of Hollywood cinema by positioning itself as a global cinema" (2004, p. 40). Their storylines do not necessarily conform to a particular formula, nor do they have the constant emphasis on romance or the musical sequences found in many Bollywood films. Desai's use of the term diasporic film is not intended to suggest that Bollywood films are not also diasporic to some degree, or that there are no spaces of overlap; indeed, she acknowledges herself 
that "South Asian diasporas are one of the largest sites of consumption of Bollywood films and are considered a distribution territory by the Indian film industry" (2004, p. 40).

However, diasporic films do not follow the same patterns of production as Bollywood, sometimes emerging due to the persistence of a single filmmaker's efforts, without significant financial backing or the lure of a well-known Indian star. As some of these independent filmmakers have become successful, they have tended to demonstrate their own moves towards hybridity, with Salaam Bombay (1988) and Mississippi Masala (1991) director Mira Nair plunging into a remake of Vanity Fair (2004) starring Reese Witherspoon, and Bhaji on the Beach (1993) and Bend It Like Beckham (2003) director Gurinder Chadha attempting to merge past and present, British and India in Bride and Prejudice (2004), featuring Indian, British and American stars. Significantly, the latter film starred one of Bollywood's most popular actresses, Aishwariya Rai, the former Miss Universe and current L'Oréal model who has spoken openly about her desire to attain broader appeal in order to provide the world with a sophisticated, educated image of India that may counteract ignorance and stereotypes. Given Rai's undoubted success as a Bollywood star, it is interesting that she apparently feels compelled to branch out into other fields in order to truly promote contextualized depictions of India and Indian culture.

Diasporic films are labelled as such because they speak, or attempt to speak, to the issues that are relevant to audiences living in diaspora. The filmmakers themselves may occupy a place in diaspora, and production may span a number of regions. However, as the diasporic audience has become a more important source of Bollywood revenues, popular Indian cinema has itself assumed some of the characteristics of diasporic film. 
Unlike many diasporic films, however, Bollywood has a strong national base and accordingly, much of its content valorizes India, in ways that are discussed more specifically in subsequent chapters. Desai suggests that these recurring, dominant themes around nationalism in Bollywood film provide that cinema's "only mode in which diasporic spectatorship is currently imagined and discussed. However, audience members, building on Hall's propositions, may construct differing relationships with these national narratives, adopting dominant, negotiated, or resistant modes of decoding in relation to (dis)identification processes" (2004, p. 113). The participants in this study identified a variety of relationships to this cinema, some more complex than others. Interestingly, Muslim participants, even those of Pakistani origin, did not identify stronger ties to Pakistan's Lahore-based film industry, nicknamed Lollywood, than to Bollywood film. They gave multiple reasons for this, including lack of availability and middling production values, but generally there seemed to be an overall consensus that Bollywood is perhaps one of the most influential venues for the promotion of a mainstream Indian culture.

Longevity, effective financing and a well-established distribution infrastructure may be some of the reasons for this influence. Content, however, is another. While there are many criticisms of Bollywood films, including the vast disparities in quality within the numerous films produced every year, there are also some consistencies. Many of the participants in this study were skeptical of or indifferent to the nationalist themes so often present in this cinema. Several, however, did point to Bollywood film as one of the few sources available that could provide detailed, pictorial information about South Asian rituals and culture. Although some rituals and practices could also be observed in 
everyday life, the visual portrayal of these in film was seen as a way to reinforce the appeal and importance. Moreover, some of the rituals shown were witnessed off screen only by those young adults who had the opportunity to travel to South Asia.

In diaspora, rituals are not always reprised in exactly the same manner that they might have been two or three generations previously. This is partly a function of time, but also of space. Sometimes exact facilities and resources are not available to maintain such practices, and occasionally families may choose to discard those rituals in an effort to integrate or to evolve. At the same time, there is an equal chance that families who wish to hold on to their memories and their cultural knowledge are at a disadvantage in terms of knowing current practices in South Asia. Occasional visits, e-mail messages and telephone calls may not offer the same window into the homeland as that offered by cinema, which can display visual images and explanations of the rites and customs that accompany life events, even if these rites and customs are not necessarily the same for each regional, religious or ethnic group. Desai notes this phenomenon in her own audience study of second-generation viewers:

Several second-generation South Asian-American viewers in my forthcoming study on the consumption of Indian cinema reported that the films function performatively and pedagogically in that they teach rituals, traditions, and social practices as well as identifications. These films are ethnographic and pedagogical for multiple audiences. In addition to Western viewers, South Asian diasporic viewers also may view these films as documents recording South Asian or Indian cultural practices. (Desai, 2004, p. 221)

Desai goes on to note the other ways in which such films may inform the lives and habits of South Asians living in diaspora. Bollywood films are the heart of a vast enterprise which includes magazines, live variety shows, television and radio programming, websites, audio recordings, DVDs, and clothing. This last feature, Desai 
(2004) notes, is especially useful in teaching young South Asians to be consistent consumers, as some viewers regularly seek out the glamourous - and expensive — clothes and jewellery worn by their favourite stars in recent movies (p. 221). Although the constant weddings and changing trends depicted in popular Bollywood films may promote a high level of consumerism, they also offer a challenge to the fashion trends popular in the West. The intense interest some young South Asians invest in Indian fashions may demonstrate an identity-affirming embrace of alternative cultural norms, although this is somewhat undermined by the ambivalent response of Gillespie's (1995) and Handa's (2003) subjects when asked about appropriate times and spaces for the wearing of South Asian clothes. Ambivalence, in fact, may be the one factor that consistently recurs in studies of Bollywood and popular Indian culture.

Bollywood itself, despite its self-assumed role as the cinematic bastion of Indian community, is a hybrid entity, and second-generation migrants are the same, demonstrating "dynamic hybridising tendencies easily sufficient to withstand the community's displacement into a Western culture" (Ray, 2001, p. 182). Ray is describing multiple migrants, people who may be especially inclined towards the fusion of numerous cultures and cultural products as they sew together an identity out of the fabrics they encounter. Music offers an obvious example of this, with digital technology providing a method for individuals living in diaspora to create their own creolized forms of song. It is not only Bollywood films that can attain the status of classics, but their songs. The soundtrack of a film may cause people to return for multiple viewings, or may serve as the background music for events such as weddings or birthdays. 
Kumar suggests that South Asian musical forms transmute into something different in diaspora, with digital sampling and remixes transforming songs of the past: "remembered songs of the parents, in Hindi or Punjabi or Bengali, are altered through repetition, scratching, and mixing, so that nostalgia is turned into an affect that is wholly different and new" (2002, p. 198). Ray, writing mainly of Fiji Indians, also notes the tendency of their youth to rely on remixes:

Fiji Indian young people use a wholly hybridised genre like the remixes to fashion a discourse of authenticity. On the one hand, they will deploy the remixes as part of syncretic metropolitan culture and thus break out of the cartography that views their culture as ethnic. On the other hand, they perceive these remixes (for them, an essentially diasporic phenomenon) as part of their attempt to promote Indian popular music by making it contemporary. (2001, p. 173, italics in original)

There are competing imperatives at work here, then: unlike those migrants who may believe that authenticity is best captured by leaving cultural products untouched and unaltered, these young people try to create a form that can retain popularity in modern times and across ethnic groups. At the same time, diaspora can sometimes offer a space in which the old becomes new again and gains widespread acceptance: Ray points out that bhangra, now listened to by a number of diasporic South Asians, was not a direct import from India in most cases (2001, p. 174). A mainly rural, masculine phenomenon in parts of the Punjab, bhangra took on a radically new cast in places such as London and then spread to other countries such as Australia; mixed with pop, reggae and rap, bhangra took on a new life, offering background music in a number of diasporic settings and providing one significant example of what Ray calls "the diaspora reworking the homeland" (2001, p. 174). While it would certainly be overstating the case to suggest that the diaspora reworks Bollywood, it is hardly surprising that Bollywood is at least aware of its diasporic audience, and makes some adjustments accordingly. 


\section{$\underline{\text { Responses, Reactions, Resistance: Reading Media }}$}

Frequently criticized for its lavish borrowing from the Western musical oeuvre, Bollywood has responded to the dispersal of some of its audience by incorporating even more sounds, rather than scaling back to basics: "From being mostly a combination of Indian folk music, light classical Indian music and the standard Western popular music, Bollywood now freely mixes rap, Latin American and Black music with traditional Indian music" (Ray, 2001, pp. 172-173). This is simply a musical example, but in Bollywood, music and film content are closely linked, and both can be incorporated into the diasporic lifestyle. They do, as Ray and Kumar note, function in part to evoke nostalgia, but they also evolve and transform to meet the competing demands of various audience members, and these demands may indeed be markedly different. India produces roughly 700 to 1,000 films a year (Shohat \& Stam, 1994, p. 29), and while the Indian film industry is far more heterogeneous than one might guess, in commercial terms Bollywood continues to lead the pack. As a way of maintaining this status, Bollywood has acknowledged the challenges of diaspora, and the demands of hybridity, yet it has also, as the following chapter discusses, found its own methods for ensuring that those demands are met only if they enforce a commitment to Indian culture as envisioned by that industry. The simultaneous and intersecting tendencies of Bollywood, and Bollywood viewers or listeners, to work towards the creation of popular hybrid forms makes it difficult to assess if the efforts of youth in diaspora to create their own cultural capital will always be commodified. While shared online files and mixed compact discs allow an underground musical culture to thrive, it is debatable whether Bollywood's attempts to tap into this may dilute some of the significance. 
Some directors and producers do make a sincere effort to address the meaning of migration and hybridity, functioning as the filmic version of what Pico Iyer has described as a seasoned translator, one "who commutes between cultures and writes from a space of 'in-betweenness.' As hybrid souls, these writers give voice to hyphenated identities" (Kumar, 2002, p. 178). However, in many cases, Bollywood uses its position as a way to call members of the diaspora home, to remind them of what it perceives as an essential Indian identity. As Karim notes, despite the best efforts of diasporas to use media in the re-creation of a new, more fluid understanding of home, electronic media can be used equally frequently in the attempt to reterritorialize diasporas (2003, p. 10), to use electronic tentacles to reach those populations that might otherwise be outside of a country's orbit. There are many possible examples to be examined here, but the focus is on Bollywood because of its consistent emphasis on nationalism, its attempts to promote a certain kind of culture and its longstanding global appeal, even as times change and people disperse. As the following chapter notes, Bollywood has been overwhelmingly successful in its ability to address change and dispersal while presenting clear messages about the ultimate consequences of wandering too far away from a purportedly authentic culture. Although much of the emphasis in this study remains on the interpretation of these messages, it is worth examining the production and content of Bollywood at greater length in order to assess why it has the myriad effects that it does, and why, in a hypermediated landscape, it manages to adapt continuously to a hybrid existence without surrendering its insistence that identity need not be constructed. For young South Asians, wherever they may live or however removed they may be from the subcontinent, an identity already exists, waiting to be claimed, affirmed and reproduced. 


\section{Chapter 5}

\section{East Meets West—and Everything Else: Living La Vida Loca in Bollywood}

While Bollywood is hardly the only film industry in India, it is one of the most powerful, the most commercially successful and certainly the most contradictory. It consciously mimics some American norms and features other aspects of Western culture, yet it also repudiates the same, suggesting the superiority of Indian culture and of India as the only really desirable location for the authentic South Asian. In its avowal of nationalism and cultural tradition, it presents a significant challenge to American domination of international film and culture. At the same time, however, Bollywood itself plays the role of imperialist, primarily marketing Hindi-language films to an enormous community characterized by a high level of linguistic diversity, and working to promote a kind of Hindu, Hindi-speaking, middle-to-upper class pan-Indian identity that overwhelms the specificity of various regions and cultures. Identity, in fact, is one of several recurring themes in Bollywood movies, many of which focus on romance but an equal number of which emphasize the importance of Indian nationalism and Hindu tradition.

The treatment of identity is also a source of contradiction, offering mixed messages about the ability and the obligation to retain an authentic Indian identity, with authenticity often linked to physical residence in India and adherence to Hindu values. These themes, and their potential implications for non-Hindu viewers who do not live in India, are discussed in detail in the following sections. While diasporic audiences and their reception of these themes will be examined in the final chapters, this chapter offers an overview of Bollywood cinema, its operations, its evolution and its content, with particular emphasis on the subjects of nationalism, diaspora and religion in these films, 
topics that demonstrate consistent tropes but also some change, as Bollywood partially acknowledges the realities of change and migration.

\section{Creating a Monster? Behind the Bollywood Scenes}

At the same time that Bollywood struggles to portray an authentic sense of Indianness, it also comes under fire for lacking its own sense of self as an industry. Bollywood films have been accused of mimicking selected Hollywood tendencies in terms of production, writing and marketing (Nayar, 2003), and indeed, there are marked similarities. Plots are borrowed routinely and obviously from popular Hollywood films, even if they are then tailored for an Indian audience; those plots are sometimes dotted with a similar patriotic undertone and glancing references to a nationalist politics; a similar star system flourishes; distinct writing and production formulas underpin major films; there is often considerable emphasis on cross-marketing film-related merchandise; much of the film's budget may be poured into star salaries, special effects, and costumes; vast revenues can often be recouped outside of the country where the production was based; major releases are now as likely to show New York or London in the background as Mumbai or Delhi, reducing — although not eliminating - the disparity even between settings. Indeed, as taboos around the depiction of overt sexuality continue to collapse, some of the most notable distinctions between Bollywood and Hollywood are crumbling into apparent nothingness, a complaint raised during this research by several viewers who felt that Bollywood was working too hard towards a goal of Westernization.

All the same, Bollywood films do possess characteristics that distinguish them from foreign films as well as from other Indian movies. Pendakur notes the multilingual nature of Indian film production, as well as the many different venues for studios and 
processing, including Madras, Hyderabad, Bangalore, Mysore, and Tiruvananthapuram (2003, pp. 24, 26). Commercially, however, Bollywood films, which take their moniker from Bombay, the former name of Bollywood's production centre Mumbai, are dominant, and while fears of cultural imperialism from American films abound, Bollywood has its own patterns of cultural domination, primarily offering Hindi-language films to a diverse community whose languages include Bengali, Telugu, Kannada, Malayalam and Tamil, among others. While regional language films can claim a following within their own communities, Hindi-language films, "which make up about $20 \%$ of the total production, have captured the all-India market and have reached out to Indians settled in Africa, Middle East, South East Asia, North America, and Australia" (Pendakur, 2003, p. 27).

The use of Hindi (a modified, hybrid form) can perhaps be explained by the fact that it was declared a national language after independence, even though it is native to only five northern states (Virdi, 2003, p. 18). Language aside, even regional "markers of costume, dress, and culture are either erased or deployed arbitrarily, and elements from different regions are mixed to figure as signs of cosmopolitan culture that account for a particular type of kitsch" (Virdi, 2003, p. 2). Dwyer does single out the different cultural influences on Indian cinema, from Urdu writing, which found a rare venue where it could flourish commercially, to Punjabi actors and their ideals of beauty (tall and fair-skinned) (2000, pp. 110, 120), but also acknowledges the degree to which Punjabi and Muslim participants in the film industry attempted to minimize any regional or religious markers (2000, pp. 120-121). 
The pan-Indian gloss applied to Bollywood movies may upset some, but as a commercial strategy it has paid off handsomely. It is estimated that roughly ten million people a day purchase tickets to see a Bollywood movie, and some of these will return repeatedly to view a favourite movie (Gokulsing \& Dissanayake, 1998, pp. 10, 14; also see Rajadyaksha, 1996, 2000). Despite producing more films a year (believed to be around 900, but figures vary) than any other country, including the United States, India typically does not export its films at the same rate. Indian films, reflecting the country's diversity, may come from various regions, including Mumbai, Chennai, Kolkata, Karnataka, Kerala and others. However, Bollywood films, mainly produced in Mumbai, are the ones that have significant international recognition and a global market (Ogan, 2002, p. 212). Most of the costs generated by Bollywood films are actually recouped through the overseas market, rather than within India, due to "the growing market of nonresident Indians, or Indian expatriates, nostalgic for all things Indian" (Mann, 2001, p. F3). The exporting of Bollywood films is not new, but the areas of greatest popularity have shifted along with geopolitics. In the 1950s, stars such as Raj Kapoor gained enormous audiences in areas such as the Soviet Union with Russian-dubbed releases such as Awaara (1951) (Pendakur, 2003, p. 40), but this popularity waned as the Soviet territory began to break apart. Former Prime Minister Jawaharlal Nehru, although he was not particularly a fan of such films, was convinced that it was necessary to maintain good relations with the film world when he saw "the political advantages of Raj Kapoor's popularity in the Soviet Union and elsewhere" (Dwyer, 2000, p. 98). African, Arab and Latin American audiences still maintain a longstanding enjoyment of Indian cinema, while audiences can generally be found in countries that have become home to South 
Asian migrants (Pendakur, 2003, p. 40). The financial impact of this diasporic audience is enormous, with hit films such as Dilwale Dulhania Le Jayenge (The Lover Takes the Bride, 1995) reportedly earning 200 million rupees internationally, a substantial figure even when viewed against the domestic gross of 500 million rupees (Pendakur, 2003, p. 42).

Perhaps partly in recognition of this global market, as well as a belief that the new generation of viewers has different requirements, Bollywood cinema has demonstrated some recent changes in its operations. In an industry populated by hundreds of different producers, some of whose projects are fuelled by substantial investments from criminal organizations, costs have crept up steadily over the last two decades. Increased economic liberalization has paved the way for more foreign imports, including films, television programs and the ubiquitous MTV, offering alternatives to young viewers whom film directors argue must be met with "visual exuberance with eye-popping images and renditions of sounds to draw this generation of audiences into the theaters" (Pendakur, 2003, p. 33).

The producer Yash Chopra, no stranger to this thought process or to the lure of a foreign audience, has already set up distribution offices in the United Kingdom and New York City (Pendakur, 2003, pp. 43-44). Similarly, in 1999, Sony Entertaiment Television opened an office in New Jersey to market Indian films in North America, staging a New York premiere and advertising the film in diasporic newspapers and television programming (Pendakur, 2003, p. 44). Kabhi Alvida Naa Kehna (Never Say Goodbye, 2006), Karan Johar's controversial film about infidelity, enjoyed a gala showing at the Toronto Film Festival and Guru (2007) marked a Bollywood first by holding its world 
premiere in Toronto. In turn, South Asian audiences have demonstrated their desire to see such films, visiting South Asian-owned theatres in places such as New York, Chicago, Los Angeles, Toronto and Vancouver in order to view the latest Hindi language movies. Within India itself, movies have often been seen as promoting nationalist or religious beliefs, to the extent that British colonial powers once saw fit to censor the film industry rigorously. Indian film, then, despite its strength in centres such as Chennai, Kolkata, and particularly Mumbai (previously Madras, Calcutta and Bombay), was profoundly affected by the vestiges of colonial practice governing cinema, and reflects, in some ways, the political turmoil that has characterized the nation at different times in its history. Notions of censorship still exist in Indian cinema, but as the economy has liberalized, so have the themes and depictions in that industry, with producers adjusting their ideas to what they believe the audience wants to see. Increasingly, this audience is considered to be middle-class, at least partly diasporic, with some knowledge of Hindi or English. English, then, can be found more frequently in some Bollywood films than any number of regional Indian dialects which remain marginalized by the mainstream film industry. One of the greatest sources of conflict within the industry and its accompanying music sector is the linguistic diversity of India, pluralism that fails to be reflected in the majority of Bollywood films. This neglect has prompted speakers of minority languages to mount fierce opposition to the dominance of Hindi (Dhareshwar \& Niranjana, 2000; Dickey, 1993; Gokulsing \& Dissanayake, 1998; Oommen \& Joseph, 1991; Rajadhyaksha, 2000).

This fragmenting at the linguistic level is ironic, given the crucial role that sound, language and song have played in establishing India's success in film. Music is a key 
element of Indian cinema, as is dance. As opposed to a Hollywood style of categorization, Indian movies are not specifically designated as musicals or nonmusicals. Almost all Bollywood movies tend to incorporate musical sequences, a characteristic that has been enormously influential in determining an individual film's popularity and the profits it can generate (Bhimani, 1995, pp. 127, 316; Pendakur, 2003, pp. 119-144). Although Hollywood musicals can be seen as an influence on the Bollywood tradition, there is not a similar attempt to reconcile the divergent elements of "narrative and spectacle. Instead, song and dance sequences were and are used as natural expressions of emotions and situations emerging from everyday life" (Gokulsing \& Dissanayake, 1998, p. 21). Many different forms of South Asian music co-exist in these movies, including the ghazal, usually identified with a Muslim/Urdu tradition. While its popularity has fluctuated and, indeed, the popularizing of such a classic form has attracted criticism, the ghazal remains prominent in Hindi films and their accompanying musical CDs (Dwyer, 2000, p. 41).

Song-and-dance sequences in Bollywood are crucial for conveying emotion, offering catchy or heartrending tunes that capture the viewer's attention, and for subtle expressions of sexuality, which was once impossible to depict openly in Indian film lest it provoke the disapproval of the all-powerful censors, who had been notoriously strict in ensuring that Bollywood films do not promote sexual licentiousness or any other type of potentially corrupting activity. This is less true now, but for many years a belief prevailed that it was impossible to show kissing or anything explicitly sexual in a Bollywood film. Such sights still remain rare, particularly in the films featuring the most popular stars. Even in the absence of censorship, the desire to keep Bollywood content family-friendly 
has contributed to the use of romantic dances rather than open love scenes. Songs and sound are among the more compelling elements of Hindi film, with the introduction of sound in 1931 touted by some as the reason for the rise of Indian cinema's popularity and the failure of Western cinema to secure the Indian market (Chowdhry, 2000, p. 13). Interestingly, Hindi film music's dominance can be credited partly to its incorporation of Western rhythms, though these sounds do not mask the presence of other influences, such as folk traditions (Barnouw \& Krishnaswamy, 1980, p. 73; see Pendakur, 2003, pp. 121, 126-139).

While linguistic minorities remain largely unheard, filmmakers outside of Mumbai fare little better. Lesser-known producers compete with dozens or hundreds of others in terms of financial resources and smaller potential markets, while nearly all Indian filmmakers are alert to the potential competition presented by foreign films, particularly American ones. Indians who do not speak Hindi, the primary language of Bollywood cinema, can and have made an argument that Bollywood films tend to ignore local ethnic differences in favour of a homogeneous portrayal of India. This portrayal is easier to produce given the financial restraints on smaller film production centres in India. Gokulsing and Dissanayake (1998) have tracked a significant increase in the number of films being created in centres outside of Mumbai and in languages other than Hindi (also see Prasad, 2000, p. 145), yet few of these have offered a serious challenge to Bollywood's dominance. It is also worth noting that these smaller industries, or even Pakistan's Lollywood (so called because of its base in Lahore), often do not seem to have the same grip on the South Asian imagination as does Bollywood. 
Bollywood's strength was asserted further when the dreaded American imports finally arrived in India. After India took out a loan from the International Monetary Fund in 1991, Washington and the Motion Picture Export Association of America placed increasing pressure on the Prime Minister to allow dubbing of Western films into Hindi and to permit direct imports, a pressure to which he eventually succumbed (Alessandrini, 2001, p. 321). Despite fears that the import of foreign films, combined with the increasing cost of making Indian films and challenges from television, would destroy the Indian film industry, it only grew stronger (Alessandrini, 2001, pp. 321-322). Popular Hollywood films generally do not perform well within India itself, unlike massive Bollywood successes such as Dilwale Dulhania Le Jayenge and 1994's Hum Aapke Hain Koun (Who Am I to You?), commonly abbreviated as $D D L J$ and $H A H K$, respectively (Rajadhyaksha, 1996, p. 28). Hindi films that borrow liberally from Hollywood storylines are far more common, and more likely to experience success, than American films brought into India. While the extraordinary popularity of a Hindi-dubbed version of Jurassic Park raised hopes in the United States of finally capturing the stubbornly elusive Indian market, several dubbed American films released subsequently demonstrated little or no appeal to the masses (Sidhva, 1996, p. 49), who seem to prefer the version of America most often found in Bollywood, one where hedonistic tendencies can be detected.

Although major blockbusters are still relatively chaste, a number of movies now make overt sexual references, feature heated scenes and make reference to premarital pregnancy, adultery or steamy affairs. Such material was not completely absent from previous films, but the depictions have become more pointed and explicit, and while 
certain expressions of sexuality do still meet with the expected punishment, a few characters now manage to live happily following their premarital affairs. Bollywood films also now incorporate- or emphasize-a number of features that appear to be nods to non-resident Indian watchers. Subtitles, of course, are now de rigeur in most Bollywood films, but perhaps as an added guide, or as a way of indicating Bollywood's careless cosmopolitanism, the characters have been increasingly prone to add English phrases at random. This lack of consistency may be seen as further evidence of Bollywood's nonchalance regarding barriers of language or dialect-it may also be seen as a game, though confusing, attempt to meld East and West, leaving no viewer out in the cold.

Similarly, there is a definite movement afoot to portray Bollywood heroes and heroines as the epitome of sophistication in their physical appearance. Rich or poor, the main characters usually have access to a number of different costumes, but these are not exactly what they used to be. Saris, achkhans, salwars and lenghas still dot the landscape, as extravagant and appealing as ever, but they are usually now presented in turn with increasingly revealing sundresses, jeans and halter tops. Of course, the global flow of goods and the exposure to other cultures through travel and media do mean that clothing practices can change from one generation to the next. In fact, it may be worth noting that scanty costumes can be found in some of the earlier films, although these were sometimes donned by non-Hindu characters or disparate characters coded as somehow Other. In the same way that it has now become far more common for diasporic Indians to wear Indian clothing and accessories in their host countries, there is no need to assume 
that resident Indians would live in a static world where chaste costumes of an earlier era would remain reified.

However, it is puzzling that many of the so-called Western clothes depicted in these films appear to be revealing or glamourous in a way that is unlikely to be seen in everyday life. The vampy clothing of many female stars in today's Indian films seems best calculated to display toned midriffs and inevitably fair skin that are a departure from the days when modestly dressed, relatively dark-skinned, dark-eyed women were more likely to be seen. Light-eyed, fair-skinned, sporting miniskirts and tube tops, these young women appear to be catering to a different audience than their predecessors. This may be due to any number of factors, but one possibility is that directors targeting a global audience may assume that diasporic viewers would be most likely to embrace those Indian stars who appear, essentially, a little less Indian. Although this will be discussed further in subsequent chapters, it is fair to say that the viewers in this study were deeply conscious of this change, and resentful of the implication that they would only be interested in actors who did not look Indian.

The irony is poignant; while India, as the exoticized former colonial subject, may be perpetually misunderstood and exploited for commercial gain, the vision of the colonizer — past or potential—is equally skewed in popular Indian cinema. Influenced, perhaps, by the fact that Hollywood television shows and films depict characters in revealing clothing or increasingly explicit sexual situations, Bollywood producers insert similar sequences but even take them further on occasion, dressing women in ways that seem out of place or surprising. In economic terms, this attempt to reach out to audiences in other countries remains successful, but in terms of conveying messages, something 
may be lost in translation. Several interviewees commented that Bollywood films once had more meaning and significance, but this was now being lost. In fairness, most found it difficult to name better alternatives, suggesting that Hollywood films contained no more depth or meaning than Bollywood ones. Some could still enjoy the aesthetics of Bollywood movies, without finding the subject matter particularly absorbing, as the characters and storylines often appeared facile to them. Similarly, the young Americans in Durham (2004) indicate that Bollywood and Hollywood films are both unrealistic in terms of their storylines, yet they felt a sense of cultural connection and continuity to Bollywood films that was not present when they viewed Hollywood productions (pp. 153-154). While there is some alignment here between Durham's research and the present study, it is interesting to note that even American-raised adolescents did not feel a closer sense of connectedness or representation to Hollywood media, voicing the same indifference apparently felt by most of the Canadian informants here. If a vacuum in representation or meaning exists, it is not dictated simply by geography, then.

Despite its apparent shift towards Hollywood norms, Bollywood continues to draw on some of the same influences it has always used, such as the two great epic stories, Ramayana and Mahabharata, classical Indian theatre, folk theatre, nineteenthcentury Parsi theatre, musical television and of course, Hollywood (Gokulsing \& Dissanayake, 1998, p. 17; also see Booth, 1995, p. 169; Pendakur, 2003, p. 103). Both traditional Indian themes and modernity underpin many Bollywood films. Sumita Chakravarty (1993) notes that Hindi cinema is the ideal vehicle for presenting old myths with a new veneer, reminding audiences that Indian culture can continue to thrive even in times of change and globalization. No matter how strong the foreign influence, it cannot 
truly injure "all institutions of our traditional culture that are now under severe threatthe joint family, patriarchy, the traditional qualities of the image of the Indian woman, and also, the nation" (p. 55), an observation echoed by Sheila Nayar, who notes that Western life may be incorporated into Bollywood only in superficial ways, not in any sense that would affect the filmic depiction of family ties and togetherness (1997, p. 86).

The influence of Ramayana and Mahabharata can be seen not only in plots that feature this kind of familial devotion, but also in their emphasis on divine intervention, sacrifice, and the fulfilment of dharma, "one's 'sacred duty,' a code of conduct that is appropriate to (and expected of) each individual depending on his or her social rank, stage in life, or kinship ties" (Nayar, 2003, p. 81). Individual fulfilment is not always the goal of these characters, each of whom is acutely aware of their place within their family and society, and who makes their decisions accordingly. This idea of a greater good is ever-present in many Bollywood films, but the way this enacts itself is generally different in more contemporary films, where sudden changes of heart and miraculous events may lead to happy endings, a stark departure from the bleak politics of earlier films.

\section{All About India: The Evolution of an Industry}

There is little question that the content of Bollywood films has changed markedly, at least in terms of those films that are most popular. The industry is so undeniably prolific that it is not possible to discuss many of the best-known films in any great depth. While specific films are examined briefly later in the chapter for their depiction of particular topics, this section provides an overview of major themes in mainstream Indian cinema, with later sections offering more detailed emphasis on questions of nationalism, diaspora and globalization in Bollywood film. Some participants in this study were 
highly attuned to nationalist content in Indian cinema but most were able to identify different and equally obvious thematics, pointing to the prevalence of romance, marriage and family. It is currently the case that these topics anchor most of the major Bollywood hits, but at one time Bollywood was distinguished for mixing romance with questions of social justice and political commentary. As Thoraval notes, serious dramas have more or less gone out of style, supplanted by purely entertaining features, such as historical romances $(2000$, p. 49$)$.

Certain stories do recur, and screenplay writer Javed Akhtar has suggested that most Bollywood narratives can be traced back to "ten master plots" derived from Roman, Greek and Hindu mythology. He names stories of lost and found items, vendettas and, of course, romances, arguing that most of these stem from classic myths (cited in Kabir, 1999, p. 34). He rejects the claim that most Bollywood films are essentially Hollywood remakes, though he does acknowledge that there are some commonalities in the way Hollywood has created a mythical story of its past, embodied in the genre of the western, and the way that Hindi cinema has formulated its own myths, describing the latter as a type of "contemporary folklore" (quoted in Kabir, 1999, pp. 35, 72). He also discusses the universal nature of the romance (quoted in Kabir, 1999, p. 94), a constant in many Bollywood films over the years.

Stories about love are frequently found in Bollywood films. In the late 1980s, politically-infused tales of marginalized young men began to disappear and give way to an abundance of romantic young heroes who are spiritually devout, possessed with extraordinary filial piety, and hopelessly in love. These stories usually have some kind of happy ending, as opposed to the older, more tragic strain of the genre, where hero and 
heroine alike suffered enormous travails only to be separated in the end, sometimes by death. The emphasis on heroes, rather than heroes and heroines, is no coincidence. While female characters are infused with enormous symbolism, generally representing the salvation of the nation and the successful transmission of positive values, many of the best-known films are distinguished by the hero's role. Pendakur notes that in Bollywood, similar to Hollywood, male stars are better-paid and receive better stories (2003, p. 145). In the 1970 s, viewed by some as a kind of golden era in popular Indian cinema, Amitabh Bachchan shot to fame as a brooding young antihero whose female leads were sometimes abused or abandoned as he vented his rage at a society characterized by injustice and inequality. The marginalization and caricaturization of female characters were among the features commented upon negatively by some of the viewers who participated in this study.

Indeed, Bollywood's preoccupation with gender and sexuality is so marked that it is almost impossible to ignore. Catering to an audience whose members are presumably raised to believe that marriage and reproduction are the ultimate goals, Bollywood films refuse to address the issue of homosexuality, except in the form of transvestites who are the butt of jokes. Men and women are called upon to unite, and to do so in marriage, as relationships outside of marriage are dishonourable and shaming to one's family. While both partners are required to contribute to the marriage and creation of children, both Hindu society and Bollywood film place greater domestic expectations upon women. Pendakur suggests that many ideas regarding appropriate gender-specific behaviour are drawn from

...Manusmriti, considered the pivotal text of Hindu orthodoxy. Although India is richly diverse in its traditions and belief systems, popular cinema for the most part 
is a conservative force and I argue here that ideas from Manu resonate in the daily lived experience of people as well as in their consumption of popular cinema. (2003, p. 146)

Dwyer quotes from some of these ideas: "Her father guards her in childhood, her husband guards her in youth, and her sons guard her in old age. A woman is not fit for independence. (Manu 9.3)" (2000, p. 26).

As female participants in this study commented wryly, Bollywood keeps raising the bar for young women, asking them to be all things to all people. Female characters often combine bright minds with beautiful bodies and a demure, respectful attitude to elders. While sweet virgins once stood in stark contrast to alluring seductresses (often explicitly coded as Christian, in order to justify their irreligious activities), the modern female star must combine the qualities of both, offering spunky assertiveness that in no way detracts from her ability to metamorphose into a suitable wife, one who "wears more conservative clothing and follows tradition to behave as a 'respectable' daughter-in-law or a married woman" (Pendakur, 2003, p. 151). That conservative clothing may become the hallmark of the married woman, but the single young miss may traipse around in micro-minis and tube tops as frequently as salwaar kameez and saris, displaying a toned, thin body that is a notable departure from previous standards of beauty in Indian cinema. Maira describes a feminine ideal of light skin and overt sexuality (2002, p. 171; also see Nayar, 2003, p. 74), an ideal that must also offer some indication that this sexuality is intended to be expressed fully following marriage. While fair skin has long been prized in much of Indian society, the new requirements for slenderness are more recent and may demonstrate some influence from Western media. Former beauty queen Aishwarya Rai has long been model-thin and has the added advantage of extremely light colouring, but 
other stars such as Rani Mukherjee have slimmed down noticeably in recent years, perhaps in response to the growing requirement to wear revealing clothing.

One feature that has not changed is the use of these major stars to attract audiences, so that celebrity-studded blockbusters distinguish themselves sharply from lesser lights in the waves of films entering the Indian and diasporic South Asian market every year. Similar to Hollywood, Bollywood operates on a clear celebrity hierarchy, and magazines and websites that track the activities of the stars only help promote the films. Features in the movies that have changed include growing use of English mixed in with more commonly used Hindi, the increased appearance of non-Indian settings, and an amplified emphasis on consumerist pleasures in many of the newer films, including lavish dress, enormous homes and expensive cars. Several interviewees noted, usually rather self-consciously, that these stories allowed them to enjoy the sight of new fashions, songs and dances, since many of the major rituals in Bollywood cinema are accompanied by costume changes and musical routines. Following the release of a major film, it is common to find similar fashions and CDs with the movie's music widely available within the diaspora.

These costume changes and song-and-dance sequences, often mixed into a meandering, derivative script that is marked by improbable coincidence, miraculous acts of salvation and some degree of predictability, combine to offer a form of film that is often dismissed as escapist. The participants in this study tended to concur, although only to a point, but interestingly this characterization was more frequently invoked by those who rarely watched. Regardless of the perceived negativity associated with the notion of escape or fantasy, some commentators have greeted such charges with a shrug, arguing 
that Indian film audiences can be composed largely of people whose lives contain limited pleasures (see Chakravarty, 1993). Nonetheless, Bollywood producers often do find themselves on the defensive, particularly when their work is weighed against that of the so-called parallel cinema, a more artistic stream of Indian film (Pendakur, 1990, p. 248) which has focused on tackling taboo subject matter and winning worldwide recognition for its serious treatment of issues pertinent to Indian life and culture. While these films only account for ten percent of India's total cinematic output, they are central to artistic attempts to "capture a segment of Indian reality" (Gokulsing \& Dissanayake, 1998, p. 23), and their makers sometimes add to criticisms of Bollywood as superficial and outdated (Baghdadi \& Rao, 1995, pp. xii, 34, 46, 76, 113).

Such critiques of Bollywood are similar to Max Horkheimer and Theodor Adorno's vigorous condemnation of mass culture as instruments used to solidify the power of the elite in a capitalist society, espousing ideological values that promote a false consciousness amongst media consumers. Indian and foreign opponents of Bollywood films suggest that the movies are vulgar and ridiculous, demonstrating no discernible worth when compared to a more artistic type of cinema (Gaur, 1973, pp. 100, 168; Pendakur, 2003, p. 98). As Sara Dickey notes, those artistic films are frequently judged in terms of their resemblance to European ideals of what constitutes important cinema (1993, p. 5; also see Bhaskar, 1999, p. 140), while Bollywood filmmakers more frequently look to the United States for inspiration (Baghdadi \& Rao, 1995). Likewise, the notion persists that film viewing is a pursuit of the uneducated masses, whereas filmmaking is the responsibility of higher-class individuals, who have considered themselves obligated to control the moral and educational tone of film content for the 
sake of the audience (Dickey, 1993, p. 6). This divide becomes significant when one considers audience reception of cinematic messages about values, national and ethnic unity and religious tradition. As the following chapters go on to suggest, the way these questions may be read can vary widely, and in almost no case did participants absorb nationalist messages passively and without question.

Bollywood films may address cultural and political issues on occasion, although in a different way from parallel cinema, and certainly they have done so in earlier classics. Pendakur explains that British censorship during the pre-Independence era prevented some films and selected scenes from being shown, but "screen writers circumvented the censors by using coded language in dialogue, which the audience understood and admired. Instead of locating stories about corruption and nepotism to indict contemporary political regimes, the writer would place the film in some distant past" (2003, p. 99). Kumar, expressing some disappointment with Bollywood's current treatment of globalization and nationalism, points to films that "offered criticism of the nationalist project and its skewed modernity," such as the 1950s films Do Bigha Zameen (Two Acres of Land, 1953), Jagte Raho (Stay Awake, 1956), and Pyaasa (Eternal Thirst, 1957). In these films, Kumar argues, it was possible to detect commentary on divisions of class, gender and geography in a country that touted its status as a modern democracy (2002, p. 50).

Films such as Mother India (1957) may have enforced the gendered nature of nationalist ideology, but they were certainly films that spoke powerfully about poverty, corruption, and despair. In Mother India, the actress Nargis comes to represent the nation as a mother whose various trials drive her son to angry action, including a physical threat 
against a young woman. Despite maternal love, Nargis acts to subdue this violence against woman/nation and the natural social order, and kills her son, an iconic moment in Indian cinema and one re-enacted in a variety of films calling upon women to make difficult choices between personal feelings and social obligation. Mother India, an enduring classic, remains one of a handful of Indian films to be nominated for a Best Foreign Film Oscar-the others are Bandit Queen (1994) (Dwyer, 2000, p. 130) and Lagaan [Land Tax]: Once Upon a Time in India (2001).

Stories of star-crossed lovers mixed with those depicting the new nation and its various tensions. The emphasis on the political only became more noticeable with the rise of stars such as Amitabh Bachchan in the 1970s, when Indian cinema began to address unemployment and inequality in a society where youth had been raised to expect more. The anger that Bachchan's characters displayed at the political system, at corruption, at inequality, spoke strongly to the nation, and his films during that period became some of the best-known of all time. They also embodied the physicality that later alienated some of the young viewers interviewed here, who were unable to understand why several fight scenes were mandatory in every major Indian movie.

These fight scenes and some social commentary do remain, but they are generally less common in current films than storylines centred around star-crossed lovers. When more serious issues do arise, they are rarely addressed in a way that will threaten the societal status quo. Discussing, for instance, the question of gender in the enormously popular Hum Aapke Hain Koun, Shoma Chatterji suggests that the film replicates patriarchal norms embedded in an affluent, conventional lifestyle that every urban Indian family would see as ideal (1998, pp. 5-7; also see Gokulsing \& Dissanayake, 1998, pp. 
75-79, for a discussion about the female figure and her symbolic identification with India, as well as Virdi, 2003). In discussing $H A H K$, Alessandrini opines that Bollywood entered a new era by dispensing with questions of social justice and subalterns $(2001$, p. 323). It is interesting to note that while some participants specifically cited films that dealt with history or social issues of interest, others pointed to a film such as $H A H K$ as holding special meaning for them. Several commented on the importance of family and the rituals around weddings and births depicted in this film, while others also indicated that they saw $H A H K$ as heralding a new type of film altogether: one that was more modern, fun and interesting. None passed any explicit commentary on the open promotion of consumerism and Western products (such as Cadbury or Pepsi) found in this film, which would come to set the standard for future blockbusters, but their approval may be implied from their separate suggestions that they looked to Bollywood films in order to assess new trends in fashion and music.

$H A H K$ has been viewed by many as a turning point in Bollywood cinema, a revival that allowed families, including the young, to enjoy movies in a way that threatened no one and benefited everyone. A story of marriage and family-essentially, the entire movie consists of an ill-fated love story between one couple and a slowly unfurling courtship between another- $H A H K$ "reinforces India's cultural heritage" through its depiction of various rituals, including engagement, marriage and the mendhi, the traditional tracing of decorative patterns on the bride's hands using henna (Gokulsing \& Dissanayake, 1998, p. 44). Religious traditions are also affirmed in this movie as in so many others, providing a backdrop of divinely determined justice (Gokulsing \& Dissanayake, 1998, pp. 62, 70). $H A H K$ also heralds an era in which movie characters will 
almost always represent a form of national identity that is largely upper-caste, uppermiddle class, Hindi-speaking and Hindu (Alessandrini, 2001, p. 323).

Other movies that followed and matched $H A H K$ 's success, such as Kuch Kuch Hota Hai (Something Happens, 1998) and Kabhi Khushi Kabhi Gham (Sometimes Happy, Sometimes Sad, 2001), were also careful to combine homage to the consumerist dream (the characters wear prominently displayed logos for DKNY, Tommy Hilfiger and Gap) with respect for perceived Indian values and culture. In other words, family conflicts are avoided or resolved by the end of each movie, marital harmony prevails in a way that allows the male head of the family to retain (most of) his authority, and Indian culture is celebrated in many ways, including the inevitable dances, various traditional costumes, and scenes depicting religious festivals or ceremonial events. Kuch Kuch Hota $H a i$, which was notable for the fact that its popularity with South Asian fans helped it enter top-ten lists in the United Kingdom, is described as "a bubble-gum romance in which clean-cut students sport American designer clothes and live by traditional Indian values" (Lakshmanan, 1999, p. W3). There is a cultural conflict presented by this juxtaposition, which some viewers acknowledged, but others appear merely to have accepted this as a reflection of their own composite existence.

\section{"My Heart's Indian for All That": Themes of Nationalism and Migration in Bollywood}

I've been doing a lot of travelling. I just came back from South Africa. I was in the motherland. Not my motherland, obviously, you know what I mean, it's black people's motherland. You know, I'm Indian, we have our own motherland: England. (Comedian Russell Peters, 2007)

The refusal in films such as $H A H K$ and Kuch Kuch Hota Hai to allow for change or transformation at any significant level is in sharp contrast to other movies aimed at a diasporic South Asian audience, movies Desai identifies explicitly as diasporic: 
"Diasporic films are not always oppositional, however, they employ repetition with a difference and are focused on the politics of displacement, alienation, or loss" (2004, p. 43). Admittedly, this distinction is difficult in the context of the current study. Bollywood films also represent a form of diasporic cinema in terms of their target audience, their distribution and in some of their content, but they rarely explore difference or displacement in ways that are oppositional or even necessarily alternative. However, this can occur, and so it is not possible to make a distinction strictly on the basis of content.

When making any distinction regarding Indian cinema, it is important to note that there can be considerable overlap in categories, with some films demonstrating elements of Bollywood stylings compared with those of other regional cinemas or of more highbrow films. For the sake of simplicity, I will also adopt the category of diasporic films but I do recognize the complexity of such a term. In this dissertation, the term diasporic films can be seen as separate from Bollywood films and would apply to movies such as Mississippi Masala (1991), East is East (1999), A Touch of Pink (2004), Bend It Like Beckham (2003) and Monsoon Wedding (2001), which do feature oppositional content but more importantly, are not produced by the Bollywood system. Filmmaking is rarely an entirely linear process, and so co-productions do occur; Bollywood screenwriters or actors may lend their talents to a diasporic film, as is often seen in the work of Toronto-based filmmaker Deepa Mehta. All the same, I maintain that a diasporic film is primarily made outside of the Mumbai-based Bollywood industry, and is often or frequently made by producers or directors who are themselves diasporic.

These filmmakers work hard to convince audiences that change in South Asian communities is not only possible, it is already happening. The heroine of Mississippi 
Masala leaves her family to be with her African-American lover, while the entire family revolts in East is East against their father's authoritarian rule, and the strict Punjabi father in Bend It Like Beckham suddenly withdraws his previously staunch opposition to his daughter's decision to play soccer and to move to California. Some of the young adults interviewed here expressed more ability to relate to these stories simply on the basis of language, if nothing else — diasporic films are usually filmed mainly in English — but several criticized them for being as unrealistic and simplistic as Bollywood films. Some suggested that stereotypes were equally at work in these films, pointing to the extremist and hypocritical Muslim father in East is East or to the overbearing mother in Bend It Like Beckham. Others critiqued the easy solutions to problems posited by some of these films. The taboo issue of homosexuality is a source of never-ending tension in East is East, but in $A$ Touch of Pink it is played up within an environment of such caricatured characters that the resolution has a rather false ring, only marginally more realistic than Bollywood's pretence that homosexuality is nothing more than the implied source of humour through drag queens and transvestites who merit no real stories of their own. Similarly, while Monsoon Wedding does wink at stereotypes by offering a young Indian woman whose romantic aggressiveness takes a diasporic relative by surprise, its treatment of pedophilia is handled rather neatly by a family willing to discuss and address it with some degree of promptness.

Regardless of the assumed merits or failings of such movies, they do resonate within the diaspora to a certain degree, and this popularity is not something that Bollywood has ignored. Always fiercely proud of its Indian identity, Bollywood has worked hard to address issues of nationalism and migration, although in the past this 
migration was more likely to be reflective of the move from rural to urban life. Indeed, in Shri 420 (Mr. 420,1955) ${ }^{2}$, the rural boy who attempts to survive in the cold, corrupt city expresses his love for the nation, as well as his awareness of foreign influence, in a song whose lyrics continue to be well-known today:

Meera jota hai japani, ye patloon englishstani, Sar pe lal topi rusi, phir bhi dil hai Hindustani...

(My shoes are Japanese, these pants are British, A red Russian cap on the head, but still, my heart is Indian). (In Virdi, 2003, p. 99)

The hero's sentimental patriotism, maintained in the face of deprivation and disappointment, remains the model for many a main character to follow as "India, imagined in films over the decades through binary oppositions - the feudal vs. the modern, country vs. city, east vs. west, rural vs. urban—now pits the national against the transnational" (Virdi, 2003, pp. 202-203). Popular films within the last fifteen years have spoken more to the encroachment of perceived Western ways and ideals upon traditional Indian life, even as they valorize an ethos of economic achievement and consumerism that seems drawn particularly from the United States. More protagonists engage with the world outside India, and several succeed there, although in the end nearly all return to the motherland, and India, in this case, is positioned heavily as the national incorporation of a mother figure. The goal is not to ignore life outside South Asia, but to overcome its lures - to return from overseas, a place of much temptation, and apply one's knowledge to the betterment of India is a laudable goal. The West is a behemoth that cannot be put aside, yet in the end it is no match for India, with its traditions and deep sense of self.

\footnotetext{
${ }^{2}$ The 420 in the title reportedly refers to anti-fraud laws in India, meaning that a person characterized as Mr. 420 was being labelled a criminal of some kind.
} 
Along with a number of other critics, Pendakur points out a growing tendency in Indian film to address "this duality of living in two cultures and longing for a past that just does not exist anymore" (2003, p. 43). Suggesting that economic liberalization policies may have inspired some of the major producers, he notes that 1990s films began increasingly to look at people living abroad (2003, p. 110). He names some of the betterknown examples of the form, such as $D D L J$ and Subhash Ghai's Pardes (Foreign Land, 1997), yet there are forerunners in films stretching as far back as Purab aur Pachhim (East and West, 1970), whose protagonist, Bharat, studies in England and falls in love with his host family's daughter, Preeti, whose smoking and leather miniskirts distinguish her from a typically demure Indian woman. Convinced by Bharat to visit India once before their marriage, Preeti "slowly becomes enamored of the country and transformed by the 'spirit' and 'essence' of the land, kicks her smoking and drinking habits, and chooses to live like a 'traditional Indian woman.' The family never returns to England" (Virdi, 2003, p. 63). While economic liberalization may have accelerated the production of movies addressing diaspora, then, it is not the only explanation for Bollywood's longstanding fascination with foreign lands and their perceived inadequacies.

Films such as Pardes will later revisit many of the themes found in a film such as Purab aur Pachhim, valorizing India's purity when compared to the jungle of the West, a catch-all term that encompasses England, the United States and other countries: "the west - specifically England, once the colonial master-is an emotional wasteland of derelicts without 'family life': alienated individuals seeking refuge in sex, alcohol, and promiscuity" (Virdi, 2003, p. 64). In Pardes, as in the earlier film, it is also inevitable that the female character must be the one to rediscover her Indianness, as she is the one 
responsible for preserving and transmitting culture. Interestingly, however, in films such as Kuch Kuch Hota Hai, the miniskirt-wearing young woman from abroad is wrongly accused by her eventual lover of not being Indian enough. When he mocks her, she rebuts by singing fluently and beautifully in Hindi, a response that silences him and wins his heart. It becomes clear that these young women will need to dress demurely once they are married, but until then, it is no longer possible to judge a woman's cultural purity by her appearance.

The question of diaspora is not new in Bollywood, then, but both Desai (2004) and Dwyer (2000) suggest that the way diaspora is treated changes by the 1990s. As opposed to "earlier films where foreign locations were used only for spectacle" (Dwyer, 2000, p. 141), the 1990s marks the beginning of a rash of films that explore diasporic themes, such as Yash Chopra's Lamhe (Moments, 1991), part of which takes place in London but indicates its lack in comparison "to Panjab's extended family and traditional hospitality" as well as the belief that Indianness is not simply about citizenship, but about "family values" (Dwyer, 2000, p. 141). These themes resonate in other films, such as Pardes and Kabhi Khushi Kabhie Gham, but both Desai and Mishra assign a singular importance to the very popular Dilwale Dulhaniya Le Jayenge, described by Mishra as "an indispensable archival material for a sociology of diasporic formations" (2002, p. 250).

From its first frames, as Desai notes, $D D L J$ is a song of nostalgia for the motherland, yet it also grapples with the reality that the motherland is by no means the space of purity and reliability imagined from the disconnected shores of diaspora. While the father in this film longs for home and Indian grooms for his daughters as a way of 
fending off Western corruption, ultimately the "real" Indian son-in-law he has chosen turns out to be a schemer who hopes to advance himself through settling abroad. In contrast, Raj, a young man living in diaspora, proves to be sincere in his love for the heroine, as well as in his respect for her family: “The true son of Hindustan proves to be the British Asian Raj who is honorable and loyal; Raj is shown to be more than capable of maintaining his 'Indian values and culture' though residing abroad" (Desai, 2004, p. 134; also see Mishra, 2002, pp. 253-256). Unusually in a film of this nature, Raj and Simran, blessed with her father's consent, return to England, while her family remains in the Punjab. Interestingly, too, the character of Raj is played by Shahrukh Khan, who makes a return appearance in other films with diasporic themes (Pardes, Kabhi Khushi Kabhie Gham) and has become, argues Mishra, "the first Indian star to play some of his best roles in Bombay's own version of films about the Indian diaspora" (2002, p. xv). $D D L J$ 's importance as a film, says Desai, lies in the fact that "it is one of the first to signify the diasporic subjects as Indian national subjects rather than as corrupted Westerners. The 'Indian and his family' can and have remained intact despite its transplantation abroad" (Desai, 2004, p. 133). The unusual ending clearly resonated in the diaspora, where the film was an enormous success, yet it did not herald the beginning of a new era in Bollywood cinema. Films continue to grapple with the question of movement and living abroad, but for the most part, the nostalgia experienced by the characters is appropriate and justified.

Most movies have departed, however, from the heavyhanded condemnation found in works such as Pardes (1997), in which a daughter of India is exported to the United States as a potential bride for a young man whose American upbringing has left him 
spoiled, selfish and violent. The heroine is the archetype of all that is good about India and Indian values: she is respectful, demure, virginal and extremely patriotic. Yanked from her simple village life and thrust into the world of wealthy NRIs in Los Angeles, she is overwhelmed by the superficiality and coldness she espies, contrasting it to the warmth and love of her home. It is this film that provides a modern-day counterpart to Raj Kapoor's earlier pro-India anthem:

London dekha, Paris dekha, aur dekha Japan

Michael dekha, Elvis dekha, sab dekha meri jaan

Saare jag mein kahin nahin hai doosra Hindustan

(I saw London, I saw Paris, and I saw Japan

I saw Michael, I saw Elvis, I saw it all, my dear

But there is nothing in the world that is like India). (In Kumar, 2002, p. 217)

While the opposition between East and West is not always bifurcated quite so clearly, one aspect does remain very common, as Kumar points out: it is often, though not always, the woman in these movies who remains the standard-bearer for Indian culture. While others may experience a similar sense of yearning for home, it is the woman who will bear the responsibility for preserving and transmitting culture (Kumar, 2002, p. 218), a burden seen clearly in Kabhi Khushi Kabhie Gham.

Kabhi Khushi Kabhi Gham serves as an interesting example because of its layering of identities, its strong bias towards Indian culture and its suggestion of the sense of exile that can afflict diasporic communities. In this case, the exile is almost literal, since the main characters have left India in reaction to the strong disapproval of their marriage displayed by the husband's parents. Having relocated to London with the heroine's younger sister, the family enjoys an affluent lifestyle, complete with wealthy non-Indian neighbours and friends, expensive cars, and extravagant Western clothes, especially those worn by the younger sister. In the midst of plenty, however, the heroine 
is perpetually dissatisfied, longing for return, equating the reconciliation of her currently fractured family with restoration to India. Significantly, despite the differences between the younger woman's revealing Western clothing and flirtatiousness, and the heroine's constant wearing of saris and her status as devoted homemaker, eventually both sisters are united in their desire to return to India and to be accepted into the family home, a desire that is fulfilled by the end of the movie. In describing films such as Kabhi Khushi Kabhie Gham and Yaadein (Memories, 2001), a story where a father who is upset with his London-bred daughters' excesses packs up and takes them to India for maturity and marriage, Desai suggests that "the trope of the family is employed to reproduce national narratives of belonging to satisfy diasporic desires" (2004, p. 194).

There are subtle differences in these films: while the daughters in Yaadein and the American-raised son in Pardes may risk losing their identity in the face of Western corruption, the son and daughter-in-law in Kabhi Khushi Kabhie Gham and the son in $D D L J$ are all capable of maintaining their patriotism and Indian identity while in diaspora. However, there is a risk of eventual loss in that separation from the mother/land in Kabhi Khushi Kabhie Gham leaves the heroine unable to learn all of the rituals she needs from her mother-in-law, yet at the same time, it is worth noting that her English neighbours, whom she ridicules constantly, eventually make an effort to learn about India and to show respect for it. While it is clear that the family cannot stay in England if they wish to remain wholly Indian, it is also clear that London need not be a space of complete alienation, representing a departure from Purab aur Pachhim. The latter film serves to validate Virdi's assertion that "the figure of the diasporic Indian is metonymic of this anxiety of the invasion of the west and disappearance of an 'Indian identity,' which it 
cleverly manipulates to reimagine the nation in response to changing conditions" (2003, p. 197), as well as Kumar's comment that films such as Pardes and its 1999 companion feature, Taal (Rhythm), indicate a willingness on the part of diasporic viewers to "see the West as urban, and as tainted with modernity, while India continued to be fixed in the imaginary as rural, bound to fixed locations of home and heart" (2002, p. 216; also see Nayar, 2003, p. 78).

In most of these films, the return to India and to a united family is inevitable, as Nayar remarks (2003, p. 78), as is the condemnation of diasporic life as a permanent solution to globalization. At the same time, Bollywood is unable to dismiss the fact of diasporic life, and it continues to address this in ways large and small, for instance through the use of North American and European settings that diasporic viewers are most likely to recognize (Mishra, 2002, p. 260). Additionally, while few movies have validated a diasporic existence quite as significantly as $D D L J$, some films do exist that present characters living outside of South Asia with very little reference to a politics of return. For instance, Kal Ho Naa Ho (Tomorrow May Never Be, 2003), another very popular film, depicts characters settled in the United States. While the pivotal character does visit from India, there is minimal emphasis on the superiority of India or the possibility of moving there. In fact, in one unusual sequence, the hero performs a dance where his backdrop is a prominent American flag. Although the insertion of this flag is never explained, it may perhaps speak to the nuclear and political alliances being built at that time between the United States and India. Whatever the reason, the central characters of Kal Ho Naa Ho do not appear to experience any kind of national identity crisis. 
Similarly, the characters in Kabhi Alvida Naa Kehna are settled quite clearly in diaspora, with most of the action occurring in the United States. Admittedly, they engage in behaviours that may well be linked to their settings - placing career demands, individualism and New York's social scene before their spouses-but if their corruption is linked to the environment, this is not explicitly stated, and so it is possible to suggest that this is another case where characters are seen living in diaspora with no weighty nationalist implications attached. Notwithstanding examples such as these, many films do exhibit a frequent inability to address the realities of diasporic life, which these films most often equate with materialism, loss of values and engagement in immoral activities (Mishra, 2002, p. 267; Virdi, 2003, p. 202). When promiscuous, disrespectful or otherwise immodest behaviour is perceived, this is criticized as Western, or inauthentic, non-Indian conduct, a binary construction that discredits both cultures by suggesting that they can even be categorized as such. Curiously, these films still value certain aspects of Western culture at the same time they offer it as threat.

In South Asia, colonialism has left a more complex legacy than some would admit. An English-style education can be seen as a passport to economic success. Speaking English may denote a higher class. In popular Indian cinema, characters may speak English to attract diasporic viewers or to indicate high levels of education and attainment, yet ultimately truly heroic or good characters are expected to embrace Indian culture and to exhibit proof that this culture is what really represents them. A character who can fit easily into the West-most often presented as the United States or Englandis accomplished and admirable, but a character who cannot fit into India is lost. The West is seen as a place where people can lose their values and morality, and are often cast 
adrift in a sea of individualism, a state of affairs to be avoided at all cost. Exceptions do exist, such as Kal Ho Naa Ho, but they appear to be rare.

As films like East is East (1999), Bend It Like Beckham (2003) and Bollywood/Hollywood (2002) demonstrate, in the same way that some colonizers once feared the contagious disease and dirty habits of the natives, the natives fear an entirely different disease - that of Westernness. The implied anxiety expressed in Indian movies, especially Bollywood ones, suggests that the perceived amorality of Westernness may be infectious, affecting otherwise demure and obedient Indian youth and turning them towards an empty and meaningless life. Yet even as Indian cinema rejects the values it assumes to be consonant with Western culture, it is increasingly likely to feature lightskinned, sometimes light-eyed, young men and women as their stars and as the archetypes for attractive Indians, and is also capable of simultaneously promoting and critiquing modes of dress, language and behaviour that are perceived as socially liberal and hence Western. The contradictions that underpin this indicate the extent to which even the West, and whites, can be exoticized. In the same way that travellers from the Occident once — and to a certain extent, still —-ventured into the heart of darkness to find evidence that they were superior to the primitive cultures of the East, the Orient is now reversing that gaze, alternately curious and cautious.

The result is a caricaturized version of diasporic life that young viewers outside of India may find inaccurate and offensive, yet at the same time they recognized some of their parents' and grandparents' ideas in these films, ideas that speak more, perhaps, to the experience of first-generation immigrants, battling a sense of loss and alienation. These films are most likely to address the poignancy of leaving, or never having 
experienced life in, a homeland, and to suggest a facility of return, even after an absence of many years. In Indian films, at least those of the Bollywood genre, one can go home again, and whenever possible, one certainly should. Until that idyllic moment arrives, one should nurture memories of traditions and cultural values, protecting them against loss and preserving them for transmission to potential offspring. Bollywood cinema may well be consumed for the reasons that some critics have suggested, such as its ability to remind the departed, or educate those who have never been to India, of Indian values, traditions, music, clothing, and culture. However, it may also participate in a mythical structure suggesting that there is such a thing as Indian culture and an Indian homeland, to which members of the diaspora certainly belong and which they should reclaim in some form.

In the United States, diasporic audiences, especially South Asian youth, can be courted by organized political groups, such as the right-wing nationalist parties BJP and Shiv Sena, an influence discussed further in a later chapter, but the significance of these parties' global reach may have some connection to the fervent nationalism seen in a number of Bollywood films. After all, audiences may be affected differently by the spilling of the political process into the diaspora, but they receive largely the same cinematic content if they are viewers of Bollywood film. Alessandrini posits the question of whether or not the film industry intentionally plays into the hands of nationalists such as the Shiv Sena, since the industry has done well under Shiv Sena's rule in Mumbai (2001, p. 336).

Given the long history of promoting nationalism in popular Indian cinema, and the complexity of South Asian history, it is difficult to say if groups such as Shiv Sena 
bear any significant responsibility for the heavy patriotism, especially the Hindu-inflected Indian nationalism, in many Bollywood films. It is possible to say, however, that these pro-Indian elements are unlikely to disappear, but they may, as in the case of $D D L J$, present themselves in ways that are more sympathetic to diasporic characters. Certainly these films do accommodate, in their own ways, the pressures of modernity. For critics such as Homi Bhabha (1994), modernity allows local and/or minority populations to resist the pressures of a dominant culture and simultaneously avoid marginalization by creating an entirely new entity, a hybrid culture that differentiates itself from the other traditions pulling at it while still fulfilling the needs of the alienated (see Araeen, 2000, pp. 9-17; Karim, 1998, p. 6; Khan, 2000; Kraidy, 1999).

In terms of Indian cinema, these alienated individuals can be easily found in an age that has scattered members of the South Asian diaspora around the globe, attempting to reconcile the values embedded in Indian culture with the practices seen in their new homes. The rigidity of these values varies from one film to the next; the unyielding father in Kabhi Khushi Kabhie Gham is eventually convinced to soften his position and accept his son back into the family following the intervention of his wife and his younger son, both of whom challenge his position as patriarch if he cannot recognize his own injustice. However, once he has been induced to look more forgivingly on his son, the family is reunited back into the same order they once occupied, and no essential change occurs. Interestingly, in Veer-Zaara, a substantial change can be said to take place, given that the Pakistani Muslim Zaara's father eventually withdraws his sustained insistence that she marry a pre-selected Pakistani despite her love for an Indian man, Veer. Eventually Veer and Zaara will find their way back to one another and to happiness, a 
rare occurrence for an interfaith couple. All the same, the collapse of the father's opposition occurs off screen, and is only described to the audience by a peripheral character. Oppositional discourses are often smoothed over in such ways, offering mild alternatives that can satisfy viewers of different generations, ethnicities and beliefs. In a sense, then, the individuals who watch these films come to inhabit an entirely new space constructed to meet their layered needs, and as part of that process, the film can be seen as creating a "new space of signification" (Dhareshwar \& Niranjana, 2000, p. 195), one which recognizes the importance of the local but also acknowledges that the "MTV culture, as well as more generally the global televisual culture, is here and we have to negotiate it" (Dhareshwar \& Niranjana, 2000, p. 193).

In this formulation, then, the notion of displaying spirited resistance to the imperialist culture by encouraging the development of untainted local practices becomes an outdated paradigm. While resistance to cultural imperialism is still widely discussed and promoted by some scholars, advocates of hybridity seem to suggest that it is almost naïve, and restricting, to attempt to avoid altogether the dictates of a dominant culture. Rather, it is more realistic to acknowledge that those who feel threatened will find a need for both their (perceived) cultures of origin and for the culture that saturates every aspect of their present-day lives. As Nayar points out when speaking of present-day Indian practices, “modern life, 'western' life, is very much a part of Indian culture, of urban Indianness, and with it comes numerous "universal cultural trends"" (1997, p. 77). She argues that selective borrowing from the West can palliate the problems caused by the many competing cultures within India:

[s]ince Hindi popular cinema's intention was always to appeal broadly across the subcontinent - a nation ceaselessly struggling to keep its commercial, regional 
and linguistic factions from splintering-Bollywood came to rely, ironically, on the uniformity of the West (or rather, what it chose from the West) to provide its films with a generic coat of all-Indianness. (1997, p. 75, italics in original)

There is, then, an argument to be made for Indian cinema demonstrating its cultural roots through a melding, however opportunistic, of a time-honoured marketing formula with ideas extracted from more traditional forms of drama (Booth, 1995; Dickey, 1993; Vasudevan, 2000). Under this argument, it is possible to view the popularity of films such as Hum Aapke Hain Koun through the glocalized lens: "Western culture and glitter are very attractive. So Maine Pyar Kiya and Hum Aapke Hain Koun offer the solution: a happy marriage between the two worlds. I can have everything offered by modernisation, and still hold on to family values and tradition at the same time" (Kabir, 1999, p. 95; also see Gokulsing \& Dissanayake, 1998, p. 11). Nandy seems to see Bollywood as a venue for more clearly defined resistance than can be found elsewhere: when much of the oppression and violence in society is inflicted in the name of categories such as development, science, progress, and national security, there has grown a tacit demand for a different kind of political attitude towards cultural traditions. However much we may bemoan the encroachment of mass culture through the commercial cinema, the fact remains that it is commercial cinema which, if only by default, has been more responsive to such demands and more protective towards nonmodern categories. (1995, p. 235)

At the same time, Bollywood's struggle to reconcile India and diaspora, tradition and modernity, does produce a form of nationalist pride that may be oppressive in itself to groups whose history and positionality are not acknowledged within these films.

Undoubtedly, Bollywood has done well in transmitting nationalist themes and highlighting tradition and ritual. In the same way that Bollywood does not always speak to its diasporic viewers with absolute success, it also does not speak with equal weight to other members of its audience. For the most part, the traditions and rituals promoted so 
heavily in Bollywood films tend to be derived from Hindu mythology and symbolism, and this presents an interesting paradox given that its audience is not composed exclusively of Hindu viewers. The focus of this study, of course, is a Canadian audience, particularly a Muslim one, and members of this group did indicate their awareness of Bollywood's inability—or refusal—to portray Islam in a rounded way.

\section{Popular Indian Cinema: Froth, Friction and Faith}

This tension may seem odd given that Bollywood's production and content are touched by the influences of other cultures and religions, including Islam, and Muslims may constitute a significant part of the Bollywood audience. This section focusses specifically on the role of Islam in Bollywood films, analysing central themes and production practices and assessing whether these have changed substantially over time. Given India's complicated political, cultural and religious history and the more global concern with Islam's meaning and significance, Islam inevitably plays an important-and somewhat transformed - role in popular Indian cinema. However, in the films discussed here, it also carries familiar associations with terrorism, violence and intercultural misunderstanding, in contrast to Hindu symbolism and mythology, which carry considerable dominance and authority. Danger to Hindu—or Indian, as the two are often elided—values can come from many sources in Bollywood cinema. The most innocuous threats may come from frivolous youth who dismiss the importance of culture and history, while greater danger may lie with outright colonizers, such as the British, or anyone who embodies difference, such as people of other religions or cultures who would challenge Hindu primacy. Islam, already the focus of stereotyping and misrepresentation 
in various forms of media, is presented in some Bollywood films as one such threat to the Hindu nation.

There is a rich body of literature that discusses media representations of Muslims in general, but the case of Bollywood is a rather unique one. Like North American and European media, Bollywood does reference some of the usual stereotypes, such as terrorism and extremism, but the complicated history of India and its peoples means that Indian films may provide a different context for producing and viewing stories about Muslim characters. Thoraval suggests that in order to address the sizeable Muslim minority still living in India following Partition, Indian cinema worked hard to provide positive Muslim characters, even if there were only one or two per film (2000, p. 90). Prior to Independence, there were films depicting Muslim stories and themes, such as Noorjehan (1923) and the big-budget Phool (Flower, 1944), made by Karimuddin Asif, who would also go on to create the major hit Mughal-e-Azam (1960), described as an attempt to emphasize the common history of Hindus and Muslims while depicting the glamourous, lost empire of the Mughals. While Mughal-e-Azam remains one of the bestknown Bollywood movies and has been re-issued over the years, other films, such as Umrao Jaan (1981), about a $19^{\text {th }}$ century cultured courtesan in Lucknow, have gone on to be re-made (Thoraval, 2000, pp. 91, 103-104)

At the same time, these attempts at representing diversity are not wholly positive. Not surprisingly, given the overarching importance of Partition in the lives of so many Indians and Pakistanis, this event and its aftermath underscore a number of themes related to Islam and to Muslims (Mishra, 2002, p. 210). While September 11 may have raised global awareness regarding Islam and Muslim practices, India has long struggled 
with its relationship with Pakistan and with the Muslim minority within its own borders, and the shadows of this struggle fall over a number of Bollywood films. Where Muslims are given important roles, which is hardly common, they are frequently presented as threats of some kind: terrorists, sexual predators, traitors or abnormal in some way, departing from the cherished values of the nation. As Amit Rai (2003) points out, the danger the Muslim represents to the nation in Bollywood cinema is sometimes so pronounced that the state must adopt its own violent techniques to put down such a threat. If not for aberrations such as Muslims and other minorities who refuse to respect Indian practices and boundaries, India could otherwise easily maintain its status as a pluralist, united family.

Western films, novels and news reports have been accused of fetishising Muslim men and women, treating the former as lustful predators and the latter as mysterious figures who veer between innocent damsel in distress and exotic seductress, a kind of Madonna/whore complex revisited and tweaked for the Orient (Ahmed, 1982, 1999; Kabbani, 1986; Karim, 1997, 2000). The topoi of hypersexualised Muslim men are even more powerfully charged when placed in an Indian setting where the honour of women is often equated with that of the country. In the controversy over the filming of Deepa Mehta's Fire (1996), where the two female leads, neglected by their husbands, become romantically involved, one group of protestors indicated their distaste for seeing Hindu women's sexuality portrayed in such a way by suggesting that they would withdraw their objections if the main characters were given Muslim names instead (Desai, 2004, p. 180).

The symbolism of Indian female purity is invoked, Mishra points out, in the Inter Dominion Treaty which was in effect between 1947 and 1957 and aimed to recover those 
Hindu and Sikh women who had apparently been abducted by Pakistan during the chaos of Partition (2002, p. 214). The exact number of women who were lost to each sidesince, of course, Muslim women were also abused, abducted and displaced-is difficult to ascertain and there are hints that some women voluntarily chose their new location. However, the recovery of those women was framed as a matter of honour and principle. The film Chhalia (The Trickster, 1960) discussed this very issue, featuring a woman from each side who was lost during the struggles that erupted and who took a number of years to reach home or family. That film also manages to invoke the dark spectre of consequence for Indian women who may have been sexually assaulted during or after Partition - in the movie, the main character, who had found refuge, eventually finds her way back to her family only to be rejected by her husband, who is unable to believe that she was not assaulted on the other side and who thus considers her tainted, echoing an oft-repeated story from the Ramayana.

Given the emphasis on female chastity and female honour, it then follows that an implied fear of intermarriage or cross-cultural romance seems to run through a number of Bollywood films, as it once —and some might argue, still—formed a constant undercurrent in so many American films. This may seem contradictory, since there are a number of pronounced similarities between Muslims and Hindus on the subcontinent, whereas the themes of miscegenation that anchor so much early American film consistently emphasize difference. In those films, even the most light-skinned AfricanAmerican will eventually be found out and punished for daring to cross the colour barrier. Clearly the barriers are bound to be different in Bollywood films. In fact, the 
threat of the Muslim is greater because of the fact that he or she can "pass" for Hindu so much more easily than an African-American could pass for white.

In fact, in the $1940 \mathrm{~s}, 1950$ s and part of the $1960 \mathrm{~s}$, when Muslims were explicitly singled out as potential threats to the film industry, many Muslim actors did make the choice to pass themselves off as Hindus, at least at the most superficial level. Facing the All India League of Censorship, which designated itself as a type of House of Un-Hindu Activities, hunting down Muslims and Parsis who might destroy the Indian film industry with their "decidedly anti-Hindu agendas," Muslim actors took the path of least resistance by adopting Hindu names (Mishra, 2002, p. 217). Examples include Dilip Kumar (an alias employed by Yusuf Khan), Meena Kumari (Mahjabeen Bano), Madhubala (Mumtaz Jehan Begum Dehlavi) and Ajit (Hamid Ali Khan) (p. 217). An atmosphere that would persuade actors to suppress markers of their Muslimness, then, may explain why, when Muslims were not lustful, threatening or terrorists, they were sometimes invisible in stories that could have reasonably included them (Chakravarty, 1993).

An alternative point of view, however, is provided by Thoraval, who waxes enthusiastic about the fusion of cultures in Bollywood cinema, seen in the linguistic combination of Hindi and Urdu into Hindustani, a language which came to be understood by many despite its mixed origins. Noting the number of Hindus and Muslims working together in the Bollywood of the 1940s to the 1960s, Thoraval suggests that "directors or artistes, whether they are working in commercial or art cinema, and whether they belong to any of the faiths, Hindu, Muslim, Sikh, Parsi, Christian, etc., almost always portray the 'other' culture in a fair and impartial way with all its wonders and grandeur" $(2000, \mathrm{p}$. 
69). Similarly, Mohammad, claiming that Bollywood is one of those rare artistic forms

that has managed to overcome differences within the audience, displays similar

admiration for the cultural crossover that defines Bollywood operations:

In the subcontinent itself, the Bollywood cinema is hailed as one of the most efficient instruments for the promotion of communal harmony: this harmony can be observed in the industry itself (actors, directors, play-back singers, and so on, working together whatever their ethno-religious background) as well as in the popularity of this cinema which largely crosses boundaries, Pakistanis for instance being particularly fond of Bollywood films. (Mohammad, 2001, p. 299)

While Thoraval's positivity may be somewhat overstated, there is a case to be made for Bollywood cinema as a place where certain aspects of Muslim culture do thrive. While the Hindu epics do indeed play a major role in Bollywood film, there are Muslim influences to be found throughout, such as the use of Urdu and the continued popularity of musical forms such as the ghazal and the qawwali. Indeed, Virdi cites Kesavan's belief "that popular Hindi film is the last 'stronghold' of Urdu in India" (2003, p. 19). Denied the state approval bestowed on Hindi, which was taught in schools and then made the language of administration, Urdu might have disappeared from widespread use. As it stands, Urdu is no longer as common in Hindi films as it was in the 1950s, but some words do live on through that medium (Virdi, 2003, p. 20).

Many Muslims producers, writers, lyricists and actors have made and continue to make significant contributions to popular Indian cinema. As Mishra remarks:

The discourse of Hindi cinema remains to this day markedly Urdu and many of its key personalities have been Muslim-Mehboob Khan and Nazir Hussain (producers/directors), Javed Akhtar and Majrooh Sultanpuri (scriptwriters and lyricists), Naushad and A. R. Rahman (music directors), Dilip Kumar, Madhubala, Aamir Khan, Shah Rukh Khan, and, of course, Nargis (actors). Add to this financiers and the largest single group of Hindu/Urdu speakers (some 120 million), and we begin to get some sense of the importance of Muslims to the industry. (2002, p. 63) 
Thoraval also names actors Waheeda Rehman, Shabana Azmi and Naseeruddin Shah, music directors Ghulam Haider and Ghulam Mohammed, singers Talat Mehmood, Shamshad Begum, Ghulam Ali and Mohammed Rafi and lyricists such as Sahir Ludhianvi, Kaifi Azmi and Shakeel Badayuni (2000, p. 71).

Since there is clearly not a question of underrepresentation within the industry, inaccurate portrayals may instead have to do with how Muslim producers and actors have been schooled to present themselves, and with the limitations posed by working within a form of cinema that has so forcefully come to equate Hinduism and a unified India, fortified against any and all threats. If performers came to limit Muslim signifiers behind the scenes, the same was true on the screen, where Muslim traditions and history often fell by the wayside. When they did make an appearance, they often appeared as token characters or as ones whose roles served to emphasize the impossibility of a real relationship with Hindus, who are generally the principal characters in popular Bollywood films.

Moving Forward: Admitting Muslims into the Nation?

This story is set on the bank of the Jhelum river, which begins in India and flows through Pakistan. On one side, Hindus worship it, praying to the rising sun, and on the other side Muslims offer prayers to their Allah at sunset. The water doesn't make distinctions between different human beings. Then why do people observe difference in their hearts? (Virdi, 2003, p. 35; her translation of the voice-over that opens the film Henna)

Examples of films that explore Muslim themes do exist, of course. Ghuman (2006) notes that in the past, Mere Huzoor (My Lord, 1968), Nikaah (Marriage, 1982), Pakeezah (Pure of Heart, 1972), and Mughal-e-Azam (1960) ensured a “distinct Muslim presence. The Muslim political film also carved a niche for itself' (para. 2) and he goes on to cite Salim Langde Pe Mat Ro (Don't Cry for Salim, the Lame, 1990)'s treatment of poverty 
and despair, as well as Garam Hawa (Hot Wind, 1973)'s depiction of the personal tragedies created by Partition. So politically charged was Garam Hawa felt to be, with its pioneering depiction of a Muslim family's experience during Partition, that censors prevented its release for almost a year (Pendakur, 2003, p. 77). After such films as this, however, Ghuman believes that the Muslim presence in Indian cinema actually takes a turn for the worse, moving towards marginalization and extremism.

Ghuman is citing a rather broad range of films, moving all the way between the 1960 s and the early 1990s. Mishra agrees that the portrayal of Muslims does change markedly, but he identifies a more specific moment when this occurs. Discussing the film Amar Akbar Anthony, the Amitabh Bachchan hit which featured three brothers separated and then raised under three different religious traditions, including Islam, Mishra suggests that this film represented a liberal and inclusive politics of India that would eventually dissipate as, following the late 1970 s, India began to experience intensified regionalism and political fragmentation. Events such as the Iranian Revolution, in which the Western-supported Shah was ousted from power by a revolution led by religious leader Ayatollah Khomeini, and later, the fatwa or death sentence issued against writer Salman Rushdie by Khomeini “confirmed old Hindu phobias about Islam's essential inflexibility. Two factors define the post-Amar Akbar Anthony world: the rise of Hindu fundamentalism and cultural globalization" (Mishra, 2002, p. 203).

Bollywood cinema began to reflect a protectionist tendency found elsewhere in Indian society. I have suggested earlier that the events of September 11, 2001 affected the way Muslims are perceived in North America and Europe, as well as the way they have come to view their own position. Bollywood producers are unlikely to be unaware of the 
increased debate over the role of Muslims after September 11, but they are also in a rather different position than writers, producers, politicians and other commentators in North America and Europe. The notion of Muslims as threat is not new to those living in India, who have grown up with stories of recurring interfaith conflict and may have even witnessed the results of such tensions. While Muslim viewers of Bollywood may be more acutely aware than ever before of negative portrayals, Bollywood's insularity and its refusal to privilege Islam, Sikhism or Christianity in its texts are hardly new. Seeking to protect Hindu values in the midst of a cultural onslaught coming from different corners of the globe, Bollywood restored Hinduism to its primary, authoritative place at the centre of most films. Muslims did appear in films and could contribute to the salvation of India, as in Karma (Action, 1986), when three convicts of different religions worked with a police chief on behalf of the nation. However, in Karma, it is perhaps no coincidence that the Muslim character is the one who must die for the cause, while the other convicts are permitted to survive.

Similarly, in Henna (1991), a Pakistani female character falls in love with the Indian hero, only to be killed while attempting to help him return to India and to his true love there. While Henna does seem to be sending a message of peace and unity, it also concludes with a reminder of the impossibility of cross-border, or cross-cultural, love. Virdi suggests that while this film attempts to deconstruct notions of essential difference, it also offers a tale of Hindu-Muslim love that can only be realized during a temporary, unusual event—the hero's experience of amnesia (2003, p. 36). As soon as the Hindu hero, accidentally stranded in Pakistan, has been nursed back to health by the title character, he embarks on a journey home, one that kills Henna even as it returns him to 
his true (Hindu) love. The tragic Henna, however, does offer a rare entity: "In Henna, perhaps for the first time ever, the 'enemy,' Pakistan, is given a face - even a humane one" (Virdi, 2003, p. 42). As Virdi points out, while the state itself is associated with manipulative and unsympathetic characters, the ordinary people of Pakistan are shown to be simply that, ordinary people, rather than sworn enemies of India, a trend that is echoed more than a decade later in Veer-Zaara.

Mani Ratnam's Bombay (1995) takes the Hindu-Muslim romance further, allowing the Hindu hero and Muslim heroine to marry and have children, but it also depicts the brutal consequences for those children when rioting breaks out and anyone who cannot claim to be strictly Hindu or Muslim, rather than a mix of both, is at risk. Bombay, like Garam Hawa, attracted negative attention from censors who continually requested that the political content be diluted (Pendakur, 2003, p. 79). Viewers also had mixed reactions to Bombay, which appeared relatively neutral in its portrayal of Muslim and Hindu political parties as equally complicit in stoking interreligious tension, yet also "shows angry Muslims taking to the streets with weapons after the Babri mosque is destroyed by Hindu fundamentalists" (Pendakur, 2003, p. 79). In cities with large Muslim populations, such as Hyderabad and Secunderabad, reaction was sometimes negative and some Muslim fundamentalist politicians were displeased, especially by a scene that depicts the Muslim protagonist discarding her veil (Pendakur, 2003, p. 81). It may be significant that Bombay was itself a kind of hybrid cinematic form, initially made in Tamil and walking a fine line between Bollywood and art film (Virdi, 2003, p. 73), a rarity that might align comfortably with Ratnam's willingness to tackle the previously taboo. 
Prior to Bombay, Ratnam also courted some controversy by making Roja (1992), a film set against a Kashmiri backdrop and featuring Muslim militants. Again, if Hollywood turned its attention to Islam and Muslims after particular events, such as the Iranian Revolution, the Gulf War or the World Trade Centre attacks, Bollywood has inflected its portrayals of Muslims with its own cultural and historical nuances. Drawing on ongoing issues such as tensions with Pakistan, Bollywood films provide a depiction of Muslim enemies that would hold some familiarity for an Indian audience. Unlike later films such as Khalid Mohammad's Fiza (Air, 2000) or even, to a lesser extent, Ratnam's own Dil Se (From the Heart, 1998), Roja does not explore the issue of how such extremism is fostered; Ghuman suggests that it instead paves the way for "a number of slash-and-burn movies that target Pakistan and the Indian Muslim (not explicitly stated but implicitly implied) without making any attempt to delve into the several complex processes that breed or sustains terrorism" (2006, para. 4). As examples, he cites movies such as Sarfarosh (Self-Sacrifice, 1999), Maa Tujhe Salam (I Salute You Mother, 2002), and Gadar (Revolt, 2001), the first of which bears particular scrutiny.

Among many insidious messages, Sarfarosh features a ghazal singer who publicly preaches cultural unity and understanding while privately working as an arms smuggler and insurrectionist. Even those who pretend to be friends of the Indian nation, and who appear to fit in, may in fact pose a serious danger (Rai, 2003). Sarfarosh does attempt to offer counterposing narratives, providing a Muslim inspector, Salim, who works hard and has valuable contacts, but whose actions all fall under suspicion due to his religion. Removed from a major case because of his failure to detain a Muslim suspect, a hurt Salim is brought back into the fold following the alternating entreaties and 
rebukes of his former student, Ajay. Ajay, now leading the investigation, implies that Salim should swallow his pride and provide assistance in order to prove his Indian patriotism. Insulted by Ajay, Salim makes a quick transition from offended victim to subservient helper, the loyal subordinate who is willing to defend Ajay at any cost. Despite the fact that Salim taught Ajay much of what he knows, the resulting scenario presents Ajay, the Hindu protagonist, as the natural authority between the two.

Salim, however, at least bears the distinction of bravery. Two of the other prominent Muslim characters, Sultan and Gulfam, are depicted as cowards who also exhibit other Orientalist tropes. Sultan is sensual and hedonistic, indulging in massages from his mistress and sunbathing when he should be attending to business. His failure to accomplish the tasks assigned to him is punished by death, meted out by Gulfam's minions in a way that evokes even more stereotypes--a terrified Sultan, forced to flee the country, is decapitated by a turban-wearing, camel-riding companion using a sword as they ride across the desert. If Sultan is incapable of handling his own work and pays the ultimate price, Gulfam takes this to another level. Enjoying the luxury of being a musical star, Gulfam spares no one who fails to live up to his expectations, yet he does not directly involve himself in the arms trade or in murder. Quick to condemn Sultan and others, he is shown as someone who commits crime after crime without taking responsibility for his actions. At the end of the movie, prodded by Ajay, he loses his head in fear that he will lose his reputation, and shoots another suspect. Only then does he see himself as sinful, an impression Ajay swiftly corrects by noting that all of Gulfam's actions have been wrong. Worse, Ajay suggests, Gulfam has rewarded India's hospitality with treachery. 
Gulfam's counter-argument that Muslims have been damaged by Partition is dismissed easily, partly because Gulfam has already been revealed as evil and duplicitous, but also because this argument is framed by Ajay as simply a refusal on the part of Muslims to let go of the past, and to accept that people of all faiths on both sides of the border paid the price for Partition. In this part of the movie, which finally touches on the history that could be valuable and enlightening, Ajay offers facile, simplified conclusions that offer easy resolutions to viewers on this and on all points involving Indian-Pakistani, Hindi-Muslim conflict. Indeed, when the character of Gulfam faces obvious racism, condemned as a "mohajir" or refugee because he is an Indian by birth but a Pakistani following Partition, this bigotry stems from his fellow Pakistanis. Indian characters are seen as friendly and open, representatives of a pluralist and welcoming India, whereas the representatives of Pakistan are sly, manipulative and corrupt, including military and diplomatic personnel.

The only trustworthy Muslims in Sarfarosh and in other movies are those who place India first and who do so in an overt manner. Muslims may be allowed to pray and to assert pride in their religion, but they must do so in a way that also proclaims profound loyalty to the nation. As Rai notes, the title character in Fiza, Sarfarosh's Salim and Mission Kashmir's (2000) Inayat Khan, are all religiously devout but they are also devoted to India. A more recent film, Fanaa (Annihilation, 2006), raises the stakes with a Kashmiri heroine, Zooni, who opens the film with patriotic song, continues it with a dance dedicated to the unity of her country India, and closes it by murdering her husband and the father of her child, a man whose terrorist activities place the entire nation at risk. Zooni's loyalty to India is well-established throughout Fanaa, but Salim has to indicate 
his clearly, especially in a scene where he remonstrates with a fellow Muslim who attempts to solicit his cooperation. In one of the few moments where the film actually delves into the question of religion, Salim denies that the arms smugglers' brand of Islam has any authenticity or relevance to him, and goes on to assert his loyalty to his country and compatriots. Similarly, in the film Fiza, the heroine is constantly forced to defend her own patriotism, in one case rebuking a cynical and bigoted politician who implies that Pakistanis and Muslims are always causing trouble. Despite learning of, and experiencing, much discrimination and hostility, Fiza continually expresses love for India.

Fiza, in fact, will serve as the character who must protect India from any potential threat, including that posed by her brother, in the movie that speaks perhaps most poignantly to issues of Muslim alienation. The movie stars Hrithik Roshan in a role similar to the one he will play in Mission Kashmir, where the main character turns toward terrorist activity after a traumatic event. In this case, the event is the 1993 Bombay riots, in which Roshan's Amaan flees for his life, coming across acts of brutality and even a policeman who refuses him aid, advising him to go back to Pakistan. Backed into a corner, Amaan joins a terrorist group where he thinks he will be able to defend Muslims, only to discover, as does Altaaf in Mission Kashmir, that he has been manipulated. Having carried out a high profile political assassination, Amaan is targeted by his own comrades. Fleeing for his life and his freedom, Amaan is found by Fiza.

After discovering what her brother has done, Fiza kills him at his own request, ensuring that the dissident Muslim meets the only possible fate in store for him. As a reminder that the problematic character is Muslim, Amaan offers a last expression of 
faith as he dies, uttering the Shahadah ("There is no God but Allah and Muhammad is his final prophet"), the recitation of which is considered by many Muslims to be a pillar of Islam. Having removed this threat to the nation, Fiza confirms her own worthiness as a heroine who can preserve the correct state of affairs despite her personal feelings, an echo and simultaneously a perversion of that most symbolically weighted film in Indian cinema, Mother India, in which the mother shoots her rebellious son in order to protect female honour-and, in effect, India herself.

Mission Kashmir, similarly, requires a female figure to act as nation and as unifier. The mother in Mission Kashmir, Neelima or Nilu, is the Hindu wife of Kashmir's Inspector General, Inayat Khan, and for a brief time, the adoptive mother of Altaaf, a youngster whose biological family is accidentally killed by Khan during a terrorist raid. Khan and Nilu adopt Altaaf, but when the boy discovers Khan's role in the death of his parents and sister, he runs away from the couple and devotes his future days to seeking revenge against Khan. Embittered and isolated, Altaaf is exactly the type of youth preyed upon by terrorist groups seeking new members. While Mission Kashmir explores the familiar territory of Muslim men as people inevitably linked to violence, terrorism and destruction, it does successfully depict the confusion and despair of youth such as Altaaf, portrayed as a man who genuinely loves his childhood sweetheart, Sufi, and Nilu, but whose torment is used to advantage by mercenaries such as the villain Hilal. Mouthing religious platitudes, Hilal convinces his young charges that he is leading them on a path of righteousness, even as he lies to them about their real mission-to create interreligious chaos by bombing a mosque and a temple - and even as he extracts large fees for himself in order to carry out this task. Hilal is not a man motivated by Islam, but he uses 
religiosity to drive his charges while discouraging them from maintaining any contact with their outside lives or with loved ones.

It is the appearance of loved ones that offers a counterpart to the angry Muslim men, Altaaf and Inspector Khan. In a dreamed exchange with Sufi, who has found out that Altaaf is a terrorist and refuses contact with him, Altaaf tries to win her over by explaining that he is carrying out a religious mission. Sufi, depicted as an honest and patriotic young woman in the same mode as Fiza, rejects this explanation, responding: "I'm a Muslim, too. Islam doesn't permit the murder of innocents." She points out the truth to him-that his real motive is revenge. Trite as this scene may appear, it does offer one of the few positive commentaries on Islam, since it is mainly used elsewhere as the backdrop to discussions about jihad and war. It is another woman who will finally, though belatedly, effect a resolution to this film. In this, as in so many other Bollywood movies, the Hindu mother becomes a thinly veiled metaphor for the nation, and the war between Altaaf and Khan ultimately results in her destruction when a bomb intended for Khan kills Nilu. Khan seeks Altaaf in order to enact revenge, but in the end his love for the nation overcomes all else. Having learned the true goal of Mission Kashmir, Khan finds Altaaf and secures his assistance by invoking Nilu's memory and Altaaf's own childhood ties to the temple that would be destroyed by Hilal's missile. Altaaf ultimately sacrifices himself in the effort to save the mother country, offering his life-which is later saved by Khan-in a necessary ritual in order to secure redemption.

A very different film from these previous ones is the 2004 blockbuster, VeerZaara. The Zaara of the title is a young woman whose fate becomes determined, in part, by her connections on both sides of the Indian-Pakistani border. The Muslim daughter of 
a prominent Pakistani politician, Zaara travels to India in order to fulfil her surrogate grandmother's last wish — that her ashes be scattered in the place from where she came, prior to the division of India. While there, Zaara encounters Veer, with whom she falls in love despite her preexisting engagement to a Pakistani man. Her fiancé successfully conspires to separate the two for many long years, during which Veer languishes in a Pakistani prison and Zaara, unaware that Veer is alive, moves to the Punjab to continue his adoptive parents' work in the community. Eventually a Pakistani lawyer assigned to Veer's case serves as the instrument of his release and the couple's reunion, and Veer and Zaara are free to live together at last. As in 1942 A Love Story (1993), where Muslim and Hindu revolutionaries work together for a just national cause, the emphasis is on romance and political tensions are merely alluded to, not fully explored.

The clash of religions does come into play at more than one point, however, as when a Muslim prison guard who had sneered at Veer is answered sharply by Veer's lawyer, Saamiya, who asks him to consider why Veer, the Indian, has been assigned a prisoner number of 786 , the number many Muslims treat as spiritually significant. Taken aback, the guard eventually accepts Saamiya's proposition that Veer may in fact be under the protection of Allah. Most religious and cultural differences are resolved with equal ease if they are acknowledged at all. For instance, Veer's adoptive father suggests that Zaara is the perfect match for his son, and dismisses Veer's instinctive protest that Zaara is Pakistani. Rather than dwelling on the differences between India and Pakistan, the film constantly establishes universalities and cultural melding. The Sikh priest asked to assist the Muslim Zaara in immersing her surrogate grandmother's ashes does so gladly, 
praising her devotion. Zaara fits easily into Veer's home and family and embraces Punjabi tradition.

However, Pakistani and Muslim traditions are also highlighted, with at least two major climactic moments set against the backdrop of stirring qawwalis ${ }^{3}$ while others are set against soaring Islamic architecture, an ode to Muslim culture and Indian diversity also found in Fanaa's poetry and song. As in Fanaa, where the heroine emphasizes her belief that all elements in the country are one, people and places are shown to be the same no matter where they are. Zaara's mother shows herself to be the same kind of loving parental figure for Veer that his Maati and Bauji were for Zaara. When Veer assents to the tearful request of Zaara's mother that he allow Zaara's marriage to go forward without interfering, she asks if every son from his country is like him. He declines to answer but responds that every mother from India is just like her. Later, Saamiya responds to a comment from Veer by agreeing on the universality of maternal habit. Again, maternal figures serve to provide a sense of uniformity and similarity.

As opposed to Bombay, religion becomes highly unproblematic by the end and is not really the chief obstacle to this romance. Even the hostile prison guard opines eventually that "this Hindu here [Veer] is Allah's noble servant," and a freed Veer comments on how alike Pakistan and India really are. In a dramatic speech, he remarks on the features of Pakistan that brought his own home to mind, asking, "[t]hey say that this is not your country then why does it feel like mine." Political tensions vanish in this epic love story where personal relationships transcend borders. The difference between Pakistan and India is treated as minimal —although it may be significant that Veer and

\footnotetext{
${ }^{3}$ My thanks to Rajinder Dudrah for pointing this out to me during the 2006 Journal of South Asian Popular Culture conference.
} 
Zaara leave to make their new life in India- and indeed, early in the movie, the two leads offer a kind of "This land is my land" song-and-dance set in the Punjab during which they conclude that their countries are truly far more similar than different. Saamiya's legal opponent, not unlike Ajay in Sarfarosh, acknowledges her victory and suggests that the future belongs to those who can ignore religious difference and who are not compelled to continually invoke India and Pakistan's troubled past. Positive as this message is, it does seem a bit of a truism, ignoring the fact that Partition is rooted in a tangled and complicated history, and has left a legacy that some feel must be addressed. Conclusion: On Melding and Masalas

Bollywood cinema is both more and less than it seems, offering films that appear designed for easy consumption and that avoid some hard questions, yet still manage to encode social and nationalist commentary into their storylines. While a relatively new wave of films that are not Bollywood productions per se, such as American Desi (2001), Monsoon Wedding (2001) and East is East (1999), undertake a more detailed and daring exploration of the type of issues that diasporic South Asians struggle with, such as the inability to reconcile longstanding conservative values surrounding love, religion and behavioural norms with so-called modern standards (see Desai, 2004), these films do not necessarily displace the crucial role played by Bollywood cinema. Ultimately, Nandy sees Bollywood as exhibiting not India's faults but its overall strength: "the uniqueness of Indian culture," he hypothesizes, "lies not so much in a unique ideology as in the society's traditional ability to live with cultural ambiguities and to use them to build psychological and even metaphysical defences against cultural invasions" (1983, p. 108). 
These cultural invasions can be seen as approaching from a variety of sides: the idea of an all-Hindu, middle-class, united India can only exist without complication in film, and even in this area, some fissures are being addressed. Bollywood is not blind to changing trends, although it does employ its own methods in an attempt to control them. Increasingly it chooses to speak to South Asians living in diaspora, and it does, at times, try to offer commentary relevant to those who are not Hindu. In both attempts, it experiences its failures and its successes, although members of the diaspora, especially Muslims, may be more likely to remember the first. Veer-Zaara, rather than marking a wholly triumphant and pluralist new era in Bollywood cinema, merely serves as a reminder that themes of religion have not become significantly more nuanced. It may, however, reflect a more global emphasis in Bollywood. Observers of Indian film (Desai 2004) have suggested that Bollywood films are increasingly marketed to the affluent diaspora, a shift in focus which may explain why "a Punjabi ethos (Sikh and Hindu) is displacing the old North Indian Hindi ethos of Bombay Cinema" (Mishra, 2002, p. 260).

This focus does not necessarily open the door to more Muslim themes or to a clear interpretation of diaspora, but it may indicate some loosening of the previous guidelines that privileged one particular culture as that of all India. Ideally, the current political and media focus on Muslims in diaspora would prompt Bollywood to treat issues around Islam seriously. Certainly there has been a concerted attempt to talk about Islam more directly than before, and it is interesting to note the ambivalence underpinning two of the films that do address cross-border themes-Veer-Zaara and Fanaa-and were produced after September 11. Both reproduce familiar tropes about Indian patriotism, but VeerZaara makes a concerted effort to avoid the political and to emphasize Indian-Pakistani 
unity at the expense of treating Indian and Pakistani history seriously, while Fanaa raises the issue of politics and even allows one character to explain the position of Kashmiri nationalists, but ultimately ensures death for those nationalists, who prove themselves to be corrupt and ruthless. Despite the superficial departures from the norm in these films, most of the evidence to date ultimately suggests that expanded consideration of other cultures and other religions continues to rely largely on many of the same stereotypes, misrepresentations and lack of contextualisation.

Mission Kashmir, attempting to speak to a critical political and social moment in history—one that is larger than Kashmir itself—both encompasses current global realities and raises the possibility that Muslims can only be viewed in relation to violence and crime. Films that try to offer a rounded portrayal of Muslims through the lens of recent fears regarding global terrorism and Islamist radicalism both hurt and help Muslims everywhere. There are films that manage to break through the stereotypes, and some make a praiseworthy attempt to promote cross-border or cross-cultural harmony, but for the most part, ideology either seeps into many recent films, or is replaced instead by an apolitical, dehistoricized depiction that ignores crucial facts. The same can be said of films with diasporic themes such as Pardes and Taal, with their refusal to fully acknowledge what it means to live outside of South Asia and to still nurture a sense of cultural identity. Neither approach serves Bollywood viewers well.

Ultimately, as films such as $D D L J$ and Fiza indicate, there is some recognition that diasporic and Muslim characters, respectively, can be multi-faceted, interesting and relevant, but the very different ways these films handle the challenge of Islam and diaspora also implies that it is still not possible to view Bollywood cinema as a venue in 
which people belonging to either or both are completely understood or appropriately portrayed. Nonetheless, there is much to be said for a trend in filmmaking that seeks to address difference and to acknowledge the reality of Islam and diasporic South Asians, and as directors and writers continue to tackle these topics, it can only be hoped that they will do so with sensitivity and balance. This study, however, seeks to address the present implications of such work as much as it tracks recent change in the industry. This chapter has attempted to cover some of the most relevant themes and characteristics in Bollywood cinema, especially works that address nationalism and religion. The following chapters seek to examine whether selected audience members living in diaspora read such themes in a particular way, and what meaning this holds for them. 


\section{Chapter 6}

\section{Up Close and Personal: Methodology for Obtaining Audience Opinion}

Extensive research already exists in terms of analyzing Bollywood films and their content, and some speculation does take place regarding the role of the audience in interpreting this material. For the most part, however, first-hand audience accounts continue to be rare, although this is changing, particularly as social scientists turn their attention to viewers living in diaspora. Dwyer claims, with some justification, that one "of the most important gaps in the study of Hindi cinema is the absence of any ethnographic study of the cinema audience" (2000, p. 169). Indeed, while some of the major films have been discussed at such length that their importance in academic literature is perhaps now greater than their significance to the average filmgoer, the audience's reactions are often assumed, rather than investigated.

Dwyer's comment applies more to the audience found within India itself, where it is sometimes suggested that viewers are likely to be "urban, male, lower-class industrial workers" (2000, p. 169). This belief is based on calculations about cost and leisure time in India, and certainly in rural areas many people, especially women, might lack the resources to visit theatres for viewing movies. However, this is not to say that such movies are not viewed in the home. Within the diaspora, as the participants in this study and elsewhere indicate, the setting often dictates when Hindi films will be viewed. The presence of other family members is often fundamental, as Bollywood films may provide a form of entertainment accessible to the entire family. This may also be the case in India, but there does not appear to be any research available on the number of families who treat film viewing as a mainly domestic activity. The audience in India is still neglected as an 
object of study-ethnographic or otherwise-whereas viewers in diaspora are acquiring a definite allure for researchers. In particular, Jigna Desai (2005) and Meenakshi Gigi Durham's (2004) recent studies on second-generation viewers in the United States, as well as Yasmin Jiwani's (1989) research on young Canadians of South Asian origin in the late 1980s, indicate that there are a number of approaches and areas of interest worth investigating in terms of diasporic audience reception.

The current research also maintains a focus on diasporic viewers, but ones living in major Canadian cities. While young Canadian Muslims of South Asian origin are the primary focus of this research, young people of other religious backgrounds were included for the purposes of comparison. The initial research plan consisted of focus groups and follow-up interviews in Toronto and Vancouver, two cities with significant Muslim South Asian populations in relatively different settings. A large, ethnically diverse city, Toronto provides an environment in which South Asians and Muslims may theoretically integrate but may also attempt to mark out space that is distinctly their own. Vancouver is equally diverse, but with a different ethnic composition and with a high proportion of South Asians, including some who wield considerable political influence. In their own study of immigration in Toronto and Vancouver, Hiebert and Ley (2006) illustrate the significance and diversity of these cities:

In Canada, Toronto and Vancouver have emerged as the nation's two primary windows on the world, and both, if not yet global cities, are in the process of gaining this stature. In 2001 these cities had some of the highest proportions of foreign-born residents among advanced societies: $43 \%$ in the Toronto Census metropolitan area (CMA) and $37 \%$ in the Vancouver CMA. These ratios are much higher than those found in Los Angeles, New York, London, and Tokyo, the quintessential global cities of our era. (p. 71) 
The main aspects of this research plan were carried out in both cities, but the differing availability of participants meant that many of the discussions were conducted as individual interviews or as interviews in small groups, which provided more in-depth data but also reduced the planned number of participants. Accessibility to participants in Ottawa also led to the inclusion of that city as a third research venue. In total, I interviewed 22 young adults from 2006 to 2007 , bearing in mind questions about the overall purpose of the research, the challenges of eliciting information without influencing it, and my own positionality as a researcher who is Muslim and of South Asian ancestry, and hence closely linked to the groups under investigation. The results were diverse in some respects but surprisingly consistent in others, particularly on questions of nationality, nationalism and the ability to integrate.

\section{Starting Points: Theory Meets Primary Research}

My hope entering this research was to obtain first-hand evidence of the strategies employed by young Canadians of South Asian origin, especially Muslims, and the shortcomings they perceive, if any, in the existence they lead. Although the early stages of my research sketched out a theoretical framework addressing ethnicity, hybridity, diaspora and transnationalism, I was also cautious about the use of theory as a beginning point in qualitative research (Bryman, 1988, pp. 97-98, 120). Rather than treating such theory as reified fact intended to be merely confirmed by my own study, I genuinely wished to discover whether any of it is applicable in the lives of the people under discussion. I anticipated the possibility, discussed in Orona's (1997) use of grounded theory, that in conducting and transcribing interview proceedings, I would discover that the theoretical frameworks I had chosen were not as relevant as I had supposed, and that 
other possibilities would arise. Ultimately I found that they were applicable and provided an ideal lens through which to interpret respondents' comments, although the level of applicability and specificity varied greatly from one person to the next.

To discover this information, I had planned to conduct focus groups, or as Schensul prefers to refer to them, focused group interviews (1999, p. 51), which ended up being a more accurate description of the discussions that did take place. As discussed further in the following sections, I did conduct loosely structured interviews with young Canadians of South Asian origin to elicit further information regarding issues such as the way they view themselves in terms of national identity, the degree of belonging they experience in different communities and what role diasporic media play in affecting their notions of identity, nationalism and civic responsibility. For comparative purposes, I conducted interviews or focus groups with young Muslim, Hindu, Sikh and Christian subjects in Toronto, Vancouver and Ottawa in an effort to determine whether young Muslims of South Asian origin really do occupy a unique position within the larger Canadian community, and whether their readings differed significantly from those of other young South Asians.

The reasons for maintaining a focus on subjects who are South Asian and Muslim, rather than one or the other, may seem obscure, but they stem from a belief that this particular group embodies a number of overlapping tensions in terms of its relationship to what is loosely characterized as Canadian culture, which is often an implicit shorthand for white culture. South Asians form one of Canada's largest and most visible ethnic minority groups, while Muslims practise Canada's second-largest religion. Although individual experiences varied considerably, a significant number of South Asians and 
Muslims underwent considerable fear and isolation following September 11, 2001, when Canadian anti-terrorism legislation and anti-immigrant sentiment were perceived as directly affecting their communities in a markedly negative manner. Such events illustrated the fact that South Asian Muslims occupy a rather uneasy place in Canadian society as double minorities, despite Canada's ostensible commitment to pluralism and diversity, and despite the fact that South Asians and Muslims have both been part of the Canadian cultural and religious mosaic for many years. Since global economic realities and Canada's declining rate of natural increase ensure that immigration to Canada will only continue to increase in coming years (Statistics Canada, 2002), any politician or educator with an interest in promoting healthy civic discourse must investigate the social impact of failure to successfully integrate minority groups into the larger circle of Canadian society. The way in which young Canadians construct identity and sense of self will directly impact their ability to engage positively in civic life, as students, workers, parents, professionals and voters. In other words, it will influence their very status as citizens, people who feel that they belong in Canada and are not, as Neil Bissoondath (2002) has suggested, mere visitors with easily transferred loyalties.

In the early stages of planning, in fact, I had identified a need to study both the process of identity formation and the construction of a civic sensibility. The latter remains an area of interest and potentially an area of relevance. However, in the interests of narrowing the parameters of an admittedly large project, I chose ultimately to structure the central questions around identity construction as this related to media reception, while using the eventual findings about identity construction to generate hypotheses for further research regarding implications for citizenship. Given the variety of topics that arose in 
the interviews, it appears that it was prudent to limit discussion to a single cultural domain, within which subdomains or subtopics can be identified, rather than inserting numerous topics for discussion (Schensul, 1999, p. 63).

\section{Early Stages: Establishing Participant Criteria}

When you talk to young people who came from Islamic-majority countries (or whose parents did), you increasingly hear them describe themselves as 'Muslims' and identify themselves with a broader worldwide community of believers. Their religion has become their primary identity. (Saunders, 2007, p. F3)

Accordingly, once the research question was narrowed down, the next parameters that had to be established involved the choice of participants, a delicate task when approaching a community that is highly heterogeneous. The reports of post-September 11 hostility towards some non-Muslim South Asians, or towards Muslims whose beliefs are quite different from those of the September 11 hijackers, demonstrates that some of the North American public may consider these groups to share the same ethnicity and religion. In actual practice, however, Islam is home to many different sects which hold, on selected points, very distinct and sometimes conflicting viewpoints, and in fact, certain branches, such as Ismaili Muslims or Ahmaddiyas, are sometimes not recognized by others as Muslim, but this is not a study which seeks to establish the correct meaning of religion or ethnicity. At the most basic level, the Muslim participants could probably only have been expected to agree on their belief in Allah and the prophet Muhammad. I anticipated some possibilities for disagreement, but either the subject matter or the interview format prevented this. Even in groups where participants expressed differences, they treated this more as a point of interest than as a source of friction. My initial expectation was that participants who were both South Asian and Muslim might produce more Sunni subjects than Shi'ites. Instead, of 11 Muslim interviewees, 8 identified 
themselves as Shi'ites, but since questions about normative versions of Islam and religious doctrine rarely entered the conversation, this difference became irrelevant to some degree.

However, the real problem in terms of sampling arose in relation to the question of selecting participants of South Asian origin when, I hypothesized, their processes of integration do not bear out the conventional literature on generational immigration (see, for instance, Glazer \& Moynihan, 1963). In determining whether focus group participants should be restricted to first, second or third generation immigrants, it appeared that sufficient numbers exist in all three categories to compose reasonably sized focus groups, but the question became whether this was a study of the contrasting ways different generations of immigrants construct identity. Ultimately I decided that it was not. Rather, this study aims to examine whether young adults (regardless of whether they were first, second or third-generation immigrants) from these communities, who have resided in Canada and operated in enough Canadian socializing institutions for enough years to understand Canadian sociocultural norms, consider themselves fully integrated Canadians. In keeping with this, as well as Schensul's advice that focus groups should include sufficiently diverse representation but should also bear in mind the population the researcher truly wishes to address (1999, pp. 63-65), I placed less emphasis on recruiting specific generations of immigrants than on the fact that participants, regardless of place of birth, should have lived in Canada at least from the age of five years.

This provided participants who have undergone the bulk of their schooling in Canada, even if the actual institutions vary. Many of the participants were born in Canada following their parents' immigration in the 1970s, while other participants were born 
outside of Canada but they immigrated to Canada at such a young age that they remember nothing of their homeland and feel no real connection to other, somewhat more recent immigrants (see Gillespie, 1995 and Handa, 2003 for related discussions). As Maira (2002) explains in her own decision to apply the term "second generation" to children of immigrants or to those immigrants who arrived in the United States before age seven or eight, "the rationale... is that second-generation Americans 'come of age' in the United States, that is, share in the rites of passage of American high school and have socialization experiences very different from those who come here as young adults" (p. 17).

As Handa (2003) notes, a number of young immigrants, regardless of generation, share the experience of double migration, since it is not uncommon for them, or their parents, to have lived in colonies in East Africa, the Caribbean or Fiji, for instance, prior to coming to Canada, which adds another layer to their experience as South Asians whose notion of homeland is already complex. It is clear, though, from Handa's (2003) and Khan's (2000) studies that such double migrants nonetheless identify themselves as South Asian based on their ancestry, while alluding to East Africa—or other countriesas steps within the migratory experience. Thus, participants may identify as South Asian for reasons other than their place of birth, which gives rise to complications in terms of restricting samples on the basis of generational patterns, as might be the case in other studies of immigration. Since this is largely a study about identity construction, it can encompass any participants who can explain in what way they are descended from one of the South Asian countries under investigation. For the sake of convenience and consistency, I have followed Desai’s (2004) categorization here by including Pakistan, 
Nepal, India, Sri Lanka, Bangladesh, Bhutan, the Maldives and Tibet under the banner of South Asia.

I elected to limit the sample to participants between the ages of 19 and 29 years who were Muslim, Hindu or Sikh, although later I included two individuals who practised Christianity since all of these groups are represented in the films in question, and thus there was no legitimate reason to exclude one. No participant needed to be actively practising a religion at the time of the study. Participants also had to be residents of Canada from the age of 5 years or earlier, as this study aims to examine whether immigrants from these communities, who have lived in Canada and operated in Canadian socializing institutions for enough years to understand Canadian sociocultural norms, consider themselves fully integrated Canadians. In regard to the selection of participants between the ages of 19-29 years, the initial justification for this criterion rested on the importance of citizenship for Canadians in this age range. Though it may be argued that these are still formative years in terms of identity, these years also represent a period in which young adults start to think about, or already are thinking about, what kind of life they would like to lead, what kind of city/country they want to live in, how they perceive themselves and their sense of belonging. The key relationships in the major Bollywood films often take place between characters within this age range, so it is possible that participants in their mid to late twenties may constitute a primary target audience. Such respondents may have already pondered some of the issues so frequently discussed in Bollywood films, such as marriage, children, where to settle down, what values to embrace, etc., while the younger adults may be wrestling with intergenerational or cultural conflicts and may also be aware of competing cultural values and possibilities. 
My sample, then, was still relatively broad in some respects, as was the choice of cities in which to conduct research. Although I initially considered confining the research to Vancouver and Toronto, the easy accessibility of Ottawa, as the base of my research, convinced me to include it as another setting. My original supposition was that these particular cities present an interesting possibility for research in terms of their differing multicultural composition and practices, and I think that this remains true, even though I did not interview sufficiently high numbers of people in each city to compare and contrast attitudes. Indeed, the size of my sample does not allow for widespread generalizing about any of the groups included in this study, although my findings were similar in significant and interesting ways to those of Desai (2005), Durham (2004), Gillespie (1995), Handa (2003), and Maira (2002), which I think does help strengthen certain conclusions, as discussed in subsequent chapters. Rather than conducting a broad survey, I chose to speak at some length with my interviewees and to delve into a variety of topics, in search of deep and detailed commentary which would help provide meaningful insight regarding the questions at hand.

Amongst the individuals I did interview, I saw little indication of difference between Toronto and Vancouver, in particular, although Ottawa residents did occasionally comment on the fact that the (multi)cultural scene was less vibrant and nuanced than in those larger cities. I excluded Montréal on the basis that its attitudes towards ethnic minorities must be examined within the context of wider societal questions, such as simmering political tensions between francophone and anglophone communities, or between separatists and federalists, with minorities assumed to fall into 
the latter category by leaders such as former Québec premier Jacques Parizeau, who famously blamed the loss of the 1995 sovereignty referendum on ethnic voters.

Like Montréal, Toronto and Vancouver are both highly multicultural but their attitude towards diversity, one might theorize, is not fraught with the same political and protectionist anxieties. Ottawa is not as multicultural as Vancouver and Toronto, and did present an interesting alternative for study. This is not to say that Ottawa is not multicultural, since it certainly is, and it does possess a substantial Muslim community, but there is room to argue that South Asians, who are not as well-represented as in Toronto and Vancouver, would need to be more active in seeking out community resources and might not possess the same sense of belonging as in the two larger cities. One possible advantage of including Vancouver and Ottawa was the fact that similar studies of South Asian or Muslim communities in Canada had already taken place in Toronto or Montréal (Alvi, Hoodfar \& McDonough, 2003; Handa, 2003), but this may be a minor point as so few studies exist generally.

\section{Proceeding with Interviews: Selecting Approaches}

Such preceding studies of South Asians, Muslims and diasporic communities have produced interesting findings but few have targeted exactly these areas, with the intersection of media use and identity construction for young Muslims of South Asian origin. The most relevant and recent, in the Canadian context, investigate the experiences of female subjects only. Both Amita Handa's (2003) and Shahnaz Khan's (2000) recent works investigate the issue of identity among Canadian women who are also South Asian and/or Muslim. Likewise, Alvi, Hoodfar and McDonough's (2003) recent anthology is devoted to the experience of Muslim women and veiling in North America, and in 
combination with Handa and Khan, helped lend more specificity to the type of research questions employed in this study. In particular, Khan and Alvi, Hoodfar and McDonough identify key reactions demonstrated by minorities when their ethnic identity represents an obstacle in the process of integration, such as denial/rejection of ethnicity, the aggressive defence of identity or alternately, a more ambivalent, hybrid standpoint.

Similar strategies can be seen in Yasmin Jiwani's (1989) interviews with young Ismaili Muslims of South Asian origin. Although a considerable amount of time has passed since these interviews were conducted, they are relevant here, especially because of the related focus on Muslims and South Asians. Despite the years and attitudes that separate them, Jiwani's participants give answers that form a bridge to the interviewees in the current research. While they have lived in Vancouver for some time, alongside other South Asians, Jiwani's respondents are less likely than the young people in this study to claim South Asian ancestry, differentiating themselves by drawing upon their African heritage and their religious identity, which is framed as specifically Ismaili, more than Muslim. They describe a Vancouver that is characterized by racism and lack of acceptance, a place where some of them feel compelled to position themselves as separate from Hindus and Sikhs, who are more subject to discrimination. Indeed, both the vertical and horizontal racism described in Tamale (1996) are present here. As Tamale explains, vertical racism is the kind most easily recognized since it originates with a person in a dominant position and is directed at the oppressed. Horizontal racism, however, occurs within oppressed groups, some of whom may believe in a hierarchy between races or even within each race. In such a case, physical attributes such as skin colour or facial features can determine one's status, but here, the participants' distancing 
seems to be related more to learned behaviours. Speaking in the late 1980s, when South Asians and Muslims are integrating in different ways, some of the participants comment on the ways that they have assimilated, and critique other South Asians who retain traditional dress or who have not learned English. In one case, an interviewee condones the racist discourse that whites use towards such immigrants, and even employs some of it himself.

My own study turns up considerably different findings, but Jiwani's provides important context, particularly since my participants do identify racism from their childhood. The denial of South Asian heritage expressed by Jiwani's interviewees is something that the informants in the current study can also recall, although this is not necessarily widespread. Several speak to the increasing acceptability of South Asian culture, which coincides with the further entrenchment of pluralist attitudes and beliefs in Canada, as well as with a corporate mainstreaming of minority cultures. The confusion regarding identity and belonging experienced by some of the youth Jiwani interviews may also help shed some light on the determined search for cultural and religious information cited by several individuals in this dissertation. There is also some important foreshadowing of their answers regarding generational differences, the loss of linguistic ability and their desire to consume media that speak to diasporic issues, a desire that Jiwani's interviewees could not satisfy even if they wished to do so. The fact that the young people in this study have such media at their disposal, and are slightly more likely to see themselves represented in media discourse, may play a role in explaining the gap between Jiwani's participants, with their self-consciousness about their South Asian 
origins, and the respondents here, who identify these origins with very little such diffidence.

Gillespie's work on South Asian teenagers in the UK (1995) focussed on slightly different questions but is highly applicable here, particularly given the fact that she was one of the first researchers to explicitly address the educational and socializing role of Indian and non-Indian cinema for South Asian families. Although her work addressed only certain aspects of nationalism and identity, the pedagogical role she identifies for Indian cinema is pertinent because questions of identity, tradition and nationalism are so strong in these films. Like Kraidy (1999), Gillespie employs ethnography in her study, an appropriate choice in her case considering that, as a teacher of numerous Punjabi youth, she already had command of the language and subjects who were accessible and who felt at ease in her presence. Similarly, Maira (2002) interviewed her participants but also observed them at close quarters, immersing herself in a New York-based South Asian social scene. I chose not to pursue this route, due to a conviction that ethnography would not necessarily allow me to gain insight into the kind of perceptions and beliefs under examination, based on the foundational questions underpinning my research.

My research question asks what role Bollywood films play, if any, in the process of constructing a sense of identity and belonging for young Canadians of South Asian origin, particularly Muslims. I hoped to elicit further information regarding issues such as the way participants view themselves in terms of national identity, the degree of belonging they experience in different communities, and what role Bollywood films play in affecting their notions of identity, nationalism, citizenship and responsibility. These personal questions regarding individual perceptions and beliefs were unlikely to be 
answered in an entirely cohesive way through ethnography. In one sense, immersing myself in a participant's life would not have answered my questions. It might have allowed me to see how participants interact with other South Asians or non-South Asians and to guess at the role that religion and culture play in their lives. Even protracted observation at close quarters, or participant observation, might not have allowed significant insight into these issues. One respondent in my study noted her conflicting feelings on her religious obligations, since she fulfilled these in less overt ways after moving out of her parents' suburban Toronto home and into her own home in Ottawa as a student. Although she remained religious and interested in questions of culture and belonging, she rarely attended mosque on her own or consumed Bollywood films, a media form that had been very important in her childhood as a means of acculturation and education. Immersion into her Ottawa life might have suggested to me that she was not very interested in her Muslim or South Asian identity, as she apparently does not see her everyday life as substantially different from that of many other Canadian students. Her most poignant observations, which I think would not have been captured through ethnography as well as through interviews, were on her upbringing, the conflicting emotions she felt when comparing her outsider status in Pakistan to her outsider status in Canada, and her internal confusion over what makes someone Canadian. However, ethnography was an entirely valuable and relevant method in studies such as Gillespie's (1995), where her focus was at least partly on the uses of media in a familial setting. Similarly, Maira's study aimed to examine Indian American youth culture in some detail, so it seemed quite logical to combine ethnography with interviews. 
In terms of logistics, ethnography was also a more sensible choice for Gillespie because of her choice to study a relatively homogeneous group, requiring knowledge of the Punjabi language and culture to blend into her surroundings, whereas a more varied study of South Asians and Muslims would require an ethnographer to be multilingual at a bare minimum, preferably fluently multilingual to avoid miscommunication.

Additionally, though Gillespie's respondents seemed to welcome her into their homes and to speak frankly before her, I consider this level of access exceptional and I am not entirely convinced that a similar method would work here as so many topics are deemed unsuitable for discussion in some South Asian and Muslim households, even with a researcher who may be viewed as a partial insider. Moreover, in a group of young people who do juggle different behaviours, social circles and expectations, it is not entirely clear which setting would be most appropriate for evaluating a sense of identity or readings of Bollywood film. Some tended to view such films exclusively among their families--with whom they may or may not live - while others did so with friends or on their own at home. Only a few did this very regularly, so the possibility of observing them during the process of watching these movies was slim, unless this occasion was scheduled or staged especially for research purposes.

This is not to say, however, that all ethnographic methods are inappropriate. In fact, they may help to inform and develop interviews, the research method I went on to choose after noting its success in Desai (2005), Durham (2004), Handa (2003), Hoodfar (2003), Khan (2000) and Maira (2002). My original intention was to conduct initial interviews in groups and then follow up, where necessary, on an individual basis, but as I explain in subsequent sections, ultimately I ended up with a combination of group and 
individual interviews. Schensul (1999) explains how she views focused group interviews as an enhanced ethnographic method that allows for reflexivity, egalitarianism and dialogue, though she also provides suggestions for more formal and traditional structures if those are desired or appropriate in a particular context. I did develop a relatively structured interview process in that I distributed a questionnaire and also provided myself with some basic questions to direct the areas of conversation (see Appendices B and C). Each participant completed the questionnaire and answered the interview questions outlined in Appendix C, but I tried to leave the questions open-ended and in several cases this helped facilitate a free-flowing, wide-ranging discussion. Unless the conversation moved notably off topic, I allowed participants to raise their own points on this topic, and also asked at the end if they had additional comments they wanted to add.

In terms of access to these participants, I expected to rely on personal contacts and advertising through community groups. Recruiting through postsecondary institutions was prohibited by research ethics regulations governing most of the relevant schools, with the exception of Simon Fraser University in Vancouver and Carleton University itself. All of the eventual participants were recruited through direct advertising or through a form of snowball sampling, where friends, early participants and other contacts passed on the information to others in their own social networks. The drawback of this is that it can lead back to participants who are acquainted with one another (Schensul, 1999, p. 72; Seale, 1999, p. 116), but this did not seem to be a major factor in most cases, especially since the contacts recruited were not necessarily interviewed at the same time or in the same city. However, as I note below, the familiarity some interviewees had with one another did raise an ethical dilemma for me on one occasion, 
and my own sense that I knew important facts about one or two interviewees was subverted early in the process. Invitations to participate were also extended to specific community organizations, such as South Asian dance troupes, community centres and region-specific associations, but these rarely received a response. This was disappointing because of the desire to increase diversity, although the individuals who did participate still seemed to hold a wide range of views.

In fact, while it proved to be difficult to recruit from community associations, those personal contacts who did participate often demonstrated a high level of interest in the subject at hand, particularly questions of nationalism and identity. Perhaps not surprisingly, given the intense media and political focus on Islam and integration, several of the Muslim participants had clearly devoted considerable thought to the subject of personhood and belonging in Canada. Entering the project, it was difficult to predict how favourable the response would be, as past projects addressing the issue of Muslim integration suggest that there is a real hunger on the part of Canadian Muslims to discuss their own experiences and to reach out to academics and policy-makers who may be able to address their problems. While Muslims of all ages and racial backgrounds participating in such projects were mainly in agreement about the fact that they felt discriminated against, young South Asians in Canada have rejected the same notion in studies such as Handa (2003). Interviewing young South Asian women, some of whom were also Muslim, living in Toronto, Handa was impressed by the degree of confidence and comfort these subjects felt in terms of their own identity, but she also detected instances of racism and discrimination in the anecdotes her subjects would recount to her despite their insistence that they were immune from racism. 
Although the participants were all respectful of one another, I did keep in mind some of the precepts of critical discourse analysis and conversational analysis techniques (Stillar, 1998; van Dijk, 1988, 1991, 1993, 1996, 1998), which allow the reader or listener to deconstruct words or phrases typically employed in the subjugation of the Other or in the denial of racism. As I note in my discussion of findings, this was a very rare occurrence but there were a few moments where I detected a negative subtext in discussions of a particular religion, usually occurring in the absence of people who actually practised the religion in question. Tempting though it was, at that time and other moments, to address such comments directly, I felt that this would result in even more blurring of the lines between participant and observer. As it was, I did occupy a bit of a participant observer role whether or not I had intended to; some of the interviews did unfold more like comfortable conversations than interviews in the strictest sense, and I sensed that the group of young women I interviewed in Vancouver might have been especially forthcoming with opinions because they saw me as part of the group. Another contributing factor may be that some of these young people appear to view the opportunity to participate in one of two ways: they may be eager to share experiences that they cannot discuss freely in other venues (as seems to be the case in Handa, 2003; Khan, 2000 ), or they may be wary to do so because there are such strong cultural taboos around some subjects. The first case seemed to be more common, and this is where the lessstructured approach yielded both irrelevant detail and interesting revelations that might not otherwise have surfaced. The open-ended interview was helpful in this sense, allowing for a "fairly close relationship between researcher and subject" (Bryman, 1988, 
p. 96) rather than the impersonal distance sometimes created by rigid and formal structures (Bryman, 1988, pp. 96, 115-116).

With the consent of participants, I took notes and audiotaped the proceedings. Since the participants were all fluent in English, translation was rarely an issue except in the case of specific cultural terms or in the citation of films that I did not recognize, especially as a non-Hindi speaker. Related to questions of language and ethnic background is the issue of my own identity, as a researcher and as a member of the group I am studying: I am the Canadian-born daughter of immigrants whose ancestry is South Asian, although they themselves were born and raised in East Africa. I am also Shia Muslim and in my late twenties. This commonality was beneficial in the sense that it seemed to provide a sense of ease for participants when discussing cultural questions, and it also allowed conversations to flow more naturally, rather than following a rigid question-and-answer format. Sylvia A. Tamale, for one, favours such a conversational, relaxed style for its ability to produce truthful and useful points, and suggests that this style is more likely to be found in interviews where researcher and subject share commonalities, such as ethnicity (1996, pp. 489-490). For the most part, it did appear that participants in this study felt comfortable and seemed to expect that others, including the investigator, might have a sense of recognition in terms of some of the experiences they described.

Insertion of the Self: Issues of Reflexivity

As qualitative researchers engaged in contemporary practice, we accept that the researcher is a central figure who influences, if not actively constructs, the collection, selection and interpretation of data. We recognize that research is coconstituted, a joint product of the participants, researcher and their relationship. We understand that meanings are negotiated within particular social contexts so that another researcher will unfold a different story. We no longer seek to 
eradicate the researcher's presence - instead subjectivity in research is transformed from a problem to an opportunity...In short, researchers no longer question the need for reflexivity: the question is how to do it. (Finlay, 2002, p. 212)

It is possible that my identity could have complicated the findings if I had elaborated on it, or if I were to direct the conversation in terms of my own experiences rather than listening to those of others. Where I deemed it necessary, I did occasionally interject in order to illustrate what was meant by a question, but for the most part I tended to adhere to the general script and to keep my comments neutral, although I did not go as far as the interviewer discussed in Rapley (2001), whose refusal to break long silences actually helped propel conversation. Had any curiosity been expressed by my subjects, it is possible that my approach would have needed to be adjusted, since attempts on my part to conceal my subject position and identity could be viewed as an example of nonreflexive research that reinforces unequal power relations (McCorkel and Myers, 2003, p. 208; also see Bryman, 1988, p. 111). However, reflexivity, defined loosely by Finlay as "the project of examining how the researcher and intersubjective elements impinge on, and even transform, research" (2002, p. 210) was not as great an issue for me as I had thought it might be, which I think can largely be attributed to the ability of most interviewees to pay attention to the matter at hand. This potential difficulty might also have been alleviated because, unlike McCorkel and Myers (2003) and Tamale (1996), I was not called upon to interview subjects whose position in society was very different from my own; similarly, the potential problems posed by "going native" described in Bryman (1988, pp. 96-97) are minimal when the researcher is already so closely affiliated with the subjects. 
I did encounter some surprises, however, as a researcher who recruited participants via other acquaintances, and thus as someone with distinct potential to stray too far into the territory of the participant observer. In the case of one individual, who gave a thorough and insightful interview in Toronto, I collected the information she provided, transcribed the interview and thought no more of it until I returned to Vancouver, where the person who had originally put me in touch with her friend in Toronto inquired about the interview. She volunteered information about that person's upbringing and romantic history that struck me as interesting in light of the subject of the research. I grappled with the question of whether it was relevant and/or ethical to include such detail, or to conduct a follow-up interview that would allow for inquiries in that area. Ultimately I decided against referencing those details at all, a decision made easier by the fact that they were not entirely essential to the topic, but one that I would have come to nonetheless. Having opted to use interviews as my research method, I felt that I should maintain a consistent use of the data provided by my informants during their interviews, rather than drawing upon information offered through other channels. Any interview, of course, can be limiting in this sense--participants offer the data that they consider pertinent, which may exclude other interesting details.

Similarly, while participants make their own judgements about what is relevant in answering a question, I discovered that I had some preconceptions about the factors that might influence viewers to immerse themselves in Bollywood. Like Amita Handa (2003), who was favourably surprised by the ways in which younger South Asian women's realities differed from her own, I attempted to take into account the many differences that can occur even with a community, and to be honest about the expectations that have been 
produced by my own experiences, and the experiences of the people in my life. Nonetheless, despite attempting to ensure that, like Ahmed (1999), Handa (2003) and Tamale (1996), my biases and beliefs were clearly articulated in my research from the beginning, I still realized throughout the ways my standpoint may have affected my initial approach to interviews. Prior to interviewing two people who were referred to me by mutual acquaintances, I formed a general impression that they were strongly involved in their specific South Asian communities, held beliefs that might be considered relatively traditional, and were longstanding fans of Bollywood. In their interviews, however, both gave answers that indicated rather different positions, with one suggesting that he rarely watched Bollywood films and the other commenting that she did watch relatively frequently, but was critical of many elements, including Bollywood's presentation of tradition. As I conducted these interviews, I was reminded that I do have preconceptions, that these must be left behind, and that my impressions might well have been grounded in the fact that my participants and I did not all come from the exact same cultural background. What struck me as traditional and highly immersed may be different for others. Reflexivity and positionality can be drawbacks, as Finlay warns, when researchers insert themselves too often into the research: "Dangers of infinite regress, with researchers getting lost in endless narcissistic personal emoting or interminable deconstructions of deconstructions where all meaning gets lost, remains an ever-present threat" (2002, p. 226). However, reflexivity and positionality can also be, as Alvesson and Sköldberg (2000), Finlay (2002) and Mauthner and Doucet (2003) demonstrate, strengths if they are properly addressed; rather, they constitute a strength and in this case, inspiration. 
In this case, the acknowledgement of difference within a common group was the catalyst for this research. Raised in a household in Vancouver where national identification tended to be almost entirely Canadian, with occasional nostalgic references to Tanzania, I felt little or no connection to South Asia as a child, a sentiment that is also clearly found among some of Jiwani's (1989) respondents in the late 1980s. This feeling did not alter significantly even in my early twenties, when increasing pluralism and changing fashions made it more socially acceptable to claim Indian origins, to wear Indian clothing or to watch Indian films. However, at this point I did start to notice that some of my peers identified enthusiastically with aspects of South Asian culture that were literally foreign to me. Of those individuals, several seemed to have derived some of their understanding of South Asian culture from Bollywood films, which contained fashions they copied, songs they sang at parties, and a version of Hindi that they taught themselves in order to enjoy the movies. I was particularly surprised to realize how popular Bollywood films were among these youth, having been a very occasional viewer myself, and I was even more fascinated by the lure these movies held for Muslim viewers, whose own religious traditions were not likely to be depicted in these films in great depth, according to much of the literature on the subject.

I became interested in investigating this connection further, particularly when I realized how many people in this age bracket were grappling with questions of ethnic and religious identity. Explaining themselves to others at school or work was a challenge in itself, especially when sources of information were limited for some. Addressing such conundrums internally, however, was even more perplexing. Some of these young people were stymied in their attempts to express themselves when parents or other elders insisted 
on their adherence to particular rituals or practices "from back home." Often there was no real explanation for these, and-ironically, given how many of the participants commented on their parents' disapproval of interfaith relationships-at times, rituals that parents endorsed stringently as religious proved to have been influenced by spiritual traditions outside of their own.

While some parents seemed to assimilate ever more into Canadian society over the years, others clung more strongly than ever to their practices, even when such practices did not, as they believed, set them apart from other religious or ethnic groups. Instead, a kind of unintended melding of South Asian cultural and religious influences seemed to come together in the lives of some of these families, leaving some young people with an unclear impression of what it means to be Indian or Pakistani, for example, or Hindu or Muslim. The hybrid nature of the identity forged here by parents or other influences is not in itself an issue of concern for me; rather, I began to consider what some of these common influences might be, such as Indian films, and whether they might contribute to the determination some individuals felt to maintain a truly South Asian identity, even though in many cases they were not direct migrants from South Asia. Moreover, I questioned what role these influences might play in helping young adults articulate a clear sense of self, and, since I was aware that much of the literature on Bollywood suggests that it is infused with a strong sense of pro-Indian, Hindu nationalism (see, for example, Dickey, 1993; Mitra, 1999; Vasudevan, 2000), I began to construct research questions that examined how such themes might be interpreted by viewers who were both inside/outside the group being depicted in such movies. 
I approached this research then as someone who was also, in essence, both inside and outside the group under study. I was of approximately the same ethnicity and age as my participants; in some cases we shared a religion. In some cases, interviewees were infrequent viewers of Bollywood such as myself, while others ranged from avid to utterly indifferent. Some of the participants, with educational backgrounds or interests not dissimilar to my own, offered an analysis of Bollywood that was thoughtful and insightful, while others clearly did not perceive any greater depth in the films and could not comment on them at length. The individuals being interviewed at any given time, then, helped determine the extent to which I was an insider or an outsider, although I tried to conduct myself relatively consistently in each instance. To a certain extent, both interviewer and interviewee contribute to a state of affairs where the investigator must contend with "the knots of place and biography and...deconstruct the dualities of power and antipower, hegemony and resistance, and insider and outsider to reveal and describe how our representations of the world and those who live there are indeed positionally organized" (Macbeth, 2001, p. 38).

Planning Ends, Research Begins: Adjustments and Accommodations

Thus, in embarking on this research, I had a number of factors to keep in mind, and some changes did occur along the way. I began by recruiting participants, one of the most time-consuming aspects of the process. I contacted university administrators at Simon Fraser University and asked them to forward a recruitment message by e-mail to students in larger departments. I e-mailed student associations, community organizations and religious groups that identified themselves with any connection to Islam, Hinduism or Sikhism and/or India, Pakistan or other parts of South Asia. Responses to these were 
almost non-existent; some had obsolete contact information posted on their websites, so that messages were rejected, while one or two did make contact to say that they did not know of anyone who could participate. Most did not reply at all, even following subsequent messages. The most successful avenue here proved to be recruiting through a network of contacts. Most of my friends, family members and colleagues were not eligible to participate but they passed on recruiting messages to their own friends, acquaintances and co-workers in Toronto, Vancouver and Ottawa, and where possible, provided contact information for local groups that might be able to assist. The latter technique yielded no assistance, as groups contacted were as non-responsive as those I had initially e-mailed, but the recruiting of individuals through my own contacts did garner some response.

The process did prove to be slow, however. E-mails were sent to a wide variety of people, not all of whom met the criteria. Several were older than 19-29 years of age; a few had moved to Canada after the age of five. In retrospect, it might have been advantageous to loosen the restrictions on this and perhaps accept a slightly older age, but at the time, in the interests of consistency, I maintained this requirement and excluded two or three participants for that reason. I was also hampered by the need to schedule times that were convenient, as well as by the need to travel between cities, which became more of an issue than I anticipated when some of the individuals who had agreed to attend focus groups did not do so on the arranged dates. Thus, while I began recruiting in fall 2005, and conducted my first focus group in early 2006, the interviewing process extended all the way into the spring of 2007 as I tried to arrange those interviews that I had been unable to obtain in the early stages. 
The first focus group, projected to be comprised of roughly 5 people, was held in Ottawa and consisted of only 3 . However, what this group lacked in numbers, it provided in detailed insights and commentaries on citizenship, multiculturalism and ethnicity, a trend that was often echoed throughout the project. In Toronto and Vancouver, projected groups of 8-10 individuals gave way to small groups comprised of 2-4 people or even to individual interviews. This was clearly a challenge in terms of maintaining the methodology that I had originally selected. After much consideration, I had chosen to conduct focus group interviews, employing written questionnaires and sample questions that were planned around this circumstance. My expectation and hope had been twofold: first, I wanted to interview the maximum number of participants at once, in order to cut down on the costs of travel, and second, I also hoped that conversation between participants might generate useful observations. The first group, cut in size from 5 to 3 , was not as problematic as subsequent ones where the intended and the actual numbers varied more substantially. In fact, that group had originally been intended as a pilot as I considered whether or not to include Ottawa. The outcome was unexpected in that those participants provided some of the most insightful commentary found throughout the entire process. They did indeed respond to each other, sometimes in relevant ways, sometimes not at all, but they managed to generate a fairly lengthy and in-depth discussion of the topic at hand, offering diverse viewpoints. Accordingly, that one focus group was sufficient to convince me that Ottawa should be included in the study.

However, I hoped that Toronto and Vancouver would help me recoup the numbers that were not present in Ottawa. The Ottawa experience was useful in showing me that groups of $8-10$ were simply not feasible. Transcribing the conversation of the 3 
participants in Ottawa was enough of a challenge. In Toronto, I tried to work around this problem by scheduling two consecutive groups of 4-5 people each. On the day of the focus group, some participants simply could not make it, while others did not follow up with me at all. Left with one participant in the first group, I proceeded to interview her using the same methodology I had already employed in Ottawa, as I felt that I did not have the option of asking her to return on another day for a potential focus group, especially as the turnout might be similar. This proved to be fruitful and I then proceeded to do the same when participants arrived for the next focus group. Again, only 2 of the projected 4 arrived.

Clearly, the situation was not ideal, nor was the solution. I have suggested throughout this study that I conducted individual interviews, and this is true in the sense that I was often left to conduct interviews with one person at a time, rather than working with a group. However, I had spent some time developing my methodology for focus groups. Left in a position where some participants appeared individually, I decided that I could not let the opportunity go by. I did return to Toronto and Vancouver on other occasions, but there was a limit to the time and money that could be invested in repeated trips in the event that participants did not appear. Where possible, then, I interviewed even those respondents who were now effectively focus groups of one. I employed the same questions and methods I had originally designed, and that I used when I did manage to secure a focus group. This at least provided some consistency on my end and still managed to produce good results.

In total, I conducted four group interviews, with one group of 3 in Ottawa, one group of 2 in Toronto, one group of 4 and one group of 2 in Vancouver. The remaining 
interviews were all individual. In cases where participants absolutely could not make themselves available, which were rare, I conducted one interview by telephone and two through e-mail/mail, with the latter providing contact information in case further discussion was required. The majority of interviews, however, were held in person. There were positive and negative aspects of holding group and individual interviews; in some of the individual interviews, in-depth feedback emerged, providing a level of detail which made follow-up interviews unnecessary. Such depth was also found in the group interviews, but at times tangential points were inserted into some of the group discussions and in one particular case, a respondent seemed inclined to align her answers largely with those of her co-interviewee, a woman who was more confident and definite in her responses. This was fortunately not a significant issue in most cases, although it is a common danger of group interviews. Participants in these group interviews, similar to those in the individual ones, varied widely in terms of how much they had to say, and with what level of insight. The extent to which individuals were willing to share personal sentiments and insights did not seem noticeably different from one format to the next, which may be true at least in part because the groups were small and held in relatively private locations.

Interviewees in groups were asked to respond to the same questions as individual interviewees, and all completed the same questionnaires. I started with the basic questions found in Appendix C, but where necessary, I added questions for the purposes of clarification or to elicit further information on an interesting point that was raised. In some cases, participants spontaneously raised and expanded upon points of their own while answering a particular question. For instance, in discussing a selected film, a 
respondent in one Vancouver group mentioned the portrayal of gender, sparking an animated discussion of gender relations in South Asian culture that occupied at least ten minutes and then recurred throughout the remaining questions and answers. Similarly, the first group members in Ottawa lapsed into discussions amongst themselves at times, commenting on their own personal histories of migration and integration at some length, comparing childhood experiences, and offering film recommendations, a type of conversation that also occurred in an individual interview held in Toronto. In terms of time and breadth, then, these interviews all varied considerably. The first group interview in Ottawa was nearly three hours, including the time needed to complete questionnaires, and the larger group interview in Vancouver was over an hour and a half. However, the group of two in Vancouver took no more than 20-25 minutes, while individual interviews ranged anywhere from 20 minutes to an hour and a half.

There was no predicting which interviews would take the longest, but a depth of detail did emerge in some of the group and individual interviews that was surprising. While I was disappointed by the fact that my groups were not nearly as large as I had hoped - I had hoped to hold groups of 8-10 Muslim participants in Toronto and Vancouver, with smaller groups of non-Muslims in both cities, and a small pilot group in Ottawa - the level of insight, and the type of insight, that emerged in some of the smaller groups and the individual interviews also suggested to me that larger groups might not have been manageable. In the interviews I did hold, everyone had a chance to speak and sometimes even quiet interviewees offered valuable commentaries. Ultimately, although I would have preferred a larger number of interviewees, I felt that the 22 who did participate gave me a wide variety of viewpoints, some of which were unexpected, as 
well as depth and detail that helped highlight points whose salience I had not realized before beginning the interviews. As I realized from looking at several previous studies, there was no exact number of interviewees that would provide me with all of the possible answers. In interviewing Muslim women in Toronto, Khan (2000) discovered repetition and redundancy after 16 interviews, reporting ultimately on 14; Desai (2005) used 16 interviews in her study of South Asian American youth in New York and New Jersey; Durham (2004) settled on conducting 3 focus groups at different times with the same 5 girls, and then following up with individual interviews. In the end, I had 10 people who participated in individual interviews and another 12 who participated through groups.

Groups were not divided on the basis of gender, country of origin or religious identification, and this actually proved to be rather interesting. Interviewees sometimes explained religion and culture to others, as an aside, in ways that were illuminating to me as I observed and took notes. This was one of the advantages of the group interviews: at times, the participants addressed one another's responses and were prompted into new revelations by these. On occasion, the group dynamic seemed to facilitate commentary from respondents who might otherwise have been quiet, causing them to speak in response to a particular point. In the very first interview, in fact, the participants seemed to drive the discussion and to continually raise new points through talking to one another, while a group of young women in Vancouver engaged in a prolonged and animated conversation about the questions that were being asked, but they also moved beyond these in their shared observations regarding ethnicity, religion and gender. Not all of what they raised was strictly relevant to the study; at times, they talked about perceived injustices within their families or their concerns about the future, but they also peppered 
these discussions with remarks that were pertinent, fascinating, and demonstrated considerable overlap between participants. Rapley's observation, then, that interviews are "spaces of finely co-ordinated interactional work in which the talk of both speakers is central to producing the interview" (2001, p. 306, emphasis in original), is true but can be extended to this situation, where the talk of every speaker proved to be essential and valuable.

Early in the research process, I decided not to prompt particular responses from interviewees by suggesting films of significance or highlighting relevant themes in media. I tried to stand by this decision in actual practice and generally did so, with the exception of times when respondents seemed at a loss and required an illustrative example. This approach may have been the reason that some interviewees did not provide expansive answers to the questions that related to media, while others were able and willing to go into considerable detail with minimal prompting. Some participants were a bit cautious about responding to queries regarding media that may have influenced them, seemingly rejecting the notion of media effects, while others answered this without any hesitation. For the first group, subsequent questions using different wording, as well as their own conversation and observations throughout the interview, seemed to produce better responses. I tried to steer away from suggestions of media effects in the remaining interviews, explaining instead that the questions about media were intended to evaluate the importance, utility or significance of various media. This seemed to alleviate some concerns.

In total, the 22 people to whom I spoke included 11 Muslims, 5 Hindus, 4 Sikhs and 2 Christians (see Table 1 at the end of this chapter). Their ages ranged from 22 to 29 
and the majority were born in Canada, with 2 or 3 exceptions. 4 traced their ancestry back to Pakistan although one of these also noted a familial history of migration that involved Burma, Pakistan and Canada. 11 identified Indian origins only and another 7 noted Indian ancestry combined with a history of African migration. There were more young women than men, with only 5 males in the total group. As Gillespie notes with some regret in her own study, male participation can be more difficult to secure, particularly for female researchers (1995, pp. 71-72). Even with the best of intentions, my own study, like hers, is informed more strongly by young women than by young men. The representation by city was almost equal for Vancouver and Toronto, with 9 participants in the first and 8 in the second, followed by 5 for Ottawa, although not surprisingly some individuals identified with more than one place of residence, especially if they were students or had recently moved to assume a new job. This did present limited, anecdotal opportunities to contrast the cities, as interviewees raised comparisons on their own. However, as mentioned previously, the sample per city was too small to allow for any real generalization. Although I think the individual observations still carry merit and points of interest, the use of the different sites tended to confirm some general conclusions rather than provide a means of comparison. As I mention in the following chapters, key findings around national identification, beliefs about gender and about stereotyping or lack of realism in Indian cinema tended to repeat themselves across cities, suggesting that these were relatively consistent.

Overall, there were certain commonalities that recurred in the participants' answers although very few responses were universally the same. Within the group, there remained sufficient difference to render it almost impossible to offer generalizations 
about religious groups. However, there was one factor that did appear to be unifying: the Sikh and Muslim respondents were often more critical about the media they viewed, including Bollywood, a trend that appeared attributable to a pervasive consciousness about outsider status. While these young people were able to consume many different media and enjoy them, they seemed more sensitive to inadequacies of representation, and, as Ferguson describes below, they indicated that these shortcomings were not new but longstanding and pervasive.

Sherry Devereux Ferguson, responding to critics who characterize Canadian youth as apathetic and possibly antisocial (2002, p. 5), cites the opinion of teachers who argue that perceived apathy may stem from the inability of social institutions to address a diverse young population: "young people should be allowed to bring their own multicultural stories and heritage into the classrooms and to learn about citizenship by becoming active in political rallies and institutions (rather than just reading about the civic rights of Canadians)" (2002, p. 6). Bollywood films may provide some of these multicultural stories, but if not, other forms of media or socializing influences could be considered important by these respondents. The subject matter of the dissertation continues to be Bollywood cinema, but in cases where the messages embedded within these films are not being received as they are presumably intended, I attempted to discover why this was the case, and to know what alternatives are favoured by these participants.

Regardless of the answer, I also sought to ascertain whether factors related to the viewing of these films are as important as the films themselves. For example, Gillespie (1995) suggests that the viewing of Indian films is an important family activity for some 
Punjabi youth living in diaspora, and may provide a gateway for discussion of other cultural and religious matters. Similarly, Pendakur notes that in India, movie-going "is still very much a family affair," although he adds that in India, the experience of visiting a theatre with family or friends is a very enjoyable social activity $(2003$, p. 97), while many of the participants here highlighted such viewing as a domestic, familial activity. This may well be a function of the difference between living in or outside South Asia, as films tend to circulate quickly throughout the diaspora on pirated DVDs, viewed easily at home by a large number of people. Accordingly, questions related to the context of viewing were asked and some of the interviewees elaborated further on this of their own accord, indicating that the reasons for viewing were not necessarily linked to the content as much as the experience itself. The experiences were different for many of the participants but family and cross-generational bridge-building were clearly key in a number of cases, and it was also apparent that film watching was linked to other discussions or activities, as discussed further in Chapter 7. While few of the participants cited a level of engagement quite as pronounced as that described by Pendakur (2003) in his discussion of cinema-going in India, where viewers may dance, use musical instruments or recite dialogue while watching, nonetheless it appears that viewing is far from a passive activity for many of the families, affirming the belief that "the cinematic experience and meaning-making by the audience is not idle, analytic activity but real engagement with the film" (p. 97).

At times, such real engagement is neither achieved nor desired, and in some cases participants attempted to offer alternative media that would satisfy their needs, or to explain why Bollywood fell so far short of accomplishing this. Others gave answers that 
corresponded extremely strongly with Jigna Desai's findings following her own study of second-generation immigrant youth in the United States:

Several second-generation South Asian-American viewers in my forthcoming study on the consumption of Indian cinema reported that the films function performatively and pedagogically in that they teach rituals, traditions, and social practices as well as identifications. These films are ethnographic and pedagogical for multiple audiences. In addition to Western viewers, South Asian diasporic viewers also may view these films as documents recording South Asian or Indian cultural practices. Watching films is identified as pedagogical in these viewers' method of learning about India and Indian culture, what it means to be Indian; it is also a lesson in how to be good consumers, as some commented on how they watch films to get ideas about the latest fashions in India. In this manner, visual media, especially cinema, functions as a significant site in constructing and disseminating discourses on weddings and marriage, family, and culture. (2004, p. 221)

These same themes came through strongly in my own investigation, although they were also juxtaposed against the cynicism and wariness of some viewers who felt that these practices were depicted against an unrealistic cultural backdrop that fed misconceptions about India. At times, even the factors that participants spoke of in a dismissive fashion proved to be significant and meaningful.

For the most part, answers were thoughtful and revealing but there were few predictors for what the responses would be, as interviewees of the same religious background, gender or age could still vary widely in many of their observations. Even heavy viewing did not indicate the eventual answers, as some heavy viewers were entirely uncritical and others were highly analytical. Some of the salient points that emerged, such as discomfort with increasing sexuality and revealing clothing, were not ones I had necessarily anticipated as carrying such weight, yet they came up persistently over time, and interviewees whose lack of familiarity with Bollywood might have been seen as a drawback sometimes proved to be of enormous assistance. 
Participants whose approach vis-à-vis Bollywood was entirely oppositional also offered revealing commentary when explaining the source of their disaffection and light viewers, despite referring to their input rather deprecatingly, sometimes raised highly pertinent issues around identity construction and nationalism. One such viewer spoke with definite feeling about his commitment to a Canadian identity, and noted the way that differing linguistic ability separated him from his parents when considering attachment to South Asian culture. One young woman who denied being influenced by media in any way at all, and who rarely watched Bollywood, began the discussion by insisting that she had little to contribute, but in passing made comments on her struggle to achieve a true Indian identity, the way she used some media and cultural forms (books, dance, language) to return to her roots and her desire to transmit some sense of ethnic identity to her children. In turn, her observations prompted her fellow interviewees to raise questions around class and migration, a framing which seemed to inspire her to interpret her thoughts and situation in ways that she had not done previously. In fact, in a later conversation, she suggested to me that she had never thought of many of these points before and found herself engaging with them following the interview, a comment that other participants made as well. This echoed some of what I glimpsed in Jiwani's (1989) interview transcripts, where her line of questioning prompted respondents to view ethnicity and race in different ways, with some of them modifying their understanding of ethnic origin and cultural practices following her inquiries.

The interviewing in this case was not such a pronounced two-way process, but it did seem to provide some positive outcomes for the individuals concerned. The interviews offered a framework for conversation that benefited some participants who 
were able to articulate thoughts about identity and media for the first time, and to meet others who grappled with the same issues. The benefits of such interviews for me is clear and extended even beyond the academic questions that were raised, as I am no stranger to the kinds of contradictions and complexities that these participants unearthed. The interviews did not provide definite, closed, static answers for me or, most likely, for them, but they did offer lucid commentary on issues such as being Canadian, holding insider/outsider status in home/host society, juggling competing societal pressures and the significance and/or shortcomings of a number of media. These views are detailed more extensively in the following chapter, indicating not only the percipience of these individuals, but the promise encapsulated in their clear-sighted ability to detect problems and their resolution to overcome them. 
Table 1: Participant demographic information

\begin{tabular}{|c|c|c|c|c|c|}
\hline Participant ID & Age & Gender & City & Ethnicity & Religion \\
\hline A1 & 22 & $F$ & Ottawa & Pakistani & Muslim \\
\hline A2 & 23 & $\mathrm{M}$ & Ottawa & Pakistani/Burmese & Muslim \\
\hline A3 & 29 & $\mathrm{~F}$ & Ottawa & Indian & Hindu \\
\hline $\mathrm{B} 1$ & 24 & $\mathrm{~F}$ & Vancouver & Indian (via E. Africa) & Muslim \\
\hline $\mathrm{B} 2$ & 22 & $\mathrm{~F}$ & Vancouver & Indian (via E. Africa) & Muslim \\
\hline B3 & 22 & $\mathrm{~F}$ & Vancouver & Indian (via E. Africa) & Muslim \\
\hline B4 & 24 & F & Vancouver & Indian & Sikh \\
\hline $\mathrm{C} 1$ & 26 & $\mathrm{~F}$ & Vancouver & Indian & Christian \\
\hline $\mathrm{C} 2$ & 27 & $\bar{M}$ & Vancouver & Indian & Christian \\
\hline $\mathrm{D} 1$ & 25 & $\mathrm{~F}$ & Toronto & Indian & Sikh \\
\hline $\mathrm{D} 2$ & 26 & $\mathrm{~F}$ & Toronto & Indian & Hindu \\
\hline$\overline{E 1}$ & 29 & $\mathrm{~F}$ & Vancouver & Indian (via E. Africa) & Muslim \\
\hline E2 & 26 & $\mathrm{~F}$ & Toronto & Indian & Sikh \\
\hline E3 & 27 & $\mathrm{M}$ & Ottawa & Indian (via E. Africa) & Muslim \\
\hline $\mathrm{E} 4$ & 27 & $\mathrm{~F}$ & Vancouver & Indian (via E. Africa) & Muslim \\
\hline E5 & 28 & $\mathrm{M}$ & Vancouver & Indian & Hindu \\
\hline E6 & 29 & $\mathrm{~F}$ & Toronto & Indian & Sikh \\
\hline E7 & 29 & $\mathrm{M}$ & Ottawa & Indian (via E. Africa) & Muslim \\
\hline E8 & 26 & $F$ & Toronto & Pakistani & Muslim \\
\hline E9 & 29 & $\mathrm{~F}$ & Toronto & Pakistani & Muslim \\
\hline E10 & 26 & $\mathrm{~F}$ & Toronto & Indian & Hindu \\
\hline E11 & 29 & $\mathrm{~F}$ & Toronto & Indian & Hindu \\
\hline
\end{tabular}




\section{Chapter 7}

\section{"But, I dream in Canadian": Constructing and Maintaining Plural Identities}

When I say that my mother dreamed in Canadian, it is part of an expression of hope in the potential of the Canadian Charter of Rights and Freedoms, and in the individual human rights and obligations that this document entails. The Charter does not express the society that we have, in my opinion, but the society we glimpse, and that we each create in our day-to-day choices, and in the actions we take within our communities. Where a true multicultural society exists in Canada, it exists in the choices and consciousness of the people to see minor difference for what it is, and to know that the rights we hold are equal. (Thien, 2003, p. A13)

The construction of identity for minorities in Canada is a question that has attracted attention for some time, and while some argue that integration and belonging come with increasing ease to immigrants and more particularly their children, others suggest that there are some individuals who are resistant to all attempts to fold them into the fabric of society. This study does not seek to explore every possible angle of identity construction, but it does have a consistent focus on the way media may contribute to the formation of a national identity, and the role that ethnicity and religion may play in this process.

In the discussion that follows, 22 young Canadians of South Asian origin speak on these topics for themselves, articulating their thoughts on being Canadian, on having South Asian ethnicity, on the influences that shaped them, and their reading of media that attempt to capture their attention and even, at times, their reality. Their answers vary in some respects, especially in their interpretation of the content and cultural relevance of media, including but not limited to Bollywood film, which some young adults considered an essential part of their upbringing and others dismissed as unrealistic and distorted. Some of these divisions are explained below in the participants' terms, which are often perceptive and insightful. Aside from this, there are also points of almost universal 
agreement, particularly concerning their sense of nationalism and nationality. Their thoughts in this regard seem to turn aside concerns about young people who refuse to fit into Canadian society; indeed, while they do make routine compromises in order to accommodate competing community demands and walk, to paraphrase Amita Handa (2003), a cultural tightrope, they reject attempts to exclude them from Canadian society on the basis of their ethnicity or religion.

Staunchly Canadian, clear-eyed about the cultural challenges they must face, these young people are indeed exemplars of "the Canada we are becoming. It is fashioned by the now-grown children of immigrants from 210 countries, who are blending the roots of their past with the nation of their future" (Anderssen \& Valpy, 2003, p. A8). They are not blind to the challenges of coming from one cultural tradition and having been raised in another, yet they would likely echo Madeline Thien's contention above that this existential quandary does not in any way diminish their Canadianness or their right to assert cultural authenticity within their respective ethnic and religious communities. Answering a number of questions on ethnicity, nationality and media, they indicated clearly that they know what difference is, both as they see it depicted onscreen and as they view it within their overlapping communities, and like Thien, they understand this layered sense of difference as part of their selves and part of their country. The participants in this study speak to a specific segment of society, and are not wholly representative of all immigrants or descendants of immigrants, yet their explanations of how they are arriving at a sense of self, and the strategies they employ in crafting their future, including the use of various media such as Bollywood cinema, contain lessons and insights whose significance transfers well beyond themselves or this moment in time. 
They speak, in fact, to all those who, like Thien and her mother, might answer individuals who question their sense of belonging by responding simply, "But, I dream in Canadian." "Canada is home": Articulating National Identity

$\mathrm{A} 2^{4}$ : I don't typically use the hyphenated term, I don't have any problems with anyone using the hyphenated term, I think that's one of the perks of being Canadian, you can use the hyphenated term and that's cool. But I guess my rationale behind not using it is just that being Canadian is the ultimate unifier, so once you're here-and also, given the fact that I was born here, you know, I...regardless of me not knowing necessarily what Canadian identity is, Canada is home and I'm Canadian. I've always felt really strongly about it. And almost, I guess, if you are going to nitpick about it, then, you know, I'd much rather refer to myself as a Canadian Pakistani or Canadian Burmese rather than a PakistaniCanadian type deal, because I feel the Canadian part should trump anything else.

The questionnaires and the interview in this study commenced with inquiries regarding the identification of nationality, inquiries that were simple for some to answer but more complicated for others. All of the participants described themselves as Canadian and considered themselves Canadian, but also commented that they sometimes employed different answers depending on the context. When travelling outside of Canada, nearly all would identify as Canadian first if asked. Some interviewees pointed out that they had no choice to identify as anything else when in South Asia, for instance, because the difference in their accents, dress or demeanour seemed to function as markers that they were not residents of a South Asian society. However, a number of participants noted, often with humour, that they were forced to elaborate on the identifier Canadian when speaking to others within the country itself. Despite their own belief that they were Canadian, they were asked frequently by others of South Asian origin or by non-South Asians about their real nationality. In the first case, those of South Asian origin seemed to be curious if they possessed similar backgrounds; in the second case, the query carried an

\footnotetext{
${ }^{4}$ To protect anonymity, each participant has been assigned a specific letter-number combination as an identifier. The letter $\mathrm{F}$ is used to identify the interviewer where applicable.
} 
embedded assumption that to be a minority in Canada disqualifies one from being simply Canadian. Some addressed such inquiries with hostility while others merely expanded by commenting on their birthplace or that of their parents or grandparents, but their assertion that they are Canadian, no matter the skepticism they encounter, appears to validate Anderssen and Valpy's conclusion about integration and nationalism:

with each generation, Canadians in general become more comfortable calling themselves Canadians. The youngest are most likely to do so, with 40 per cent of 20 s listing at least part of their ethnic origin as Canadian in the 2001 census, compared with 32 per cent of those over 65. (2003, p. A9)

Not only are these young Canadians increasingly comfortable describing themselves as such, they have also developed strategies to combat those who disagree. There were situations in which participants recognized a legitimate route of inquiry when questions about nationality arose, but for the most part they viewed such requests for information as a way of denying their identity, a process in which they would not engage. A3, a young woman in Ottawa, clarified the reasoning behind the inevitable question, which was also the root of her own general resistance to answering it:

Nationality would be more Canadian - absolutely it would be Canadian, and ethnicity - the only time the question comes up, what nationality are you, they're always aiming to ask where your family is from, right? They're looking for the answer Pakistani or Indian. Even though I know that I'm Canadian and my nationality is Canadian, absolutely, you realize what type of answer they're looking for.

Similarly, E4, who is also Canadian-born and whose parents migrated from East Africa, said, "I make a point of saying that I'm a Canadian, and if they seem to imply well, you're brown, you can't be Canadian, then, if pushed and depending on who it is, I'll go into the whole history of India and East Africa. But most of the time I keep repeating that I'm Canadian." Likewise, E3 said firmly, "I always identify myself as Canadian," and 
went on to explain that the reason he never changed this answer, even in a different context, was because "the inquiry is usually asking me, no, but what are you really?" and hence "my response doesn't change until they ask me the right question, which is, what's your ethnic background?"

E8, whose appearance and name are not obviously South Asian, used this to her advantage, refusing to answer the question under most circumstances. She would occasionally relent for other South Asians, explaining she felt they were less likely to judge her than non-South Asians, who she thought carried pre-existing biases about her ancestry (Pakistani) and religion (Islam). B4, whose entire interview indicated a similar degree of resistance to others' desire to categorize her, nonetheless conceded that at times she found it necessary to answer questions about nationality as Indo-Canadian, in part because the question was rarely phrased directly as a formal inquiry about nationalism. Like many respondents, she commented that the question was often-sometimes naggingly-posed as "What are you?" and she felt that "Canadian" clearly did not satisfy those who would ask the question in such a way. She expressed this with a mixture of exasperation and resignation, whereas B1, who was equally aware of these tendencies, seemed to take a rather playful, inconsistent approach. Canadian-born and of Indian ancestry, the daughter of African-born immigrants, she said that her typical answer was Indian, followed by further explanation if pressed. She was the only respondent to give this answer, which she explained by saying that she felt close to this lineage. However, at times, she would even use African, which she employed mainly to puzzle her interlocutors, not because she felt a particularly resonant connection to East Africa. 
A1, who was born outside of Canada and whose parents, as migrants who moved from India to Pakistan to Canada, had their own complicated relationship with national identity, also took a more relaxed approach to the question but unlike B1, she seemed to feel that a certain amount of effort—sometimes too much—went into answering it:

Sometimes I find that with South Asians who are first-generation, who have just immigrated, when they're talking to me, they'll do that, they'll say, well, where are you really from? They don't understand that I'm Canadian because they want to befriend me or something like that [laughs]. So they'll do that. I find that people who are like me, who are second-generation, they don't do that as much. If I want to just leave it that I'm Canadian, or that I'm from Toronto, they'll leave it at that.

Al's comments are significant on several levels. On the one hand, she indicated a kind of sympathetic current of thought amongst second-generation Canadians, who are more able than their elders to leave aside the question of ethnic difference, and this impression was echoed throughout the study by a number of individuals. She also suggested that older Canadians of South Asian origin may experience difficulty in understanding Canada as her primary residence or national identifier, and in her conclusion, as well as in comments not excerpted here, she mentioned that she experienced weariness at times with the repeated discussions of her national and ethnic origins.

A2's insistence that he is Canadian above all does not speak of this weariness, merely of his determination to be accepted for who he is, and to have Canada fulfil the promise of its vision of itself. This theme was implied on a number of occasions: although the state appears to accept plurality, the individuals within it must fight repeatedly to enforce this right. Young people such as A2 were prepared to mount this struggle, but they were also aware that it could be a continuous one. A2 dismissed the possibility of hyphenation, although he does not display criticism or hostility of those 
who embrace that choice, but like E7, quoted below, he sees himself as a product of not simply a place, but a moment in time, the Trudeau era, when Canada sought to define itself as an inclusive, multicultural nation:

The reason I identify so strongly as Canadian is that Canada allows you, by law, to identify with any culture and the country must accept it; if anything, the ability to do this makes me embrace my Canadian identity even more strongly. I never need to hyphenate; I can always say, I'm Canadian.

Similarly, asked if he saw any relation between nationality, ethnicity or religion, or whether these are completely separate, E3 replied thoughtfully, "I think there's a linkage, because obviously, your-I think especially being Canadian is well-defined by the fact that you can maintain your religious identity, your ethnic identity, and that's what makes one Canadian." Others separated nationality from ethnicity and religion, but saw the last two as intertwined, with at least two Sikh participants explaining that in their lives, religion and culture demonstrated considerable overlap.

Indeed, following some rumination by A1 regarding her sense that she does not fully belong to either Pakistan or Canada, her fellow interviewee A3 interjected that her own references to belonging had more to do with culture than with nationalism, a distinction that A1 seemed to think was arbitrary at times, since she had been taught to regard these as interwoven. A1 was one of very few interviewees who had been raised to be fervently nationalistic about her parents' home country, Pakistan, a place where she was taken for visits and one which was evoked frequently in her Toronto home. Over time she had become self-conscious regarding this process and spoke of the results in a way that indicated a greater degree of confusion and analysis than many others expressed: 
A1: I still don't feel like I belong there [in Pakistan]. Because the culture I've created for myself is a combination of the culture here and like...it's just totally different. It just can't be that culture and then this culture, because they're just sort of combined, like this big ball.

A3: Agreed. I think for all of us.

A2: ...I think what happens with us a lot of the time is we're just divided. It's like, India's supposed to be home, or Pakistan's supposed to be home, but Canada's home. But then, Canada's not really home, and I think we ultimately get really screwed in the process, because we're sitting at this transitional stage where yes, Canada is home, but then is India or Pakistan really home?

Clearly then, nationalism was still complicated for some respondents, despite the fact that they were fully integrated into Canadian society in a number of ways and would have identified themselves as Canadian with little hesitation or, as Al suggested when describing her travels in Pakistan, would have been identified as such out of necessity, due to obvious markers of difference. Speaking in the Canadian context, D2 also indicated her childhood awareness that she was different in significant ways, and she was one of the few to say that her answer about nationality would have changed over the years, linking her sense of being an outsider in Canada to her belief that she was more Indian:

I think growing up, because of reasons like racism and xenophobia, I think I definitely would have identified as being Indian more than Canadian. I never felt white, I never had blonde hair, blue eyes. But as I was growing up, and perhaps more interested in the reasons I would have felt that way, I started feeling more comfortable saying Canadian.

This comment serves as a useful reminder of the evolution that takes place among young people who are sorting out questions of identity. A few indicated their confusion or discomfort during childhood, as they grappled with the question of how they could remain Canadian when they were also different in noticeable ways from their classmates or playmates. For most, this discomfort eventually diminished, even if it did not 
disappear, but D2, who clearly grew into a confident and articulate young woman, had evidently internalized beliefs over what constituted a true Canadian. In fact, although most participants were generally quick to assert a Canadian identity, one which they saw as chiefly national, not ethnic, there was some evidence that they had been affected by implied arguments that Canadian nationalism is the purview of white Canadians. Articles such as Howard-Hassman's (1999), with her suggestion that an ethnic Canadian identity exists, skirt around this particular question of race, instead offering the possibility that ethnic Canadians are bound together by their common language-in her commentary, this is simply English-and by the dominance of Christianity, which provides some commonalities even for those who do not actively practice. This argument may sound delimiting but Howard-Hassman claims that her goals are strictly integrative; most people raised largely or exclusively in Canada, she says - not unlike the young people participating in the current study-become ethnic Canadians (1999, p. 524). They do this, she seems to say, against all odds: "both public policy and much academic analysis conspire to prevent Canadians from recognizing this by insisting that their 'ethnic' identity must be that of their ancestors" (1999, p. 524). The danger of encouraging Canadians to identify their ethnicity in this way, she persists, is that it may "render it difficult to instill a sense of Canadian identity in the population at large" (1999, p. 524), a suggestion that is repeated in a different form by Reitz and Banerjee's (2007) conclusion that second-generation immigrant youth fail to identify as Canadians, an observation based on their inquiries into the ethnic origins of these young people. In making this claim, Reitz and Banerjee seem to align with Howard-Hassman's belief that nationality and ethnicity can be collapsed into a single category. 
Interestingly, the young adults questioned here do not appear to agree, providing thoughtful answers on their ancestry, their difficulties arriving at a clear explanation of ethnicity, and the challenges of explaining their nationality to others. Several comment on Canada as a place defined by difference, a country whose identity is diverse, plural and tolerant. They may not find it simple to identify as Canadian, South Asian and Muslim/Hindu/Sikh/Christian all at once, but they find it entirely possible and even laudable that their country supports such multi-layered definitions. There is also something laudable in Howard-Hassman's purported intention of providing a strategy for social cohesion, but in explaining her logic, she also indicates her inability to understand what ethnicity means for some: arguing that ethnicity is a social construct whose meaning can change according to circumstance, she betrays her inability to comprehend the borders that enclose ethnicity for visible minorities. Even those individuals most determined to assimilate into Canadian society cannot necessarily leave behind all markers of ethnicity. As the participants in this study note from their relatively privileged position as Canadian-raised, English-speaking citizens, they can never really leave their difference behind. Speaking of this group of second-generation Canadians, Abu-Laban and Stasiulis observe that "they have developed a hybrid sense of identity. While they are of Canadian nationality, their complex ethnicity is not simply that of being of EnglishCanadian ethnic identity" (2000, p. 482, italics in original).

In keeping with this, the participants here seem to indicate their own belief that their national identity could be Canadian while their ethnic identity was different and reflected factors such as ancestry as well as parental migration. At the same time, they were aware of the existence of Canadians who, like Howard-Hassman, seemed to be 
suggesting that some people are more Canadian than others, and that this identification may be grounded in a conflation of national and ethnic identity. Acknowledging such an argument, E2 also noted that the way she articulated her national identity changed over the years, and she too echoed the sentiment expressed by most of the participants that a question about nationality was in essence a question about one's "real" origins. Her experience within Canada was one of the more varied, as she had been raised in a small town which was not particularly diverse, then had moved later to Vancouver for a brief time followed by Toronto, whereas most participants had been raised primarily in major Canadian cities. Pluralism may not have been seen extensively in that small town, yet E2 still found ways to forge a sense of belonging. A number of participants made a point of attributing their sense of acceptance to their generational position, ushered into a Canada that had become officially multicultural under Trudeau but had truly begun to realize this policy during these interviewees' formative years. A2, speaking of the effects of multiculturalism and its significance in recent years, had this to say:

...if you were to have Indians coming in now or within the past fifteen years or twenty years ago, there's a big difference between the multiculturalism-or yeah, just the multiculturalism in Canada and what existed back then [sounds of general agreement] and the whole assimilation process versus integration process.

None of the written or verbal questions asked the participants to compare this process to that found in other countries, but the interviewees brought their own experiences to bear when explaining how Canada was unique in its acceptance of immigrants. E7 was firm in his belief that he should feel no dissonance in identifying himself as a Canadian whose religion is Islam and whose ancestry is Indian, because, as he pointed out, the only Canadians who did not come from elsewhere are aboriginals. Hence, he had the same right to live in Canada and call himself Canadian as any other settler on that land, a point 
also made by $\mathrm{E} 9$, who did complicate this relationship somewhat more by suggesting that notions of nationalism can be problematized considerably by colonialism, a fact of life that is more relevant in Canada than many allow.

However, for the most part, those who commented on Canada's shortcomings were not necessarily critical of life there. Most saw their existence there as entirely natural and preferable to the alternatives they had glimpsed elsewhere. One remarked on London, England as a place that had integrated South Asians with extraordinary thoroughness, but at least two--both Muslim-observed that they considered the immigrant experience to be notably different in the United States than it was in Canada, and generally they saw this disparity as reflecting poorly on the former. The reasons for this may be manifold, including policy, but Maira (2002) also points out the external pressures brought to bear upon American immigrants, ones from which Canadians are perhaps exempt.

Explaining the influence of right-wing nationalist Indian groups on the South Asian diaspora, Maira (2002) notes the extent to which these parties have succeeded in herding American South Asian youth into religious camps which reinforce their sense of Hinduism and nationalism without necessarily explaining the political activities to which these parties are linked in India (pp. 137-140). In Canada, young adults are perhaps less susceptible to these influences; although a few identified campaigns on the part of elders and community groups to strengthen their sense of South Asian identity or their religious identity, none commented directly on Indian politics or Indian organizations. It may be that the smaller number of South Asians attracts less attention from political parties 
abroad; it may be that these parties focus their efforts on American youth in the hopes of forging stronger ties to a country distinguished for its economic and political might.

It may also be that the explicitly multicultural, relatively moderate politics of a country such as Canada provide less fodder for right-wing nationalists than can be found in the United States. At least two individuals in this study noted the difference between being a Muslim in the United States as opposed to one in Canada, suggesting that the pressures of American nationalism combined with a distinct marginalizing process end by creating young Americans who feel less at ease with their identity and who may react to this discomfort in more extreme ways. Of course, it is far too simplistic to posit that Canadian immigrants of any generation are all well-integrated and comfortable in their skins. The young people in this study appeared to be integrated, were often welleducated, and they took pride in their country and their origins. However, few considered their identity to be entirely unproblematic. Several described a process of coming to terms with their ethnicity and religion as much as their nationality, and others offered that this process was still ongoing.

\section{Can You Go Home Again? Diasporic Youth Speak Out}

B3: You realize what your culture is when you start articulating it to other people. As much as the participants expressed their firm belief that they were truly Canadian, many were also conscious of expectations and pressures regarding their cultural authenticity as individuals of South Asian origin. Some described these pressures as familial, others as mainly external-coming from South Asian acquaintances, for instance-and several commented on this as an internal dialogue, one in which they sought constantly to reconcile their own beliefs regarding their heritage and nationality. 
Although these young people may not have been courted by nationalist groups in the manner described by Maira (2002), nonetheless a type of confusion does seem to exist in South Asian culture, where individuals, especially those living in diaspora, are warned ominously not to lose their cultural values, the rituals and markers that identify their heritage. As one journalist notes, "To be brown in a white world post-9/11 is fraught with complexity. Do you become a coconut (brown outside, white inside) to survive or do you reinvent yourself, complete with a cool new brand - desi?" (Yelaja, 2006, p. A1). The coconut accusation echoes ones commonly heard among people of other races (for example, Oreos for blacks, bananas for people of Chinese ancestry), but the sting within is the same each time: it suggests a binary way of being in which the ethnically loyal consistently pledge their allegiance to their true race while denying that they have been corrupted by the West/whiteness/Canadian culture.

For A1, this emphasis on loyalty was tripartite: her parents' decision to relocate from India to Pakistan to Canada created a strong sense of nationalism and identification with Pakistan, which they attempted to transmit to her. They taught her to embrace Pakistan as a nation, as the source of her culture, and as a place identified with her religion. They succeeded in engendering an interest in some aspects of South Asian culture but they could not engender a sense of belonging when they took her to Pakistan, promoting it as a place where she could be comfortable and could eventually live if she so chose:

A1: The more I thought about it, the more I realized, oh God, I could never, ever live here. I just can't. I just can't. I wouldn't be able to fit in here. And yeah, just coming back here, my parents were saying, how does it feel to be in Pakistan, where you're in the majority? Well, first of all, we aren't really the majority, because we're Shia Muslims, so we're a minority there even, but I said to them, you know, it really doesn't feel very different to me, it just feels like we're in little 
India or little Pakistan but expanded, like as a whole country of little Indias. It just didn't feel different, like, I just didn't feel any more of a sense of belonging there than I do here. I still felt like somewhat of an outsider. So at the end of the day, I think even though I can't just fully say I'm Canadian, I'm Pakistani-Canadian, I still can't say that my heart belongs there. I just don't know the life there. It's too different for me.

Having already stated earlier that she had created a culture for herself out of disparate elements, A1 indicated here that she acknowledges her Pakistani origins and respects them but does not feel essentially bound to Pakistan. While this sense of being inbetween, of having no clear sense of full belonging anywhere, may seem marginalizing and even discouraging, it may be the best option available for some migrants and their children. Ananda Mitra advises that these individuals "find an identity for themselves that maintains the connections with their places of origin as well as develop[ing] a particular niche for themselves in the West" $(1999$, p. 18).

Resistance, after all, is clearly futile, at least for these young people, who have moved substantially past the possibility of refusing to integrate into Canadian culture at all. As A1 makes clear, there is no option of going home again to the place of origin, at least not permanently, and virtually none of the participants addressed this possibility, even if their parents had taken them for frequent trips and they enjoyed their time there. Neither complete assimilation nor complete resistance appear desirable for these interviewees, and hence several co-exist with the question of how to fuse disparate identities, a conundrum that Mitra considers the modern dilemma of the diasporic South Asian: "It is finding that critical mix that becomes the crusade of many Indians as they increasingly feel marginalized in the Western public sphere precisely because they still 
retain many of the Indian attributes which they find very difficult to jettison" (1999, p. 204).

Some interviewees defied their traditional upbringing, rejecting what they saw as outdated or absurd customs, while others took comfort in it. The most common strategy for handling the conflicting demands of South Asian and Canadian cultures, however, seemed to be a kind of attempt at hybridization. More than one interviewee suggested that they dealt with culture clashes by adopting the aspects they enjoyed most and creating a kind of shifting mélange that worked for them, although this did not mean that they could escape the inevitable ambivalences that accompany living in a constant state of flux.

Perhaps the least ambivalent sentiment expressed by most participants was a belief that they were Canadian first but that they could not dismiss their ancestry and the influence of traditions transmitted from South Asia. As A3 put it, explaining her reaction to those who prefer to identify themselves using a hyphenated label, "if you're going to label me as something, label me as Canadian and be done with it. And if you want to add extenuating circumstances, then absolutely, I am absolutely Indian. But—pick one or the other." A3's description of her ethnicity as an extenuating circumstance was apt in some ways. She recounted a childhood experience that seemed to lean towards the highly integrated side, commenting that she was not required to learn Hindi or to attend religious classes as her peers did, although she had travelled to India and described it on one occasion as a kind of safety net, a place that she could go to if, for example, she could not find a suitable spouse in Canada and needed to seek one elsewhere. 
Neither she nor any other participants expressed any real desire to "return" to India or Pakistan permanently, eschewing the idea that this was a real point of return for them after so many years spent in Canada. However, those who had visited those places voiced their pleasure at being able to do so, and the belief that such travels contributed to their sense of self. Those travels also led to expanded insights regarding societal change, difference and their place within a diasporic patchwork of traditions and beliefs. Not surprisingly, many of the participants explained their construction of ethnic identity by making some reference to their parents or to other members of the family, although they outlined some instances where their parents' views differed starkly from theirs.

Having said that, there was a certain amount of sympathy expressed for the opinions of parents or grandparents who were raised with different societal norms, and who found it difficult to believe that those norms could change in any significant way. There was some agreement that part of the culture clash experienced with immigrant parents arose, to a certain degree, from the fact that their parents and grandparents believed that Indian society remained almost the same as it was at the point of their initial departure. A3 and A1 concur that there is some truth in this viewpoint, but A3's reaction is slightly more positive while A1 seemed more inclined to comment on ways that this refusal to change may enact itself in proscriptions on her behavior:

A3: I think that what most people think is that when our parents immigrated, their idea of India froze while India itself progressed. And so they're still clinging on to that idea. But to be honest, I like that idea. Obviously I'm biased because I grew up with it. So when I do go to India, I do see things that I think are ridiculously risqué but they're things that Indian Indians think are American and are normal, whereas I think they're way too, too much.

A1: My parents, oh my gosh, are so conservative. Even when we go to Pakistan, like, we just went, and it's just so different there now. Even like the clothes, I was looking at the display windows and stuff, they have sleeveless, and they show 
their belly, and whatnot, which we never, ever do. My parents certainly don't let me dress provocatively at all. When I'm at home, I just can't show-I can't wear a short skirt or anything, and there they don't care, like, I mean, still, you would get stared at, but like in Karachi and everything, apparently people do this, they wear miniskirts.

Opinions differed among the informants regarding the exact degree of difference between culture in South Asia and South Asian culture as it unfolded in diaspora, but most tended to believe that it was impossible to overlook the dialectical interplay between these.

Whether or not they agreed with their parents' envisioning of home and culture — and it is worth noting that several participants described parents who were highly integrated and who considered Canada home — nearly all suggested that it was very difficult to dismiss the role of ethnicity in their lives, and they also offered a scenario where Indians or Pakistanis in the subcontinent were influenced to some degree by the globalization of popular culture. A3, whose own ancestry is Indian, commented on the desire that some Indians might feel to assimilate into American culture, a desire that she saw as being tempered for Canadians of South Asian origin: “now that we're in Canada, we don't feel the need to try to assimilate. We already realize we're different. We know what we can and can't do."

This comment implies a high level of confidence and comfort with identity, feelings that were echoed by several others, but Al was certainly not alone when she returned again to the notion that nationalism is not cleanly delineated when one's ethnic origins are on frequent display:

I also think that it made a big difference that my grandparents grew up with us in our house and my grandma didn't, doesn't speak English at all, so that was like a big thing. Like here is my grandma, so Pakistani and, so like, just cannot integrate or whatever, so that always reminded me as well, we'd get home or she picks up the phone, and she'd be speaking Urdu, saying hello, hello, and they're like I just want to speak to someone and she can't answer back. There's no way you could 
just say Canadian when you have that whole other aspect, that cultural aspect in your home, reminding you of that.

While A1-who does speak Urdu-identified language as important in the sense that her grandmother could not speak English and this served as a constant reminder of her ethnic background, other interviewees saw loss or limitation contained in their inability to speak the language of their parents. One participant, who remarked early in his interview upon his inability to relate to Hindi-language films because of the language barrier, later indicated that he felt he had lost a great deal culturally throughout his own life, and that he had some misgivings about the fact that his children were likely to lose even more. E7, a Toronto-born resident of Ottawa, made the following observation in the questionnaire when explaining how he perceived his culture: "I've seen my heritage as being Indian but heavily influenced by my parents' East African roots. However, without fully speaking the language (Gujarati), these cultural influences have been limited." His observations were particularly pertinent as they seemed to validate those made by another Ottawa interviewee, E3, whose ethnic background was almost identical to that of E7.

Also Canadian-born, E3 was raised in an environment where his grandparents refused to speak English with him, ensuring that he became fluent in Gujarati and conversant in other Indian languages, a legacy that he cherished and identified as central to his understanding of ethnicity. While E7 seemed to feel a sense of distance from his Indian ancestry, acknowledging it but hardly immersing himself in it, E3 was far more invested in South Asian culture and norms, conducting himself with no difficulty on trips to India or neighbouring countries, for instance, and having an obvious familiarity with and enjoyment of Indian songs, films and fashions. Having said that, while E7 and E3 differed in some ways regarding their cultural activities and their level of affiliation with 
South Asian cultural norms, both said that they would only ever identify themselves as

Canadian when asked about nationality, and both were adamant about refusing to accept other characterizations.

E8 was similarly resistant to those who would deny her nationality, but her comments on the link between ethnicity and nationality were interesting because she incorporated a rather different perspective. In fact, while many of the participants tended to address only the link between ethnicity and nationality, or between religion and nationality, E8's response indicated how much thought she had given to what she saw as a kind of widespread sea change in the way the three co-existed:

They [ethnicity, religion and nationality] are intertwined just because originally, I would say my religion is very culturally interpreted. I'm going to be a little specific here, Islam is a very Arabic culture in its interpretation but I find that real Islam is not so much Arabic interpretation; it's more, it's supposed to be universal. Pakistani culture and Islamic religious values, they can intertwine, but it won't be in the more widespread or traditional way. Most countries now, including Pakistan and India, tend to redefine Islam in a very Arabic way, and the way they use the religion to define the culture has changed a lot, so the religion itself is actually redefining the culture instead of the other way around.

E8's reasons for blending the three here are clearly articulated and imply a fairly broad concern with the interpretation of her own religion, Islam, a concern that is echoed throughout the study by other young Muslims, several of whom felt that it was difficult to speak of their identity without commenting on the role of faith in their lives.

\section{Keeping the Faith: Religion and Identity}

One group in particular interested me because at least two of the members moved quickly towards the topic of religion when discussing how they articulate their nationality. Although one said that she would identify as Indian and another noted her parents' African birth, both said that in expanding further they would explain that they 
were Ismaili Muslim. This was the only group where such an interplay occurred and it took place with some consistency. There could be any number of reasons why this might be the case, including the possibility that these individuals-who were among the youngest in the study - had not given as much thought to the parsing of these identities as the other participants, but their later comments on religion and culture suggested to me that in fact they had pondered these issues before and simply saw their faith as essential to every aspect of their identity.

Their willingness to identify as Ismaili Muslim specifically in speaking to others could also be read through the lens of their geographical placement—as B4 noted, Ismailis are relatively prominent in Vancouver, especially in the suburb of Burnaby, and so to describe oneself as Ismaili may frequently evoke recognition from knowledgeable listeners who might be quick to understand their history of migration. Ismailis are present in larger numbers in Toronto and have a small community in Ottawa, but they do not appear to be as well-known in those cities as they are in Vancouver, an impression remarked upon by B4, a Vancouver Sikh who lamented that she was unable to see any Ismailis upon a visit to Toronto. Rather, she stated, she saw large numbers of Pakistani Sunni Muslims, people to whom she felt unable to relate: "I don't relate to their thinking at all, because I find there's a lot of difference in terms of how you approach a lot of social issues."

Clearly there is considerable diversity amongst Muslims in Canada, a diversity that was perhaps not reflected entirely in this study. If there is, as B4 was apparently suggesting, a pronounced conservatism among some Canadian Muslims, particularly Sunnis, this did not come out here, where few Sunnis responded to invitations to 
participate. There were, however, Muslims of Pakistani origins, and they did describe seeing such conservatism without necessarily endorsing it. E8, a Shia Ithnashri, spoke of the considerable pressures she experienced from community members when she began to explore her religion and culture more deeply and hence made decisions with which they did not agree, such as ceasing to wear a headscarf. While her parents supported her choice, other family members and friends made it clear that they saw her decision as a repudiation of her faith, something she denied. She pointed out that her attire remained modest and that she was a practising Muslim, but she no longer saw the headscarf as a crucial element of her faith. She was certainly not the only woman in the study to describe pressure to conform to communal norms around gender, but she was one of the few whose pressures were explicitly linked to differing interpretations of religion.

In fact, the scenario E8 outlined is one that perhaps aligns most clearly with popular renderings of the Muslim woman in Canada as a potential victim of masculine and communal domination, renderings that Bhimani suggests are deeply rooted in history and that reflect "the fact that Muslims and Muslim societies have not been the storytellers of their lives" (2003, p. 6). This study cannot in itself reverse that trend but there is an attempt here to allow young Muslims to speak in their own words about the role of faith in their lives. Several spoke of a resistance to negative depictions of Islam and indicated both a sense of reservation about indicating their faith to others, who might form mistaken impressions of them on that basis, and an increased sense of identity and awareness about being Muslim. Very few mentioned the events of September 11, but there seemed to be an implicit undertone to their comments that suggested their awareness of an increased marginalization and pronounced scrutiny of Muslims and 
Islam. There seemed to be an accepted understanding that Muslims had to explain themselves to others quite frequently, and in one or two interviews, there was an acknowledgement that this requirement was more pronounced for some Muslims than for others. While the participants in one group seemed to comment in passing on the conservatism of Sunni Pakistani Muslims, they also indicated a certain amount of solidarity when critiquing non-Muslims and non-South Asians who asked uninformed questions about headscarfs, arranged marriages and terrorism.

Doug Saunders (2007), writing for The Globe and Mail, indicates something similar following an interview with several young Europeans who identify as Muslim first, a viewpoint that he admits to disliking. However, probing more deeply, he uncovers signs that these young Muslims have no desire to renounce their national identity, or to work towards creating a Muslim state. Rather, with the spotlight frequently turned on their religious identity and on other Muslims around the world, they tend to be constantly aware of their faith. In fact, Saunders concludes, it is not necessarily the Muslim youth who attempt to marginalize themselves; instead, they are simply reacting to those who consistently refuse to overlook their difference: "Once we get past the hysteria and look at the facts, something becomes apparent about the Muslims: They're just like any group of immigrants, except for the stories we tell about them" (p. F3).

None of the participants here went so far as to identify themselves as Muslim first, but it was clear that several of them had given considerable thought to their positioning as Muslims in a time when such identification might evoke preconceptions on the part of others. These feelings came out even more strongly in discussions of 
Bollywood depictions of Muslims, but A2's more general rendering of his religious

identity seemed to summarize what many of the Muslim participants felt:

I do feel the need to identify the fact that I'm Muslim, I wouldn't write it down necessarily because I wouldn't want anybody to characterize me as such, but I think it is an integral part of who I am today, and how I continue to essentially choose how I proceed in my everyday ongoings as a Muslim. Now, that may be very different in terms of how a person would perceive me to be acting as a Muslim, but I feel that everything that I do on a given day is guided by the fact that yes, I am a Muslim, and I am a Canadian Muslim.

The emphasis in this study was on Islam and it is perhaps no surprise that the Muslim participants were the ones who occasionally expressed a sense that they and their copractitioners were under siege, to a certain extent. However, one interesting aspect that emerged was the willingness of the participants here to acknowledge the hybrid and pluralist legacies that many deny when discussing the history of the subcontinent.

B4, a Sikh, commented on the fact that different religious groups had co-existed harmoniously in South Asia, a fact that she believes should be more commonly known, while E2 noted that as she grows older, she has realized the influence Hinduism had on her everyday life in her Sikh parents' home. She attributes part of this to their place of birth, which was in an area adjacent to Punjab but not in it. The closeness to other Hindus may have made her parents more aware of Hindu customs and rituals, some of which they adopted. As a child, she did not understand that any distinction might exist, but as she became more aware, especially during visits to India, she realized that she had experienced a kind of dual Hindu-Sikh legacy. Several of the Muslim participants also indicated their awareness that Hindu rituals inflected their lives, although they also commented that this was something their parents participated in without fully acknowledging this influence. Indeed, a desire to understand religion more completely 
was expressed on several occasions, with many of the young people explaining that they had to seek knowledge outside of their households. This desire was not limited to religious education but religion did seem to be a powerful motivating factor for the Muslims and the Sikhs involved in the study, many of whom found their answers in formal education but a number of whom supplemented this in other ways.

Looking for Answers: Family, Education and Media

Perhaps inevitably, most of the young adults interviewed here pointed to family as one of the primary influences in their understanding of culture and religion. Nationality was occasionally tied into this but most often seemed to be filtered through the world outside their homes. Inside their homes, individuals were acculturated in a number of ways, and even those who now live separately from their parents sometimes indicated that they participated in cultural or religious rituals more often when they visited home. Whether they were raised in small towns or big cities, the influence of family was undeniable and appeared to operate in similar ways. Although the options for participating in community events are currently widespread in Vancouver and Toronto, E8 points out that this was not the case when she was growing up and immigrants were still establishing themselves, so families often had to assume considerable responsibility for educating children about religion and culture. A2 also noted the importance of family and again the importance of language was raised, although other factors evidently played a part:

A2: Family plays an integral part, especially given the fact that you're born here, that's pretty much the first touch that you have, and given the fact that, you know, at home we did speak Urdu or Hindi or whatever. That plays a role. It definitely plays a role. In terms of other stimulus? Everything, really. You're looking at stuff like mass media, you're looking at people you come in contact with, you're looking at restaurants that you go to... 
A1 agreed with this, although in her case she described a scenario where her father's insistence on maintaining national and religious pride was far more pronounced than that of other participants' parents. A3, for instance, responding to A1's comments, commented that her own growing interest in culture, or at least language, is not parentally dictated in any way, while A1 spoke later in the interview about the fact that she has developed some different notions from her parents as she has grown older and no longer feels a strict obligation to envelop herself in Pakistani Muslim culture at all times.

A1: I think definitely my parents, or my parents-or my family. This is the biggest factor, because my parents, or my dad, has always constantly stressed the idea that we're not from here. He would go on huge rants, like, we're not Canadian, we're Pakistani Muslim, everything, just from that kind of thinking, everything else that has also reminded me of what my nationality and culture is, it's because of them. So you know, we all went as a family to see our first Bollywood film because my dad wants us to know what our culture is, and I went to Sunday school so I could know what my religion is, I was told to speak in Urdu at home because, you know, this is our culture, it's maintaining that sense of pride, so everything just goes back to them, like any other factor is related to their need to remind me of who I am.

F: All right. So a very conscious kind of process then, in your family?

A1: Yeah, for sure, like propaganda [laughs].

A3: I'm getting a drive now to learn the language, my mom speaks 14 languages, my dad speaks 3 languages, no one ever spoke anything but English at home, so I never learned anything. And now the reason I'm starting to learn is not actually if I go to India, at least I'll be able to talk to people, for some reason, that probably should be a priority but it's not particularly. The reason I'm starting is so that at least my kids can learn something.

The number of times that family and community recurred as factors seemed quite natural, and these extended into related issues around language, visits to temples/ mosques/gurdwaras, travel and media. However, one other major factor arose throughout the conversations I conducted with these informants, and that was education in a variety of forms. Perhaps naïvely, I was surprised by the number of times school or education 
were raised as factors that influenced understanding of nationality and culture, although there were manifold ways in which interviewees elaborated on this answer. Some identified school as a means of assimilation or integration, teaching new immigrants or second-generation immigrants about mainstream cultural norms. Others, however, pointed to the fact that they sought answers about their ethnic roots through their education, especially at the higher levels, at least in part because their communities or families could not always supply the information they sought. A few noted that their parents or religious leaders simply did not know the history of their cultures, countries or religions well enough to educate their children outside of a limited point of view, and formal education sometimes led to those children cultivating significantly different perspectives from their parents. At the same time, E3 also suggested that school taught him that being Canadian meant adopting a pluralist philosophy, and that it was important to embrace one's own origins but also to respect the views and beliefs of others.

The young adults in this study had a broad range of educational and occupational backgrounds, and their approaches differed accordingly. E2, whose interview was filled with thoughtful insights regarding religion, culture and media, commented on the influence that school had on her critical viewing ability, saying that she would not have been able to answer a question on nationalism in Bollywood prior to a university course on South Asian studies, taken mere months before our interview:

My professor is really focused on subaltern studies and the whole construction of nationalism, and I would say, looking at Bollywood now, yeah, they really focus on nationalism, and actually encourage this idea of a homogeneous nation that is dominated by Hindu elitists.

Others were less specific than E2, but B4 expressed a belief that there was significant religious knowledge and cultural or nationalist history that she would benefit from 
learning, and since there were few avenues for her to attain this through her community, she had chosen to pursue such education independently. As with the young woman described in Maira whose desire to know the answers resulted in frustration from religious leaders or family $(2002$, p. 119), several individuals here, especially women, indicated their refusal to accept passively a state of ignorance about religion or culture. B1's group agreed that parents' understanding of religious and cultural issues is not always the same as that of their children, a gap that B1 attributed to different educational training:

B1: I also think education is a huge part of it. If you're-I'm not saying that if you're not educated you're not going to understand, but...I've also taken Indian courses too, at school, it actually opens your eyes up into a different sort of area...I was watching Mughal-e-Azam [1960] and it was right after we finished the Mughal empire period at school in my Southeast Asian class. And I watched it, and I had already watched it previously and I was getting bored, like I don't understand why they're doing this, this is crap. I watched Mughal-e-Azam after my project, and I watched the whole thing without fast forwarding it. And I understood so much more. I could relate to so many of the themes.... They're just not depicting things in fantasy, this actually happened. And there are books out there with material that can be referenced to the movie, so if I was to do a paper on it, I could definitely use that movie [laughs].

She went on to explain, with agreement from B4, that without the kind of classes she has described, she would be at a loss to understand all of her history, as the community resources currently in place emphasize only a few aspects of this:

B1: In my class, I had a lot of people that were Punjabi and that were Hindu, and there were only two of us that were Muslim, and it was like, the both of us are sitting there going, I don't really know what's happening, because with our culture, with Muslims, you don't learn about - we learn about the Mughal empire, but we don't learn about the Muslim-Hindu-Sikh friction or anything like that. The only source of knowledge that we can get besides post-secondary education in that field would be our BUI [referring to religious education at the primary and secondary levels for Ismaili Muslim youth], and they don't even teach that.

B4: Same with Sikhism. They don't teach you what happened. 
B4 was one of the participants who referred to her travels in South Asia as a way of alleviating this lack of knowledge, and travel to India and Pakistan did appear highly formative for some, strengthening their ties to what they saw as the culture of origin. E2 spoke clearly of the influence these trips had on her, and she also articulated this influence by speaking with reference to the kind of nostalgia and connectedness that might be attributed more often to a first-generation immigrant.

E2: I was taken to India quite a few times in my life, when I was growing up. The first time was when I was about seven years old, and it was actually-I think it impacted my sense of identity, and where I belong, and when I was there, the majority of my extended family was there, so I felt very connected to the community and to the country. And for years afterward, we would talk about it as though it was this nostalgic piece in our lives, and then I went back when I was twelve, and that was just as impacting.

E2's answer indicated the strongest level of emotion and impact, which could possibly be linked to her upbringing in a small town with very few other South Asians. In contrast, A1's reference to Pakistan as evoking an expanded Little India, rather than a new and exciting site of belonging, may signify that her previous exposure to Little Pakistan or Little India in Toronto blunted the significance of this in terms of her sense of belonging. However, it is also possible that A1's frame of reference and expectations were vastly removed from E2's because of her parents' emphasis on Pakistan as another home or place of settlement, while E2 was apparently subject to no such outlook.

E8 also commented upon the importance of visits to Pakistan, where she had family, but she described a shift in attitude that disturbed her and perhaps contributed to her interest in the future of Islam. While she enjoyed being in Pakistan as a child and then again as an adult, she saw an increasingly conservative form of Islam settling in there, which she interpreted as a distinct response to the events of September 11, 2001 and the 
subsequent attention to Islam and Islamic practice. Interestingly, while E8, A1 and A2 all talked about trips to Pakistan, each noted different specifics. A2 did not necessarily agree with A1's contention that Karachi was less culturally conservative than her parents believed, but he echoed her sentiment that there was no stronger sense of belonging in Pakistan than in Canada.

E3 did not describe his trips to India-most or all of which were business-related rather than familial journeys-as having a strong formative influence, but he did seem to feel a strong level of comfort, and one factor in this was his familiarity with Indian film. Not all of the participants identified Bollywood as a major influence in shaping their sense of nationality, culture or religion, but some did, and a large number did point to media influences in general. One group in Vancouver agreed that film in general was a major media influence, regardless of the category of film being viewed. Other participants suggested that film was not particularly significant, although it was interesting to note that most were able to indicate some familiarity with English-language movies that addressed Indian subject matter, such as Water (2005), Earth (1998), Bend It Like Beckham (2003) or Monsoon Wedding (2001). This did not translate into appreciating all of these films, but it was clear that the genre had considerable reach among diasporic young South Asians.

Outside of this major source of commonality, the forms of media used varied, including books (academic and literary), news and lectures (meaning lectures organized by various community groups on religious or cultural topics). Books were raised frequently, with even A3, who refused to concede that media were influential in any way 
in her life, stating at one point that she had sought out Indian-authored novels as a way of retaining her culture:

A3: But I find that, well, I'm going out with a white guy, and I found that the minute I started going out with him, I started desperately clinging on to anything Indian-

\section{A1: Really!}

A3: - and I didn't have this sort of-explicit's the wrong word, but I never made an outward effort to grab onto it as much as I did, so now I find that Indian authors and stuff, that's how I try to relate to the culture, I mean, movies are okay, but I don't watch a lot of movies...

D2 also said that she did not watch a lot of movies and favoured books, especially those by women of colour. Radio was not mentioned in questionnaires although E2 did cite it in her interview, explaining that a multicultural station had been a link to cultural practice while her family lived in a less than diverse area. B4 also mentioned these radio stations but in the specific context of relating it to the movie Salaam Namaste (2005), which featured a deejay as the heroine. While D1 did not name radio as an influence, she talked about the fact that Punjabi culture had entered the mainstream and that this resonated with her, especially when rapper Jay-Z released a popular song that included remixed segments from South Asian musician Punjabi MC. Throughout the interviews, in fact, respondents revealed ambivalence about the increased acceptability and globalization of South Asian culture, an acceptability that made them feel less selfconscious or embarrassed about embracing this culture publicly, yet also cheapened it in some ways, diminishing authenticity and causing them to question their own motivations. The following explanation from $\mathrm{E} 1$, which begins by discussing Bollywood and then broadens into a larger discussion of Hollywood and music stars, indicates the difficulty 
some felt in breaking down cultural influences to their most basic elements in order to judge which influences were acceptable and which were not:

I think just for example when I was younger, wearing an East Indian outfit in public to me was something I just could not do. I would be too embarrassed to do that whereas now as Hollywood and Bollywood sort of merged I'm more willing to do that. You know, you see Gwen Stefani wearing a little tikka on her forehead, you know what I mean? I'm more willing to go out in public dressed like that but I don't know whether that's more due to Hollywood influence or Bollywood influence.

As the following chapter reveals, then, Bollywood does have a certain amount of influence but this was hardly universal, even in the group studied here. This influence must be judged in the context of intertwined cultural factors, and it is also filtered through these.

There are no simple answers to many of the questions that were posed here, in fact, and the apparent contradictions that arose seemed to speak to the complexity of the lives that these young people lead. E8's response, like several others that were given throughout the study, is one that considers a number of factors. It dismisses no possibilities but it does not embrace any uncritically. She spoke of Toronto as a cosmopolitan space filled with promise and choice, and in doing so, she observed throughout the ways that Canada has evolved, a point made by many participants. Their lives are not unproblematic; their identities are not simple; they do not agree on everything, but they do indicate how quickly integration may occur, and how meaningful it is to minorities when they see themselves being represented in any way, even if this way is not always as rounded or developed as it might be. That elusive and well-nigh impossible element of authenticity reared its head several times, but the group itself seemed to acknowledge the futility of finding media of any kind that were entirely 
unproblematic. As some interviewees took it upon themselves to explain to me and to one another, even the most well-intentioned efforts to disclose South Asian history may leave out important elements, including the plurality and the joint legacy of suffering that many fail to acknowledge now. There was no single solution to this gap in knowledge; some filled it through books, others through film, still others through some form of education. Within this, Bollywood was able to play some part, and it was a more meaningful role than perhaps some would envision. 


\section{Chapter 8}

\section{Bollywood: Films as Meeting Ground}

The paradoxes evidently at work in Bollywood films are by no means lost on their diasporic young viewers, whose own lives encompass a network of contradictions that they find alternately puzzling and satisfying. Bollywood carried comforting familiarity for some, but was far too alien for others. A number of participants remembered growing up with Bollywood films in the background, and several described the rituals and crossgenerational conversations that unfolded around these. Language was taught and maintained through the watching of these films, and some valued it particularly for this reason. As far as the content, opinions diverged wildly although there was a notable degree of confluence around topics such as the representation of gender, which was interwoven into discussions around inequity in South Asian culture. Depictions of diaspora and of certain ethnic or religious groups were also criticized for their exaggerations and stereotypes, which were sometimes seen as direct insults to the viewers, depending on their own origins.

The complicated, tenuous relationship Bollywood has with modernity and with what it understands to be the West elicited equally complicated reactions from viewers, who alternately deplored the consumerism, the hedonism and the lack of family values seen in films addressing Western themes. At the same time, the consumerism in the films, as well as the mainstream acceptability bestowed on Bollywood-related goods and fashions, carried their own appeal for young people who had previously experienced embarrassment in relation to their ethnic identity. Individual positioning played a distinct 
role in determining interpretation and outcomes, leaving only one real conclusion:

Bollywood is as intensely problematic as it is significant in the lives of these viewers.

One of the Family: Bollywood at Home

Of the people I interviewed, most agreed that viewing Bollywood films can, as Marie Gillespie (1995) noted in her landmark study on Punjabi families living in the UK, provide a convenient and enjoyable venue for family activities. This is particularly true because differing linguistic capabilities may play a role in determining which television or film programs may be viewed by the entire family. Older members may be unable to comprehend enough English to understand the mainstream North American programming watched by young members, who may in turn struggle with Hindi or other South Asian languages used in specialty programming watched by grandparents or parents.

Bollywood films are now frequently subtitled in a number of languages such as English, Spanish, Dutch and Arabic, and also offer action and narratives which can be easily understood even without the benefit of such subtitles.

It is notable that several young adults, even those who rarely watched Bollywood, described the constant playing of these films as a kind of ubiquitous background media presence in their parents' homes or in the homes of their relatives. Some said laughingly that they ended up viewing some of the films merely because they were so omnipresent that it was hard to avoid seeing the content. In a sense, then, Bollywood managed to become a visible and accepted part of the family setting over the course of an ordinary day. It was clear that for a number of participants, family rituals constructed around Indian films, such as a regularly occurring Hindi film night, had significantly affected their watching levels and enjoyment. Many commented that their viewing habits had 
decreased as adults, which was sometimes due to a lack of interest but could also be attributed to a change in lifestyle or in critical viewing ability:

F: Do you watch Bollywood films?

E8: I do. Not as much as I used to.

F: Okay. Did you used to watch a lot before because of your family?

E8: Yeah, because actually it was the only way of involving yourself in the culture. You really couldn't go out to a club and see a garba [a form of Indian dance] or something like that. The only way you could see it was on TV and through Indian movies, so it was just ways to remind yourself that this is what we have, and this is fun and this is how they are. Now I'm not so much immersed, I can't spend three hours watching a movie.

E3's parents made a point of setting aside one night a week that became an evening for the family to watch Bollywood films, and he does continue to watch occasionally, although he may do so now with friends or on his own. Like other young people in this study who now live away from their parents, his level of watching has dropped significantly, but in childhood his parents treated Bollywood-viewing as the prime Saturday night activity, and like B1, B2 and B3, whose parents or grandparents created similar habits in their homes, he retains affection for these films and recalls them as part of his childhood experiences.

E9 was one of the few whose change in viewing habits had affected a parent. Although she is not very likely to watch these films on her own, she commented that Bollywood-watching remains a pleasurable way to share time with her mother. Her mother is an avid viewer of popular movies who nonetheless attempted to accommodate her daughter's interest in political and social issues by selecting films that address these topics: 
E9: I really like Bollywood films with a bit of a political slant to them. So I really enjoyed Lagaan [Tax, 2001] and I liked Ek Hasina Thi [There Was a Beautiful Girl, 2004] and Swades [Our Country, 2004]. I am not into corny romance so much, so the more complex storylines are good. I am not sure what you mean if they are important to me. I see Bollywood as another form of corporate entertainment and while it contributes to identity, I don't feel it completely names or contextualizes my identity. I guess in a sense, it is a way for my mother to bond with me, for us to share with a lost culture and she tries to find the more political and feminist films for me to enjoy. She simply prefers to watch Shahrukh Khan movies only.

E2's childhood experiences tended to be rather different than those of most other participants; a student in Toronto at the time of the interview, she had spent her early years in a small town on Vancouver Island, where other South Asians were scarce. However, she comments that she did have a few other friends of South Asian origin, and they would meet regularly to watch Bollywood films and to discuss them in some detail. While she continues to watch now, she tends to select films that are more political or that address history or social issues.

Interestingly, A1, who described the distinct process of socialization upon which her father embarked, requiring his children to view Bollywood films, also recalled not enjoying the movies greatly. She had more familiarity with some of the older films than other participants, and commented upon their sociopolitical value, but for herself, enjoyment came only with the release of that oft-cited blockbuster, Hum Aapke Hain Koun (Who Am I to You, 1994, commonly abbreviated as $H A H K$ ). Several young people remarked upon lush, quasi-modern pictures such as $H A H K$, Dilwale Dulhania Le Jayenge (The Lover Takes the Bride, 1995, abbreviated as DDLJ) and Kuch Kuch Hota Hai (Something, Something Happens, 1998; $K K H H$ ) as being among the first films to catch their attention and bring them into the Bollywood-viewing fold, but of these $H A H K$ garnered the most mentions: 
A1: I mean, I remember, when I was growing up, I never really cared for Indian, or Bollywood movies or anything. Like, I don't really remember us watching them so much, but I just remember like distinctly, like, you know, I was in grade six, and my friends were like, oh, there's this movie, Hum Aapke Hain Koun coming out, and we should all go see it, everyone's talking about it, and that was like when it made its comeback. When I watched this movie, I was like, whoa, I liked the music, the family. I don't know, I liked it, after that, I was like, this is cool, and I started learning Indian stars' names and stuff.

E2 described her Bollywood-watching as more of a hobby than as a cultural influence, although I noticed at one point in her interview that she described one movie in personal and moving terms, an effect that seems difficult to dismiss as part of a hobby:

It's played a role...I guess like any hobby would play a role. I am the type of person who has used books and movies as a way of understanding issues in life so yeah, I think they probably shaped my perceptions or challenged my ways of looking.

E8, who also, like A1, cited the significance of $H A H K$, connecting its depictions of weddings and rituals to those she had seen in Pakistan, viewed Bollywood movies less than she used to but this had more to do with time and with the fact that she felt different, more authentic cultural options were available to her. However, she still felt that these films had influenced her lifestyle and habits in some way:

F: Do you think watching Bollywood has influenced the kind of person you are in any way?

E8: It's made me a little bit more cultural, for sure. If I didn't have Bollywood, I wouldn't enjoy the music as much, like Indian desi music, I wouldn't enjoy dancing, all those things, without those initially you didn't really have a venue to see that. With the Bollywood films at least they gave you that. You can recognize yourself. With the songs, you heard them all the time. They're identifiable everywhere you went because of desi functions, because everyone has their favourites and classics. Same thing with the dance, if you never saw it, you would have no idea how it would work.

E8's observation that "You can recognize yourself" was significant, as she referred often to the challenges of growing up as a young Pakistani Muslim in Toronto when the 
community was still in its formative stages. She described that as a sheltered, closed-in existence that she now saw being replicated in some places, including Toronto, as Muslims came under increasing scrutiny. In contrast, she herself had come to terms with her identity in many respects and enjoyed many aspects of South Asian culture, including some of those depicted in Bollywood films.

While E9 might not have gone so far as to say that she could recognize herself in these films, she did say that she would be willing to screen them for her children one day, provided that she picked the more political ones: "It is a great way to keep the language going. I can say that the only reason I understand Hindi/Urdu is because of Bollywood." Others remarked on this aspect as well, although some, such as E8 or A1, had no real need to view Bollywood films to develop linguistic ability. A3 commented on the fact that her cousin had specifically chosen Bollywood as a venue to teach her two children Hindi, a choice that A3 considered interesting given the other avenues available to her. E11, a Gujarati speaker, also learned Hindi partly because of this and B1 and B3, raised in Gujarati- or Kutchi-speaking homes, saw Bollywood as the chief reason they could both understand Hindi quite well.

Language, then, was an important part of the films' appeal and continuity, but B1 seemed to encapsulate the feelings of herself and of another participant in her group when she said:

It's a part of our culture, right? I would have my children watch Indian movies but I wouldn't force it upon them that oh, you have to sit here and watch it. You know what, yes, you will make it a night. And you know that every Sunday or every Friday night, that's what's going to happen. The other days, you do whatever you want. If you want to watch another Indian movie or go to a music party or go Indian shopping, we'll do it but I'd love you to have that and if they don't then that's something they don't... and that's just based all on personal upbringing and whatever. I want them to understand that it is a part that makes you who you are. 


\section{"That Movie Touched My Soul": Films as Agents of Socialization}

B1, in fact, was sufficiently affected by the influence of Bollywood in her life that she commented regretfully on the fact that her brother had strayed away from this, which she saw as a form of loss. For those young adults who did watch regularly, the family connection often tended to be of great importance, and as E8 noted, this connection then extended to other South Asians who could comment on the songs, movies and dances. While linguistic barriers and the desire for cultural continuity were key in the establishment of a family-filmi connection, participants also noted that the generally chaste nature of the productions was another strong selling point, allowing them to watch family-friendly content with their parents. Several were strongly critical of what they saw as increased sexual content and immodest behaviour in recent popular Indian films, suggesting that the presence of sexually suggestive scenes, in particular, made it increasingly difficult to use such cinema as a point of commonality with older family members. One group of young women in Vancouver quipped that they needed to be warned about these movies and recommended a rating system similar to that of Hollywood's, where PG would be replaced with "Not recommended with parents." These informants, along with others, felt that Bollywood's inclusion of such aspects was mistakenly intended to indicate that Indian cinema could be as sophisticated as North American films, although there was a certain amount of puzzlement regarding the ultimate reason for this. The majority of participants expressed discomfort over the idea of watching explicit scenes with their parents or grandparents, noting that they preferred not to watch English films with older family members because they did not wish to jointly view material seen as having a high degree of sexual content and 
perceived permissiveness. If the increase in such material in Bollywood films is meant to serve as a bridge to young South Asians living in diaspora, who presumably have become accustomed to similar content in their North American programming, the strategy appears to have backfired. E1's input seemed to summarize the general trend in opinion:

F: Since you've been watching pretty much all your life, have you noticed a change at all in terms of that?

E1: Yeah, I think that there's a lot-a lot more North American influence.

F: Do you like it better or worse because of that?

E1: [considers] I like it worse. [laughs]. 'Cause that's not-if I wanted to watch something North American, I'd watch a North American movie, you know, I wouldn't...but...it's just my opinion. I like more classical type movies.

Viewers complained of Bollywood's mistaken assumptions about people living in the West. Although most did not use these words, in fact, they seemed to be suggesting that recent Bollywood films had lost touch with the values which initially attracted their admiration, the same values that E1 felt her mother had wanted to transmit to her when they began watching Indian cinema together.

It is almost a truism in studies of Bollywood cinema, in fact, that the enduring appeal of these movies lies in their ability to convey a sense of authentic Indian values, whether this sense is accurate or not. Despite the apparently irrelevant nature of films whose chief focus is love and family, this subject matter allows for a continued emphasis on key values and traditions that might otherwise be forgotten or dismissed, especially when South Asians living in diaspora are offered a host of other cultural influences. By highlighting weddings and other family celebrations, Bollywood films affirm the importance of marriage, reproduction and respect for relatives. 
Some of the participants indicated that they were largely indifferent to the depiction of rituals in popular Indian films, noting that these held no relevance to them. This was true for some of the Muslim and Sikh respondents, who felt unable to relate to the mainly Hindu rituals shown, although a few, including E8, did suggest that they derived some pleasure from watching these. When this did occur, it was for one or both of the following reasons: they were able to draw a connection to some ritual in their own culture, or they felt that it helped them learn about other cultures. Otherwise, several felt largely alienated from what they saw, not simply because it was foreign to them, but because they saw the Bollywood version of ritual and tradition as simplistic, generic and occasionally misleading.

Asked if being Sikh made a difference to her position as a viewer, E2 replies that she did see herself as a kind of underdog when watching Bollywood movies as a younger person, a feeling that may have been emphasized by her sense of being an ethnic outsider in a small town. However, she also notes that her parents educated her about Hinduism as well as Sikhism, to some extent, which helped alleviate some of this feeling and may even have been responsible for her dislike of Punjabi-themed films and her preference for Hindu ones when she was young.

B1 also commented on a kind of outsider positioning, but not one that she necessarily blamed on Bollywood producers, admitting that the sect within which she practises is relatively minor and private:

With religion, with the Muslim religion, I don't know, I think because we're Ismaili, our faith is really closed in, we can't expect to see anything in that Sh'ia Islam be portrayed, it's always Muslims in general, that person saying his namaaz. 
On the other hand, B4, a Sikh who indicated that she did not necessarily find Bollywood to be inclusive or representative, nonetheless found films that spoke eloquently to her understanding of history, culture and religion, and in this sense Bollywood opened her eyes to facts that would not otherwise have to come to light:

B4: ...I don't think people truly understand- 'cause our parents' generation all felt the effects of that Independence, and I do not think you can truly understand what being Indian is until you understand what happened then to all three major groups that were involved. And for me it was an experience to really embrace my grandparents, my great-grandparents, to embrace my parents, and embrace what I've been given today. Because what I have today is a whole night and day difference from what a woman had back then [sounds of agreement from all]. As a female and then even in religious aspects, I mean, Sikhs and Muslims lived together like brothers and sisters and used to share turbans and now all of a sudden it's like you can't even marry a Muslim boy? Well, at one point I was your neighbor, they used to intertwine. My grandmother, I actually found this out after watching the movie [Pinjar, Skeleton, 2003], my grandmother, her side of the family there were Muslims and Sikhs intermixed. Didn't know that. That would never be heard of now. And for me, that's really hard to believe considering almost fifty years ago it was okay. Not even 200 years ago, fifty years ago. So for me, that movie touched my soul more than anything.

Bollywood films do provide a certain form of socialization for these young people, then, but in a way that is probably not anticipated by filmmakers. Some did feel slightly closer to their culture through viewing these films, but others felt either ambivalent or alienated. Some acknowledged that their parents or other relatives, all firstgeneration immigrants, might be able to relate to the values taught in these films, but they saw themselves as being differently positioned, unable to accept unquestioningly what was portrayed. Several participants, even ones who genuinely enjoyed watching Indian movies and who felt that this viewing had helped them learn Hindi and understand aspects of Hindu culture, expressed discomfiture with portrayals of gender, religion and relationships that they saw as outdated and unjust. 


\section{"Bollywood Gave Me Unrealistic Expectations...": Representations of Self}

Many of the respondents expressed disapproval of the stereotypes they found in popular Indian cinema, particularly those that revolved around gender roles, religion and South Asians living in diaspora. Even when Bollywood attempted to portray its own version of modernity, they found it to be flawed and simplistic, and resented the mixed messages this sent both to South Asians and to non-South Asians whose only knowledge of the culture might be derived from watching such films. Empowerment for women was seen as temporary and superficial, lasting only until marriage, which was still deemed to be the ultimate goal for young Indian women, and apparent signifiers of sophistication or sexiness, such as cropped tops and short skirts, were seen as contributing to an overall objectification of women.

A number of participants noted that they were so disenchanted with the portrayal of women in Bollywood films that they rarely watched them, and one participant commented flatly that she was completely unable to identify with Bollywood films for this reason. There was some ambiguity over the question of whether or not these films offered an accurate depiction of Indian women's lives. Some interviewees, rather than criticizing the films alone, expressed disgust with a culture that could allow women to be treated as subservient helpers. Others suggested that Bollywood films presented a version of womanhood-obedient to the husband and parents, educated, lovely, preferably fairskinned-that was so unrealistic and yet so prevalent in cinema that it fostered unreasonable expectations in South Asian families and men seeking potential brides. E6 and E9 also extended this analysis to a critique of the portrayal of romance in general in Bollywood cinema, with E6 expressing a concern that some young South Asian women 
develop a belief that love was meant to be tortured and difficult. E9 personalized this observation, responding to a question about Bollywood's influence by suggesting that she has moved beyond any serious effect, yet she could see the potential for these films to offer skewed portrayals of gender, love and marriage:

E9: I watch Bollywood as a form of entertainment, and try to turn my friends onto it. But in terms of who I am no. I did join a group on Facebook, though. It's called "Bollywood Gave me Unrealistic Expectations About Love" - which is a joke- - but somewhat true. As a child, I did watch these films and did have clear messages about heteronormativity and beauty. Naturally, these are unrealistic and sexist - but I had them. I think that as a feminist Muslim, fighting these sometimes sexist notions of love, monogamy and marriage is a challenge in Canada when those values are so entrenched in faith and in diasporic identities.

E6 answered the same question with a similar emphasis on the representation of gender and added that she felt distress when she thought of non-Indian people using Bollywood as a medium to understand the culture:

E6: I think so, probably. Probably in the sense that I work extra hard to avoid being lumped into that category. I think also I feel the need to explain-I have a lot of friends who aren't Indian who watch Bollywood films, who like watching Bollywood, and they'1l tell me they saw this movie or that movie...I remember we were in Ottawa, and we went to see Devdas [2002], and during the whole movie I was so angry and I was so embarrassed by the film. I was so embarrassed that I had brought friends who weren't Indian to watch it. I was really upset...I just thought it was disgusting. If anything I always feel the need to defend Indian people in the face of Bollywood, because the way that Bollywood portrays a lot of especially Indian women is very insulting, very derogatory and I don't want nonIndian people to think that our culture is like that, how it's portrayed.

D2, who repudiated these films almost entirely, tried to convey the reason for the depth

of her dislike:

And I feel a sense of - it makes me perhaps upset sometimes, because I feel it's so mainstream, that's what people think Indian culture is, Bollywood and it really bothers me, as a woman who's marked in some ways as geographically connected to India and I really don't identify at all with that. 
Gender, then, was an issue of overriding importance, with many of the womenbut also at least one man—raising the question of inequitable treatment and social mores to which they could not relate. Several young women said that they used the representation of men and women in these films to initiate a dialogue with parents, who could acknowledge the injustice of preferential treatment for sons or for beautiful daughters when they saw it onscreen, but who denied that they were guilty of the same practices in their own homes. At the same time, however, while much of the discussion around this topic was negative, B4 did locate some promise by singling out Salaam Namaste, a film that she otherwise disliked, for its attention to the intellectual talents of its heroine, an aspiring doctor. She saw that as one of the first instances where she witnessed respect for a woman's mind, and she theorized that Bollywood was undergoing a very gradual transformation and the results would eventually trickle down to the audience. She also noted that while attitudes differed, some young Canadian men of South Asian origin had developed increasing respect for women's intellect and careers. I was also struck by her comment that the depiction of gender in films was one reason that she had become a feminist, a position the other women in her group endorsed. Although their later discussion about the term evidenced some confusion over what it meant to be a feminist in the South Asian and/or Western context, they were clear that they had been inspired to seek gender equity.

Depictions of gender, religion and the West attracted considerable attention and occasional enmity, but class seemed less problematic for most of these viewers. They recognized the unreality of cinematic heroines or heroes who came from an extraordinarily wealthy family, but this did not seem to anger them in the same way that 
the other issues did. Rather, interviewees noted laughingly that such portrayals offer a strangely skewed picture of what life is like for many South Asians. At the same time, a few of the female participants, as well as one man, noted with a certain amount of guilty pleasure that the implicit consumerism of these films, where the stars could be lavishly dressed and occasionally participate in numerous costume changes, was literally a selling point, providing ideas for real-life couture. Both for casual viewers and heavy ones, music and clothing were among the chief attractions of these films, contributing to the escapist appeal. While the attractions of clothing and music were sources of embarrassment for some, E3 drew a connection between the trends depicted in these movies and his ability to have some awareness of Indian social norms when he began to travel there for work. Superficial as that knowledge might appear, he pointed out, it did give him a form of cultural capital that eased his path upon arriving in India, where he had no other handy source of acculturation, since his family is four or five generations removed from that country.

However, as some longtime viewers noted astutely, these tendencies are more recent. The lavish weddings and happy love stories that distinguished recent blockbusters were not features of many Indian cinema classics. Those viewers who were familiar with older films as well as newer ones suggested that some of the most valuable material was available in those earlier movies in terms of education about history and intercultural conflict, although there were still stereotypes present even then. Nonetheless, watching selected movies helped provide insight about Indian or Pakistani history, particularly with respect to Partition or the reasons for the conflict between different groups that they saw in the present. Several of the participants commented that those conflicts had little 
relevance for them in their Canadian setting, where they enjoyed friendships with people of many different cultural and religious backgrounds, but they benefitted all the same from the opportunity to understand their parents' and grandparents' feelings on the topic, especially when discussing issues such as intermarriage.

Related to this, the linked issues of diversity and intermarriage also arose during group discussions, with participants expressing criticism of a perceived hypocrisy both within the films and within their families. Diversity, they claimed, received only lip service, with filmmakers offering up token Muslims and Sikhs in a landscape otherwise dominated by devout Hindus. When Muslims did make an appearance, several participants suggested, they were frequently portrayed as terrorists or villains, while Sikhs were fanatical or the object of fun or derision.

B4: You either show them as, Punjabis, all they do is bhangra. All they do is feed their kids ladhoos and do bhangra, and that's about it.

B2 and B3: Such a stereotype.

B1: It's the ones that are Hindus that are the most pious. The ones that are the most religious, the ones that have the big lavish houses and the, you know, the excellent family. The Muslims are the ones that are just terrorists.

B3: They beat their kids, they don't let them show their legs...you know what I mean, it's so-

B1: So stereotypical.

In fact, the four Sikhs in the study were unanimous in their belief that Sikhs were portrayed in a stereotypical fashion and they expanded upon this, with one person describing two or three archetypes that the rest seemed to recognize: the clown, the (possibly alcoholic) party animal, and the warrior. Perhaps due to her own sensitivity on this topic, B4 also commented on the misrepresentation of Muslims in these films: "And 
I'm a Sikh, so I can even say it [other girls laugh]. I'm sorry, I don't care, this is ridiculous. Like yeah, they're all Persian Iranian terrorists. Are you kidding me?" Her group, which contained one Sikh and three Muslims, demonstrated an interesting dynamic as her comments occasionally appeared to imply a critique of Hinduism itself, although they may not have been intended in that way. There is no way of predicting if her tone might have been altered in the presence of Hindus, but on one or two occasions I wondered if I was witnessing a reaction to a sense of disempowerment, something she alluded to when describing her reaction to Bollywood:

B4: Has it influenced me as a person? Yeah, it gave me a lot more understanding into why things are the way they are. Because when you grow up and everything is Hindu-happy - that's what I call it, Hindu-happy-and you don't get a chance to really see, like for example, going to Pakistan, of course it influenced me. I was scared to death crossing that border. Scared to death about going there. You know, it's portrayed as this poor little country that has no education, all they want to do is fight and make their weapons-

Sikhs and many Muslims had little hesitation raising issues about religious and cultural stereotypes, although E3 was tolerant of perceived discrimination, commenting that there "are a lot of stereotypes that are reinforced, there are some that are broken as well." In assessing these films, the Sikh and Muslim respondents often gave some thought to the depiction of their own groups vis-à-vis Hindu, North Indian culture. In contrast, of the five Hindus in this study, none were able to comment extensively on the portrayal of their own religion or traditions, which may speak again to power relations. Unlike Sikhs and some Muslims, who felt a need to respond to inaccurate portrayals, the Hindu participants did not necessarily feel spurred in that way, although D2, who identified somewhat loosely as having been raised in a Hindu home and whose sense of disconnect was accentuated by the fact that she was not from a Hindi-speaking part of 
India, expressed anger in regard to the portrayal of Indian women generally. E11, a practising Hindu Gujarati who watched with some regularity, said that she felt her culture and traditions were not portrayed by Bollywood films. E5 suggested that the films were far more entertaining than anything else, although he allowed that they might provide some idea about Indian Hindu culture. A3 felt that she was too infrequent a viewer to comment, while E10 remarked that her own religion was well-represented but she noted her awareness that Hinduism is only one religion in India. The two Christian participants did not necessarily note any negative characterizations-although one Muslim viewer actually pointed out that immorality or promiscuity is sometimes elided with Christianity in these films - but they also said that they did not feel their religion was wellrepresented, and agreed that they might relate more easily if the opposite was true.

The issue of religious representation was not one that viewers saw as being easily resolved, yet it is also worth noting that no participants actually rejected Bollywood films on this basis. Films that they saw as unfair were simply ones that they critiqued and disliked, but they continued to view others. Gender, however, was more of a sticking point, and at least two people (one man, one woman) suggested that they could not reconcile themselves to films that depicted women as victims or objects of abuse. For others, though, the question of gender in Bollywood at least opened an avenue for discussion and debate with their parents or other relatives, which was also true of issues such as interfaith marriage, where the scenarios that met with applause in the movies were far less feasible in real life. Parents supported diversity and intermarriage on film but expressed definite resistance to the idea of interreligious unions or friendships in their own families, an echo of the attitudes expressed towards gender equality. 
Another point that arose on several occasions was tied less to a generational gap than to a geographical one. In the early 1990 s, in the wake of renewed discussions around the world about migration, diaspora and liberalization, Bollywood demonstrated its own awareness of changing social norms. Films became more explicit, more focused on the happy ending and, of course, as some accuse, more Western. There has been a concurrent trend where some Western media have incorporated aspects of Indian music and clothing, but critical viewers - a category into which most of these participants can be safely slotted-believe that the Western influence in Bollywood is far more profound. However, it is not the spectacle of Westernization itself that bothered these viewers, since Bollywood has never been shy about paying ode to Hollywood. Rather, it was their sense that the West portrayed in Bollywood films was such a caricature that they could not relate.

The viewers noted that characters denoted Western influence through random uses of English, through the wearing of provocative clothing that they found unappealing, and through participation in increasingly explicit sexual scenes that left them somewhat shocked and certainly embarrassed. The increasingly sexualized content left young viewers annoyed and insulted because it robbed them of safe entertainment for familial sharing, and it also appeared to be the product of a belief that people living in diaspora either lived this lifestyle or were drawn to it. Such material, the participants declared, only indicated the depths of Indian cinema's inability to understand all of its viewers. One of the Vancouver groups, which included some of the most constant viewers of Bollywood in this entire study, expressed frustration with the inability to provide accurate 
depictions of South Asians in diaspora, one that was identified by a large number of respondents:

B4: I have a huge issue with this. Just watching that movie, Salaam Namaste...The two main characters in the film were both born in India and then they came out to Australia, so now they're depicting Indians in another city and every Indian they depicted was an immigrant. They didn't want to show an Australian-born Indian and portray what an Australian-born Indian looked like. And that was troubling for me because every Indian you showed throughout that movie was immigrated, the taxi driver was immigrated, the little clerk here was immigrated... and it was just like, you know, I understand that, but you're totally forgetting about probably-

B3: Like all the people who were born in that country.

B4: Well, look at Vancouver, I think 50\%, maybe the ratio is higher, what, it's $70 \%$ ? You know, 50-60-70\% are all born here, you know? That's a huge number of individuals who do not relate to just the immigrant viewpoint. My parents might like that, but the kids were 21 in the movie so how do my parents relate to that? They don't. And same with Australia, right? So I find that they only like to relate to themselves. They don't really take the time and effort to go in somebody else's shoes.

Several interviewees linked this shortcoming to the films' emphasis on Indian nationalism. E11, a Canadian-born woman of Indian ancestry, suggested that the movies always valorized India above all other countries, and painted Indians living outside of the country as somehow inferior. E6 did not address directly the question of South Asians living in diaspora, but she did comment on the extreme nationalism found in these films, and on how this flourishes through the use of simplistic binaries:

E6: I think when it comes to Bollywood films, they show it in a very, very oversimplified and extreme way. Basically it's all or nothing. You're Indian and you espouse all the values that entails, and usually they show it with respect to how Indian people react to white people, how Indian people react to the British. Either you're Indian or you're not, and there's no in-between. And I think they make it very emotional, as well. You know they always have the Indian national anthem playing in the background when they have those scenes, and things like that. 
She also elaborated on a point raised by several others, that nationalist tendencies in Indian films had evolved over the years, with an early emphasis on India as an independent postcolonial entity, as opposed to a newer trend towards South Asians who are, in some sense, trying to address a kind of war within:

E6: I watched a lot of really old films, like black and white films in the '50s and '60s, and I think at that time, they were still trying to establish a national identity, because it's still so close to Partition, right, so movies like Mother India [1957], they really tried to highlight the prospect that you could be from the lowest economic class in India or from the highest, but when it comes to nationality you all have an understanding that you are all Indian first, you have to work towards that goal of establishing a national identity. But I think since then-I think at that time it was really...I can see why people's agenda was to have different Indians, people from different backgrounds come together and unite - -but I think since then, and maybe also partly because of the influence of Western culture, they're starting to highlight differences. Maybe not so much in Bollywood films, but in films like Earth by Deepa Mehta, they sort of highlight them. You have the complexities of being Indian and maybe it's not so united. Movies like VeerZaara [2004], where people are trying to say you're Pakistani or Indian, which is a category that you're put in, but really it's kind of the same thing.

While E3 observed, along with others, that it is increasingly common for Bollywood to tell stories about Indians going to America and trying to succeed there, he disputed claims that Bollywood is obsessed with the West. Rather, he pointed to a desire to establish internal order, for Indians to recognize a vision of themselves that they can endorse. In unwitting response to E2's inquiry about India— - Are we going to continue exoticizing it," she asked, "and comparing it to Western society?"-E3 ruminated:

I think one of the biggest lessons that I learned about Indian films-I think in the West I always thought that Indian films were-well, not always thought, but I thought to some degree that Indian films were sort of like what India would be like, you know, people running around in gorgeous saris, running around singing and dancing [laughs]. No, more seriously, I think you just get the sense that it's a real fantasy world, and then you go to India, and you see the reality of India, and it hits you in the face like a ton of bricks, that it's not a fantasy for those living in the West about what they think about India, it's a fantasy for Indians about what they want their India to be. 
He also addressed accusations that Bollywood mimics Western styles in music and clothing, responding that it does add its own touches: "So yes, it's changed a lot, and yes, it definitely takes inspiration from the West, but I think it's also made it its own...it's done in a way that only Indians could do it. It's Indianized."

Asked if this Indianized approach was useful in addressing important issues, respondents provided a variety of responses. Some felt that the genre was too melodramatic and simplistic in nature to really treat any serious topics in a meaningful way. Others compared the Bollywood treatment to the more nuanced approach found in alternative Indian films, or those described by Jigna Desai (2004) as diasporic films, and again provided different answers. Some found the latter far more meaningful and serious, while others complained that even the most well-meaning films of this genre still provided cut-and-dried solutions and promoted some stereotyping. E2 noted appreciatively that Bollywood is now willing to tackle issues it would never have addressed before, such as AIDS or taboo historical questions. She did not valorize this genre, but she felt that it deserved credit for raising such topics with an audience that might not otherwise have been prompted to think about them. Asked to compare this treatment to that found in alternative Indian films, she cited Bend It Like Beckham (2003) specifically and suggested that it played on stereotypes and did not go far enough to depict the kind of issues it raised.

"It Shook My Soul": Evaluating Bollywood's Significance

There were no simple answers, then, regarding whether one genre was superior to another, or whether everyone was affected in the same way by these movies. Even though the diasporic films seemed to elicit high degrees of recognition, particularly those made 
by Toronto filmmaker Deepa Mehta, they did not garner universal praise, nor did they have the same impact on all viewers. Some saw these types of films as sharing some of the basic problems of Bollywood-there were assumptions embedded within, simplistic solutions and some stereotyping. Others felt that they were more likely to relate to these films, which sometimes crossed into transgressive territory, offered more progressive depictions of women and-most importantly for some-were filmed in English and set in diasporic settings. Their format usually bypassed the structural elements cited most often by viewers as common dislikes, including fight scenes, the three-hour length of the films, the high levels of melodrama and the consistent use of formula:

A2: I enjoyed Hum Aapke Hain Koun and whatever else, but I also felt like it was the beginning of the teen-flick era of Bollywood, and I think to this day they're still following that same formula, which really becomes bothersome to me, because there's no originality and it's just the same thing over and over again.

Other dislikes were not by any means universal. One young woman said that she found a type of humour in Bollywood movies that was reflective of her culture and that she could not find elsewhere, whereas a few other respondents criticized the humour as silly and meaningless, something that did not, as E11 said, give the audience much credit.

There are, of course, other alternatives to Bollywood cinema besides diasporic movies, including mainstream North American films, which most participants watched but did not consider personally affecting or a major source of entertainment. Several commented that the infrequency of their Bollywood viewing should be considered in light of the fact that they did not watch films very much as a general rule, and the same critique of formula in Bollywood was applied at times to Hollywood as well. Asked about Pakistani films (sometimes dubbed Lollywood films), the participants who were familiar with them dismissed them as any competition to Bollywood, suggesting that they 
attempted to follow the same formula but did so poorly, with lower production values. E8 did note that her cousins in the United States watched these films and enjoyed them because they felt a connection to home, but she herself found them impossible to watch, and A2, E8 and B4 all agreed that they had found many viewers in Pakistan still preferred Bollywood films, which could be accessed through black-market satellite dishes.

The observation is interesting since it seems to offer a response to the young women who complained about the demonization of Muslims and Pakistan in Bollywood, a complaint that B1 addressed by saying, "Well, because they're Indian filmmakers... they're not Pakistani filmmakers." Evidently having a Pakistani filmmaker was not in itself enough to woo viewers, although in one case E2 cites the Pakistani-made Khamosh Pani (Silent Waters, 2003) as a meaningful film. Complaints about Bollywood notwithstanding, it seemed to retain its appeal and its reach, particularly with the release of major hits. Some viewers were familiar with a wide range of films, but less frequent viewers indicated that they might make time for a film that was considered hugely popular or that otherwise generated positive feedback from family or friends.

Even among those whose viewing patterns differed widely, many of the same film titles were cited repeatedly. Perhaps not surprisingly, the most commercially successful movies were mentioned with corresponding frequency, yet the reasons given for citation were not entirely the same. As conversations unfolded, it became clear that many identified the films they found most entertaining, romantic or well-made, while others pulled out more personal factors. Like several others, E3 named HAHK, Kabhi Khushi Kabhie Gham (Sometimes Happy, Sometimes Sad, 2001), and Veer-Zaara, and he did note the high production values as a factor in his enjoyment, but he added that he also felt 
each of those movies "either pushed the limits in some ways" or brought up a modernday issue that was previously unexplored, such as the Hindu-Muslim divide in VeerZaara or family values in Kabhi Khushi Kabhie Gham. Having said that, he was evenhanded in his praise of various Indian films, including the non-Bollywood variety for their willingness to tackle topics that Bollywood would not think to approach: "On the other hand, the cultural nuances are really picked up in the Bollywood films: the clothes, again the music, the culture...I think in that way Bollywood does have its place, as does [sic] non-Bollywood films expressing India." E6 also identified an older film but one considered by many to be a classic, the film Sholay (Flames, 1975), which she saw as one of the few Bollywood films to provide high levels of entertainment without descending into campiness.

Others identified films that taught them about history, society or politics, as when E2 cited Roti Kapada aur Makaan (Food, Clothing and Shelter, 1974) as a film that had a big influence on her, an impact that she summarizes simply by saying: "It shook my soul for some reason." She then elaborated on the importance of the film, which chronicled the inability of youth to obtain education or employment, despite the grand promises of the future following Independence. Khamosh Pani also discussed youth and social unrest, but with more specific reference to increasing Muslim fundamentalism following a declaration of martial law, as well as the violence against women that followed Partition, a fact that E2 found fascinating as she looked back to the history of her own family and tried to relate their experiences to what was depicted in such films. B4's citation of Pinjar was for similar reasons, while B1 found new meaning and significance in Mughal-eAzam after learning about the Mughal period, which she perceived as part of her own 
history. E9, who reported that she prefers those films which have social relevance, cited Ek Hasina Thi, which did not provide educational components but which contained quasi-feminist elements in its depiction of a duped woman who seeks revenge on the man who used her. E6 named the original Umrao Jaan (1981) for its comments on society, as well as Heer Raanhja (1970) mainly because of the fact that it is Punjabi. Clearly the simple fact of feeling represented played some role in this choice, as with the choice of the film Gadar (2001), another post-Partition film that dealt with a Sikh-Muslim romance, praised by the commentators for its depiction both of a Sikh character and of the events that took place during that time.

Others had even more personal reasons for selecting the films that they did. E11 commented on $H A H K$ as a film that she watched repeatedly with her family while staying in India, and hence the film was associated with that period in her memories. E8 offered a bit of a twist on this reminiscence, saying that $H A H K$ resonated with her because the weddings and rituals depicted within the film reminded her of events that she had attended while visiting Pakistan. B1 linked her choice to her feeling of sadness following the diagnosis of a chronic disorder:

Mine is Dosti [Friendship, 1964]....the older version, the black and white one.... It was about this orphan that was blind and he met this other boy who wasn't .... and the other friend gave him that confidence, that regardless of your disability...you can take the talent that you have and make somebody of yourself. He was a singer, he had this amazing, amazing voice... So it was that voice that ended up giving out the message to the rest of them that just because I have a disability, or because I don't have parents, I'm an orphan, just because I have these misfortunes, it doesn't mean that I'm not normal. I can live a normal life and it truly hit me because I watched it when I was-I think it was about two years ago, when I was diagnosed with my...disorder and at that point I was feeling helpless and whatnot, and when I watched it it truly showed me that there are people out there that are going to be able to look at you as a normal person regardless of your disability...It made me feel better to know or to believe that there were people in-like, Indian people quote unquote that could be like that. 
Clearly, some viewers remembered films in a way that was highly personal, which often made the memory favourable, although E7 and E6 both mentioned Devdas yet their memories of that movie were so vivid because both were repelled by the depiction of women in the movie. E7 in particular was strongly affected by a scene in which the title character strikes his childhood love in order to mark her as his, prior to her marriage to another man. Similarly, B4 clearly did not like the negative depiction of Indians living in diaspora in Salaam Namaste but she returned to it repeatedly because she felt that it broke new ground, going so far in some respects that she could not relate, but also moving into territory that she felt had to be addressed. I did expect some degree of personal reminiscence when naming films of importance, but I was interested in the fact that the viewers criticized certain elements in a general way-unfair depictions of South Asians living in diaspora, skewed representations of women and particular religious or ethnic groups - without these observations always entering into their comments about a specific film, even one where these viewpoints would be quite relevant.

For instance, a number of young people complained here about the way that diasporic individuals are represented, a trend that some critics felt was addressed in complex and transformative ways in $D D L J$. Several ranked this as an important film, citing the romance, the music, and the production values, but none made reference to the diasporic themes embedded so clearly within this movie. One participant named Pardes (Foreign Land, 1997) as an important film without making any reference to its clearly negative portrayal of diasporic Indians. Swades, a strongly pro-nationalist Indian film which returns to the familiar treatment of the heroine as the preserver of culture and tradition, was named by a participant whose origins were Pakistani and who described 
herself as a feminist. For the most part, the judgement seemed to be simply that Bollywood was far behind where it should be in terms of speaking to the diasporic audience, although attempts at increasing representation of marginalized religious and cultural groups did elicit cautious praise. Veer-Zaara did not seem to be universally popular and its treatment of the two main characters was seen as rather fantastical and caricatured in some ways, but one or two respondents suggested that its subject matter indicated a willingness on Bollywood's part to move beyond constructed rivalries and to suggest that all South Asians have commonalities and should seek unity.

Thus, there were some obvious contradictions that recurred throughout the study, some of which may be attributed to lack of critical insight on the part of viewers, yet I believe that this was not necessarily the case, at least not in a frequent or protracted way. For the most part, respondents gave thoughtful, perceptive answers, but they also indicated that their lives and their habits have come to be characterized by contradiction. Some of the young women complained about sexism in Bollywood, and then continued to watch; similarly, complaints about inaccurate religious or ethnic depictions did not cause cessation in viewing. These movies could still satisfy a need for these viewers, who were aware of their shortcomings but extracted the elements that were meaningful to them.

This was why context and situational positioning seemed most important for some when they were asked whether they would find any benefit in screening these films one day for their children. The heaviest viewers agreed that they would do so despite their criticisms of the genre, linking the experience to family and culture, while one young man who very rarely watched said that he would also show his children those films as a 
way of preventing further erosion of Indian culture than he had experienced himself. E8, who frequently referenced her comments by offering comparisons to other countries or to the past, answered the question by returning to the evolution of Toronto into a truly diverse city, as opposed to other parts of North America, and also by indicating, as did many others, that Bollywood was one of the less authentic ways to explore South Asian culture:

E8: I think it would depend where I live. If I lived in the States, where again it's like it was here maybe ten years ago, where there's not a huge community and you wouldn't see yourself or your culture reflected in the places and the people around you, then yeah. I've noticed that, I have family there, like cousins and such, and besides having specialty channels, they really don't have anywhere to explore their desi culture. I find in Toronto, it's becoming a lot more like London, where it's become a lot more mainstream, everyone knows about it, you can easily explore yourself there on any given night. You can do it in a very specific way as well, if you only want to do a certain part of it, it's so easy now. So if I was living in Toronto that's different. I'd rather have them experience the real culture as it is.

\section{Diversity, Diaspora and Media}

In explaining what they saw as the "real" culture, several individuals described scenarios where their parents' beliefs regarding nationalism or culture might be quite different from theirs, but parents and children alike had learned to respect each other's choices even though neither side was above promoting its own ideas where applicable. Unlike the informant in Maira (2002, p. 133) who saw himself as diluted because he was separated from the authenticity supposedly found within South Asia, the young adults here did speak of practising culture and religion differently but they did not necessarily consider this less authentic. Some noted that living outside of South Asia, where religions and culture were less likely to be questioned, had prompted them to search for the meaning of these entities, a search that led to an understanding that they saw as entirely 
authentic because it was relevant and valuable to them. For those respondents, diaspora is indeed, as Mandaville (2001) might suggest, a place that provides the possibility of more incisive exploration and understanding of faith. Their parents may have had a stronger sense of ethnic and religious identity because they lived in places where these were rarely questioned, hence adding to their sense of immutability and permanence, but these young people, living in a place where they are surrounded by various understandings of ethnicity and faith, are more likely to ask questions and to make comparisons. This does not always — or often — translate into a weakening of traditions and beliefs. However, it means that the traditions that remain are ones whose meaning has been interrogated, thus the significance is better understood and perhaps even more valued.

Having said that, some participants did speak in terms of loss, particularly as this encompassed language. As Murji and Hébert point out, language is an important component of ethnicity, and this was referred to at several points over the course of the project. Language did appear to provide some participants with an increased sense of closeness to their culture, although this was not an exact predictor of strong identification with a particular ethnic community. The hybrid nature of language and community was reflected often in these comments, as one woman noted that an increasing move globally towards interpreting Islam as a religion that is most authentic when couched in Middle Eastern, Arabic terms, marginalized those Muslims who are fluent in Urdu yet conduct many rituals in a language that is not native to them. This dilemma arose for other Muslims, more than for any other group, although something related did arise for a Gujarati Hindu who acquired Hindi-speaking capability through a variety of means, partly because she was surrounded by it so often in media aimed at South Asians. Young 
people who were raised in Gujarati-, Kutchi- or Punjabi-speaking homes sometimes did become relatively competent in other languages, including Hindi or Urdu, because so much South Asian media content called for this, and they learned to switch between languages or even to mix them with ease. However, even those who understood well sometimes expressed regret that they were not more fluent speakers, and made reference to the eventual loss of some of these linguistic capabilities. This loss was happening rapidly in some cases, as one might expect from reading Murji and Hébert (1999), who seem to indicate a swift generational change, but as with Jiwani's informants (1989), those who were losing their command of South Asian languages, or who saw this occurring among others, were juxtaposed with other individuals who were highly fluent in at least one South Asian dialect, if not more. Moreover, while the informants who did possess this linguistic competency saw its value and expressed pleasure, those who did not were not always regretful, at least not openly.

There was a kind of spectrum in these matters, among others, that unfolded over the months during which I conducted my interviews. In the case of Bollywood, for instance, some participants distanced themselves as much as possible from popular Indian films while others were utterly immersed in it. Having said that, there was not a single interviewee who had never seen a Bollywood movie, indicating, perhaps, the industry's enormous reach, or the consistent use of these films by South Asians living in diaspora. Moreover, some of the most devoted or most longstanding viewers were Muslim, an interesting discovery given this study's emphasis on the confluence between Bollywood viewing and identity construction among Canadian Muslims. It was also true, though, that even the avid viewers were not wholly uncritical of the industry; nearly all saw 
shortcomings, beginning with a melodramatic treatment of serious issues and moving on to stereotypical or unappealing depictions of women, Muslims, Sikhs and people living in diaspora. Muslim viewers were well aware of the problematic depictions of themselves and their rituals in these films, yet many continued to watch or to retain some vestige of affection for them. Several saw them as integral to their upbringing and to their understanding of South Asia, a sentiment that they did not express towards the movies made by Pakistan's film industry, Lollywood. This may speak partly to Bollywood's hegemonic authority, to a perceived lack of quality in Lollywood films, and/or to the fact that young people who have lived many years in a society where they rarely see themselves depicted may come to depend on even the most absurd portrayals of South Asian life as long as some representation does exist. Whatever the exact reason, it appears that even those respondents who could not trace their roots directly to India still felt the influence of its media, a point also referenced in Jiwani (1989), where youth who seemed unaware of — or unwilling to acknowledge - their Indian heritage might make reference to their enjoyment of Indian movies and music.

A related point in terms of the films' appeal seems to demonstrate how a medium described by participants and critics as superficial and purely entertainment-driven can affect viewers' everyday actions and self-esteem. Asked if Bollywood had influenced the kind of person she now is, one young woman replied that she felt it had helped increase her comfort level when she wore Indian clothes in public. While this may seem trivial to some, I think the recurrence of this theme--the shame associated with marking oneself as South Asian in public_-in Gillespie (1995) and Handa (2003) demonstrates its significance, and also emphasizes the degree to which individuals may internalize shame 
and discomfort over their race and ethnicity, rather than attributing negativity to those who single them out as different. With the possible exception of one very light-skinned, light-eyed participant, the young adults in this study were always and already marked as South Asian, but choosing to wear South Asian fashions indicated, as Gillespie's and Handa's informants claimed, a willingness to demonstrate that South Asian identity in public, something that could result not only in marginalization from the mainstream, but from other young South Asians who felt that such identity was best confined to the private sphere wherever possible.

One group of interviewees raised a similar point, noting that Bollywood and Indian popular culture had become mainstream, increasing the acceptability of wearing such fashions or mendhi (henna) in public, an acceptability that had been withheld from them as children growing up in a society more multicultural in name than in action at that time. Yet the same informants indicated the inherent contradiction in this, debating whether their culture had simply become appropriated and they should feel offended, rather than proud. Although few engaged with this terminology, there is an implied ambivalence towards the global flow of capital that has helped shape diasporas through the movement of people and goods. Pushing Bollywood into the public eye, this capital flow has increased its visibility and elicited recognition from non-South Asians, but at the same time it has also simplified the public image of South Asian culture in a way that some participants found troubling.

Those who subscribe to that image might only have been familiar with a few very popular movies that were consumed, at some level, for purely escapist purposes, somewhat but not entirely similar to major Hollywood hits. As Durham's (2004) 
respondents explain, Bollywood still carried a ring of cultural familiarity, and this gave them a considerable affection for Indian films that they were unlikely to transfer to Hollywood. Some of the respondents who knew Indian cinema more intimately-though interestingly, none of the Hindu interviewees - pointed to Bollywood as an alternate system of education about their cultural and religious history. Many scoffed at the amplified nationalism running through many of the films, especially if this concerned a conflict between India and Pakistan, or India and the diaspora, but several suggested that they had gathered information about South Asian history through selected films. One group in particular complained about an inability to obtain information about their culture and history through community associations or family, and further remarked that formal education had helped not only to fill in some of the gaps, but had also intensified their understanding of selected Bollywood films.

Participants such as these expressed themselves in emotive terms that initially surprised me. While these comments were specific to Bollywood, several young adults brought emotion and feeling to their descriptions of nationalism and their efforts to bridge cultures. Based on Gillespie's (1995) observations about Punjabi youth who used television programs - usually mainstream ones-as a way of initiating conversation with their parents on sensitive topics, I had expected that movies might be relevant in some respect to real-life issues, but I did not anticipate the level of emotion and personal identification that occurred in selected cases.

There is one point about the consumption of Bollywood that I found increasingly interesting as I transcribed interviews, and in a sense this may be the most significant point. There was clearly some level of dissonance present for several of the young 
people, particularly those who were Muslim or Sikh. Nearly all of the viewers, especially casual ones, described a frothy world of escape that meant very little. At the same time, Muslim and Sikh viewers were entirely conscious of the religious and cultural archetypes that circulated in these films, and they expressed dislike of this. Similarly, several participants demonstrated equally intense repugnance when discussing the depiction of women, and last but certainly not least, a large number indicated awareness that proIndian discourses could easily be read as narratives that excluded South Asians in diaspora, especially those born outside of South Asia. This consciousness was perhaps expressed most fervently by three young women who were frequent viewers and who had no intention of relinquishing this activity, and in fact, very few of the individuals in this study contemplated doing this entirely, which is a telling point in itself.

\section{Discussion}

The intention of this study has not been to establish the overriding importance of Bollywood, but to understand its significance in the lives of diasporic viewers, who increasingly seem to form the target audience for some of the biggest films. That significance appears mixed but it is there for a number of viewers, although I think that the percipience of these same viewers might take some Bollywood producers by surprise. Having said that, some of the hybrid elements in Bollywood film were greeted by participants with exasperation, but others did appear to capture the imagination in some ways. The attempt at capturing a new modernity in films such as $H A H K$ and $K K H H$ does not go unnoticed, although equally strenuous attempts at speaking to previously neglected groups, such as Punjabis or Muslims, are greeted with criticism if they do not go far enough. Moreover, the overwhelming nationalist sentiment in these films seems to leave 
many viewers cold. Some noticed it, especially in films such as Kabhi Khushi Kabhie Gham, Veer-Zaara and the older Mother India, and one or two did comment on it favourably, but there were also instances where many complained that the pro-India themes were utilized at the expense of another, equally important group—diasporic individuals such as themselves who were capable of respecting cultural and religious values while also declaring fidelity to their own country. Films such as Kal Ho Naa Ho (2003), which did depict people settled in the United States and even displayed an American flag prominently in the background of one dance sequence, or Dilwale Dulhania Le Jayenge (1995), which reverses the anti-diaspora sentiment, were mentioned as favourites but with no reference at all to these themes. In the minds of these young people, Bollywood left very little room for compromise, and compromise was essential to individuals who made no attempt to deny their South Asian heritage but also refused to be identified as anything other than Canadian.

If Bollywood has generally been seen as a kind of hybrid beast, one that works to provide a niche for nearly everyone, this is rarely viewed as the innovative hybridity that Bhabha (1994) has endorsed enthusiastically in the past. The term hybrid culture recurs frequently in discussions of Indian cinema as a pejorative, as when Dharker states that the "trouble with hybrids, especially when they are too deliberately forced to adapt to another culture, is that they don't work" (1997, p. 400; also see Barnouw \& Krishnaswamy, 1980, p. 157; Dickey 1993, p. 58). The observations of participants in this study seem to endorse at least part of that perspective; hybrids themselves are not the problem, but imposing one culture upon another in a way that is forced creates tension and hinders success. The same, in fact, may be said of the young people I cite here; in one instance 
after another, they suggest that the reason they can make their composite identities work is because they live in a society that encourages them to do just this.

Marwan Kraidy echoes the belief of several participants that the hybridization of cultures has been occurring as an actual practice for far longer than many have admitted, so that any attempt to distinguish clearly between local and global spaces "glosses over years of osmosis between different national and cultural entities" (1999, p. 459). This process is referred to by García-Canclini as cultural reconversion, in which local cultures accommodate the influence(s) of the global "without being destroyed because tradition is re-articulated in modern processes" (1999, p. 460). Bollywood, then, may be simply one element where tradition is being re-articulated, although the viewers here are correct to point to its flaws. However, I think they may also be justified in continuing to negotiate the meaning and significance of these films, not just for themselves but as a way of communicating with parents or others. It is not possible for most of the young adults here "to exclusively belong to one or the other of what they saw as two irreconcilable worldviews" (Kraidy, 1999, p. 464), and hence they take the tools they have at their disposal, use them as best as they can, and supplement them where necessary.

Tensions such as these clearly demonstrate that the creation of a hybrid culture is a tenuous and imperfect process, and one that never really concludes. Several participants did suggest that they had found creative and meaningful ways to form a lifestyle that embodied elements of old and new, North and South, but no one went so far as to deny the fissures and contradictions within. Some, in fact, seemed to realize the complexities of their positioning as they considered different questions and scenarios. Most felt, as Mandaville (2001) and Bhabha (1994) would perhaps suggest, that migration had given 
them a different kind of freedom to explore knowledge and culture than their parents possessed, but at the same time, they also felt that exposure to different settings and forms of education meant that their understanding of many cultural elements, including cinema, would always be more tinged with frustration. Diaspora, then, is a meaningful space for these young people, allowing for syncretic melding of elements and beliefs, but it is also a space where freedom is intertwined with constraint and paradox.

Along those lines, nearly all of the participants agreed that Indian cinema did nothing to project a more realistic view of Indian society. Several were deeply disappointed that Bollywood depicted both India and the West in a skewed manner, doing little to promote a positive image of the genre or the industry. Others were less critical, dismissing such films as mere entertainment with a limited role to play in terms of education. Some participants noted, with a certain amount of nostalgia, that Bollywood had indeed been used, as Gillespie suggests in her 1995 work on Punjabi families in the UK, to educate them about their culture and history. More than one person explained that older Bollywood films had been the only source of information they received regarding Partition and the history of discord between specific ethnic groups. Although they were not interested in reviving such discord in Canada, pointing out that life in a multicultural country is a different matter, those participants who did learn their history in such a way were gratified that they had done so.

In short, in the case of those I interviewed, even Bollywood's rampant nationalist tendencies did not manage to call these young people home in any literal way, not least because they clearly identified with the home they already had. However, both have helped maintain some sense of continuity and connection for those living in diaspora, and 
it was a sense unlikely to be broken now or in the future. Even when viewers expressed offense, indignation or outright rejection of what they saw on screen, very few contemplated the possibility of leaving these films behind entirely. Flaws and all, Bollywood offers a reflection of a struggle these individuals live daily: an attempt to reconcile competing cultures in a way that makes sense to them in the context of their own upbringing and ambitions for the future. This attempt never meets complete success but it must be undertaken, since there is no possible way to dismiss the multiple nature of their identities. South Asia may not have called them home for good, but it lives within each of these young people, and the possibility, the promise and the obligation of their plural identities were not aspects that they were willing or able to ignore. 


\section{Conclusion}

\section{Beyond Futility: The Future of Young Canadians of South Asian Origin}

This is what her note said: "My name is Pratiti Kaka. As a child I learned dancing, and my mom thought I'd grow up to be a dancer of renown. I soon joined skating classes. She assumed I'd break Olympic records. When I started swimming, she hoped I'd swim across the English Channel someday. But all her dreams crashlanded when I grew up to be an ordinary, amiable girl with varied interests. After managing an office, I married a wonderful man of my choice and am enjoying life. Just the other day, someone told Mom, 'I want my daughter to be like yours." The confidence in the unexceptional, rather, the dream of being part of the ordinary, is also indicative of the process of the immigrant becoming a citizen. You don't stand out, or stick out, anymore. You are like any other American. (Kumar, 2002, p. 180)

Never studied properly because they are so numerous and undefinable..., immigrant children seem to be the major source of wealth and entrepreneurship in Canada. They dominate most innovative academic fields. They seem to run every business. Even a cursory examination of Canada will tell you that it is a country being built not by struggling immigrants, but by their fluently literate, culturally integrated, wealth-generating, numerous children. (Saunders, 2003, p. F2)

Returning to the question that opened this research, what role does Bollywood cinema play in the construction of identity for young Canadians of South Asian origin, particularly Muslims? Despite the protestations of one participant that media are not very influential in her life, and the comments of others that media may not be the most important aspect of identity formation, film does seem to have a role, although the nature of this role varies significantly. Nearly all of the interviewees identified problems with Bollywood cinema, and several detected shortcomings in its representations of nation and culture, elements that are presumably intended to speak to people such as themselves. All the same, many continued to consume it, although this viewership was sometimes sporadic and often critical. Bollywood seemed to satisfy, at minimum, a need to see South Asian individuals and rituals depicted on screen, yet those whose specific realities were portrayed more peripherally, as was the case for Muslims, perceived a tendency for 
popular Indian cinema to stereotype or marginalize them, much like North American media.

A sense of being ignored by popular media and by society in general made Bollywood more valuable for some participants, a feeling that has generally tended to diminish as South Asian populations increase in Canada and as some markers of South Asian culture become accepted more generally in mainstream society. These young adults charted changes in Canada, in their own ethnic and religious communities, and in their families that have sometimes been negotiated through the use of media, particularly popular Indian cinema. As these informants explained and as this dissertation has attempted to suggest, there are a variety of factors that contribute to identity formation, including media. It would be overstating the case to imply that media alone create identity, but it would also be saying too much to argue that most young people are entirely oblivious to the influence of media. Some of the individuals in this study pointed out evolution in the media that had affected them throughout their lives, while also describing their own transformation into adults, a growth that involved evaluating a number of influences. Watching Bollywood was undoubtedly among these influences for some of the respondents, and the reasons for this are worth evaluating.

Bollywood provides viewers with images that purport to be like them, and however farfetched these images might seem, they signify an attempt at representation. As interviewees note here, the options available to them have improved over the years, and they do have more ways of seeing themselves, but Bollywood can sometimes exercise an ameliorative effect in societies where South Asians feel that their rituals, activities and faiths exist on the margins. Bollywood's increasing acknowledgement of 
the fact that one of its key markets lies outside of South Asia and is centred more specifically in an entity as amorphous as diaspora, demonstrates the importance that diasporic peoples can have in the maintenance of a nation-state and its chief industries. Bollywood is perhaps unique in its ability to talk to the diaspora, to feed it nationalist discourse and to benefit from diasporic capital at the same time. Once this relationship prospered on the basis of nostalgia, but if the responses given in this study are any indication, such nostalgia is unlikely to persist for the second generation of immigrants and may be unthinkable for the third generation.

The young people in this study see themselves as Canadian, not just in terms of a piece of paper that marks them as such or because they appear integrated, but because Canada is the home they have known for most of their lives. Like the children of immigrants described by Saunders at the beginning of this chapter, they are indeed the building blocks of Canada, a Canada whose plurality is a factor that resonates considerably for these participants. Even when they do not meet with full acceptance, they express their right to it, and are willing to do battle over and over again to claim those rights. Deeply conscious of the massive transition their parents or other family members made in coming to Canada, they have attempted to integrate into Canadian society without fully assimilating, seeking to maintain knowledge of their origins andfor the most part - respecting those of others. This is not a perfect process, and it occurs at a different pace and in different ways for those who undergo it. This finding does echo some of the integration found among Haji-ar-were's (2006) Australian and Thai subjects, as well as the complicated acculturation taking place among Maira's (2002) South Asian American ones. However, the assertion among participants here that their right to 
belonging is something enshrined in Canadian policy, and something they will not surrender, is perhaps unique to this study and to the avowed multiculturalism of the host society in this case.

Participants spoke of a variety of exclusionary and racist practices that they encounter, even though they rarely attached these labels to them, and it appears that these experiences were formative in each individual's sense of self. Indeed, it was interesting to note that many young people made implicit reference to racial stereotyping and ignorance on the part of other Canadians, yet only a few spoke frankly of racism and its deleterious effects. Rather, most were inclined to use diplomatic and optimistic language reminiscent of that accompanying policy claims to multiculturalism and diversity, avoiding most commentaries around race as it related to them, although there were references to the prejudice experienced by other South Asians and Muslims around the world, a prejudice whose existence seemed so palpable that few expanded upon it, merely speaking of it as an accepted fact. Moreover, a few participants were quick to note that Canada has been a colonizer, not just a victim of colonization, and thus those who describe themselves as truly Canadian, by virtue of English or French heritage, are no more indigenous to the land than recent immigrants. Nearly all raised the issue of being asked frequently about their origins, and described meeting this inquiry with acceptance, indifference or anger.

Indeed, their refusal to give any quarter when their Canadian nationality is challenged could speak either to their ability to resist prejudice, or to their willingness to adapt themselves to a place that may never fully accept them. In spite of recurring reminders that not all Canadians viewed them as Canadian, most of these young people maintain their insistence that they are as Canadian as anyone else. The level of insight 
that emerged in response to Canadian and South Asian nationalist discourses indicates that there are numerous influences that will enter into acculturation, many of which these individuals appear to be capable of evaluating critically and confidently as they continue fostering not only their identity, but that of a diverse new Canada.

\section{Part of the Ordinary? Young Minorities and Integration}

In terms of answering the study's main questions, the participants provided thoughtful and diverse commentary. Methodologically, there may be some value in conducting more interviews with the non-Muslim participants, in order to make better comparisons, or in securing more male participants. Nonetheless, the findings of this research still managed to display certain consistencies, confirming the conclusions of others while indicating the way that a later generation than that found in Jiwani (1989) as well as an older sample might show some maturing and consolidating of the insights provided in Durham (2004) or Maira (2002). Jiwani's respondents provide mixed responses and appear occasionally unsure of how they view themselves, signifying some uncertainty about their place in Canadian society, while the American informants in Durham and Maira walk a fine line between considering themselves American and Indian all at once. Most participants here offered a position on nationality that was almost unequivocal, even if they felt they were constantly made to account for their ethnic origins and/or religious background, which most described as lending considerable richness to their lives and upbringing, even if this richness was occasionally complicated by the challenge of juggling multiple identities. Muslims and Sikhs seemed particularly conscious of the burden of explaining themselves to others, and especially aware of skewed representation of their communities in media. 
While the fact of the September 11 attacks was hinted at in some Muslim respondents' remarks, particularly when they spoke of the way others perceived them, no such demarcating event was addressed by Sikh participants, who appeared to be referencing a long history of discrimination. Although the emphasis in this study was on Muslims, whose responses did seem to indicate a high degree of consciousness around identity formation and expressions of that identity in a society most saw as biased, Sikhs gave answers that were similar in some respects. This fact, combined with the very close coherence between these Sikh participants' answers and the ones provided in Desai (2005), suggests to me that a study on Sikhs might be equally warranted if one wanted to narrow the scope of participants. This may be because Muslims and Sikhs experienced a similar sense of marginality; while Muslims appeared to express awareness of a global trend towards intense scrutiny of Islam, Sikhs also implied that they had long been the subject of stereotyping, in media and elsewhere. As a quasi-insider with a pronounced interest in and knowledge of Muslim South Asians, I was nonetheless struck by the consistent nature of the observations made by the Sikh respondents, even in their small numbers. Any of these religious groups, in fact, deserves further examination in the context of identity construction, and this type of research need not be done by an insider. Indeed, I am unsure if my identity as a Canadian Muslim of South Asian origin played a significant role here. It may have helped me interpret interview comments, but I think that this process was also theoretically informed to a large extent. If it did play an ameliorating role, it may have been in the sense that participants seemed to speak to me with a sense of ease, perhaps feeling that I might recognize the kinds of observations they made. In retrospect, I think that reflexivity did not affect the results of the research, but it 
could have done. The temptation to voice my own opinions or to share experiences was strong, and occasionally I did share an experience if I felt it might illustrate a point better, but for the most part I tried to act more as a researcher than a deeply involved participant, preferring to hear these young people speak in their own voices without notable interference. In choosing to follow this path, I came across findings that I had not anticipated, but this had its advantages. The issue of gender surfaced over and over again, even though it was not built into my research questions, demonstrating that it continues to be salient in studies of film and/or South Asian culture, and a real source of discontent as well as a catalyst for change.

If one wanted to further broaden the scope of such research, a cross-generational study might prove interesting. As noted in previous chapters, young people are a source of fascination to many academics because of the role they will play in shaping the future. This study provides a glimpse into what thought processes and behaviours may arise following adolescence or the very early stages of adulthood for those second-generation immigrants who have been largely raised in Canada, but who are still affected by their parents' experiences of migration, or their own memories of this. Adding to this, the young adults who are already members of the third generation might prove especially interesting in indicating whether acculturation simply increases, if this gives way to assimilation, or if feelings of marginalization do persist and, as Glazer and Moynihan (1963) speculate, cause third-generation youth to seek out a connection to their cultural origins (also see Patel, 2006, p. 159). A look at older members of the family may also provide insight into the parenting techniques that were used to foster an awareness of ethnic origins, or may also help establish a comparative reading of the degree to which 
older members are able to integrate. Studies of immigration sometimes suggest, in alignment with the responses provided here, that first-generation immigrants are more likely to nurse beliefs in the immutability of the society left behind, while their children, whose chief or initial source of exposure is often the oral history provided by parents, may eventually rebel against imposed mores that they see as outdated and meaningless, only to learn later that these are indeed out of date everywhere except in diaspora. Participants in this research simultaneously endorsed the importance of their upbringing in providing a sense of ethnic identity, and critiqued the contradictions found in the practice of their relatives. Moreover, they themselves made predictions regarding the way in which their own children would be less affected by some traditions and practices, predictions whose outcomes might be useful to monitor.

Despite their own awareness of change, though, it is not possible to say that the young people in this study are immune to the lure of the countries in which they or their parents were born. It is not at all uncommon for immigrants to embark on return trips, sometimes even with the intent of settling down permanently. Some return for personal reasons, others for economic ones, although there are those who carry out a limited return, establishing a home but maintaining multiple citizenship in order to facilitate frequent travel or to allow overseas alternatives for the schooling of their children. This does occur and, indeed, is among the practices currently being encouraged by the government of India as it seeks to benefit from diasporic human capital.

The young people in this case, however, may maintain considerable interest in the countries where they or their parents were born and may even pursue relevant travel or study of their own accord. Unlike the frequent flyers in Ong (1999), though, very few 
suggested any possibility of moving back and forth constantly between these places, and even fewer hinted at any permanent settlement in the place(s) of their parents' birth. Several did note that they had taken trips to these places, trips that some saw as a form of homecoming and others as tourism and still others as career development, but if any saw it as the first step in a circular process of return, they did not say so. More often, these young adults suggested that places like India, Pakistan or East Africa were still not ones where they fully belonged, and very few used the language of "going back," a constant refrain among Maira's participants, many of whom were second-generation immigrants who had never been to India (2002, pp. 112-113). Having been educated and raised in Canada, with extensive familial, professional and/or peer networks and with an emotional investment in their Canadian citizenship, my own respondents found it difficult to adopt a mentality that would see their parents' home countries as their own. Some remarked sentimentally on these places and felt affection for them, but they did not comment on them as home.

This may hearken back to what appeared to be a widespread belief that Canada was a place where they could balance the multiple layers of their identities, a departure from the British youth of Pakistani/Kashmiri origin in Cressey (2006), some of whom dislike Pakistan and Kashmir intensely while others finally find a belonging there that they think will never be possible in Britain. In contrast, Canada seems to be a place where Muslims and South Asians continue to seek a new home. As observed throughout this dissertation, both Muslims and South Asians are significant contributors to immigration growth in Canada, especially in major cities. As a 2007 poll conducted by Environics and CBC indicates, many Muslims living in Canada acknowledge the presence of hostility or 
prejudice, but for the most part, they are happy to live in Canada, wish to fit into mainstream society, and demonstrate higher levels of satisfaction than what is displayed by Muslims in other parts of the world ("Canada's Muslims", 2007). For the young people in the present study, the difference from Canada was not the only aspect that struck them when they embarked on these trips. Some were also well aware that they were seen as fundamentally foreign from locals, a fact that they thought was unlikely to change, even if they worked constantly to acquire the correct linguistic skills, dress or behaviours.

Some, similar to the young people in Maira (2002), may continually seek out those avenues of cultural retention that they believe to be the most genuine, despite the fact that this intensity is likely unmatched in South Asia. As one of Maira's interviewees observed, those who live in South Asia are more likely to take cultural and religious practice for granted, while those living in diaspora, continually reminded of the possibility of loss, may approach these matters from the perspective of work or obligation. For instance, Maira notes the fact that some of her participants worked hard to ensure they were speaking the most technically correct Hindi possible in order to appear optimally authentic, even when employing terms that were generally Anglicized by Indians living in India (2002, p. 146). The young people I interviewed had widely varying approaches to language and culture, similar to the diversity exhibited by other participants in Gillespie (1995) or in Maira (2002). Some were fluent in South Asian dialects, others not at all, while many occupied a hazy middle ground that they admitted would leave them unable to pass on any linguistic skills in this area to their children. However, not all of them saw this as genuine loss. There was deep regret for a few and 
acceptance from others, as well as a suggestion that other languages would prove to be more useful to them in their Canadian settings. While some embraced the fact that they could communicate with their parents and eventually their children in South Asian dialects, others saw this as a convenience but not a necessity. Indeed, some acquired proficiency in Hindi or Urdu independently of any urging from their parents, learning this skill almost accidentally during the watching of Hindi films.

Overall, there were numerous differences in the ways the young adults in this study saw the retention of language, culture and religion. Compared to their parents, some were less likely to engage in related rituals, others continued to seek seemingly authentic methods of practice, and most tended towards a rather selective approach where they did not feel bound to all the rituals that were important to their parents, but they would continue to observe those that carried meaning for them. Unlike the participants in Maira (2002), who seemed to experience some pressure to fit into South Asian communities where failure to conform was condemned, these young people appeared to feel more free to move in and out of different social circles, including South Asian ones, and they were able to find places for themselves in each, echoing the observations of Handa (2003). Most seemed to feel that evolution was natural; the loss of linguistic skills or cultural memories was unfortunate in some respects, but they were working to forge new cultural opportunities, doing so in a way that had been unavailable to their parents. If one culture was unfamiliar, most seemed to see it as a learning experience, while others saw these experiences as interesting but not crucial to their identity.

The participants here defined that identity differently in terms of ethnicity or religion, but most found common ground in their national identity. National identity was 
seen as separate from ethnic identity, countering Howard-Hassman's (1999) reasoning for seeing these as the same. This distinction may well explain the considerable disparity between the findings here and those of Reitz and Banerjee (2007), who claim that second-generation immigrant youth, including South Asians, are unlikely to self-identify as Canadian. Reitz and Banerjee explain the process they used to try and discover whether these youth saw themselves as Canadian:

"What is your ethnic or cultural identity?" This was asked following the series of questions on ancestry, and for which the respondent was read the statement: "I would now like you to think about your own identity, in ethnic or cultural terms. This identity may be the same as that of your parents, grandparents or ancestors, or it may be different. (2007, p. 539, italics in original)

The inability of the researchers in this case to acknowledge the difference between nationality and ethnicity leads them to conclude that these youth are improperly integrated and that each generation of visible minorities is less likely to see themselves as Canadian. In actual fact, Reitz and Banerjee's (2007) study is simply one more example of the ways in which the complex identities of minority youth are misunderstood and misrepresented. For the most part, my own informants were likely to articulate a belief that nationality may have a connection to ethnicity and religion, but they did not see these as the same.

It is true that some Muslims in the current study, like the European Muslims cited in Saunders (2007), placed their religion first when summarizing their identities, while others spoke of their cultural origins, but in several cases they also indicated that they did this because their self-identification as Canadian was so often seen as insufficient by others. In the case of Muslim informants, their awareness that Islam was the subject of both scrutiny and criticism may have contributed to their emphasis on religious identity. It was clear that several had been led to consider their religious identity, and the 
positioning of Islam within various societies, more carefully because of a perception that their religion was misunderstood. While this misunderstanding may have intensified in the wake of September 11,2001, it did not arise simply out of the events that occurred that day. Several participants were able to identify longstanding problems of religious representation in media and among their acquaintances, problems that are hinted at even by the informants in Jiwani (1989). The young people in this study, even those who operated from a position of relative privilege because their parents were middle-class and/or educated, knew what it meant to be excluded from society for a protracted period of time and they had developed techniques for addressing this. Some used these moments as teaching experiences for those who would question their identity, while others were dismissive, but none seemed to feel shaken in their beliefs regarding their nationality or their right to claim it. Unlike the young South Asian women in Durham (2004), who had their own methods of creating hybrid identities but also indicated a kind of outsider status in American society, the respondents were more likely to exhibit resistance to any attempts to confine them to the margins.

As detailed by Hoodfar's (2003) and Khan's (2000) interviewees, marginalization and resistance can come from several sources, encompassing acts both large and small. One approach assumed by some of the young women in Hoodfar (2003) was to educate themselves about their culture and religion, in order to answer the criticisms of others, while simultaneously refusing attempts to exile them to the private sphere or to otherwise silence them. The young people in this study evidenced something similar, rejecting attempts to downgrade or deny their citizenship. Is Kumar's description of the process of becoming a citizen, cited at the beginning of this chapter, too simplistic? Perhaps. It can 
be read as valorizing the assimilative functions of such a process, but at the same time it may also speak to an eventual diminishing of the emphasis upon Canadians of South Asian origin as something other than Canadian. The young people in this study make clear the fact that they are often singled out as different, and sometimes this marking occurs both in Canadian society and in the communities or countries that might be identified as places of ethnic communality. At the same time, however, they also indicate their refusal to accept this categorization, at least in terms of their national identity. Asked repeatedly over the years about their origins or their "real" nationality, each has developed his or her strategies for answering such questions from strangers, but few seem to find it necessary to ask of themselves. They were and remain Canadian, citizens rather than immigrants, as Kumar summarizes.

It may be too much, however, to say that Kumar's prognosis is entirely accurate. These young people do stand out, even when they have been born here, educated here and speak English, sometimes exclusively. At the same time, they saw-or wanted to see- their society as a place in which they were free to stand out in any number of ways. Their Canadian birthright, as several of them described it, was to embrace the cultures or religions in which they had been raised without shedding one ounce of their national pride or sense of belonging. They were exceptional, but not by choice. They sketched a picture of a society which has yet to fully understand them and their positioning, but they also recognized its promise. As Anderssen and Valpy (2003) suggest in their article on young Canadians in their twenties, they were conscious of having been raised in a country where multiculturalism is enshrined in law, and they attempted to make the most of that right. 
All of them acknowledged their origins, but in different ways. Some of them problematized their culture and their religion, while others accepted these legacies with apparent ease. Even when an interviewee did acknowledge tensions with ethnic or religious communities, this did not necessarily translate into a repudiation of either, perhaps because, like the participants in Bhimani (2003), they realized the extent to which cultural and religious dictates have been matters of interpretation, rather than representing something intrinsic and static. They seemed to indicate an awareness of others and where they fit into society - Canadian, diasporic or otherwise. Close to two decades have passed since Jiwani's (1989) interviewees expressed some puzzlement over their ethnic identity and their relationship to other South Asians, and in that time, Canada has become increasingly diverse while the world has seen the social and political consequences of failing to bridge cultural clashes. These young people, like those in Maira (2002) and Desai (2005), have given a great deal of thought to who they are, and who they want to be, in part because they feel that ignoring their heritage and identity is simply not an option. This attention to identity dovetailed with efforts by the Canadian state to acknowledge them, as well as the consistent attempts from diasporic industries to market to them as a loosely grouped global community. Many of these themes emerged in their interviews, as discussed in the following section.

Even within this small group, there were a range of issues and points covered in the interview recordings and transcripts. Firstly, the diversity of the respondents' thoughts and opinions was sufficiently pronounced to demonstrate that there are no definite factors that can simply and predictably dictate the way that young people will internalize their thoughts about culture, faith and nationality. I opened this dissertation by 
making reference to various studies from The Globe and Mail (in Anderssen \& Valpy, 2003) and from Reitz \& Banerjee (2007) which made differing claims about the nature of nationality for Canadian youth, and suggested that I hoped to add the perspectives of my own participants to such claims. The sample was too small to allow for broad generalizations, but provided rich and complex data, demonstrating apparent contradictions that appear to be the hallmarks of cultures, societies and people in flux. Many of these, however different in detail, had links to previous studies: the young adults here indicated the generally confident sense of self cited in Handa (2003), but they also noted their awareness of, and occasional vulnerability to, pressures from a variety of sources, such as those chronicled in Hoodfar (2003), Khan (2000) and Maira (2002). Moreover, even their most confident assertions were sometimes undermined by their descriptions of upbringing or everyday life. The findings regarding media and nationalism were similar in some respects to those in Desai (2005), Durham (2004), Gillespie (1995), Jiwani (1989) and Maira (2002), where informants were often aware of attempts to impose patriotic readings upon them but generally resisted these, instead embracing an enhanced sense of ethnic self. It was clear that the period in time as well as the geographical location of the participants were definite factors in establishing a sense of nationalism and a particular reading of media.

Although this research project was constructed around media, particularly Bollywood, as the central concern, I was also interested in assessing the other factors that would have contributed to identity construction. No one factor seemed to indicate the reason for the strong national identification that emerged as the first finding of this study. Some participants did identify themselves using hyphenated terminology, such as Indo- 
Canadian or Pakistani-Canadian, but with one exception, all identified as Canadian to some degree. A significant number would only identify as Canadian. Many were Canadian-born and pointed out that they had no other home to which they could make such definite reference, even if parents or strangers attempted to emphasize their role as outsiders in Canadian society. Few consciously identified as members of a South Asian or Muslim diaspora, but when they did comment on their relationships with states, industries or individuals in diaspora, this was almost always in the context of ethnic or religious identity, not as national subjects.

Socialization in Canadian educational institutions appeared to be a key factor in helping with the construction of a Canadian identity, although participants named different aspects of this experience. One pointed to official rituals such as the learning and performing of the national anthem, while others spoke more to the acquisition of a kind of cultural capital - interaction with other Canadians from different walks of life helped them understand the forms of behaviour, language and dress that would be deemed normative by the mainstream. Some also described the more formal learning that takes place in such institutions, commenting on the significance they attached to the history of the country, its politics and laws, and in some sense, its linguistic legacies. One participant, seeking to denote the extent to which his parents had distanced themselves from their former country, explained that they wanted him to be fully Canadian and to settle into that society in every way, including developing advanced capability in the country's two official languages. Although creating a sense of nationalism is not a primary purpose for educational institutions, one seems to arise informally, even if it is not the impassioned patriotism found elsewhere. Participants did occasionally note 
instances of discrimination or reminders of difference from their childhood experiences of school, but several cited it as a place that helped them acculturate into Canadian society and to succeed there. Other, less formal activities also contributed to this acculturation, including the formation of a diverse circle of friends and acquaintances, and simple engagement with the neighbourhoods in which they lived.

If the public sphere was the place where young people learned how to feel Canadian in (nearly) every way, the private sphere was more often the space where ethnic practice was learned and maintained. Parents were often cited as a cultural influence, rarely as a national one. One young woman did describe an upbringing in which her father reminded her constantly that she was not truly Canadian, since their family was from Pakistan, but for the most part parents appeared to emphasize ethnic and religious identity more than the notion that their nationality was other than Canadian. Parental influence is hardly surprising, and the importance of extended family and community was also emphasized. Some individuals, especially young women, pointed to rather traditional expectations imposed upon them by their parents, and did discuss the fact that they could not always relate to their parents in the same way that they might relate to friends or others. However, the extreme code-switching described by Maira (2002), in which American youth of South Asian origin transformed themselves in radical ways when leaving the familial domain and entering the social scene, is not mentioned here. It is possible that it takes place, but it was not referenced by any of the participants. The different scope of this study may account for this-Maira's study was specific to a particular manifestation of South Asian culture, one built around parties and clubs in New 
York City, whereas this research does not perform the ethnographic work of Maira's and mainly restricts itself to identity and the interpretation of media.

Other possible reasons do come to mind that might explain this difference in behaviour, if indeed there is a significant disparity. Contrasting Muslims in Canada to those in the United States, two participants suggested that for the latter, an intense pressure to retain traditional ways of thinking is at war with an equally strong compulsion to assimilate into American society. If this is the case, then it might not be that unusual for youth who feel the necessity of appearing comfortable in both cultures to switch, as Maira describes (2002), between the two by wearing conservative clothing and appearing demure with family, then moving to the other extreme by donning-for women-more seductive clothing and for men, clothes often associated with hip-hop culture. The young people in this study were hardly immune to clashes with their parents or others in their communities, but they seemed to have negotiated compromises in some respects and acceptance in others.

The use of media involved other compromises. Despite some level of dissonance and even occasional repugnance, many of the participants continue to view Bollywood films. The simple explanation for this might be that the activity of watching Bollywood films is seen as meaningless in many respects for those participants who single out problematic aspects, including those that denigrate them, and yet continue watching. Possibly they think the significance of these films is minimal. However, it seems to me that their own responses indicate otherwise. One woman, who actually does try to limit the films she watches to those that satisfy her principles and beliefs, points out that experience and education have helped her discard some of the ideas she had earlier 
internalized from Bollywood films regarding romance, gender and beauty, but she thinks it is important to note that she did have them, and she is likely not alone. Another woman, one who is familiar with a broad range of Indian films but also expressed notable dislike of the representation of gender in Hindi movies, voiced a concern about many young South Asian women who appear susceptible to the notions of star-crossed love found in these films. Notions of gender that were perceived as distorted were crucial to the way that some viewers judged these movies, which also spilled over into a distaste for increasingly explicit costumes on women as well as an emphasis on sexuality, a finding whose recurrence was both unexpected and notably pronounced. This emphasis on sexuality was seen as distasteful in part for the way women were portrayed, but also because it seemed to speak to a disconnect with the values of Bollywood viewers, including the purportedly liberal ones living in diaspora. Participants here saw this suggestion both as a personal insult, and as a way of depriving them of family-friendly entertainment that they could otherwise enjoy safely with elders. According to their interpretation then, there was a genuine possibility of being influenced by Bollywood cinema in a variety of ways, even when one focusses on the themes that are seen as being most frivolous.

If we dismiss the possibility that these films have no significance, then, what compels critical young viewers, who have numerous entertainment options available to them and who indicate themselves that watching a Bollywood film involves a considerable investment of time, to continue watching? Even if that viewing is infrequent, it remains a fact. Based on the interviewees' comments, I am inclined to conclude that Bollywood does in fact play some role in the constitution of identity. The 
role may be largely negative, inspiring resistance to the social paradigms alluded to these in the films, or it may be minimal, but it does exist, and in several cases, the role is significant. Despite placing emphasis on a variety of factors, a number of young people did see meaning in Bollywood films, at least in part because of the context in which they consumed these films, and the ability to see themselves represented in some form, however caricatured or unrealistic this depiction might be. Many of them saw the strong nationalism in popular Indian cinema, and the concurrent marginalization of themselves as diasporic subjects, but they professed to be largely unaffected by this, except in the sense that they did sometimes see it as insulting. Media were not seen as having a significant effect on a sense of nationalism, although some did take pride in the Indian film industry itself.

Given the fact that the concept of resistance and its accompanying limitations formed part of the framework of this study, I am interested in the fact that resistance was a recurring theme and yet not fully realized in some respects. Resistance occurred in ways large and small; participants refused to surrender their sense of identity in the face of external challenges, and they offered critical readings of many of the media under discussion. They were invested in a belief that Canada was a pluralist and accepting place, but not necessarily naïve about this. At the same time, there was a distinct ambivalence to their understanding of nationality, an ambivalence that is perhaps less troubled than that in Cressey (2006) or Maira (2002), where racism and prejudice are invoked openly, but it is ambivalence nonetheless. Similarly, in the reading of Bollywood films, there was enormous ambiguity in the way they approached the very thematics they identified. Concerns about gender, diasporic portrayals, religious stereotyping and 
Westernization were debated, sometimes hotly, and informants displayed a keen eye for contradictions or prejudices in the text. Nonetheless, many continued to consume some of these media, and to speak of their favourites in ways that did not always reflect the insightful critique they displayed elsewhere.

Criticisms of diasporic portrayal aside, very few referred to the positive depictions of diaspora in some films, such as $D D L J$, preferring instead to comment on its romantic themes and its production values. Stated rejections of supposedly Western, consumerist themes warred with a cautious affection for films that were seen to be modern and more interesting than older films with darker storylines and fewer special effects. However, some were open about the guilty complicity they felt with such media; they did not always agree with what they saw, yet they continued to watch it. They would have preferred a better alternative, but none was available. Some of this same sense of unwilling complicity also slips into Desai (2005) and Maira (2002), where Bollywood becomes one of the few options for seeing oneself on screen, even if it is in a limited way. The hybrid, transitory strategies for cultural survival that are seen in the way these young people assert identity is also seen in their consumption of media; their reading of Bollywood texts cannot be seen as wholly passive or oppositional, but as part of a multilayered, contradictory, partially satisfactory philosophy of identity-building.

\section{$\underline{\text { You Really Are Global Citizens: Resistance and Reconciliation }}$}

Most find comfort and solace in nationalism; it is an indication of home, comfort, and friends. To be an exile is to be without a nation, a nationality, a home, and security. Nationalism, in Said's estimation, is a God that always fails because it reduces human experience and lines of solidarity between people to territories and borders that in reality carve up the world in unproductive and destructive ways. To be an exile is to relate to all people regardless of their country of citizenship or place of birth. (Abraham, 2006, p. 139) 
The use of Bollywood as a means for identity construction, and that use in combination with other socializing agents, suggests that, similar to the young women in Durham (2004), the respondents in this study are capable of drawing upon myriad cultural elements in coming to terms with who they are. None would align themselves entirely with one identity, preferring instead the richness of the many selves available in a pluralist society. I have commented earlier that a kind of chameleon-like quality exhibits itself in some young minorities, where they learn to move between worlds, a tendency documented as well by Ballard in his study of South Asian Britons (cited in Patel, 2006, p. 158). This quality might not have been overt in all of the individuals studied here, and the ease of this movement undoubtedly varies, but there did seem to be a flexibility in terms of their willingness to engage with a host of elements. Indeed, that engagement seemed consonant with a wish to mine the best of Canadian culture, whose plurality they viewed as imperfect yet necessary and highly desirable. As diversity has become more embedded into Canadian society, it has also become less necessary to move so constantly between worlds, and more possible to combine them. Although this study was not intended to examine romantic relationships, it is interesting to note that several participants made reference to non-South Asian partners, and to the ways they might introduce their culture to those partners. Others noted that they engaged in a variety of cultural activities, South Asian and otherwise, encompassing different religious traditions, as their social circles presented them with the opportunity to learn about others and to demonstrate mutual respect.

In a scenario such as this, which echoes Anderssen and Valpy's (2003) portrayal of a society marked by increased melding of groups and traditions, Kraidy's notion of 
hybridity becomes ever more relevant, with his description of "re-formulating intercultural and international communication beyond buoyant models of resistance and inauspicious patterns of domination" (1999, p. 472). This is not to say that resistance and domination do not take place. Bollywood itself is a medium that embodies, rather curiously, domination, resistance and hybridity all in the same venue. Running roughshod over less powerful competitors, drowning out regional voices, it nonetheless works to establish South Asian pride in the face of foreign media conglomerates, particularly American ones, whose global hegemony is challenged all too rarely. Bollywood does hew to standard formulae and it does endorse many aspects of the very culture it critiques, such as consumerism and excess, but at the same time, it has bent slightly in acknowledgement of the changing needs of diasporic South Asians. According to the respondents in this research and to my own analysis, this attempt at change is often misguided, representing diaspora in ways that only indicate its physical and intellectual distance, yet the effort is there to speak to a number of cultures. In many respects, the hybridity that is thus achieved only validates Araeen's criticism that victory of Bhabha's (1994) hybrid Other means "a triumph of neo-liberal multiculturalism, a part of the triumph of global capitalism" (2000, p. 15).

Undoubtedly, one does not want to romanticize the kind of messy, contradictory, simplified creolization found in these films, aptly dubbed masala films by some for their combination of disparate elements. However, it is a hybridity that allows many in, even if some are accorded more belonging than others. Araeen (2000) comments critically on Bhabha's belief that the hybrid Other is destined to exist on the margins or in an altogether new space, rather than moving freely from the periphery to the centre. The 
young people in this study seem somehow to reconcile the two, bypassing notions that a hybrid space is the same as an exilic space - despite the resistance they encounter when they position themselves in the centre, they continue to attempt moving into that area, even as they maintain an awareness of what it is like to exist on the periphery.

In the analysis these participants offered, the new space they create can be found simultaneously in the centre and on the margins. Muslims in particular seemed to feel that they were asked to exist on the margins, but that did not stop any of the young people in this study from pushing back against such attitudes, similar to the kind of defiance exhibited by some of the subjects in Hoodfar (2003) and Khan (2000). As in those studies, some tended to gain confidence by assimilating into Canadian society, minimizing as many ethnic markers as they could, while others tried as much as possible to hold onto ethnic and religious traditions, but nearly all moved towards a complicated middle ground. They researched their options, educated themselves and attempted to teach others about difference. In fact, although Abraham's (2006) quote at the beginning of this section refers to the plurality and sensitivity to difference exhibited by exiles, these young people demonstrated some of those same traits while refusing to be classified as exiles. Naturally, this comes with its own set of contradictions: they have concerns that stretch well beyond the borders of Canada or their own ethnic or religious communities, but many of them did fall back on the solace of finding home in Canada, at least the Canada they envisioned. Referring to the willingness of migrants to see vast promise and hope in an imagined America, Harzig and Hoerder describe a place that is "neither the United States nor Canada but a transnational image of potentialities" (2006, p. 44). The potentialities these young people seem to glimpse are touched, as May Joseph suggests in 
her discussion of nomadic identities, with "incomplete desires of community and allegiances" (1999, p. 19), but their citizenship is not really nomadic, performed across and within boundaries (1999, p. 17).

Citizenship is a concrete entity, as is nationalism. It places demands upon the self, of course, and these are demands that must be weighed against the equally pressing demands of ethnic and religious communities. Citizenship, in this formulation, is work, as is identity construction, and neither can be denied. The young people here suggest that they have devoted much thought to who they are and how they want to live, but not necessarily where they want to live. Having been raised in Canada, they have considered how to carve out their existence here, even if they live with memories or stories of other places. The complexity of living such an existence, actually inhabiting that transnational vision of potentialities, may seem burdensome, and no doubt it has been at times. Undoubtedly, there is a form of labour involved here, yet it is a labour that appears to offer considerable rewards and that cannot be neglected if one wishes to continue the process of societal and communal change. The creation of hybrid selves appears to be a natural process in some ways, one bound to occur over time and across space. Some young people seemed to refer to this rather casually, accepting this as a fact of life. In their specific comments about their influences, mediated interpretations and perceptions of nationalism and ethnicity, however, they indicated that creation of the self was work, and was an ongoing construction. Overall, the methods that these individuals used to blend resistance, assimilation and integration, sometimes all at once, are testament to their ability to continue building not just their selves, but the Canadian and global society that they envision, a space of extensive diversity and acceptance. 
At the beginning of this dissertation, I commented on an initial desire to explore the participants' feelings towards citizenship and civic engagement. Although this aim soon moved into the background, comments regarding citizenship did filter into a few of the interviews, demonstrating the fact that the young adults here have indeed, as predicted, been devoting thought to their place in Canadian society, and the obligations and rights attached to their citizenship. At a time when dual citizenship and multiculturalism experience protracted attack for their failure to integrate minority Canadians (DiManno, 2006; Ford, 2006), nearly every respondent here indicated a belief that they are Canadian and that Canada is their home, regardless of any messages received to the contrary from any source. They took Canada's claims to multiculturalism seriously, and expected their country and their fellow citizens to live up to these claims. In their conviction that this was possible, many found a sense of belonging, however uneasy.

This very uneasiness, this awareness of possible unsettlement, might be the reason that nationalism did not translate here into parochialism or assimilation. They took the subject of their origins seriously and seemed to feel a certain global consciousness in relation to this. The global citizenship, the constant travel, the feeling of belonging to nowhere or nothing--informants were aware of these, but not necessarily defined by them in the same way as the individuals described in Joseph (1999) or Ong (1999). Global citizenship was abstract for some and a serious concept for others, and cosmopolitanism was something they endorsed rather loosely. Nearly all indicated a home base, and a distinct national identity, which they combined with a sense of solidarity to others in diaspora, for instance. Many of the participants were well-travelled 
and several were multilingual. It would be stretching the point to suggest that all of these young adults are cosmopolitan in every sense or even in most senses, but several expressed an obligation to understand other cultures and regions in a manner that indicated they felt the commitment to pluralism works both ways. Asked if he would use Bollywood films to acculturate his children in the same manner that his parents employed, E3 said that he would but that he would also seek to provide a balanced experience, incorporating other foreign films, for instance. His comments here serve as perhaps the best summary regarding the participants' attitudes, as well as the role they will undoubtedly play in Canada's present and future:

Because I think we're living in a world and a time now where you do have to be in touch with your own identity, otherwise you seem to lack one and it's tougher to keep up with that when you have so many different-not necessarily conflicting — but different influences. With that said though, I think there's a need to be much more aware of the larger world, so knowing your own is important but knowing others is important as well, because you really are global citizens.

The global citizenship described here is a state of mind, an acknowledgement of obligation. It is not a political manifestation of cosmopolitanism or world citizenship (Heater, 1996, 1999), but an outcome of growing up in an environment where transnationalism is a known fact. Various forms of transnationalism and diaspora have been witnessed by these young people and others during their upbringing. Even when constant movement, remittances or transnational communication are not directly part of their experience, they are aware of such practices and may be further reminded by flows of media and goods.

Transnationalism and diaspora are undoubtedly more real to some people than to others. Some might argue that the individuals in this study are particularly privileged ones. Although they possessed varying educational levels and backgrounds and may have 
been different in terms of class, their time in Canada had provided them with linguistic and social capabilities that more recent immigrants, or older immigrants, might have struggled to obtain. These informants were less likely than some of their parents or grandparents to have spent many years making significant adjustments to Canadian life. At the same time, this was part of the history that some of these young people shared, and this gave them an insight into a transnational or a diasporic existence. This insight also may have arrived at least in part due to their awareness that a transnational reality was inscribed onto their bodies by those who saw them; non-South Asians saw them as immigrants, regardless of how hard they had worked to adapt to Canadian society, while South Asian Canadians might be equally inclined to view them as outsiders on a variety of levels: they could be insufficiently South Asian, they might not subscribe to the same beliefs, and/or they were simply among those who did not belong to the mainstream. At the same time, governments such as that in India, as well as a number of Indian industries, make clear their belief that individuals of South Asian origin belong to a transnational economic network, and they attempt to speak to them as members of a global family or market.

There is work involved in the construction of identity, then, and a number of factors enter into this. Some are the purview of the state, others of media or upbringing, but ultimately every individual will combine these differently in arriving at a space that allows for a workable combination of nationality, ethnicity and religion, a blend that can be explained to the self and to others. This was a work in progress for several participants, although some acknowledged this frankly from the very beginning and others seemed to arrive at this conclusion once they had interrogated their own beliefs 
further. There is nothing simple about the identity of the Canadian nation, the one with which these young people identified primarily, nor is there anything simple about creating an identity that allows one to live in multiple worlds without sacrificing a sense of unified self.

Hybridity is not an easy solution, nor is it the only one. However, even the most optimistic participants interviewed here knew the impossibility of simply stepping outside of the socializing institutions they described and entering mainstream Canadian society as fully-fledged and completely accepted. Marked from the very beginning as different, placed under additional pressure when stereotypes and generalizations are imposed onto them following events involving Muslims or South Asians, they must find a way to cope. Each person in this study subscribed, unconsciously or not, to some degree of hybridity as a result. Most sought to bridge the differences between their various social networks, introducing non-South Asian friends to their culture and lives.

Whether or not they were equipped for the task, they found themselves, as Kumar suggested (2002, p. 178), performing the roles of cultural interpreters, facing the need to educate themselves and then translate to those whose own experiences might not have been as broad. For the latter, inhabiting one space while drawing-at least mentallyupon the influences of many others may seem like an impossibility, an impingement upon citizenship and nationalism. All the same, this is the choice with which diasporic individuals, especially those whose difference is as marked as that of South Asians and Muslims, are faced. In a space that simultaneously is and is not displacement, that is home and not home, that is both acceptance and exclusion, these young people are freed from instinctive commitments to unitary identities and accepted beliefs, but such apparent 
liberty is accompanied by the requirement to apply conscious thought and effort to new identities, to bridge-building, to cultural, religious and societal transformation.

The glorious optimism expressed by Valpy and Anderssen (2003), in which immigrant youth come to change the face and the future of Canada, may be going too far, but if diasporic individuals do maximize the possibility of the liminal space they inhabit, they may well transform the communities and institutions in which they dwell. The participants in this study, like the young woman from whom Kumar (2002) quotes at the beginning of this chapter, were well aware of the considerable obstacles attached to effecting such evolution, in which difference becomes the norm, yet most refused to shy away. Surrounded by various pressures, conscious of their responsibilities and rights, they nonetheless saw themselves as capable of undertaking the challenges of a hybrid, fluctuating, not-entirely-definable identity. To avoid doing so is, like unthinking resistance, simply futile. 


\section{References}

Abraham, M. (2006). History, memory, and exile: Edward Said, the New York intellectuals, and the rhetoric of accommodation and resistance. The Journal of the Midwest Modern Language Association, 39(2), 133-155.

Abu-Laban, Y., \& Stasiulis, D. (2000). Constructing "ethnic Canadians": The implications for public policy and citizenship: Rejoinder to Rhoda HowardHassman. Canadian Public Policy, 26(4), 477-487.

Abu-Lughod, L. (1991). Writing against culture. In R. G. Fox (Ed.), Recapturing anthropology: Working in the present (pp. 137-162). Santa Fe, NM: School of American Research Press.

Ackah, W., \& Newman, J. (2003). Ghanaian Seventh Day Adventists on and offline: Problematising the virtual communities discourse. In K. H. Karim (Ed.), The media of diaspora (pp. 203-214). London: Routledge.

Ahmed, L. (1982). Women and gender in Islam: Historical roots of a modern debate. New Haven, CT: Yale University Press.

Ahmed, L. (1999). A border passage: From Cairo to America-a woman's journey. New York: Farrar, Strauss and Giroux.

Albers, H. (Producer), Avril, P. (Producer), \& Sumar, S. (Director). (2003). Khamosh Pani [Film]. Karachi, Alsace \& Potsdam: Vidhi Films, Unlimited \& Flying Moon Filmproduktion.

Alessandrini, A. C. (2001). "My heart's Indian for all that": Bollywood film between home and diaspora. Diaspora, 10(3), 315-340.

Ali, M. (Producer \& Director). (1981). Umrao Jaan [Film]. Mumbai: Integrated Films. Allemang, J. (2005, September 24). The limits of tolerance. The Globe and Mail, p. F6.

Alvesson, M., \& Sköldberg, K. (2000). Reflexive methodology: New vistas for qualitative research. Thousand Oaks, CA: Sage Publications.

Alvi, S., Hoodfar, H., \& McDonough, S. (Eds.). (2003). The Muslim veil in North America: Issues and debates. Toronto, ON: Women's Press.

Amrohi, K. (Producer \& Director). (1971). Pakeezah [Film]. Mumbai: Mahal Pictures and Sangeeta Enterprises.

Anand, C. (Producer \& Director). (1970). Heer Raanjha [Film]. Mumbai: Himalaya Films.

Anand, D. (Producer \& Director). (1971). Hare Rama Hare Krishna [Film]. Mumbai: Navketan International Films.

Anderson, B. (1983). Imagined communities: Reflections on the origin and spread of nationalism. London: Verso.

Anderssen, E. (2003, June 7). Two weddings, one marriage. The Globe and Mail, pp. F1, F3-7, F12.

Anderssen, E., \& Valpy, M. (2003, June 7). Face the nation: Canada. The Globe and Mail, pp. A8-9.

Ang, I. (2001). On the politics of empirical audience research. In M. G. Durham \& D. M. Kellner (Eds.), Media and cultural studies keyworks (pp. 177-97). Malden, MA: Blackwell Publishers Inc.

Appadurai, A. (1991). Global ethnoscapes: Notes and queries for a transnational anthropology. In R. G. Fox (Ed.) Recapturing anthropology: Working in the 
present (pp. 191-210). Santa Fe, New Mexico: School of American Research Press.

Appadurai, A. (1996). Modernity at large: Cultural dimensions of globalization. Minneapolis: University of Minnesota Press.

Araeen, R. (2000). A new beginning: Beyond postcolonial cultural theory and identity politics. Third Text, 50, 3-20.

Asif, K. (Director). (1945). Phool [Film]. Mumbai: Famous Films.

Asif, K. (Producer \& Director). (1960). Mughal-e-Azam [Film]. Mumbai: Sterling Investment Corp.

Baghdadi, R., \& Rao, R. (1995). Talking films. New Delhi: Indus.

Barjatya, S. R. (Producer \& Director). (1994). Hum Aapke Hain Koun [Film]. Mumbai: Rajshri.

Barnouw, E., \& Krishnaswamy, S. (1980). Indian film. New York: Columbia University Press.

Baron, C. (Producer) \& Nair, M. (Producer \& Director). (2001). Monsoon Wedding [Film]. New York, NY: IFC Productions \& Mirabai Films.

Basch, L., Glick Schiller, N., \& Szanton Blanc, C. (1994). Nations unbound:

Transnational projects, postcolonial predicaments, and deterritorialized nationstates. Postfach, Switzerland: Gordon and Beach Publishers.

Beck, U. (1994). The reinvention of politics: Towards a theory of reflexive modernization (M. Ritter, Trans.). In U. Beck, A. Giddens, \& S. Lash (Eds.) Reflexive modernization: Politics, tradition and aesthetics in the modern social order (1-55). Stanford, CA: Stanford University Press.

Beck, U. (2000). The cosmopolitan perspective: Sociology of the second age of modernity. British Journal of Sociology, 51(1), 79-105.

Bedi, B. (Producer) \& Kapoor, S. (Director). (1994). Bandit Queen [Film]. London \& Delhi: Channel Four Films \& Kaleidoscope Entertainment.

Bhabha, H. K. (1994). The location of culture. London and New York: Routledge.

Bhabha, H. K. (2001). Unsatisfied: Notes on vernacular cosmopolitanism. In G. Castle (Ed.), Postcolonial discourses: An anthology (pp. 39-52). Oxford: Blackwell Publishers Ltd.

Bhaskar, I. (1999). Postmodernism and neo-Orientalism: Peter Brook's Mahabharataproducing India through a body of multicultural images. In S. B. Plate \& D. Jasper (Eds.), Imagining otherness: Filmic visions of living together (pp. 133-65). Atlanta: Scholars Press.

Bhimani, H. (1995). In search of Lata Mangeshkar. New Delhi: Indus.

Bhimani, S. (2003). Majalis al-ilm: Sessions of knowledge-Reclaiming and representing the lives of Muslim women. Toronto: TSAR Publications.

Bhushan, P. (Producer) \& Anand, S. (Director). (2005). Salaam Namaste [Film]. Mumbai: Yashraj Films.

Bissoondath, N. (2002). Selling illusions: The cult of multiculturalism in Canada (2nd ed.). Toronto, ON: Penguin Books.

Biswas, M. (2000). The couple and their spaces: Harano Sur as melodrama now. In R. S. Vasudevan (Ed.), Making meaning in Indian cinema (pp. 122-142). New Delhi: Oxford University Press. 
Booth, G. D. (1995). Traditional content and narrative structure in the Hindi commercial cinema. Asian Folklore Studies, 54(2), 169-190.

Bose, S. (Director). (1964). Dosti [Film]. Mumbai: Rajshri Productions.

Boyarin, D., \& Boyarin, J. (2003). Diaspora: Generation and the ground of Jewish identity. In J. Evans Braziel \& A. Mannur (Eds.), Theorizing diaspora: A reader (pp. 85-118). Malden, MA: Blackwell Publishing.

Brah, A. (1996). Cartographies of diaspora: Contesting identities. London and New York: Routledge.

Braziel, J. E., \& Mannur, A. (2003). Nation, migration, globalization: Points of contention in diaspora studies. In J. E. Braziel \& A. Mannur (Eds.), Theorizing diaspora: $A$ reader (pp. 1-22). Malden, MA: Blackwell Publishing.

Brenner, N. (1999). Globalisation as reterritorialisation: The re-scaling of urban governance in the European Union. Urban Studies, 36(3), 431-51.

Cairns, A. (1995). Reconfigurations: Canadian citizenship and constitutional change. Toronto: McClelland \& Stewart.

Canada's Muslims, an international comparison. (2007). Retrieved August 1, 2007 from http://www.cbc.ca/news/background/islam/muslim-survey.html

Carens, J. H. (2000). Culture, citizenship, and community: A contextual exploration of justice as evenhandedness. Oxford: Oxford University Press.

Cesari, J. (2002). Islam in France: The shaping of a religious minority. In Y. Y. Haddad (Ed.), Muslims in the West: From sojourners to citizens (pp. 36-51). New York: Oxford University Press.

Chakravarty, S. S. (1993). National identity in Indian popular cinema, 1947-1987. Oxford: Oxford University Press.

Chopra, A. (Producer), Chopra, Y. (Producer), \& Kohli, K. (Director). (2006). Fanaa [Film]. Mumbai: Yashraj Productions.

Chopra, B. R. (Producer \& Director). (1982). Nikaah [Film]. Mumbai: B.R. Films and United Productions.

Chopra, V. V. (Producer \& Director). (1993). 1942: A Love Story [Film]. Mumbai: Vinod Chopra Productions.

Chopra, V. V. (Producer \& Director). (2000). Mission Kashmir [Film]. Mumbai: Vinod Chopra Productions.

Chopra, Y. (Producer \& Director). (1991). Lamhe [Film]. Mumbai: Yashraj Films.

Chopra, Y. (Producer) \& Chopra, A. (Director). (1995). Dilwale Dulhania Le Jayenge [Film]. Mumbai: Yash Raj Films.

Chopra, Y. (Producer \& Director). (2004). Veer-Zaara [Film]. Mumbai: Yash Raj Films.

Chowdhry, P. (2000). Colonial India and the making of empire cinema: Image, ideology and identity. Manchester, UK: Manchester University Press.

Crichton, M. (Producer). (1994). ER [Television series]. Burbank, CA: NBC.

Clifford, J. (1997). Routes: Travel and translation in the late twentieth century. Cambridge, MA: Harvard University Press.

Cohen, R. (1997). Global diasporas: An introduction. Seattle: University of Washington Press.

Coleman, A., \& Higgins, W. (2000). Racial and cultural diversity in contemporary citizenship. In A. Vandenberg (Ed.), Citizenship and democracy in a global era (pp. 51-76). New York: St. Martin's Press. 
Cottle, S. (Ed.) (2000). Ethnic minorities and the media: Changing cultural boundaries. Buckingham, UK: Open University Press.

Cressey, G. (2006). Diaspora youth and ancestral homeland: British Pakistani/Kashmiri youth visiting kin in Pakistan and Kashmir. Boston: Brill.

Dagger, R. (2002). Republican citizenship. In E. F. Turner \& B. S. Turner (Eds.), Handbook of citizenship studies (pp. 145-57). Thousand Oaks, CA: Sage Publications.

Darling, M. (Producer) \& Donnelly, C. (Producer). (2007). Little Mosque on the Prairie [Televisions series]. Regina and Toronto: CBC.

Day, J. (Producer), Dean Pilcher, L. (Producer), Gigliotti, D. (Producer) \& Nair, M. (Director). (2004). Vanity Fair [Film]. Universal City, CA: Focus Features.

Dayan, D., \& Katz, E. (1992). Media events: The live broadcasting of history. Cambridge, MA: Harvard University Press.

Desai, J. (2004). Beyond Bollywood: The cultural politics of South Asian diasporic film. New York and London: Routledge.

Desai, J. (2005). Planet Bollywood: Indian cinema abroad. In S. Davé, L. Nishime, \& T. G. Oren (Eds.), East Main Street: Asian American popular culture (pp. 55-71). New York: New York University Press.

Desai, M. (Producer \& Director). (1977). Amar Akbar Anthony [Film]. Mumbai: Hirawat Jain and Company, M.K.D. Films and Manmohan Films.

Desai, S. (Producer) \& Desai, M. (Director). (1960). Chhalia [Film]. Mumbai: Subhash Pictures.

Deutsch, K. W. (1966). Nationalism and social communication: An inquiry into the foundations of nationality. (2nd ed.). Cambridge, MA: The M.I.T. Press.

Deutsch, K. W. (1969). Nationalism and its alternatives. New York: Alfred A. Knopf.

Deutsch, K. W. (1974). Politics and government: How people decide their fate. (2nd ed.). Boston: Houghton Mifflin Company.

Dhareshwar, V., \& Niranjana, T. (2000). Kaadalan and the politics of resignification: Fashion, violence and the body. In R. S. Vasudevan (Ed.), Making meaning in Indian cinema (pp. 191-214). New Delhi: Oxford University Press.

Dhariwal, M. (Producer) \& Verma, T. (Director). (2002). Maa Tujhhe Salaam [Film]. Mumbai: Eros International.

Dharker, A. (1997). Sorry, not ready: Television in the time of PMdarshan. HarperCollins Publishers, New Delhi.

Dickey, S. (1993). Cinema and the urban poor in South India. Cambridge, MA Cambridge University Press.

DiManno, R. (2006, October 25). Since when is covering women's faces feminism? The Toronto Star, p. A2.

Dossa, P. (1988). Women's space/time: An anthropological perspective on Ismaili immigrant women in Calgary and Vancouver. Canadian Ethnic Studies, 20(1), 45-65.

Durham, M. G. (2004). Constructing the "new ethnicities": Media, sexuality, and diaspora identity in the lives of South Asian immigrant girls. Critical Studies in Media Communication, 21(2), 140-161.

Dutt, G. (Producer \& Director). (1957). Pyaasa [Film]. Mumbai: Guru Dutt Films.

Dwivedi, C. (Director). (2003). Pinjar [Film]. Mumbai: Lucky Star Entertainment. 
Dwyer, R. (2000). All you want is money, all you need is love: sexuality and romance in modern India. London: Cassell.

Faire, S. (Producer) \& Dayot, T. (Producer). (2007, April 1). Comedy Network Presents Russell Peters [Television broadcast]. Toronto, ON: Comedy Network.

Ferguson, S. D. (2002). A cacophony of voices: Competing for the future. In S. D. Ferguson \& L. R. Shade (Eds.), Civic discourse and cultural politics in Canada: A cacophony of voices (pp. 3-14). Westport, CT: Ablex Publishing.

Fernandes, L. (2000). Nationalizing the "global": Media images, cultural politics and the middle class in India. Media, Culture \& Society, 22(5), 611-628.

Finlay, L. (2002). Negotiating the swamp: The opportunity and challenge of reflexivity in research practice. Qualitative Research, 2(2), 209-230.

Ford, T. (2006, October 2). We're changing our ideas on national purpose. The Winnipeg Free Press, p. Al1.

Gaur, M. (1973). Other side of the coin: An intimate study of Indian film industry. Bombay: Vinod Billa.

Ghafour, H. (2006, June 10). Terrorism cases strikingly similar. The Globe and Mail, p. A16.

Ghai, S. (Producer \& Director). (1986). Karma [Film]. Mumbai: Mukta Arts.

Ghai, S. (Producer \& Director). (1997). Pardes [Film]. Mumbai: Mukta Arts Limited.

Ghai, S. (Producer \& Director). (1999). Taal [Film]. Mumbai: Mukta Arts Limited.

Ghai, S. (Producer \& Director). (2001). Yaadein [Film]. Mumbai: Mukta Arts Limited.

Ghuman, G. (2006). The Muslim as the "Other" in Bollywood. Countercurrents.

Retrieved June 19, 2006 from http://www.countercurrents.org/artsghuman210206.htm

Gillespie, M. (1995). Television, ethnicity, and cultural change. London and New York: Routledge.

Gilroy, P. (1993). The black Atlantic: Modernity and double consciousness. Cambridge, MA: Harvard University Press.

Gilroy, P. (1987). There ain't no black in the Union Jack: The cultural politics of race and nation. London: Hutchinson.

Glazer, N., \& Moynihan, D. P. (1963). Beyond the melting pot: The Negroes, Puerto Ricans, Jews, Italians, and Irish of New York City. Cambridge, MA: The M.I.T. Press.

Gokulsing, K. M., \& Dissanayake, W. (1998). Indian popular cinema: A narrative of cultural change. New Delhi: Orient Longman Limited.

Gottschalk, P. (2000). Beyond Hindu \& Muslim: Multiple identity in narratives from village India. New York: Oxford University Press.

Gowariker, A. (Producer \& Director). (2004). Swades [Film]. Mumbai: Ashutosh Gowariker Productions.

Grazer, B. (Producer), Gordon, H. (Producer), Cochran, R. (Producer), \& Surnow, J. (Producer). (2001). 24 [Television series]. Century City, CA: Fox.

Gripsrud, J. (2002). Understanding media culture. London: Arnold.

Guha, P. (Producer) \& Mohamed, K. (Director) (2000). Fiza [Film]. India: UTV Motion Pictures.

Gupta, A. (Producer). (1998). Goodness Gracious Me [Television series]. London: BBC. 
Haji-ar-were, S. R. (2006). Muslim diasporas in a modern world: A study of strategies of adaption. Unpublished doctoral dissertation, Macquarie University, Sydney.

Hall, S. (1980). Encoding/decoding. In S. Hall, D. Hobson, A. Lowe, \& P. Willis (Eds.) Culture, media, language (pp. 128-138). London: Hutchinson.

Hall, S. (1990). Cultural identity and diaspora. In J. Rutherford (Ed.), Identity: Community, culture, difference (pp. 222-237). London: Lawrence \& Wishart.

Hamilton, D. (Producer) \& Mehta, D. (Director). (2002). Bollywood/Hollywood [Film]. Toronto, ON, Amsterdam and Mumbai: Bollywood/Hollywood Productions, Different Tree Same Wood, Fortissimo Films and iDream Productions.

Hamilton, D. (Producer) \& Mehta, D. (Director). (2005). Water [Film]. Toronto: Mongrel Media.

Handa, A. (2003). Of silk saris and mini-skirts: South Asian girls walk the tightrope of culture. Toronto: Women's Press.

Harzig, C., \& Hoerder, D. (2006). Transnationalism and the age of mass migration, 1880s to 1920 s. In V. Satzewich \& L. Wong (Eds.), Transnational identities and practices in Canada (pp. 35-51). Vancouver: UBC Press.

Heater, D. (1996). World citizenship and government: Cosmopolitan ideas in the history of Western political thought. London: Macmillan Press.

Heater, D. (1999). What is citizenship? Cambridge, UK: Polity Press.

Hiebert, D., \& Ley, D. (2006). Characteristics of immigrant transnationalism in Vancouver. In V. Satzewich \& L. Wong (Eds.), Transnational identities and practices in Canada (pp. 71-90). Vancouver: UBC Press.

High Level Committee on the Indian Diaspora. (2001). Report of the High Level Committee on the Indian diaspora. New Delhi: Ministry of Overseas Indians Affairs, Government of India.

Hoodfar, H. (2003). More than clothing: Veiling as an adaptive strategy. In S. Alvi, H. Hoodfar \& S. McDonough (Eds.), The Muslim veil in North America: Issues and debates (pp. 3-40). Toronto: Women's Press.

hooks, b. (1994). Outlaw culture: Resisting representations. New York: Routledge.

Howard-Hassman, R. E. (1999). "Canadian" as an ethnic category: Implications for multiculturalism and national unity. Canadian Public Policy, 25(4), 523-537.

Husaini, Z. (1990). Muslims in the Canadian mosaic: Socio-cultural and economic links with their countries of origin. Edmonton, AB: Muslim Research Foundation.

Isin, E. F., \& Siemiatycki, M. (2002). Making space for mosques: Claiming urban citizenship. In S. Razack (Ed.), Race, space and the law: The making of a white settler society (pp. 185-209). Toronto: Between the Lines.

Jiménez, M. (2007, January 12). How Canadian are you? The Globe and Mail, p. A1.

Jiwani, Y. (1989). [Situating identity]. Unpublished raw data.

Jiwani, Y. (1993). By omission and commission: 'Race' and representation in Canadian television news. Unpublished doctoral dissertation, Simon Fraser University, Burnaby, British Columbia.

Jiwani, Y. (2006). Discourses of denial. Vancouver: UBC Press.

Johar, H. (Producer) \& Johar, K. (Director). (2006). Kabhi Alvida Naa Kehna [Film]. Mumbai: Dharma Productions.

Johar, K. (Producer), Johar, Y. (Producer), \& Advani, N. (Director). (2003). Kal Ho Naa Ho [Film]. Mumbai: Dharma Productions. 
Johar, Y. (Producer) \& Johar, K. (Director). (1998). Kuch Kuch Hota Hai [Film]. Mumbai: Yash Raj Films.

Johar, Y. (Producer) \& Johar, K. (Director). (2001). Kabhi Khushi Kabhie Gham [Film]. Mumbai: Dharma Productions.

Johnson, B. D. (2007, February 5). Blazing a northern passage to India. Macleans, p. 55.

Joseph, M. (1999). Nomadic identities: The performance of citizenship. Minneapolis: University of Minnesota Press.

Kabbani, R. (1986). Europe's myths of Orient: Devise and rule. London: Macmillan.

Kabir, N. M. (1999). Talking films: Conversations on Hindi cinema with Javed Akhtar. New Delhi: Oxford University Press.

Kaplan, W. (1993). Who belongs? Changing concepts of citizenship and nationality. In W. Kaplan (Ed.), Belonging: The meaning and future of Canadian citizenship (pp. 245-264). Montreal and Kingston: McGill-Queen's University Press.

Kapoor, R. (Producer \& Director). (1956). Awaara [Film]. Mumbai: All India Film Corporation \& R. K. Films.

Kapoor, R. (Producer \& Director). (1955). Shri 420 [Film]. Mumbai: R. K. Films.

Kapoor, R. (Producer) \& Mitra, A. (Director). (1956). Jagte Raho [Film]. Mumbai: R. K. Films.

Kapoor, R. (Producer \& Director). (1991). Henna [Film]. Mumbai: R.K. Films and Studios.

Karim, K. H. (1997). The historical resilience of primary stereotypes: Core images of the Muslim Other. In S. H. Riggins (Ed.), The language and politics of exclusion: Others in discourse (pp. 153-182). Thousand Oaks, CA: Sage Publications.

Karim, K. H. (1998). From ethnic media to global media: Transnational communication networks among diasporic communities. Ottawa, Ontario: Department of Canadian Heritage.

Karim, K. H. (2000). The Islamic peril: Media and global violence. Montréal: Black Rose Books.

Karim, K. H. (2002). Crescent dawn in the Great White North: Muslim participation in the Canadian public sphere. In Y. Y. Haddad (Ed.), Muslims in the West: From sojourners to citizens (pp. 262-277). New York: Oxford University Press.

Karim, K. H. (2003). Mapping diasporic landscapes. In K. H. Karim (Ed.) The media of diaspora (pp. 1-17). London: Routledge.

Karim, K. H. (in press). At the interstices of tradition, modernity and postmodernity: Ismaili engagements with contemporary Canadian society. In F. Daftary (Ed.) The modern history of the Ismailis. London: IB Tauris.

Katz, E. (1987). Communications research since Lazarsfeld. Public Opinion Quarterly, $51, \mathrm{~S} 25-\mathrm{S} 45$.

Kawaja, J. (Producer), Pope, M. (Producer), Sereny, J. (Producer) \& Rashid, I. I. (Director). (2004). A Touch of Pink [Film]. London \& Toronto: Martin Pope Productions \& Sienna Films.

Kellner, D. (1995). Media culture: Cultural studies, identity and politics between the modern and the postmodern. London and New York: Routledge.

Keni, N. (Producer) \& Sharma, A. (Director). (2001). Gadar: Ek Prem Katha [Film]. Mumbai: Zee Telefilms Ltd. 
Khan, A. (Producer), \& Gowariker, A. (Director). (2001). Lagaan [Film]. Mumbai: Aamir Khan Productions.

Khan, D-S. (2004). Crossing the threshold: Understanding religious identities in South Asia. London and New York: I.B. Tauris Publishers in association with The Institute of Ismaili Studies.

Khan, M. (Producer \& Director). (1957). Mother India [Film]. Mumbai: Mehboob Productions.

Khan, S. (1995). The veil as a site of struggle: The hejab in Quebec. Canadian Woman Studies, 15(2), 146-151.

Khan, S. (2000). Muslim women: Crafting a North American identity. Gainesville, Florida: University of Florida Press.

King, T. (2003). Rhodesians in hyperspace: The maintenance of a national and cultural identity. In K. H. Karim (Ed.) The media of diaspora (pp. 177-188). London: Routledge.

Koewing, C. E. (Producer), Katdare, D. (Producer), \& Pandya, P. D. (Director). (2001). American Desi [Film]. Secausus, NJ: Eros Entertainment.

Kolar-Panov, D. (2003). Video and the Macedonians in Australia. In K. H. Karim (Ed.), The media of diaspora (pp. 105-118). London: Routledge.

Kraidy, M. M. (1999). The global, the local, and the hybrid: A native ethnography of glocalization. Critical Studies in Mass Communication, 16, 456-476.

Kumar, A. (2002). Bombay-London-New York. London and New York: Routledge.

Kumar, M. (Producer \& Director). (1974). Roti Kapada aur Makaan [Film]. Mumbai: V.I.P. Films \& Vishal Productions.

Kumar, M. (Producer \& Director). (1970). Purab aur Pacchim [Film]. Mumbai: V.I.P. Films.

Kumar, V. (Producer \& Director). (1968). Mere Huzoor [Film]. Mumbai: Movie Mughals.

Kymlicka, W. (2001). The new debate over minority rights. In F. Requejo (Ed.), Democracy and national pluralism (pp. 15-39). London: Routledge.

Lakshmanan, I. A. R. (1999, March 27). Hooray for Bollywood: India's film industry doubles Hollywood's annual output. The Hamilton Spectator, p. W3.

Leonard, K. (2002). South Asian leadership of American Muslims. In Y. Y. Haddad (Ed.), Muslims in the West: From sojourners to citizens (pp. 233-249). New York: Oxford University Press.

Lorimer, R., \& McNulty, J. (1996). Mass communication in Canada. (3rd ed.). Toronto: Oxford University Press.

Lyall, S., \& Fisher, I. (2006, August 13). Many Muslims in Britain tell of feeling torn between competing identities. The New York Times, p. 6.

Macbeth, D. (2001). On "reflexivity" in qualitative research: Two readings, and a third. Qualitative Inquiry, 7(1), 35-68.

MacFarquhar, N. (2007, February 4). Iraq's shadow widens Sunni-Shiite split in U.S. The New York Times, p. 1.

Madan, J. J. (Director). (1923). Noorjehan [Film]. Kolkata: Madan Theatre.

Maira, S. M. (2002). Desis in the house: Indian American youth culture in New York City. Philadelphia: Temple University Press.

Malkani, G. (2006, August 19). Sounds of assimilation. The New York Times, p. A15. 
Mamdani, M. (2004). Good Muslim, bad Muslim. New York: Pantheon Books.

Mandaville, P. (2001). Transnational Muslim politics: Reimagining the umma. London and New York: Routledge.

Mann, J. (2001, January 5). Hooray for Bollywood. The Vancouver Sun, p. F3.

Manning, E. (2003). Ephemeral territories: Representing nation, home, and identity in Canada. Minneapolis: University of Minnesota Press.

Marotta, V. (2000). Democracy and difference in American social and political thought. In A. Vandenberg (Ed.), Citizenship and democracy in a global era (pp. 51-76). New York: St. Martin's Press.

Marsh-Edwards, N. (Producer) \& Chadha, G. (Director). (1993). Bhaji on the Beach [Film]. London, UK: Channel Four \& Umbi Films.

Martin, M. (1997). Communication and mass media: Culture, domination, and opposition. Scarborough, ON: Prentice Hall Allyn and Bacon Canada.

The Masala Trois Collective. (2003). Foreplay. In D. Barretto, G. Singh Jolly, \& Z. Wadhwani (Eds.), Desilicious (pp. 11-13). Vancouver, BC: Arsenal Pulp Press.

Matthan, J. M. (Director). (1999). Sarfarosh [Film]. Mumbai: Cinematt Pictures.

Mauthner, N., \& Doucet, A. (2003). Reflexive accounts and accounts of reflexivity in qualitative data analysis. Sociology, 37(3), 413-431.

McCorkel, J. A., \& Myers, K. (Summer 2003). What difference does difference make? Position and privilege in the field. Qualitative Sociology, 26(2).

Mehta, D. (Producer \& Director). (1996). Fire [Film]. Mumbai: Kaleidoscope Entertainment and Trial By Fire Films.

Mehta, D. (Producer \& Director). (1998). Earth [Film]. New York: Cracking the Earth Films Inc.

Miladi, N. (2003). Mapping the A1-Jazeera phenomenon. In D. K. Thussu \& D. Freedman (Eds.), War and the media: Reporting conflict 24/7 (pp. 149-160). Thousand Oaks, CA: Sage Publications.

Mirza, S. A. (Director). (1989). Salim Langde Pe Mat Ro [Film]. India: National Film Development Corporation of India.

Mishra, G. (Producer), Nayyar, M. (Producer), \& Bhansali, S. L. (Director). (2002). Devdas [Film]. Mumbai: Eros Entertainment.

Mishra, V. (2002). Bollywood cinema: Temples of desire. New York: Routledge.

Mitchell, K. (1997). Transnational discourse: Bringing geography back in. Antipode, 29(2), 101-114.

Mitra, A. (1999). India through the western lens: Creating national images in film. New Delhi: Sage Publications.

Mohammad, A. T. (2001). Relationships between Muslims and Hindus in the United States: Mlecchas versus Kafirs? In C. Bates (Ed.), Community, empire and migration: South Asians in diaspora (pp. 286-308). New York: Palgrave.

Morley, D. (2000). Home territories: Media, mobility and identity. London and New York: Routledge.

Morley, D., \& Robins, K. (1995). Spaces of identity: Global media, electronic landscapes and cultural boundaries. London and New York: Routledge.

Munro, D. (2005, August 18). Is multiculturalism on its deathbed? The Toronto Star, p. A27.

Murji, R., \& Hébert, Y. M. (1999, May). Collectivized identity among Shi`a Imami 
Ismaili Muslims of Calgary: Implications for pluralism and policy. Paper presented at Youth in the Plural City: Individualized and Collectivized Identities, Rome.

Naficy, H. (1993). The making of exile cultures: Iranian television in Los Angeles. Minneapolis: University of Minnesota Press.

Naficy, H. (2001). An accented cinema: Exile and diasporic filmmaking. Princeton, NJ: Princeton University Press.

Naficy, H. (2003). Narrowcasting in diaspora: Middle Eastern television in Los Angeles. In K. H. Karim (Ed.), The media of diaspora (pp. 51-62). London: Routledge.

Nair, M. (Producer \& Director). (1988). Salaam Bombay [Film]. Paris, London \& New Delhi: Cadragee, Channel Four \& Doordarshan.

Nandy, A. (1983). The intimate enemy: Loss and recovery of self under colonialism. New Delhi: Oxford University Press.

Nandy, A. (1995). The savage Freud and other essays on possible and retrievable selves. Princeton, NJ: Princeton University Press.

Nayar, D. (Producer) \& Chadha, G. (Producer \& Director). (2003). Bend It like Beckham [Film]. Beverly Hills, CA: Fox Searchlight Pictures.

Nayar, D. (Producer) \& Chadha, G. (Director). (2004). Bride and Prejudice [Film]. New York, NY: Miramax.

Nayar, S. (1997). The values of fantasy. Journal of Popular Culture, 31(1), 73-90.

Nayar, S. (2003). Dreams, dharma, and Mrs. Doubtfire: Exploring Hindi popular culture via its "chutneyed" Western scripts. Journal of Popular Film and Television, 31(2), 73-81.

Nozik, M. (Producer) \& Nair, M. (Producer \& Director). (1991). Mississippi Masala [Film]. Cape Breton Island, NS, London, \& New York: Black River Productions, Channel Four Films \& Mirabai Films.

Ogan, C. L. (2002). Communication and culture. In Y. Kamalipour (Ed.), Global communication. (pp. 207-228). Belmont, CA: Wadsworth.

Oommen, M. A., \& Joseph, K. V. (1991). Economics of Indian cinema. New Delhi: Oxford \& IBH Publishing Co.

Ong, A. (1999). Flexible citizenship: The cultural logics of transnationality. Durham and London: Duke University Press.

Orona, C. J. (1997). Temporality and identity loss due to Alzheimer's disease. In A. L. Strauss \& J. Corbin (Eds.) Grounded theory in practice (pp. 171-196). Thousand Oaks, CA: Sage Publications.

Patel, D. (2006). The Maple-Neem nexus: Transnational links of South Asian Canadians. In V. Satzewich \& L. Wong (Eds.), Transnational identities and practices in Canada (pp. 150-163). Vancouver: UBC Press.

Pehme, T. (Producer), Roberts, K. (Producer), \& Sarin, V. (Director). (2007). Partition [Film]. Montréal, QC: Seville Pictures.

Pendakur, M. (1990). India. In J. A. Lent (Ed.), The Asian film industry (pp. 229-252). London: Christopher Helm.

Pendakur, M. (2003). Indian popular cinema: Industry, ideology and consciousness. Cresskill, NJ: Hampton Press.

Pipes, D. (2001, October 3). This American feels safer. The Globe and Mail, p. A15. 
Pipes, D., \& Hedegaard, L. (2002, August 27). Muslim extremism: Denmark's had enough. The National Post, p. A14.

Poole, E. (2002). Reporting Islam: Media representations of British Muslims. London: I.B. Tauris \& Co. Ltd.

Prasad, M. M. (2000). Signs of ideological re-form in two recent films: Towards real subsumption? In R. S. Vasudevan (Ed.), Making meaning in Indian cinema (pp. 145-167). New Delhi: Oxford University Press.

Qiu, H. (2003). Communication among knowledge diasporas: Online magazines of expatriate Chinese students. In K. H. Karim (Ed.), The media of diaspora (pp. 148-161). London: Routledge.

Radhakrishnan, R. (2003). Ethnicity in an age of diaspora. In J. Evans Braziel \& A. Mannur (Eds.), Theorizing diaspora: $A$ reader (pp. 119-131). Malden, MA: Blackwell Publishing.

Raghavan, S. (Director). (2004). Ek Hasina Thi [Film]. Mumbai: K Sera Sera, S.R.B. Films \& Varma Corporation Ltd.

Rai, A. S. (2003). Patriotism and the Muslim citizen in Hindi films. Harvard Asia Quarterly, 7(1). Retrieved September 17, 2006 from http://www.asiaquarterly.com/content/ view/136/40/

Rajadhyaksha, A. (1996, August). Strange attractions. Sight and Sound, pp. 28-31.

Rajadhyaksha, A. (2000). Viewership and democracy in the cinema. In R. S. Vasudevan (Ed.), Making meaning in Indian cinema (pp. 267-296). New Delhi: Oxford University Press.

Ramadan, T. (2002). Islam and Muslims in Europe: A silent revolution toward rediscovery. In Y. Y. Haddad (Ed.), Muslims in the West: From sojourners to citizens (pp. 158-166). New York: Oxford University Press.

Rapley, T. J. (2001). The art(fullness) of open-ended interviewing: Some considerations on analysing interviews. Qualitative Research, 1(3), 303-23.

Ratnam, M. (Producer \& Director). (1992). Roja [Film]. Mumbai: Hansa Pictures.

Ratnam, M. (Producer \& Director). (1995). Bombay [Film]. Mumbai: Amitabh Bachchan Corporation Ltd. and Madras Talkies.

Ratnam, M. (Producer \& Director). (1998). Dil Se [Film]. Chennai: India Talkies and Madras Talkies.

Ratnam, M. (Producer \& Director). (2007). Guru [Film]. Chennai: Madras Talkies.

Ray, M. (2001). Bollywood down under: Fiji Indian cultural history and popular assertion. In S. Cunningham \& J. Sinclair (Eds.), Floating lives: The media and Asian diasporas (pp.136-184). Lanham, MD: Rowman \& Littlefield Publishers, Inc.

Ray, M. (2003). Nation, nostalgia and Bollywood: In the tracks of a twice-displaced community. In K. H. Karim (Ed.), The media of diaspora (pp. 21-35). London: Routledge.

Razack, S. (1998). Looking white people in the eye: gender, race, and culture in courtrooms and classrooms. Toronto, ON: University of Toronto Press.

Reitz, J.G. \& Banerjee, R. (2007). Racial inequality, social cohesion, and policy issues in Canada. In K. Banting, T. J. Courchene, \& L. Seidle (Eds.), Belonging? Diversity, recognition, and shared citizenship in Canada (pp. 489-545). Montréal: Institute for Research on Public Policy. 
Robbins, B. (1999). Feeling global: Internationalism in distress. New York: New York University Press.

Rogers, E. (1969). Modernization among peasants: The impact of communication. New York: Holt, Rinehart and Winston, Inc.

Roy, B. (Producer \& Director). (1953). Do Bigha Zameen [Film]. Mumbai: Bimal Roy Productions.

Rushdie, S. (2005, December 15). In defence of multiculturalism. The Toronto Star, p. A27.

Said, E. (1978). Orientalism. New York: Vintage Books.

Santianni, M. (2003). The movement for a free Tibet: Cyberspace and the ambivalence of cultural translation. In K. H. Karim (Ed.), The media of diaspora (pp. 189-202). London: Routledge.

Sassen, S. (2006). Territory, authority, rights: From medieval to global assemblages. Princeton: Princeton University Press.

Sathyu, M. S. (Producer \& Director). (1973). Garam Hawa [Film]. Mumbai: Unit 3 mm.

Satzewich, V. \& Wong, L. (2006). Introduction: The meaning and significance of transnationalism. In V. Satzewich \& L. Wong (Eds.), Transnational identities and practices in Canada (pp. 1-15). Vancouver: UBC Press.

Saunders, D. (2003, June 7). The kids are all right. The Globe and Mail, p. F2.

Saunders, D. (2007, April 14). Why the fear of a 'Muslim tide' makes too much of a splash. The Globe and Mail, p. F3.

Schensul, J. J. (1999). Focused group interviews. In J. J. Schensul, M. D. LeCompte, B. K. Nastasi, \& S. P. Borgatti (Eds.), Enhanced ethnographic methods: Audiovisual techniques, focused group interviews, and elicitation techniques (pp. 51-114). Walnut Creek, CA: Altamira Press.

Seale, C. (1999). The quality of qualitative research. Thousand Oaks, CA: Sage Publications.

Shafir, G. (1998). Introduction: The evolving tradition of citizenship. In G. Shafir (Ed.), The citizenship debates (pp. 1-28). Minneapolis: University of Minnesota Press.

Shoemaker, P., \& Reese, S. (1996). Mediating the message: Theories of influence on mass media content (2nd ed.). White Plains, NY: Longman.

Shohat, E., \& Stam, R. (1994). Unthinking Eurocentrism: Multiculturalism and the media. London and New York: Routledge.

Shukla, S. (2003). India abroad: Diasporic cultures of postwar America and England. Princeton and Oxford: Princeton University Press.

Siddiqui, H. (2006, June 11). Muslim-bashing dilutes our democratic values. The Toronto Star, p. A17.

Sidhva, S. (1996, July 18). Hollywood nudges in on India's movie market: India has the world's keenest moviegoers, and the U.S. wants a piece of the action. The Financial Post, p. 49.

Sinclair, J., \& Cunningham, S. (2001). Diasporas and the media. In S. Cunningham \& J. Sinclair (Eds.) Floating lives: The media and Asian diasporas (pp. 1-34). Lanham, MD: Rowman \& Littlefield Publishers, Inc.

Sinclair, J., Yue, A., Hawkins, G., Pookong, K., \& Fox, J. (2001). Chinese cosmopolitanism and media use. In S. Cunningham \& J. Sinclair (Eds.), Floating 
lives: The media and Asian diasporas (pp. 35-90). Lanham, MD: Rowman \& Littlefield Publishers, Inc.

Sippy, R. (Producer \& Director). (1975). Sholay [Film]. Mumbai: Sippy Films Pvt. Ltd..

Smith, J. I. (2002). Introduction. In Y. Y. Haddad (Ed.), Muslims in the West: From sojourners to citizens (pp. 3-16). New York: Oxford University Press.

Sreberny-Mohammadi, A. (1996). Globalization, communication and transnational civil society: Introduction. In S. Braman \& A. Sreberny-Mohammadi (Eds.), Globalization, communication and transnational civil society (pp. 1-19). Cresskill, NJ: Hampton Press, Inc.

Sreberny-Mohammadi, A., \& Mohammadi, A. (1994). Small media, big revolution: Communication, culture, and the Iranian revolution. Minneapolis: University of Minnesota Press.

Statistics Canada. (2002). Profile of the Canadian population by age and sex: Canada ages. Ottawa, ON: Government of Canada.

Statistics Canada. (2003). Canada's ethnocultural portrait: The changing mosaic. Ottawa, ON: Government of Canada.

Statistics Canada. (2003). Religions in Canada. Ottawa, ON: Government of Canada.

Stillar, G. F. (1999). Analyzing everyday texts: Discourse, rhetoric, and social perspectives. Thousand Oaks, CA: Sage Publications.

Sun, W. (2002). Leaving China: Media, migration, and transnational imagination. Lanham: Rowman \& Littlefield.

Tamale, S. A. (1996). The outsider looks in: Constructing knowledge about American collegiate racism. Qualitative Sociology, 19(4), 471-493.

Thien, M. (2003, December 27). But, I dream in Canadian. The Globe and Mail, p. A19. Thoraval, Y. (2000). The cinemas of India. Delhi: Macmillan India Limited.

Tsaliki, L. (2003). Globalisation and hybridity: The construction of Greekness on the Internet. In K. H. Karim (Ed.), The media of diaspora (pp. 162-176). London: Routledge.

Turner, B. S. (2000). Liberal citizenship and cosmopolitan virtue. In A.Vandenberg (Ed.), Citizenship and democracy in a global era (pp. 18-32). New York: St. Martin's Press.

Turner, B. S. (2002). Religion and politics: The elementary forms of citizenship. In E. F. Turner \& B. S. Turner (Eds.), Handbook of citizenship studies (pp. 259-275). Thousand Oaks, CA: Sage Publications.

Udwin, L. (Producer) \& O’Donnell, D. (Director). (1999). East is East [Film]. London: Assassin Films, BBC and Film Four.

Ujimoto, K. V. (1990). Studies of ethnic identity and race relations. In P. S. Li (Ed.), Race and ethnic relations in Canada (pp. 209-230). Toronto: Oxford University Press.

Valpy, M., \& Anderssen, E. (2003, July 1). 10 ways the 20 s will challenge us. The Globe and Mail, p. A6.

Van den Bulck, H., \& Van Poecke, L. (1996). National language, identity formation, and broadcasting: The Flemish and German-Swiss communities. In S. Braman \& A. Sreberny-Mohammadi (Eds.), Globalization, communication and transnational civil society (pp. 157-177). Cresskill, NJ: Hampton Press, Inc. 
Van Dijk, T. A. (1988). News analysis: Case studies of international and national news in the press. Hillsdale, NJ: Lawrence Erlbaum.

Van Dijk, T. A. (1991). Racism and the press. London and New York: Routledge.

Van Dijk, T. A. (1993). Stories and racism. In D. K. Mumby (Ed.), Narrative and social control: Critical perspectives (pp. 121-142). Newbury Park, CA: Sage Publications.

Van Dijk, T. A. (1996). Discourse, power and access. In C. R. Caldas-Coulthard \& M. Coulthard (Eds.), Texts and practices: Readings in critical discourse analysis (pp. 84-104). London and New York: Routledge.

Van Dijk, T. A. (1998). Ideology: A multidisciplinary approach. Thousand Oaks, CA: Sage Publications.

Van Leeuwen, T. (1996). The representation of social actors. In C. R. Caldas-Coulthard \& M. Coulthard (Eds.), Texts and practices: Readings in critical discourse analysis (pp. 32-70). London and New York: Routledge

Vasudevan, R. S. (2000). Shifting codes, dissolving identities: The Hindi social film of the 1950 s as popular culture. In R. S. Vasudevan (Ed.), Making meaning in Indian cinema (pp. 99-121). New Delhi: Oxford University Press.

Virdi, J. (2003). The cinematic imagination: Indian popular films as social history. New Brunswick: Rutgers University Press.

Warah, R. (1998). Triple heritage: A journey to self-discovery. Nairobi: Colour Print Ltd. Wayland, S. V. (2006). The politics of transnationalism: Comparative perspectives. In V. Satzewich \& L. Wong (Eds.), Transnational identities and practices in Canada (pp. 18-34). Vancouver: UBC Press.

Wente, M. (2001, October 2). Tipetoeing through Islam. The Globe and Mail, p. A17.

Wiwa, K. (2005, August 27). Workers of the word world, unite! The Globe and Mail, p. A15.

Yelaja, P. (2006, 27 October). South Asian youth rebrand for a new era. The Toronto Star, p. A1. 
Appendix A

Films Cited by Participants

\begin{tabular}{|c|c|c|}
\hline Film Title & $\begin{array}{l}\text { No. of } \\
\text { times } \\
\text { cited }\end{array}$ & Description \\
\hline Hum Aapke Hain Koun & 6 & $\begin{array}{l}1994 \text { film described as one of the most successful of all } \\
\text { time; a lavish love story which shows two families } \\
\text { going through the rituals of marriage and childbirth, } \\
\text { among others. Believed to mark the beginning of a } \\
\text { youth-oriented, modern era in Bollywood }\end{array}$ \\
\hline Kabhi Khushi Kabhie Gham & 5 & $\begin{array}{l}2001 \text { star-studded movie about marriage opposed by } \\
\text { patriarch and the resulting discord, which drives part of } \\
\text { the family to exile in London, only to return to India in } \\
\text { the end for a happy reunion }\end{array}$ \\
\hline $\begin{array}{l}\text { Dilwaale Dulhaniya Le } \\
\text { Jayenge }\end{array}$ & 5 & $\begin{array}{l}1995 \text { film hugely successful both in and outside of } \\
\text { India. For perhaps the first time, a couple raised outside } \\
\text { of India but with true Indian values finds happiness and } \\
\text { returns to England to live their lives }\end{array}$ \\
\hline Kuch Kuch Hota Hai & 4 & $\begin{array}{l}1998 \text { love story which, like } H A H K \text {, attracted many } \\
\text { youth back to Bollywood, possibly because of high } \\
\text { production values and depiction of popular brands }\end{array}$ \\
\hline Devdas & 3 & $\begin{array}{l}2002 \text { remake of popular classic in which the title } \\
\text { character who sinks into alcoholism after his family } \\
\text { prevents his marriage to his childhood love }\end{array}$ \\
\hline Kal Ho Naa Ho & 3 & $\begin{array}{l}2003 \text { film, again with Shahrukh Khan as character who } \\
\text { helps the dejected heroine learn how to love and live } \\
\text { anew }\end{array}$ \\
\hline Black & 3 & $\begin{array}{l}2005 \text { film which won major accolades for Rani } \\
\text { Mukherjee as blind and mute woman }\end{array}$ \\
\hline Hum Tum & 3 & 2004 romance between two long-time friends \\
\hline Lagaan & 2 & $\begin{array}{l}2001 \text { film nominated for Foreign Film Oscar and } \\
\text { depicting a makeshift cricket team playing to oppose an } \\
\text { unfair tax by the British }\end{array}$ \\
\hline Qurbani & 2 & $\begin{array}{l}1980 \text { movie, renowned partly for its music, featuring a } \\
\text { love triangle and an intricate criminal plot }\end{array}$ \\
\hline Baghban & 2 & 2003 film about children's neglect of loving parents \\
\hline Veer Zaara & 2 & $\begin{array}{l}2004 \text { film about cross-border romance between Indian } \\
\text { man and Pakistani woman }\end{array}$ \\
\hline Dil & 2 & 1989 love story \\
\hline Gadar & 2 & $\begin{array}{l}2001 \text { romance between Sikh man and Muslim girl } \\
\text { during post-Partition chaos }\end{array}$ \\
\hline Khamosh Pani & 1 & $\begin{array}{l}2003 \text { film depicting widow's fears for her son in a } \\
\text { Pakistan transformed by martial law and } \\
\text { fundamentalism; also raises history of women's }\end{array}$ \\
\hline
\end{tabular}




\begin{tabular}{|c|c|c|}
\hline & & experiences following Partition \\
\hline Roti Kapada aur Makaan & 1 & $\begin{array}{l}1974 \text { film depicting the despair of youth who cannot } \\
\text { obtain employment }\end{array}$ \\
\hline Banjaran & 1 & 1991 movie of star-crossed love \\
\hline Raja Hindustani & 1 & 1996 romance between wealthy woman and poor man \\
\hline Judai & 1 & $\begin{array}{l}1997 \text { film based loosely on Indecent Proposal: wealthy } \\
\text { NRI woman attempts to buy married man's } \\
\text { companionship }\end{array}$ \\
\hline Dosti & 1 & 1964 film about two friends beset by misfortune \\
\hline Pinjar & 1 & $\begin{array}{l}2003 \text { movie that depicts the mistreatment of women of } \\
\text { various backgrounds as a way to settle scores during the } \\
\text { partitioning of the Punjab }\end{array}$ \\
\hline Bombay & 1 & $\begin{array}{l}1995 \text { Tamil film about Hindu-Muslim romance and the } \\
\text { turmoil visited upon their sons during intercommunal } \\
\text { rioting in Bombay }\end{array}$ \\
\hline Mughal-e-Azam & 1 & $\begin{array}{l}1960 \text { classic about doomed romance between prince and } \\
\text { courtesan; notable for its lush depictions of the Mughal } \\
\text { era }\end{array}$ \\
\hline Dil Lagliya & 1 & $\begin{array}{l}\text { No information found unless same as Dillagi, a } 1999 \\
\text { film in which a man accidentally arranges a marriage } \\
\text { between his brother and the girl he himself loves }\end{array}$ \\
\hline Pardes & 1 & $\begin{array}{l}1997 \text { film about an Indian girl who travels to the United } \\
\text { States to stay with her fiance's family, only to discover } \\
\text { that life in the States is cold, corrupt and dissolute }\end{array}$ \\
\hline Amar Akbar Anthony & 1 & $\begin{array}{l}1977 \text { hit about three brothers separated and raised as } \\
\text { Hindu, Muslim and Christian, respectively }\end{array}$ \\
\hline Mohabbatein & 1 & $\begin{array}{l}2000 \text { movie about a music teacher who honours his dead } \\
\text { love by encouraging romance and love at the school } \\
\text { where his lover's father is the stern principal }\end{array}$ \\
\hline Parineeta & 1 & 2005 movie set in 1960s Kolkata, depicts love triangle \\
\hline Ram aur Sham & 1 & $\begin{array}{l}1967 \text { movie where mistaken identity fuels a complicated } \\
\text { series of events }\end{array}$ \\
\hline Dus & 1 & 2005 action film about an attempt to foil a terrorist plot \\
\hline Dhoom & 1 & 2004 action-packed film that led to a sequel \\
\hline Kalnayak & 1 & $\begin{array}{l}1993 \text { film about, as the title says, a "bad man" who } \\
\text { eventually finds a type of redemption through the very } \\
\text { people who sought to imprison him }\end{array}$ \\
\hline Namak Halal & 1 & $\begin{array}{l}1982 \text { comedy-drama in which the main character moves } \\
\text { to the big city only to become embroiled in a plot } \\
\text { involving family and crime }\end{array}$ \\
\hline The Burning Train & 1 & $\begin{array}{l}1980 \text { thriller about a train designed to be the best in } \\
\text { India, and an attempt to foil its inaugural run }\end{array}$ \\
\hline Ek Hasina Thi & 1 & $\begin{array}{l}2004 \text { movie in which the heroine is framed and sent to } \\
\text { jail, where she plots her revenge }\end{array}$ \\
\hline Swades & 1 & $\begin{array}{l}2004 \text { movie in which the star is convinced to leave his } \\
\text { prestigious job in the United States and apply his talents }\end{array}$ \\
\hline
\end{tabular}




\begin{tabular}{|l|l|l|}
\hline & & towards improving an Indian village \\
\hline Sholay & 1 & 1975 classic revenge drama with romantic elements \\
\hline Heer Raanhja & 1 & $\begin{array}{l}1970 \text { Punjabi romance (a number of other versions } \\
\text { exist) }\end{array}$ \\
\hline Umrao Jaan & 1 & $\begin{array}{l}1981 \text { tragic romance about courtesan named Umrao } \\
\text { Jaan }\end{array}$ \\
\hline
\end{tabular}

Non-Bollywood films cited by participants

\begin{tabular}{|c|c|c|}
\hline Film Title & $\begin{array}{l}\text { No. of times } \\
\text { cited }\end{array}$ & Description \\
\hline Water & $\overline{6}$ & $\begin{array}{l}2005 \text { film completing Deepa Mehta's trilogy; } \\
\text { Oscar-nominated story about a group of widows } \\
\text { condemned to poverty }\end{array}$ \\
\hline Monsoon Wedding & 3 & $\begin{array}{l}2001 \text { film about preparations for a wedding } \\
\text { where family secrets are revealed }\end{array}$ \\
\hline Bollywood/Hollywood & 3 & $\begin{array}{l}2002 \text { film set in Toronto; Mehta's comedic take } \\
\text { on a Bollywood-themed romance }\end{array}$ \\
\hline American Desi & 2 & $\begin{array}{l}\text { Comedy released in } 2001 \text {; one of the first films } \\
\text { to explore being an ABCD or American Born } \\
\text { Confused Desi, someone who battles his or her } \\
\text { Indian identity }\end{array}$ \\
\hline Earth & 2 & $\begin{array}{l}1998 \text { film by Mehta about intercommunal } \\
\text { conflict following Partition }\end{array}$ \\
\hline Mississippi Masala & 1 & $\begin{array}{l}\text { Mira Nair's } 1992 \text { breakout film about interracial } \\
\text { romance in the Deep South and a family's } \\
\text { struggle to integrate following their departure } \\
\text { from Uganda }\end{array}$ \\
\hline Bride \& Prejudice & 1 & $\begin{array}{l}\text { Perhaps best known as Aishwarya Rai's } \\
\text { crossover vehicle, this } 2004 \text { film remakes Pride } \\
\text { and Prejudice as an American-Indian romance }\end{array}$ \\
\hline Guru & 1 & $\begin{array}{l}2003 \text { comedy about an Indian immigrant in New } \\
\text { York who finds success posing as a sex guru }\end{array}$ \\
\hline Murder Unveiled & 1 & $\begin{array}{l}2005 \text { film based on the real story of an Indo- } \\
\text { Canadian woman murdered for refusing to } \\
\text { marry into a higher caste }\end{array}$ \\
\hline Bend It Like Beckham & $\begin{array}{l}\text { Not } \\
\text { mentioned in } \\
\text { questionnaires } \\
\text { but discussed } \\
\text { in interviews }\end{array}$ & $\begin{array}{l}2003 \text { comedy about young British woman of } \\
\text { Punjabi woman who aspires to be a soccer star } \\
\text { in the face of parental opposition }\end{array}$ \\
\hline
\end{tabular}




\section{Appendix B}

\section{Questionnaire}

Resistance is Futile: Diasporic Media, Canadian Muslim Youth and the Construction of Identity

Thank you for your participation. Your responses will be of great value in completing this research, so please be as honest and clear as possible in your answers. All data collected on this form will be kept entirely confidential and will only be used by the researcher for the purposes of completing her dissertation and related publications or conference presentations.

1. Gender: $M / F$ (please circle one)

2. Age:

3. Occupation (if a student, please specify year and area of study):

4. Citizenship:

5. Were you born in Canada? Y/N (please circle one)

6. If you were not born in Canada, how old were you when you first moved here?

7. Where else have you lived, and for how long?

8. If/when you are asked about your nationality, how do you identify yourself?

9. If/when you are asked about your ethnicity, how do you identify yourself?

10. Are you currently practicing any religion? If not, in what religious tradition were you raised, if any? 
11. What factors in your life have most strongly influenced your understanding of your nationality and culture?

12. Which mass media (e.g. television, movies, books) are most important to you?

13. Do you watch Bollywood films? If so, how often?

14. If you do watch Bollywood films, do you normally do so with your family? Your friends? Both or neither?

15. If you answered yes to \#13, please name the Bollywood films you consider the most important to you (you can name up to 5).

16. If you answered no, is there a reason why not?

17. Do you watch other types of film that are produced in India or make reference to Indian culture? 


\section{Appendix C \\ Interview Questions}
Resistance is Futile: Diasporic Media, Canadian Muslim Youth and the Construction of Identity

Thank you for your participation. Your responses will be of great value in completing this research, so please be as honest and clear as possible in your answers.

1. If/when you are asked about your nationality, how do you identify yourself? (if further prompting is required, Do you consider yourself Canadian, or are you likely to give another response?)

2. If/when you are asked about your ethnicity, how do you identify yourself?

3. Do you view your nationality, ethnicity and religion as linked, or are these all separate?

4. What factors in your life have most strongly influenced your understanding of your nationality and culture?

5. Which mass media (e.g. television, movies, books) are most important to you?

6. Do you watch Bollywood films? If so, how often?

7. If you do watch Bollywood films, in what setting do you normally do this? i.e. at home with your family? Your friends? Others?

8. If you do watch Bollywood films, please name the Bollywood films you consider the most important to you, and explain why.

9. What aspects of Bollywood films do you most enjoy?

10. If you don't watch Bollywood films, is there a reason why not? Is there an aspect you particularly dislike?

11. Do you watch other types of film that are produced in India or make reference to Indian culture? For example, films such as Bend It Like Beckham, East is East, etc., which clearly target an Indian market but are not really Bollywood films?

12. How do you think Bollywood films portray your culture and your traditions?

13. How do you think Bollywood films portray your religion? 
14. How do you think Bollywood treats the issue of nationality and ethnicity? Has this changed in recent years?

15. When Bollywood films discuss issues such as being truly Indian, or truly religious, how do you react to this, if at all?

16. Bollywood films clearly have a strong — some might say dominant-element of fantasy, and yet they also attempt to tackle some issues that are topical, such as intergenerational conflict, class barriers, marriage between people of different religions, etc. When they do try to explore more "realistic" subject matter, do you think that they are successful in this?

17. For those of you who watch Bollywood films, do you think they have influenced the kind of person you now are?

18. Would you advise your own children to watch these films, and if so, would it simply be for entertainment purposes?

19. For those of you who do not watch Bollywood films, do you think that any other form of mass media, Indian or otherwise, has affected the kind of person you now are? 